\title{
Spinal cord stimulation for chronic reflex sympathetic dystrophy
}

Citation for published version (APA):

Kemler, M. A. (2000). Spinal cord stimulation for chronic reflex sympathetic dystrophy. [Doctoral Thesis, Maastricht University]. Universiteit Maastricht. https://doi.org/10.26481/dis.20000922mk

Document status and date:

Published: 01/01/2000

DOI:

10.26481/dis.20000922mk

Document Version:

Publisher's PDF, also known as Version of record

\section{Please check the document version of this publication:}

- A submitted manuscript is the version of the article upon submission and before peer-review. There can be important differences between the submitted version and the official published version of record.

People interested in the research are advised to contact the author for the final version of the publication, or visit the DOI to the publisher's website.

- The final author version and the galley proof are versions of the publication after peer review.

- The final published version features the final layout of the paper including the volume, issue and page numbers.

Link to publication

\footnotetext{
General rights rights.

- You may freely distribute the URL identifying the publication in the public portal. please follow below link for the End User Agreement:

www.umlib.nl/taverne-license

Take down policy

If you believe that this document breaches copyright please contact us at:

repository@maastrichtuniversity.nl

providing details and we will investigate your claim.
}

Copyright and moral rights for the publications made accessible in the public portal are retained by the authors and/or other copyright owners and it is a condition of accessing publications that users recognise and abide by the legal requirements associated with these

- Users may download and print one copy of any publication from the public portal for the purpose of private study or research.

- You may not further distribute the material or use it for any profit-making activity or commercial gain

If the publication is distributed under the terms of Article $25 \mathrm{fa}$ of the Dutch Copyright Act, indicated by the "Taverne" license above, 
Spinal Cord Stimulation for Chronic Reflex Sympathetic Dystrophy 


\title{
Spinal Cord Stimulation for Chronic Reflex Sympathetic Dystrophy
}

\author{
PROEFSCHRIFT
}

ter verkrijging van de graad van doctor aan de Universiteit Maastricht

op gezag van de Rector Magnificus

Prof. dr. A. C. Nieuwenhuijzen Kruseman

volgens het besluit van het College van Decanen

in het openbaar te verdedigen

op vrijdag 22 september 2000 om 14.00 uur

\author{
door \\ Marius Adriaan Kemler
}

geboren te Enschede op 18 januari 1971 


\section{Promotor:}

Prof. dr. G. Kootstra

Co-promotores:

Dr. M. van Kleef

Dr. H.C.W. de Vet (Vrije Universiteit Amsterdam)

Beoordelingscommissie:

Prof. dr. J. Troost (voorzitter)

Prof. dr. E.A. Beuls

Prof. dr. R.J.A. Goris (Katholieke Universiteit Nijmegen)

Prof. dr. F. Spaans

Prof. dr. W.W.A. Zuurmond (Vrije Universiteit Amsterdam)

Studies in this thesis were supported by a grant (OG 96-006) from the Dutch Health Insurance Council. Publication of the thesis was supported by the Dutch Health Insurance Council, Medtronic (Eindhoven, the Netherlands), and Medoc (Ramat-Yishai, Israel).

(C) M.A. Kemler, Maastricht, 2000.

ISBN 90-9013865-X

Cover by Erik Boot of Byton New Media, Hilversum

Typeset in Minion by Peter Kahrel, Lancaster

Printed by Datawyse, Maastricht 
I thought I saw upon the stair,

A little man that was not there.

He wasn't there again today.

Gee, I wish he'd go away.

Hughes Mearnes

(1875-1965) 


\section{CONTENTS}

\section{A. Introduction}

1. General introduction

B. Pilot Study and Development of Assessment Methods

2. Electrical Spinal Cord Stimulation in Reflex Sympathetic Dystrophy: Retrospective Analysis of 23 Patients

3. Health-related Quality of Life in Chronic Refractory Reflex Sympathetic Dystrophy

4. An Objective and Standardized Test of Foot Function: Normative Values and Validation in Patients with Reflex Sympathetic Dystrophy

5. Thermal Thresholds in Reflex Sympathetic Dystrophy: Sensitivity and Repeatability of the Methods of Limits and Levels

6. Does Randomization Introduce Bias in Unblinded Trials?

C. Results of the Randomized Trial

7. The Effect of Spinal Cord Stimulation in Patients with Chronic Reflex Sympathetic Dystrophy-A Randomized Controlled Trial

8. Economic Evaluation of Spinal Cord Stimulation for Chronic Reflex Sympathetic Dystrophy

9. Impact of Spinal Cord Stimulation on Sensory Characteristics in Reflex Sympathetic Dystrophy-A Randomized Trial

10. Pain Relief in Reflex Sympathetic Dystrophy Due to Spinal Cord Stimulation Does Not Depend on Vasodilation

11a. Relapsing Ulcerative Colitis Associated with Spinal Cord Stimulation

11b. Recurrent Rejection of a Spinal Cord Stimulation System

D. Discussion and Summary

12. General discussion

Summary

Samenvatting (Summary in Dutch) 156

Dankwoord (Acknowledgements) 159

List of Publications $\quad 163$

$\begin{array}{ll}\text { Curriculum vitae } & 165\end{array}$ 
CHAPTER 1

General Introduction 


\section{Pain}

Pain is the most common symptom in health care, but despite this it is one of the least understood. There is no agreement on how to assess pain, how to define it, or how exactly the phenomenon comes about. Two main types of pain are distinguished: nociceptive pain, which is pain induced by activity in the nociceptor and nociceptive pathways after tissue damage, and neuropathic pain, which is caused by a primary lesion, dysfunction, or transitory perturbation in the peripheral or central nervous system.

One cannot assess pain directly, and so must always depend on patient's own reports of their subjective experiences. Such reports will depend on how the patients think and feel and how they communicate it. Consequently, we cannot define or identify pain independently of the person who experiences it. ${ }^{1}$ Taking this into account, the International Association for the Study of Pain has defined pain as follows: 'an unpleasant sensory and emotional experience associated with actual or potential tissue damage, or described in terms of such damage'. ${ }^{2}$

The debate on what exactly is the origin of pain has a long history. Descartes, the leading thinker of the European Renaissance, has been a major influence on the philosophical approaches to the problems of pain over the last three centuries. ${ }^{3}$ The Cartesian model takes a very mechanistic view of pain, suggesting a specific pain pathway, thus considering pain as a modality like vision or hearing with its own central and peripheral apparatus. This model does not, however, explain why various patients with the same injury seem to experience very different amounts and kinds of pain, and therefore react in very diverse ways. In addition, the model is purely a psychological assumption and has no factual basis. Indeed, recent positron emission tomography studies have shown that multiple cortical areas are activated by painful stimuli, confuting the existence of a specialized 'pain center'. ${ }^{4}$

As a reaction against the psychological assumption put forward in the Cartesian model, the pattern theory was proposed, suggesting that all fiber endings are alike, so that the pattern for pain is produced by intense stimulation of nonspecific receptors. ${ }^{5,6}$ Hence, this theory completely denies the existence of structures specialized to signal pain but, on the other hand, allows for central control over afferent input.

The Gate Control Theory of pain is consistent with concepts of both the specificity (physiological specialization) and pattern (input control) theories. This theory states that signals from pain conducting small fibers are modulated by signals from large fibers in the substantia gelatinosa of the spinal cord: the balance of activity in large and small fibers determines the resulting signal to the central nervous system.? According to this view, the process of selection and abstraction of information will continue in brain-stem pathways and in the brain itself. Interactions among all these systems will produce what the patient perceives. The theory was criticized and considered conjectural because its underlying work was an electrophysiological investigation carried out in decerebrated cats, instead of an investigation of pain or cutaneous sensation. ${ }^{8}$ In a reply to the criticism above-a confutation which still holds 
true today-it was admitted that the mechanism by which the control is achieved remains completely unknown, but that a Gate Control beyond doubt exists.

\section{Reflex Sympathetic Dystrophy}

\section{Introduction}

Before describing any characteristic of reflex sympathetic dystrophy, it is necessary to note that this constellation of symptoms occurring after trauma is one of the most controversial of pain syndromes. The only thing which most patients have in common is that they have experienced an inciting event of some kind-a trauma or an operation on a limb-but, in fact, there is little uniformity in the presentation of symptoms. Many symptoms (sensory abnormalities, diminished strength, pain) cannot be measured objectively, and others (hyperhidrosis, skin colouring changes) are present only intermittently. However, the diagnosis of reflex sympathetic dystrophy has to be based solely on these clinical symptoms since no test or blood value can prove or exclude presence of the syndrome. The weakness of the diagnosis, together with our very limited understanding of the pathophysiology, and the resulting lack of successful therapies, have led to great controversy. Even the very existence of reflex sympathetic dystrophy has been questioned. ${ }^{10}$

An apparently inexhaustible set of names exists for the same constellation of symptoms - a situation which appears to be parallelled in all languages. ${ }^{11}$ Although it would seem obvious that having so many names for the same phenomenon is not going to help researchers to follow the same path in seeking a solution to the problem, nevertheless each group of workers seems to be devoted to their chosen nomenclature. Even today new names - or more particularly abbreviations and acronyms - are being coined: CPSMV (chronic pains associated with various combinations of negative and positive sensory, motor and vasomotor phenomena) ${ }^{12}$ and CRPS type 1 (complex regional pain syndrome). ${ }^{2}$ It was later argued that CRDS (dysfunction) would be more appropriate than CRPS.$^{13}$ In our opinion, new names simply do not help. Although admittedly the label 'reflex sympathetic dystrophy' does not accurately describe either what the syndrome is or what its effects are, nevertheless it is the best known and most widely used name for the disorder. ${ }^{14}$ For the sake of clarity, we will use the term reflex sympathetic dystrophy (henceforth RSD) for the condition in this thesis.

\section{Clinical Characteristics}

Classic RSD is initiated by a seemingly minor trauma and characterized by spontaneous pain, allodynia (pain due to a stimulus which does not normally provoke pain), motor dysfunction, abnormal sweating and abnormal vascular reactivity, plus trophic changes in later stages of the disorder. All symptoms occur in a distal distribution of a limb, and all are disproportionate to the inciting event. A distinguishing characteristic of RSD is that both pain and other somatosensory abnormalities 
extend outside the distribution of peripheral nerves, even if the inciting injury had involved a peripheral nerve. ${ }^{15}$ Most patients demonstrate only a selection of all possible signs and symptoms associated with RSD, while the severity of symptoms is also variable. In a large prospective study, the most common findings were found to be pain ( 93 percent of patients), discoloration of the skin ( 92 percent), altered skin temperature (91 percent), a limited range of motion ( 88 percent) and an increase in complaints after excercise (96 percent). ${ }^{16}$ While sensory symptoms like allodynia (79 percent) and hypoesthesia (76 percent) were often present, sympathetic symptoms which were thought to be characteristic of RSD, like hyperhidrosis (47 percent) and changed growth of hair ( 55 percent) and nails (60 percent) were less common.

Classically, RSD is subdivided into three successive stages: a warm 'acute' stage of 6 to 12 weeks; a 'dystrophic' stage with vasomotor instability and dystrophic changes, also of 6 to 12 weeks, and a cold 'atrophic' end-stage, characterized by progressive atrophy of skin and subcutaneous tissue. ${ }^{17}$ Full recovery is said to be unusual once these changes have evolved. I have found no prospective studies in which this staging is confirmed. On the contrary, in the aforementioned prospective study, RSD started with a cold extremity in 13 percent of patients, while some other patients still had a warm extremity 8 and 12 years after the complaints started. ${ }^{16}$ Thus, although there are cold and warm forms of RSD, staging of the syndrome would appear to be inappropriate. ${ }^{18}$

\section{Incidence}

Since in the past many different diagnostic criteria were used, the exact incidence of RSD is not precisely known, but has been assumed to be one case in every 2,000 accidents. ${ }^{19}$ While in most patients symptoms will subside after some years, ${ }^{20}$ a smaller percentage - again the incidence is unknown-will suffer chronically from RSD.

\section{Hypotheses on Mechanisms Underlying Reflex Sympathetic Dystrophy}

Many theories have been proposed to explain RSD, but none has proved satisfactory. A crucial reason for this lack of success is the denial of therapeutic failure. ${ }^{14}$ To a large extent, the theory on which therapy is based is circularly based upon anecdotes of successful therapy. ${ }^{12}$ For example, theories unable to explain the relief of pain by sympathetic block are often considered to be irrelevant. ${ }^{21,22}$

In 1864, Mitchell suggested that the syndrome was the result of an ascending neuritis affecting a damaged peripheral nerve. ${ }^{23}$ However, failure of peripheral nerve block or surgery to abolish pain indicates that more than a simple irritating peripheral lesion is involved.

Lewis, in 1920 , postulated the syndrome to be a state of painful vasodilation caused by the liberation of pain-producing vasodilator substances in response to antidromic impulses arising from the area of nerve injury. ${ }^{24}$ Later on, this process, also known as neurogenic inflammation, was confirmed and found to be mediated 
largely by the neuropeptides substance $\mathrm{P}$ and calcitonin gene-related peptide. ${ }^{25}$ Leriche, on the other hand, felt that pain was the result of tissue ischemia caused by vasoconstriction at the site of injury. ${ }^{26}$

Livingston (1943) suggested that a partial nerve injury creates an irritative focus. ${ }^{27}$ This focus then presents the spinal cord with a constant bombardment of noxious impulses that overwhelm and upset the normal functioning of the internuncial pool' of neurons, resulting in reverberating circuits in the spinal cord. This reverberating activity sends nerve impulses to the brain that are recognized as pain, and also to the anterior and lateral horns of the spinal cord, giving rise to skeletal muscle spasms and sympathetic hyperdysfunction with vasoconstriction. This increases the noxious stimulation in the periphery, which, added to the original irritative focus, sustains and augments the abnormal central activity, thereby establishing a vicious circle.

Sunderland tried to describe the missing pathological basis for Livingston's theory and proposed the 'turbulence hypothesis. ${ }^{28,29} \mathrm{After}$ damage to a peripheral nerve, the distal portion degenerates completely, while the proximal portion may undergo retrograde changes that can affect the structure and function of parent cell bodies. Sunderland argued that the retrograde reaction can in fact cross a synapse and effect changes in neurons with which the initial damaged neuron communicates. This can create hyperactive foci of abnormal spinal cord activity that become self-sustaining. These disturbances can induce similar change along pathways as far centrally as the cortex itself, with RSD forming the terminal effect of this abnormal activity.

Doupe stated in 1944 that efferent sympathetic impulses which are tonically active can cross over to sensory fibers in the area of injury via a newly created artificial synapse or ephapse originated from a breakdown in the normal insulation between adjacent fibers. ${ }^{30}$ Impulses that cross over to the afferent pain fibers could be directed toward the central nervous system (orthodromically) resulting in pain, or toward the periphery (antidromically), also causing pain by sensitizing the peripheral nociceptor, possibly through the release of vasoactive substances. This results in impulses directed back toward the central nervous system in the damaged fibers themselves or in neighboring fibers. However, this theory cannot explain the persistent pain seen after complete section of the nerve.

In the late fifties, Drucker observed that RSD can result from minor soft-tissue injuries and suggested that minuscule peripheral nerve twigs could be damaged in soft-tissue injury and form artificial synapses in the same manner as major nerve trunks. ${ }^{31}$ It was hypothesized that the resulting increased activity of the internuncial pool would stimulate anterolateral sympathetic efferents causing a further increase in the activity of the peripheral ephaptic synapse. Hence, a vicious circle of pain and sympathetic hyperactivity is thereby established.

Many textbooks have suggested that the pathogenesis of RSD may be related to hyperactivity of autonomic sympathetic axons. ${ }^{18,32-35}$ About 80 percent of cases would be relieved by sympathectomy. ${ }^{32}$ Later, it was recognized that RSD does not 
depend on hyperactivity of the sympathetic nervous system. Studies of the biochemistry and microcirculation of patients have even indicated a hypofunction of the sympathetic nervous system, which it was speculated results in denervation hypersensitivity to catecholamines. ${ }^{36,37}$ This theory, however, could not account for the sometimes very rapid onset of symptoms after injury. Sympathetically maintained pain (SMP) can occur in RSD, but pain may also be sympathetically independent (SIP). ${ }^{14,18,34}$ Thus, in contrast to many previous definitions, ${ }^{38}$ sympathetic blocks have a value in the diagnosis of the type of pain, but not in the diagnosis of RSD.

Other authors stress that since a significant number of patients 'respond' to therapeutic maneuvers such as sympathetic blocks, while a physiologic involvement has not been conclusively demonstrated, there must be a psychogenic etiology in some cases. ${ }^{39}$ Unfortunately, there has been little research, using standardized measures of mood and illness behavior, comparing patients with RSD to patients with other chronic pain disorders. In these few studies that have been reported, no evidence was found to suggest that in comparison to sufferers from chronic back pain, patients with RSD were psychologically unique. ${ }^{40-42}$ In an attempt to prove the contrary, Geertzen and colleagues chose to compare RSD patients to patients without a chronic pain disorder. ${ }^{43}$ Stressful life events appeared more common in the RSD group. However, the authors ignored the crucial fact that a trauma is also a stressful life event.

In 1983, Devor described how any form of injury or inflammation damages Schwann's cells, or the axons themselves, resulting in local demyelination or sprout outgrowth. ${ }^{44}$ The sprout or demyelinated segment incorporates excessive numbers of sodium and calcium channels as well as $\alpha$-adrenergic receptors, thus forming an ectopic pacemaker that discharges spontaneously, as well as in response to any depolarizing stimulus. Experimentally, there exists extensive evidence to support this theory. ${ }^{21}$

Three years later, Roberts proposed that trauma in some peripheral tissue first activates $\mathrm{C}$-nociceptors, thus exciting wide-dynamic range (WDR) neurons in the spinal cord and also causing these neurons to become more responsive to all subsequent afferent inputs (sensitization). ${ }^{45}$ If this sensitization of WDR neurons is persistent over time, even after healing is complete, mechanical stimulation of A-fiber mechanoreceptors leads to allodynia. In this hypothesis, the only abnormal neuronal state required is a persistent sensitization of WDR neurons.

Hannington-Kiff (1991), who had noticed similarities between the principal clinical manifestations of opioid withdrawal and the signs and symptoms of RSD, proposed that injury gives rise to an opioid-based modulation of activity in regional sympathetic ganglia. ${ }^{46}$ Failure of this process in some susceptible individuals leads to localised signs of opioid withdrawal. The reduction of neural traffic between limb and spinal cord, because of immobilisation, would contribute to the abolition of regional opioid modulation. In addition, Hannington-Kiff claimed that regional nerve blocks during limb surgery, solely or as a supplement to general anaesthesia, might help to avoid sensitization of WDR neurons as suggested by Roberts. 
In 1996, Burnstock proposed the involvement of purines in pain. ${ }^{47}$ Both ATP and, to a lesser extent, adenosine can stimulate sensory nerve endings in the skin, resulting in intense pain and pronounced increase in sensory nerve discharge. ATP is released as a cotransmitter with noradrenaline and neuropeptide $Y$ from sympathetic nerves, and consequently hyperactivity of these nerves could contribute to pain. The fact that ATP induces synthesis of the inflammatory mediator prostaglandin is indicative of the indirect role that ATP has in the generation of pain.

As noted by Woolf, the key to the causes of RSD is likely to be that, in certain individuals, peripheral nerve injury leads to development of maladaptive compensatory changes in both the peripheral and central nervous systems. ${ }^{48,49}$ He stresses that pain is not simply the consequence of the activation of a defined set of sensory pathways in the periphery, but rather a descriptor of a variety of different, unpleasant, uncomfortable and distressing sensations that may be elicited in quite a number of different ways. For example, peripheral nerve injury-probably of $\mathrm{C}$ fibers ${ }^{50}$ - has been shown to result in sprouting of $A \beta$ fibers into dorsal horn lamina II, thus causing mechanical allodynia. ${ }^{51}$ Continual nociceptive input to the dorsal horn may lead to central sensitization, which is the increased excitability of neuronal membranes. ${ }^{52}$ As a result of this mechanism, the dorsal horn neurons will exhibit an exaggerated and prolonged response to normal inputs of $A \delta$ and $C$ fibers.

Why one patient with peripheral nerve injury develops painful sequelae to the injury, while another with apparently very similar injuries does not, remains baffling. The tendency to develop RSD has been attributed to tobacco smoking, ${ }^{53}$ the temperament of the individual, ${ }^{54}$ and to genetic factors. ${ }^{55}$ In patients with RSD, the frequency of human leucocyte antigen-DQ1 - and also the closely linked DR15(2) - has been found to be significantly increased as compared with control frequencies. $^{56,57}$ This association indicates that RSD may indeed be organic in origin.

An exciting new development is the finding that vitamin $\mathrm{C}$ intake following trauma is capable of reducing the incidence of RSD. ${ }^{58}$ This study found a frequency of RSD of 7 percent in wrist fracture patients who had been given a daily dosis 500 $\mathrm{mg}$ vitamin $\mathrm{C}$, versus 22 percent in patients taking placebo. The reason why vitamin $C$ is capable of preventing RSD was ascribed to its function as an antioxidant, but, is in fact unclear.

\section{Diagnosis}

Probably the most repeated statement on RSD is that with early diagnosis and prompt treatment, prognosis is excellent. Apart from the fact that only few treatments with any proven effect actually exist, acceptability of this idea is hindered by there being no clearcut way of diagnosing a case.

RSD may be transient, permanent, migratory or recurrent; it may occur in one area, bilaterally or be more widespread throughout the body. Laboratory, radiological, histological and neurophysiological studies have not revealed any diagnostic features. ${ }^{14}$ Therefore, there seems no good reason to list here all the diagnostic criteria that have ever been reported. The most widely used are those put forward by 
the International Association for the Study of Pain (IASP), which require the presence of continuing pain, allodynia or hyperalgesia where the pain is disproportionate to any inciting event; evidence at some time of oedema, changes in skin blood flow or abnormal sudomotor activity in the region of the pain; and exclusion of other conditions that could account for the degree of pain and dysfunction. ${ }^{2} \mathrm{How}-$ ever, researchers continue to use arbitrary definitions, some of which do not require the presence of pain. ${ }^{16}$ Although such workers effectively limit the comparability of their studies, thus reducing the value of their research, they can hardly be blamed for this: a positive diagnosis following IASP criteria is likely to be correct in a mere 40 percent of cases, ${ }^{59}$ and in fact this figure has little meaning in the absence of a gold standard for diagnosis.

\section{Treatment}

\section{Physical Therapy}

Although physical therapy has been widely recommended as a first line treatment for RSD for many years, ${ }^{60,61}$ recommendations are provide no clarity on what modality of therapy is most appropriate. Only recently a randomized controlled trial has been used to examine the efficacy of physical therapy. This study found that in cases of RSD physical therapy produced a significant reduction in the severity of disability, impaired mobility and pain. The effects were already considerable by the first weeks of treatment. ${ }^{62}$

\section{Blocking the Sympathetic Nervous System}

Regional intravenous blocks aim at depleting noradrenaline in the post-ganglionic axon, thus regionally blocking the sympathetic nervous system. By this procedure, a tourniquet cuff is first applied and secured around the affected extremity. The arm or leg is raised above heart level for $60 \mathrm{sec}$ to drain venous blood and the tourniquet is then inflated to $50 \mathrm{~mm} \mathrm{Hg}$ ( $\mathrm{arm}$ ) or $100 \mathrm{~mm} \mathrm{Hg}$ (leg) above the systolic pressure. After returning the extremity to the horizontal position, the active solution - usually guanethidine - is injected intravenously. Approximately fifteen minutes later, the tourniquet is removed, and treatment is complete. This method has been recommended as the simplest, most effective, and safest way to relieve pain associated with sympathetic hyperactivity. ${ }^{63}$ Randomized controlled trials in later years have all demonstrated that guanethidine blocks in RSD patients are no more effective as analgesics than placebo or no treatment. ${ }^{64,65}$ In addition, administration of intravenous guanethidine peri-operatively has been shown not to protect patients from post-operative RSD. ${ }^{6}$ Results of radiofrequency lesions of the sympathetic nervous system in RSD patients have not been associated with better results. ${ }^{67}$ Therefore, interrupting the sympathetic nervous system may be considered futile for obtaining long-term relief of pain in many if not most of RSD patients. ${ }^{68}$

\section{Treatment of Neuropathic Pain}

Opioids Although they may produce side effects, opioids nevertheless have a strong 
effect on nociceptive pain. However, these drugs are only moderately succesful in the treatment of neuropathic pain. In randomized controlled trials, both morphine and tramadol have been shown to have some effect on neuropathic pain; the frequency of side effects-nausea, constipation, headache and somnolence-is somewhat smaller in the case of tramadol. ${ }^{69-71}$

Non-steroidal Anti-inflammatory Drugs Non-steroidal anti-inflammatory drugs (NSAIDs) are effective for the treatment of nociceptive but probably not for neuropathic pain. This has been shown by two well-designed studies that found no analgesia. ${ }^{72,73}$

Tricyclic Antidepressants Tricyclics have since long been recognized as being effective in the treatment of neuropathic pain, probably because of the facilitation of the analgesic action of norepinephrine and serotonine released by endogenous analgesic systems, and the blockade of sodium channels in peripheral sprouts from damaged nerves. ${ }^{74}$ Whereas the pain relief produced by amitriptyline and nortriptyline is similar, nortriptyline has fewer unacceptable side effects, such as constipation, dry mouth, drowsiness and slurred speech. ${ }^{75} \mathrm{~A}$ degree of controversy exists as to whether the analgesic result is separable from the impact of the antidepressants on mood, although many reports have shown analgesic benefit without significant change in mood measurements. According to a systematic review, as compared with placebo, on average, out of 100 patients with neuropathic pain given antidepressants, 30 will obtain more than 50 percent pain relief; 30 will have minor adverse reactions; and four will have to stop treatment because of major adverse effects. ${ }^{76}$

Anticonvulsants Anticonvulsants have a similar mode of action to tricyclic antidepressants, but appear to have fewer side effects. In two randomized controlled trials, the most important drug in this group, gabapentin, has been shown to be successful in the treatment of pain and sleep interference associated with neuropathy. Side effects were somnolence, dizziness, confusion and peripheral edema. ${ }^{77,78}$

NMDA Receptor Antagonists NMDA (N-methyl-D-aspartate) receptors are involved in the development of neuropathic pain. To date, it has not proved possible to block only the specific pain-related regions of the receptor. Consequently, the available drugs - ketamine and dextromethorphan - result in moderate pain relief together with a number of side effects. ${ }^{79}$ No reports of large randomized controlled trials are available.

Sodium Channel Blockers Sodium channel blockers, which are commonly used as antiarrhythmics, are reported to possess local anesthetic properties. The drugs are thought to inhibit the hyperexcitability of dorsal root ganglion neurons that occurs after nerve trauma, as a result of up- and down- regulation of sodium channels. ${ }^{80}$ Reports of large randomized controlled trials on the effect of carbamazepine and mexiletine for neuropathic pain are not available but results to date are not hopeful. ${ }^{81}$ 
Calcitonin Calcitonin has been used to relieve skeletal pain from cancer metastases or osteoporotic fractures. Several small case studies have reported an antinociceptive effect of this treatment in RSD. A major disadvantage of calcitonin is the need for its parenteral administration but, nowadays, it can be given intranasally. Randomized controlled trials have produced results ranging from 'no demonstrable effect' to significant improvements of pain, range of motion and motor functions. ${ }^{82-84}$ Thus, further studies are required before the place of calcitonin in pain therapy can be established.

Topical Treatments Although there is some inconvenience associated with longterm topical application, results are not disappointing. Topical application of both capsaicin and lidocaine have been found to be both safe and effective in the treatment of neuropathic pain. ${ }^{85,86}$ About 10 percent of patients report a burning or stinging sensation at local sites of application of capsaicin-the pungent component of red peppers.

Transcutaneous Electrical Nerve Stimulation

Transcutaneous electrical nerve stimulation (TENS) is a non-invasive form of neurostimulation that gives electrical stimulation via electrodes attached to the skin, either at the level of the painful area, or at the level of the nerve trunk. Because of the paraesthesiae that accompany stimulation, it is effectively impossible to perform blinded randomized controlled trials. A study on chronic low-back pain applied sham TENS in the control group; TENS appeared no more effective than placebo. ${ }^{87}$ In a small series of RSD patients, TENS was found to be effective in the majority of sufferers. ${ }^{88}$

Miscellaneous

Many other treatments for RSD are in use, which have proved to have only limited effect, or, on the other hand, have not as yet had their effectiveness studied. In the Netherlands, for example, it is common practice to apply drugs which are thought to act as oxygen radical scavengers-mannitol, $\mathrm{N}$-acetyl-cysteine and dimethylsulfoxide (DMSO) ${ }^{89,90}$ Several studies have described pain relief lasting for months with bisphosphonates. ${ }^{91,92}$ These drugs bind to bone and inhibit bone resorption by inhibition of osteoclasts; pain relief may result from effects on prostaglandin E2 and other nociceptive substances. Others have propagated the use of vasodilatory drugs like calcium channel blockers to treat cold and bluish limbs, ${ }^{93,94}$ systemic or epidurally administered drugs to block the sympathetic nervous system, ${ }_{3}^{95,96}$ or corticosteroids to reduce swelling and possibly nerve compression. ${ }^{97,98}$ As stated, the effectiveness of these treatments has not or only partly been shown in controlled studies.

\section{Spinal Cord Stimulation}

\section{History}

The treatment of pain by electricity has a long history. The ancient Egyptians and 
the Greeks used electric eels to apply shock therapy in painful conditions, while the ancient Romans applied electric rays (torpedinae) to the human body to treat cephalgia and arthralgia. ${ }^{99}$ Genuine treatment possibilities became available after 1800 once the electrochemical battery had been invented. A variety of ailments, including paralysis, pain and angina were treated in the nineteenth century by using direct current. The first external cardiac pacemaker suitable for clinical use was developed in 1958, and very shortly afterwards the first implantable pacemaker became a reality. ${ }^{100,101}$

The Gate Control Theory for pain put forward by Melzack and Wall, ${ }^{7}$ encouraged the development of the first spinal cord stimulator, which was first inserted in a human being in $1967 .{ }^{102}$ Inappropriate application of the treatment to patients suffering from almost any type of painful condition resulted in many poor outcomes, and consequently, enthusiasm faded. In 1974, even Shealy, who had performed the first ever implantation, gave up once and for all implanting spinal cord stimulation (henceforth SCS) systems. ${ }^{99}$ Towards the end of the eighties, the procedure regained some acceptance, and it is now mainly being used to treat pain in peripheral vascular disease, failed back surgery syndrome and angina pectoris.

There had been insufficient research carried out on the effect of SCS in RSD. Although what studies were available reported optimistic results, these retrospective surveys lacked information on selection criteria, or presented solely results from patients who had reacted positively to test stimulation. ${ }^{88,103,104}$

\section{Technique}

SCS is indicated in the following situations. ${ }^{105}$

1. An objective basis for the complaint of pain has been established.

2. Alternative treatments have been exhausted or are unacceptable by comparison.

3. Psychological clearance has been obtained to rule out: (a) significant drug habituation problems, $(b)$ major psychiatric diagnoses or significant personality disorders, and $(c)$ to address issues of secondary gain.

4. The efficacy of the procedure has been demonstrated technically by a therapeutic trial with a temporary electrode.

Apart from applying percutaneous electrodes, SCS can also be carried out using plate electrodes that require a laminectomy for implantation. ${ }^{105}$ A temporary percutaneous electrode may be placed under local anesthesia without the need for any sedation or premedication that might compromise patient participation in the procedure. With the patient in the prone position, the epidural space is localised with a Tuohy needle. Using direct fluoroscopy, the electrode is advanced into the posterior epidural space, connected to an external screener and positioned until the patient reports that the paresthesiae overlap the topography of the painful area. Then the needle is withdrawn, the electrode is tunneled 5 to $10 \mathrm{~cm}$ and fixed to the skin with a stitch. After a testing period, the temporary lead is removed. 
The criteria for proceeding from a temporary to a permanent implant have varied widely and arbitrarily: some researchers have required as much as 70 to 75 percent reported pain relief, ${ }^{106}$ and others no more then 30 percent. ${ }^{107}$ Trials of up to 2 months, ${ }^{108}$ and as short as single-stage implantation with only intraoperative testing, ${ }^{109}$ have all been reported. It is not clear that any of these protocols substantially influence long-term success rates. ${ }^{105}$

Implantation of the permanent electrode requires a $5 \mathrm{~cm}$ vertical midline incision in the skin overlying the thoracic or lumbar spine, depending on the affected extremity. The electrode is then positioned similarly to the temporary electrode, fixed with special clips and connected to an extension lead. Following administration of a sedative, the extension lead is tunneled toward the left-lower abdomen, where it is connected to a pulse generator positioned in a subcutaneous pouch. After closing the skin, patients are able to control the amplitude of the pulse generator by means of a patient programmer. Using a console programmer, other parameters, e.g. rate and pulse width, can also be adjusted.

\section{Hypotheses on Mechanism of Action}

SCS came about as the direct consequence of the aforementioned Gate Control Theory. The 'gate' in the dorsal horn was thought to govern the central transmission of neural activity signalling pain. Excess of large fiber activity over small fiber activity would result in a closed 'gate' and thus produce pain relief. It was claimed that in a mixed population of nerve fibers, it would be the large, rather than the small fibers, which were susceptible to recruitment by an externally applied electrical field. This suggested that at a critical stimulation amplitude, large fibers might be recruited selectively, thus closing the spinal 'gate'. Once it was demonstrated experimentally that hyperalgesia can be signalled by large fibers, ${ }^{110}$ a finding totally at variance with the Gate Theory, it became evident that the true working mechanism of SCS was in fact a mystery.

At present, one can still only speculate about the exact mechanism responsible for the effect of SCS, but several findings have helped to increase our understanding. When peripheral nerves are stimulated, there is a reduction in primary afferent conduction velocity, suggesting that stimulation results peripherally in an inhibition of normal afferent conduction. Moreover, at higher stimulus frequencies nerve fibers fail to conduct action potentials, a phenomenon known as a frequencyrelated conduction block. ${ }^{11,112}$ Since patients often report long-lasting post stimulation effect, peripheral desensitization through antidromic activation of primary afferent fibers is thought unlikely to be the sole explanation. In addition, activation of descending inhibitory pathways, effects on sympathetic systems, or brain stem loops, and thalamo-cortical mechanisms masking the nociceptive input have been suggested as possibilities. ${ }^{13-116}$ Experimental studies have demonstrated that, in the dorsal horn, the inhibiting neurotransmitter gamma-amino butyric acid, the levels of which are markedly reduced in animals submitted to peripheral nerve lesions, ${ }^{117}$ increases in concentration after SCS has taken place. ${ }^{118}$ 


\section{Aims of this Thesis}

The aim of this thesis is to assess the effectiveness of SCS on the intensity of pain in patients with chronic RSD. In addition, the effect of SCS has been evaluated with regard to function, depression, sensory characteristics and health-related quality of life. Alongside the clinical trial, an economic evaluation was performed in order to relate possible effects to their costs.

\section{Methodological Considerations}

The most appropriate approach to determine the effectiveness of a treatment is to perform a double-blind randomized controlled trial. Unfortunately, this is impracticable for SCS. During stimulation patients perceive paresthesiae and therefore blinding is impossible. The best alternative left is to perform an unblinded randomized controlled trial in which patients are randomized either into a group with SCS, or into a group without SCS. This approach was thought inappropriate in the present study since the study population consisted of patients who had been suffering from severe pain for many years, while no existing treatment had resulted in lasting relief. Because SCS would be effectively the last hope for these patients, it was considered unlikely that they would be willing to continue with the study if they found themselves randomized into a group undergoing no treatment whatsoever. Offering all patients in the study standardized physical therapy alongside possible SCS was resorted to as a means of keeping patients' premature withdrawal down to a minimum, and detering them from seeking alternative types of therapy.

Hence, patients in the present study were randomized either into a group with SCS and standardized physical therapy, or into a group receiving only standardized physical therapy.

\section{References}

1. Wall PD. The John J Bonica distinguished lecture on stability and instability of central pain mechanisms, Vth world congress on pain, Amsterdam, 1988. Elsevier.

2. Merskey H, Bogduk N. Classification of chronic pain: descriptions of chronic pain syndromes and definitions of pain terms. Seattle: IASP Press, 1994: 40-2.

3. Descartes R. L'homme. New York: Cambridge University Press, 1644.

4. Treede RD, Kenshalo DR, Gracely RH, Jones AKP. The cortical representation of pain. Pain 1999; 79: 105-11.

5. Sinclair DC. Cutaneous sensation and the doctrine of specific energy. Brain 1955; 78: 584-614.

6. Weddell G, Palmer E, Paillie W. Nerve endings in mammalian skin. Biol Rev 1955; 30: 159-95.

7. Melzack R, Wall PD. Pain mechanisms: a new theory. Science 1965; 150: 971-8.

8. Nathan PW. The gate-control theory of pain-a critical review. Brain 1976; 99: 12358. 
9. Wall PD. The gate control theory of pain mechanisms - a re-examination and restatement. Brain 1978; 101: 1-18.

10. Ochoa JL. Pain mechanisms in neuropathy. Curr Opin Neurol 1994; 7: 407-14.

11. Veldman PHJM. Clinical aspects of reflex sympathetic dystrophy. Department of Surgery. Nijmegen: Catholic University of Nijmegen, 1995.

12. Ochoa IL. Guest editorial: essence, investigation, and management of 'neuropathic' pains: hopes from acknowledgment of chaos. Muscle \& Nerve 1993; 16: 997-1008.

13. van der Laan L, Veldman PHJM, Goris RJA. Letter to the Editor. Pain 1997; 72: 291.

14. Schott GD. An unsympathetic view of pain. Lancet 1995; 345: 634-6.

15. Boas RA. Complex regional pain syndromes: symptoms, signs, and differential diagnosis. In: Jänig W, Stanton-Hicks M, eds. Reflex sympathetic dystrophy: a reappraisal. Vol. 6. Seattle: IASP Press, 1996: 79-92.

16. Veldman PHJM, Reynen HM, Arntz IE, Goris RJA. Signs and symptoms of reflex sympathetic dystrophy: prospective study of 829 patients. Lancet 1993; 342: 1012-16.

17. Steinbrocker $\mathrm{O}$, Spitzer $\mathrm{H}$, Friedmann $\mathrm{HH}$. The shoulder-hand syndrome in reflex dystrophy of the upper extremity. Ann Intern Med 1947; 29: 22-52.

18. Blumberg $\mathrm{H}$, Jänig $\mathrm{W}$. Clinical manifestations of reflex sympathetic dystrophy and sympathetically maintained pain. In: Wall PD, Melzack R, eds. Textbook of pain. Edinburgh: Churchill Livingstone, 1994: 685-98.

19. Plewes LW. Sudeck's atrophy in the hand. J Bone Joint Surg 1956; 38B: 195-203.

20. Zyluk A. The natural history of post-traumatic reflex sympathetic dystrophy. J Hand Surg 1998; 23B: 20-3.

21. Schwartzman RJ, McLellan TL. Reflex sympathetic dystrophy: a review. Arch Neurol 1987; 55: 555-61.

22. Raj P, Calodney A, Janisse T, Cannella J. Reflex sympathetic dystrophy. In: Browner B, et al., eds. Skeletal trauma. Philadelphia: W.B. Saunders Company, 1992: 471-99.

23. Mitchell SW, Morehouse GR, Keen WW. Gunshot wounds and other injuries of nerves. Philadelphia: J.B. Lippincott Co., 1864: 164.

24. Lewis D, Gatewood W. Treatment of causalgia: results of intraneural injections of 60 per cent alcohol. JAMA 1920; 74: 1-4.

25. Chahl LA. Antidromic inflammation and neurogenic inflammation. Pharmac Ther 1988; 37: 275-300.

26. Leriche $R$. De la causalgia envisage comme une neurite du sympathique et son traitement par la denudation et l'excision de plexus nerveux periarteriels. Presse Med 1916;23: 184.

27. Livingston WK. Pain mechanisms. A physiologic interpretation of causalgia and its related states. New York: MacMillan, 1944.

28. Sunderland S, Kelly M. The painful sequelae to peripheral nerves. Aust N Z J Surg 1948; 18: 75-118.

29. Sunderland S. Pain mechanisms in causalgia. J Neurol Neurosurg Psychiatry 1976; 39: 471-80.

30. Doupe J, Cullen CR, Chance GQ. Post-traumatic pain and the causalgic syndromes. J Neurol Neurosurg Psychiatry 1944; 7: 33-48.

31. Drucker WR, Hubay CA, Holden WD, al. e. Pathogenesis of post-traumatic sympathetic dystrophy. Am J Surg 1959; 97: 454-65.

32. Schaumberg HH, Berger AR, Thomas PK. Acute and chronic focal nerve injury lesions. Disorders of peripheral nerves. Philadelphia: F.A. Davis Company, 1992: 209-253. 
33. Telles-Ribeiro CR, de Oliviera LF. Sympathetic procedures for the treatment of persistent pain syndromes. In: Gildenberg PL, Tasker RR, eds. Textbook of stereotactic and functional neurosurgery. New York: The McGraw-Hill Companies, 1998: 2009-13.

34. Wilson PR. Reflex sympathetic dystrophy. In: Low PA, ed. Clinical autonomic disorders. Philadelphia: Lippincott Raven Publishers, 1997: 537-43.

35. Omer GE, Pirela-Cruz M. Complications of peripheral nerve injuries. In: Epps $\mathrm{CH}$, ed. Complications in orthopaedic surgery. Vol. 2. Philadelphia: J.B. Lippincott Company, 1994: 834-6.

36. Drummond PD, Finch PM, Smythe GA. Reflex sympathetic dystrophy: the significance of differing plasma catecholamine concentrations in affected and unaffected limbs. Brain 1991; 114: 2025-36.

37. Kurvers HAJM, Jacobs MJHM, Beuk RJ, et al. Reflex sympathetic dystrophy: result of autonomic denervation? Clin Sci 1994; 87: 663-9.

38. Weiss APC. Thermal regulatory testing for pain dysfunction syndromes. Lancet 1994; 344: 209-10.

39. Gordon TR, Goldstein IM, Waxman SG. Sensory abnormalities of the limbs and trunk. In: Bradley WG, Daroff RB, Fenichel GM, Marsden CD, eds. Neurology in clinical practice. Boston: Butterworth-Heinemann, 1996: 391-405.

40. Lynch ME. Psychological aspects of reflex sympathetic dystrophy: a review of the adult and paediatric literature. Pain 1992; 49: 337-47.

41. Ciccone DS, Bandilla EB, Wu W. Psychological dysfunction in patients with reflex sympathetic dystrophy. Pain 1997; 71: 323-33.

42. Monti DA, Herring CL, Schwartzmann RJ, Marchese M. Personality assessment of patients with complex regional pain syndrome type I. Clin J Pain 1998; 14: 295302.

43. Geertzen JH, de Bruijn-Kofman AT, de Bruijn HP, van de Wiel HB, Dijkstra PU. Stressful life events and psychological dysfunction in complex regional pain syndrome type I. Clin J Pain 1998; 14: 143-7.

44. Devor M. Nerve pathophysiology and mechanisms of pain in causalgia. J Auton Nerv Syst 1983; 7: 371-84.

45. Roberts WJ. A hypothesis on the physiologic basis for causalgia and related pains. Pain 1986; 24: 297-311.

46. Hannington-Kiff JG. Does failed natural opioid modulation in regional sympathetic ganglia cause reflex sympathetic dystrophy? Lancet 1991; 338: 1125-7.

47. Burnstock G. A unifying purinergic hypothesis for the initiation of pain. Lancet 1996; 347: 1604-5.

48. Woolf CJ. The contribution of both the peripheral and central nervous systems to the pain that follows peripheral nerve injury. In: Samii M, ed. Peripheral nerve lesions. Berlin: Springer-Verlag, 1990.

49. Woolf CJ, Mannion RJ. Neuropathic pain: aetiology, symptoms, mechanisms, and management. Lancet 1999; 353: 1959-64.

50. Mannion RJ, Doubell TP, Coggeshall RE, Woolf CJ. Collateral sprouting of uninjured primary afferent A-fibers into the superficial dorsal horn of the adult rat spinal cord after topical capsaicin treatment to the sciatic nerve. J Neurosci 1996; 16: 5189-95.

51. Woolf CJ, Shortland P, Coggeshall RE. Peripheral nerve injury triggers central sprouting of myelinated afferents. Nature 1992; 355: 75-8. 
52. Woolf CJ. Evidence for a central component of post-injury pain hypersensitivity. Nature 1983; 306: 686-8.

53. An HS, Hawthorne KB, Jackson WT. Reflex sympathetic dystrophy and cigarette smoking. J Hand Surg 1988; 13A: 458-60.

54. Leriche R. The surgery of pain. London: Baillière, Tindall and Cox, 1939: 119-201.

55. Devor $M$, Raber P. Heritability of symptoms in an experimental model of neuropathic pain. Pain 1990; 42: 51-67.

56. Kemler MA, van de Vusse AC, van den Berg-Loonen EM, Barendse GAM, van Kleef M, Weber WEJ. HLA-DQ1 associated with reflex sympathetic dystrophy. Neurology 1999; 53: $1350-1$.

57. Mailis A, Wade J. Profile of caucasian women with possible genetic predisposition to reflex sympathetic dystrophy: a pilot study. Clin J Pain 1994; 10:210-17.

58. Zollinger PE, Tuinebreijer WE, Kreis RW, Breederveld RS. Effect of vitamin C on frequency of reflex sympathetic dystrophy in wrist fractures: a randomised trial. Lancet 1999; 354: 2025-8.

59. Bruehl S, Harden RN, Galer BS, et al. External validation of IASP diagnostic criteria for complex regional pain syndrome and proposed research diagnostic criteria. Pain 1999; 81: $147-54$.

60. Kingery WS. A critical review of controlled clinical trials for peripheral neuropathic pain and complex regional pain syndromes. Pain 1997; 73: 123-39.

61. Stanton-Hicks $M$, Baron $R$, Boas $R$, et al. Complex regional pain syndromes: guidelines for therapy. Clin J Pain 1998; 14: 155-66.

62. Oerlemans HM, Oostendorp RAB, de Boo T, Goris RJA. Pain and reduced mobility in complex regional pain syndrome I: outcome of a prospective randomised controlled trial of adjuvant physical therapy versus occupational therapy. Pain 1999; 83: 77-83.

63. Hannington-Kiff J. Pharmacological target blocks in painful dystrophic limbs. In: Wall P, Melzack R, eds. Textbook of pain. London: Churchill Livingstone, 1989: 754-66.

64. Jadad AR, Carroll D, Glynn CJ, McQuay HJ. Intravenous regional sympathetic blockade for pain relief in reflex sympathetic dystrophy: a systematic review and a randomized, double-blind crossover study. J Pain Symptom Manag 1995; 10: 13-20.

65. Ramamurthy $S$, Hoffman J, Goup tGS. Intravenous regional guanethidine in the treatment of reflex sympathetic dystrophy/causalgia: a randomized, double-blind study. Anesth Analg 1995; 81: 718-23.

66. Gschwind C, Fricker R, Lacher G, Jung M. Does peri-operative guanethidine prevent reflex sympathetic dystrophy? J Hand Surg 1995; 20B: 773-5.

67. Forouzanfar T, van Kleef M, Weber WEJ. Radiofrequency lesions of the stellate ganglion in chronic pain syndromes-retrospective analysis of the efficacy in 86 patients with presumed sympathetic maintained pain. Clin J Pain 2000; 16: 164-8.

68. Schott GD. Interrupting the sympathetic outflow in causalgia and reflex sympathetic dystrophy: a futile procedure for many patients. BMJ 1998; 316: 792-3.

69. Dellemijn PL, Vanheste JAL. Randomised double-blind active-placebo-controlled crossover trial of intravenous fentanyl in neuropathic pain. Lancet 1997; 349: 753-8.

70. Watson CP, Babul N. Efficacy of oxycodone in neuropathic pain: a randomized trial in postherpetic neuralgia. Neurology 1998; 50: 1837-41.

71. Harati $Y$, Gooch C, Swenson M, et al. Double-blind randomized trial of tramadol for the treatment of the pain of diabetic neuropathy. Neurology 1998; 50: 1842-6. 
72. Max MB, Schafer SC, Culnane M, Dubner R, Gracely RH. Association of pain relief with drug side-effects in postherpetic neuralgia: a single-dose study of clonidine, codeine, ibuprofen, and placebo. Clin Pharmacol Ther 1988; 43: 363-71.

73. Weber $\mathrm{H}$, Holme I, Amlie E. The natural course of acute sciatica with nerve root symptoms in a double-blind placebo-controlled trial evaluating the effect of piroxicam. Spine 1993; 11: 1433-8.

74. Max MB, Lynch SA, Muir J, Shoaf SE, Smoller B, Dubner R. Effects of desipramine, amitriptyline, and fluoxetine on pain in diabetic neuropathy. N Engl J Med 1992; 326: 1250-6.

75. Watson CP, Vernich L, Chipman M, Reed K. Nortriptyline versus amitriptyline in postherpetic neuralgia: a randomized trial. Neurology 1998; 51: 1166-71.

76. McQuay HI, Tramer M, Nye BA, Carroll D, Wiffen PJ, Moore RA. A systemic review of antidepressants in neuropathic pain. Pain 1996; 68: 217-27.

77. Backonja M, Beydoun A, Edwards KR, et al. Gabapentin for the symptomatic treatment of painful neuropathy in patients with diabetes mellitus: a randomized controlled trial. JAMA 1998; 280: 1831-6.

78. Rowbotham M, Harden N, Stacey B, Bernstein P, Magnus-Miller L. Gabapentin for the treatment of postherpetic neuralgia: a randomized controlled trial. JAMA 1998; 280: $1837-42$.

79. Max MB, Byas-Smith MG, Gracely RH, Bennett GJ. Intravenous infusion of the NMDA antagonist, ketamine, in chronic posttraumatic pain with allodynia: a double-blind comparison to alfentanil and placebo. Clin Neuropharmacol 1995; 18: 360-8.

80. Rizzo MA. Successful treatment of painful traumatic mononeuropathy with carbamazepine: insights into a possible molecular pain mechanism. I Neurol Sci 1997; 152: $103-6$.

81. Kieburtz K, Simpson D, Yiannoutsos C, et al. A randomized trial of amitriptyline and mexiletine for painful neuropathy in HIV infection. AIDS Clinical Trial Group 242 Protocol Team. Neurology 1998; 51: 1682-8.

82. Bickerstaff DR, Kanis JA. The use of nasal calcitonin in the treatment of post-traumatic algodystrophy. Br J Rheumatol 1991; 30: 291-4.

83. Gobelet C, Waldburger M, Meier JL. The effect of adding calcitonin to physical treatment on reflex sympathetic dystrophy. Pain 1992; 48: 171-5.

84. Hamamci N, Dursun E, Ural C, Cakci A. Calcitonin treatment in reflex sympathetic dystrophy: a preliminary study. Br J Clin Pract 1996; 50: 373-5.

85. Watson CP, Tyler KL, Bickers DR, Millikan LE, Smith S, Coleman E. A randomized vehicle-controlled trial of topical capsaicin in the treatment of postherpetic neuralgia. Clin Ther 1993; 15: 510-26.

86. Rowbotham MC, Davies PS, Verkempinck C, Galer BS. Lidocaine patch: double-blind controlled study of a new treatment method for post-herpetic neuralgia. Pain 1996; 65: $39-44$.

87. Deyo RA, Walsh NE, Martin DC, Schoenfeld LS, Ramamurthy S. A controlled trial of transcutaneous electrical nerve stimulation (TENS) and exercise for chronic low back pain. N Engl J Med 1990; 322: 1627-34.

88. Robaina FJ, Rodriguez JL, de Vera JA, Martin MA. Transcutaneous electrical nerve stimulation and spinal cord stimulation for pain relief in reflex sympathetic dystrophy. Stereotact Funct Neurosurg 1989; 52: 53-62. 
89. Goris RJA. Treatment of reflex sympathetic dystrophy with hydroxyl radical scavengers. Unfallchirurg 1985; 88: 330-2.

90. Zuurmond WWA, Langendijk PNJ, Bezemer PD, Brink HEJ, de Lange JJ, van Loenen AC. Treatment of acute reflex sympathetic dystrophy with DMSO 50 percent in a fatty cream. Acta Anaesthesiol Scand 1996; 40: 364-7.

91. Cortet B, Flipo RM, Coquerelle P, Duquesnoy B, Delcambre B. Treatment of severe, recalcitrant reflex sympathetic dystrophy: assessment of efficacy and safety of the second generation bisphosphonate pamidronate. Clin Rheumatol 1997; 16: 51-6.

92. Adami S, Fossaluzza V, Gatti D, Fracassi E, Braga V. Bisphosphonate therapy of reflex sympathetic dystrophy syndrome. Ann Rheum Dis 1997; 56: 201-4.

93. Prough DS, McLeskey CH, Poehling GG, et al. Efficacy of oral nifedipine in the treatment of reflex sympathetic dystrophy. Anesthesiology 1985; 62: 796-9.

94. Muizelaar JP, Kleyer M, Hertogs IA, DeLange DC. Complex regional pain syndrome (reflex sympathetic dystrophy and causalgia): management with the calcium channel blocker nifedipine and/or the alpha-sympathetic blocker phenoxybenzamine in 59 patients. Clin Neurol Neurosurg 1997; 99: 26-30.

95. Simson G. Propanolol for causalgia and Sudeck's atrophy. JAMA 1974; 227: 327.

96. Rauck RL, Eisenach JC, Jackson K, Young LD. Epidural clonidine treatment for refractory reflex sympathetic dystrophy. Anesthesiology 1993; 79: 1163-9.

97. Christensen $\mathrm{K}$, Jensen EM, Noer I. The reflex dystrophy syndrome: response to treatment with systemic corticosteroids. Acta Chir Scand 1982; 148: 653-5.

98. Grundberg AB. Reflex sympathetic dystrophy: treatment with long-acting intramuscular corticosteroids. J Hand Surg 1996; 21A: 667-70.

99. History of neuromodulation: part one-spinal cord stimulation. Neuromodulation News 1999; 2: 3-9.

100. den Dulk K. Pacemaker and tachycardia. Maastricht, 1984.

101. Elmqvist R, Senning A. Implantable pacemaker for the heart, International Conference on Medical Electronics, Paris, 1959. Hifte and sons.

102. Shealy CN, Mortimer JT, Reswick JB. Electrical inhibition of pain by stimulation of the dorsal columns: a preliminary report. Anesth Analg 1967; 46: 489-91.

103. Barolat G, Schwartzman R, Woo R. Epidural spinal cord stimulation in the management of reflex sympathetic dystrophy. Stereotact Funct Neurosurg 1989; 53: 29-39.

104. Kumar K, Nath RK, Toth C. Spinal cord stimulation is effective in the management of reflex sympathetic dystrophy. Neurosurgery 1997; 40: 503-8.

105. North RB. Spinal cord stimulation. In: North RB, Levy RM, eds. Neurosurgical management of pain. New York: Springer-Verlag, 1997: 271-82.

106. De la Porte C, Van de Kelft E. Spinal cord stimulation in failed back surgery syndrome. Pain 1993; 52: 55-61.

107. Bel S, Bauer BL. Dorsal column stimulation (DCS): cost to benefit analysis. Acta Neurochir 1991; 52(suppl.): 121-3.

108. Meglio M, Cioni B, Rossi GF. Spinal cord stimulation in management of chronic pain. J Neurosurg 1989; 70: 519-24.

109. Feler C, Kaufman S. Spinal cord stimulation: one stage? Acta Neurochir 1992; 117: 91.

110. Campbell JN, Meyer RA. Primary afferents and hyperalgesia. In: Yaksh TL, ed. Spinal afferent processing. New York: Plenum Press, 1986: 59-81. 
111. Campbell JN, Davis KD, Meyer RA, North RB. The mechanism by which dorsal column stimulation affects pain: evidence for a new hypothesis. Pain 1990; 5: S228.

112. Struijk JJ, Holsheimer J, van der Heide GG, Boom HB. Recruitment of dorsal column fibers in spinal cord stimulation: influence of collateral branching. IEEE T Bio-Med Eng 1992; 39: 903-12.

113. Linderoth B. Dorsal column stimulation and pain: experimental studies of putative neurochemical and neurophysiological mechanisms. Department of Neurosurgery. Stockholm: Karolinska Institutet, 1992.

114. Roberts MHT, Rees H. Physiological basis of spinal cord stimulation. Pain Reviews 1994; 1: 184-98.

115. Roberts MHT. Physiological mechanisms activated by stimulation of the dorsal columns. In: Horsch S, Claeys L, eds. Spinal cord stimulation: an innovative method in the treatment of PVD and angina. Darmstadt: Steinkopff Verlag, 1995: 3-9.

116. Stiller CO, Linderoth B, O'Connor WT, et al. Repeated spinal cord stimulation decreases the extracellular level of gamma-aminobutyric acid in the periaqueductal grey matter of freely moving rats. Brain Res 1995; 699: 231-41.

117. Stiller CO, Cui JG, O'Connor WT, Brodin E, Meyerson BA, Linderoth B. Release of gamma-aminobutyric acid in the dorsal horn and suppression of tactile allodynia by spinal cord stimulation in mononeuropathic rats. Neurosurgery 1996; 39: 367-74.

118. Linderoth B, Stiller CO, Gunasekera L, O'Connor WT, Ungerstedt U, Brodin E. Gamma-aminobutyric acid is released in the dorsal horn by electrical spinal cord stimulation: an in vivo microdialysis study in the rat. Neurosurgery 1994; 34: 484-8. 

CHAPTER 2

\section{Electrical Spinal Cord Stimulation in Reflex Sympathetic Dystrophy: Retrospective Analysis of 23 Patients}

Marius A. Kemler, Gerard A.M. Barendse, Maarten van Kleef, Frans A.J.M. van den Wildenberg, Wilhelm E.J. Weber 


\section{Introduction}

Reflex sympathetic dystrophy (RSD) is a neuropathic pain syndrome of unknown origin. The syndrome is now also referred to as complex regional pain syndrome, Type 1 (CRPS 1). ${ }^{1}$ It is characterized by motor symptoms, sensory symptoms (burning pain, allodynia, and hypoesthesia), and symptoms of sympathetic disturbance (skin color changes, swelling, hyperhidrosis, and trophic changes in the skin and bone of the affected extremity). Because nearly all cases are precipitated by trauma, ${ }^{2}$ most scientists agree that nerve injury is involved in the pathogenesis of the syndrome and that this would cause secondary changes in the dorsal horn and/or pain maintaining sympathetic complications. ${ }^{3}$ Because the cause of RSD remains unknown, treatment is largely aimed at relieving the pain. Conventional pain treatments, however, appear ineffective in most cases of RSD.,

Electrical spinal cord stimulation (SCS) has been used to treat pain since $1967 .{ }^{6}$ The findings in the first studies in which SCS was used to treat RSD were hopeful. ${ }^{7,8}$ Since 1987 we have used SCS for the treatment of pain in patients with RSD who do not respond to conventional treatments such as physical therapy, radiofrequency sympathetic nerve blocks, regional intravenous sympathetic blocks, and transcutaneous electrical nerve stimulation (TENS). To assess the clinical efficacy and possible adverse effects of SCS in reducing pain in patients with RSD we have retrospectively studied all 23 consecutive RSD patients treated in the Pain Management and Research Centre of the Maastricht University Hospital since 1991. The majority of patients with RSD reported improvement after undergoing SCS therapy.

\section{Clinical Material and Methods}

\section{Patient Population}

All four absolute criteria and three out of nine relative criteria had to be met before RSD could be diagnosed in any patient; the diagnostic algorithm is presented in Table 2.1. This algorithm closely resembles the criteria for CRPS 1 that were devised by the International Association for the Study of Pain. ' All RSD patients had severe pain that was unresponsive to conventional treatments. Age, sex, predisposing cause of RSD, date of diagnosis, affected location, and previous therapies were obtained from the files in each patient who underwent implantation of a (temporary) lead for SCS.

\section{Test Stimulation}

After an intravenous injection of cefuroxim (1500 $\mathrm{mg}$ ), the patient was placed in the lateral position and a $5-\mathrm{cm}$ vertical midline incision was made in the thoracic or lumbar spine, depending on the affected extremity. The epidural space was localized with a Tuohy needle. Using direct fluoroscopy, an SCS electrode (Pisces Quad lead, model 3487A; Medtronic, Minneapolis, MN) was advanced through the needle, connected to an external screener (model 3625; Medtronic), and positioned until paresthesiae were felt in the affected area. When paresthesiae were experienced 
in the affected area, the needle was withdrawn and the electrode was fixed with special clips and connected to the external stimulator.

Since 1996, in an attempt to avoid lead wound infection, we have used (temporary) test leads for the test stimulation procedure. Implantation of the temporary lead was performed on an outpatient basis. Patients received an antibiotic prophylaxis (1500 $\mathrm{mg}$ cefuroxim). With the patient in the prone position, the epidural space was localized with a Tuohy needle. Using direct fluoroscopy, the lead (model 3861; Medtronic) was advanced through the needle in the posterior epidural space until the tip of the electrode was at the required level. After a testing period of seven days, the temporary lead was removed. In patients in whom the Quad lead was implanted (before 1996), the lead was removed only if the test stimulation procedure was negative. During the testing period, patients were advised to perform all normal daily activities to get a good impression of the implant's effect. To diminish the chance of infection, however, patients were not permitted to take a shower. The SCS system was implanted when during the testing period the patient reported a reduction in pain (50 percent decrease in original visual analog scale (VAS) score) that was estimated by the patient for the entire week of test stimulation, or if the patient reported 'much improvement' on a 7-point global perceived effect (GPE) scale. The GPE categories include best ever, much improved, improved, not improved/not worse, worse, much worse, and worst ever.

\section{Implantation of the SCS System}

In patients treated before 1996, the lead remained in situ after a positive test period. In patients treated after 1996, the Quad lead was implanted as described previously

TABLE 2.1. Diagnostic algorithm for RSD*

Absolute criteria
Pain
Impaired function
Expansion of symptoms outside the ar
Cold, warm or intermittent cold-warm
Relative criteria
Edema
Increased nail growth
Increased hair growth
Hyperhidrosis
Abnormal skin coloring
Hypoesthesia
Hyperalgesia
Mechanical and/or thermal allodynia
Patchy demineralization of bone

*All absolute and at least three relative criteria are needed for RSD to be diagnosed in a patient. 
in the Test Stimulation section. After the lead was positioned, patients received a sedative and a pulse-generator (Itrel 2 or 3, model 7424 or 7425; Medtronic) was implanted in the subcutaneous tissue in the left lower anterior abdominal wall, and it was connected to the electrode by a tunneled extension lead (model 7495-51 or 7495-66; Medtronic). After closing the skin, the pulse-generator was activated and adjusted using a console programmer (model 7432; Medtronic). Initial stimulation was started at a rate of $85 \mathrm{~Hz}$ and a pulse width of $210 \mu \mathrm{s}$. Patients in whom the Itrel 2 system was planted were able to switch between a fixed high and low amplitude, using a magnet (model 7452; Medtronic), whereas patients in whom the Itrel 3 system had been implanted could control the stimulation intensity by adjusting from 0 to $10 \mathrm{~V}$ with a patient programmer (model 7434-NL; Medtronic). Postimplantation, patients remained in the hospital for 24 hours, during which they received two doses of cefuroxim $(750 \mathrm{mg}$ ) intravenously. The following day an $\mathrm{x}$-ray was obtained. When no change in the position of the electrode was evident on the $\mathrm{x}$-ray film, the patient was discharged. Further adjustments in programming could be made on an outpatient basis. Postimplantation no restrictions were placed on patient activities. Only extreme body movements may be harmful to the system, and these disabled patients are not likely to make such movements.

\section{Patient Assessments}

Using the VAS, patients rated their daily average pain at the last outpatient visit prior to implantation (baseline pain score) and at 1 month postimplantation. Complications were recorded throughout treatment and follow-up period. At the end of the follow-up period, patients were contacted by mail and asked to rate their GPE in comparison with pretreatment scores. If patients with an implanted system indicated that their condition was 'improved' or better, treatment was defined as 'success'. Anything less than a score of 'improved' or no implanted system at the end of follow-up was defined as 'failure'. At the end of follow-up period, patients were again asked to rate their pain by using the VAS at three fixed time points per day for four consecutive days. The average of these samples was calculated. ${ }^{9}$

\section{Statistical Analysis}

Statistical analysis was performed using the $t$-test for paired samples or the Wilcoxon signed rank sum test, as appropriate. A probability value of less than 0.05 was considered statistically significant.

\section{Results}

\section{Baseline Data}

Twenty-three patients with RSD underwent implantation of a (temporary) lead for SCS. In 13 patients RSD affected the leg and in ten it affected the arm. There were eight men and 15 women. The mean age was 39 years (range $24-54$ years); the mean duration of RSD was 44 months (range 9-179 months). The RSD was preci- 
pitated by trauma in 14 patients, by surgery in seven, and by infection and an intravenous infusion cannula in the last two patients. Prior to implantation, all patients had been treated with nonsteroidal antiinflammatory drugs, opioids, antidepressants, anticonvulsants, and adrenergic blocking drugs by stellate ganglion blocks or lumbar sympathetic blocks. Twenty patients had undergone physical therapy, 16 patients had undergone TENS, and 22 patients had undergone other treatments (intravenous mannitol infusion, 50 percent dimethyl sulfoxide application) ${ }^{10,11}$ without lasting success. Demographic, treatment, and outcome data for the patients are summarized in Table 2.2 .

\section{Test Stimulation}

Eighteen ( 78 percent) of 23 patients reported improvement during test stimulation. The other five patients noted no effect in spite of adequate paresthesiae in the af-

TABLE 2.2. Treatment and outcome data in 23 patients with RSD who underwent treatment with $\mathrm{SCS}^{*}$

\begin{tabular}{|c|c|c|c|c|c|c|c|c|c|c|}
\hline \multirow[b]{2}{*}{$\begin{array}{l}\text { Case } \\
\text { no. }\end{array}$} & \multirow{2}{*}{$\begin{array}{l}\text { Age } \\
\text { (yrs, } \\
\text { sex) }\end{array}$} & \multirow{2}{*}{$\begin{array}{l}\text { Duration } \\
\text { of RSD } \\
\text { (mos) }\end{array}$} & \multirow[b]{2}{*}{$\begin{array}{l}\text { Loca- } \\
\text { tion }\end{array}$} & \multicolumn{5}{|c|}{ Preimplant Treatment Modality } & \multirow[b]{2}{*}{$\begin{array}{l}\text { Test } \\
\text { failure }\end{array}$} & \multirow[b]{2}{*}{$\begin{array}{l}\text { SCS } \\
\text { failure }\end{array}$} \\
\hline & & & & SB & TENS & $\mathrm{PT}$ & MI & DMSO & & \\
\hline 1 & $27, \mathrm{~F}$ & 54 & lt leg & + & + & + & - & - & & \\
\hline 2 & $42, \mathrm{M}$ & 40 & lt arm & + & - & - & + & - & & \\
\hline 3 & $34, \mathrm{~F}$ & 27 & lt leg & + & - & - & + & - & & \\
\hline 4 & $26, \mathrm{~F}$ & 15 & lt leg & + & - & + & + & + & & + \\
\hline 5 & $45, \mathrm{~F}$ & 49 & It $\operatorname{arm}$ & + & + & + & + & + & + & + \\
\hline 6 & $37, \mathrm{M}$ & 23 & rt arm & + & - & + & + & + & & \\
\hline 7 & $45, \mathrm{~F}$ & 20 & lt leg & + & - & + & + & + & + & + \\
\hline 8 & $37, \mathrm{~F}$ & 179 & $\mathrm{rt} \mathrm{arm}$ & + & + & + & + & + & & \\
\hline 9 & $50, \mathrm{~F}$ & 26 & It leg & + & + & + & + & + & & + \\
\hline 10 & $43, \mathrm{M}$ & 29 & lt leg & + & - & + & + & + & & \\
\hline 11 & $49, \mathrm{M}$ & 40 & lt arm & + & + & + & + & + & & \\
\hline 12 & $45, \mathrm{~F}$ & 65 & lt leg & + & - & + & + & + & & \\
\hline 13 & $29, \mathrm{M}$ & 32 & lt leg & + & + & + & + & - & & + \\
\hline 14 & $27, \mathrm{~F}$ & 50 & lt leg & + & + & - & - & - & & \\
\hline 15 & $54, \mathrm{~F}$ & 16 & lt leg & + & + & + & + & + & & \\
\hline 16 & $50, \mathrm{M}$ & 43 & $\mathrm{rt}$ arm & + & + & + & + & + & & \\
\hline 17 & $32, \mathrm{~F}$ & 9 & rt leg & + & + & + & + & - & & \\
\hline 18 & $48, F$ & 21 & lt leg & + & + & + & + & - & + & + \\
\hline 19 & $50, \mathrm{~F}$ & 54 & lt arm & + & + & + & + & + & + & + \\
\hline 20 & $28, F$ & 99 & rt arm & + & + & + & + & - & & \\
\hline 21 & $24, \mathrm{M}$ & 32 & rt leg & + & + & + & + & + & & \\
\hline 22 & $32, \mathrm{M}$ & 31 & lt arm & + & + & + & + & + & & \\
\hline 23 & $50, \mathrm{~F}$ & 55 & $\mathrm{rt}$ arm & + & + & + & + & - & + & + \\
\hline
\end{tabular}


fected area (Cases 18 and 19) or more pain (Cases 5, 7, and 23); these patients did not receive permanent implantations. During the test stimulation period three complications were recorded. In one patient (Case 5) the trial period was complicated by a defective temporary lead. In another patient the lead shifted from C-6 to $\mathrm{C}-7$ (Case 12). A new temporary lead was placed in both cases; however, it was effective in the latter patient only. One other patient suffered a subcutaneous hematoma (Case 7).

\section{Pain Relief at 1-Month Follow-Up}

One week after removal of the temporary lead, the 18 patients who had responded positively to the test stimulation underwent implantation of the SCS system. The mean baseline VAS pain score of these patients had been 7.9 (range: 6.5-10). One month after implantation patients' mean pain score was 4.2 (range: $1-7$ ).

\section{Pain Relief at Final Follow-Up Examination}

The follow-up period lasted for a mean duration of 32 months (range 6-79 months). In the group of patients who underwent implantation of the SCS system the mean pain score at the end of the follow-up period was 5.4 ( 15 patients, range: $1-8.4)$, which was a significant reduction from baseline $(7.9, p<0.001)$. At the end of follow-up review, eight of the 23 patients did not have an implanted SCS system (for reasons to be presented); these patients reported a mean pain score of 6.8 (range 2.3-9.3), which was not a significant reduction from baseline (7.3). Figure 2.1 shows the mean pain scores for the 15 patients with and the eight patients without the SCS system.

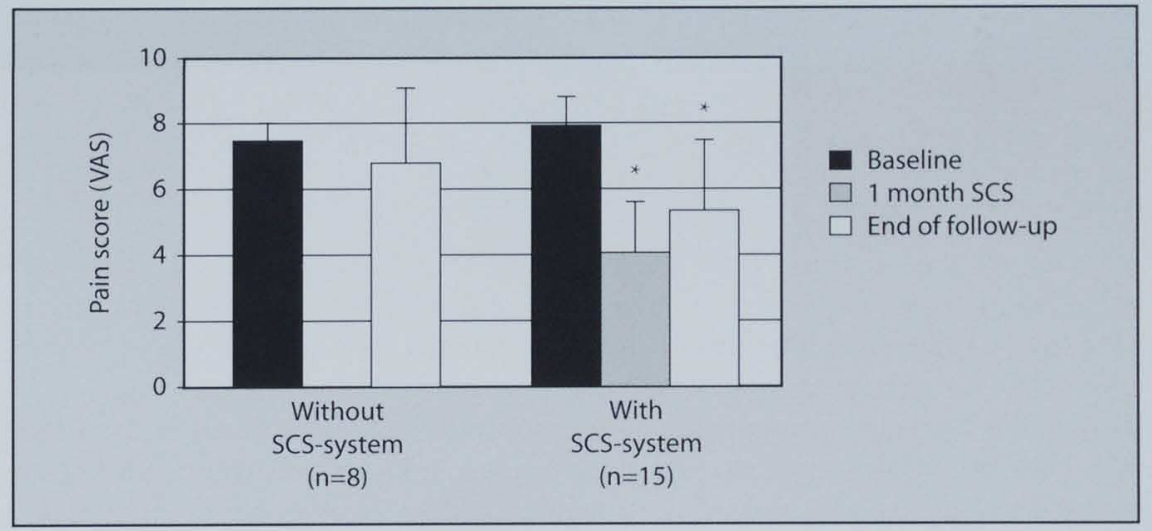

Figure 2.1. Graph depicting the mean VAS pain scores in 15 patients with and eight patients without the implanted SCS system by end of the follow-up period. Asterisks indicate significant results. 
Table 2.3. Technical and surgical complications in nine of 18 patients who underwent implantation of a SCS system

\begin{tabular}{|c|c|c|}
\hline & Complication $^{\star}$ & No. of complications \\
\hline \multirow[t]{5}{*}{ Surgical } & Infection & \\
\hline & Pulse-generator pocket & 1 \\
\hline & Lead wound & 1 \\
\hline & Hematoma & 1 \\
\hline & Tight pulse-generator pocket & 2 \\
\hline \multicolumn{3}{|l|}{ Technical } \\
\hline & Shifted lead & 7 \\
\hline & Broken lead & 1 \\
\hline & \multicolumn{2}{|l|}{ System defect } \\
\hline & Connection disconnected & 1 \\
\hline & Pulse-generator defect & 1 \\
\hline
\end{tabular}

\section{Device-Related Complications}

Nine (50 percent) of 18 patients suffered complications after implantation of the permanent SCS system (Table 2.3). Most complications were technically related to the device, and all of these complications required that the patient undergo reoperation. In four cases the system was removed. In two cases this was due to major complications (infected pulse-generator pocket 1 month postimplantation in one patient and an infected lead wound 8 months postimplantation in another). When infection had resolved, a new system was implanted in the patient with the infected pulse-generator pocket. Because the patient with the infected lead wound did not notice any worsening of the pain after the system was removed, no attempt was made to implant a new system. In the other two cases implants were removed because of lack of effect (at 12 and 20 months postimplantation). Overall, in three patients ( 17 percent) the system was removed definitively.

\section{Global Perceived Effect}

Graphic reproduction of the GPE scores is shown in Figure 2.2. In the 15 patients with an implanted SCS system, eight patients indicated a score of 'much improved', five patients indicated 'improved', and two patients indicated a score of 'worse'. Therefore, outcome was regarded as successful in 13 patients. Four of these 13 patients had scores indicating their clinical status was 'improved' or 'much improved', although their VAS pain score had either worsened or scarcely improved $(<1$ on VAS). Two patients had scores indicating their GPE was 'worse', although their pain score had improved.

In the group of patients without a SCS system, two patients indicated a GPE score of 'worst ever', whereas three patients had scores indicating their GPE was 


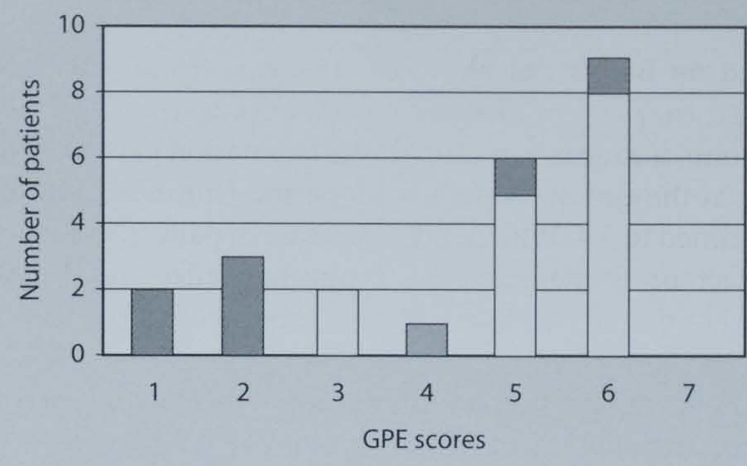

With SCS system

Without SCS system

Figure 2.2. Graph demonstrating the GPE scores in 15 patients with and eight patients without an implanted SCS system by the end of the follow-up period. $1=$ worst ever; 2 = much worse; $3=$ worse; $4=$ not improved $/$ not worse; $5=$ improved; $6=$ much improved; $7=$ best ever.

'much worse' and one patient whose score indicated that the GPE was 'not improved/ not worse'. Remarkably, two patients' scores demonstrated their GPE to be 'much improved' and 'improved', respectively.

The success of the SCS system at the end of follow up was not significantly related to age, sex, duration of illness, affected extremity, affected side, or baseline pain score.

\section{Discussion}

Although SCS has been used to treat patients with severe chronic pain since 1967, only three studies on its clinical efficacy for the treatment of RSD have been reported. ${ }^{7,8,12}$ In addition to their methodological shortcomings (sample size, lack of pain scores, patient selection, retrospective analyses), these studies are particularly difficult to interpret because they present data on only succesfully treated patients. We have therefore retrospectively studied all patients with RSD who underwent treatment with SCS in our hospital since 1991. To minimize bias, special effort was made to document every consecutive patient intentionally treated with SCS. Pain scores were recorded prospectively, and assessment of GPE was performed retrospectively.

\section{Outcome and Significance}

Test stimulation was successful in 18 (78 percent) of the 23 patients, which is in accordance with reported data. ${ }^{7}$ In three of these 18 patients in whom a SCS system was implanted, the effect waned over time and the system was removed. At the end of follow-up period 15 of 23 patients had retained their implanted SCS system. 
When success at the end of follow-up is defined as a minimum GPE status of 'improved', 13 (57 percent) out of 23 patients showed clinical improvement, which is similar to results achieved by Barolat, et al. ${ }^{7}$ Comparison with the other two studies ${ }^{8,12}$ is difficult because they do not describe patient selection.

In the successful SCS group, the mean 1-month postimplantation pain score had decreased from 7.9 to 4.2 ; at the end of the follow-up period (mean 32 months), however, this score had declined to 5.4. Whether this increase in pain scores reflects a short-term placebo effect or is mediated by diminished effect of the SCS system caused by spinal 'resetting' or epidural fibrosis around the lead remains unknown.

In comparing pretreatment with postimplant stimulation, the patient's perception depends on specific treatment but is heavily influenced by the natural course of the disease as well. This rationale suggests why two patients in whom implant failure resulted in removal indicated their clinical status was 'improved' and 'much improved'. On the other hand, it implies that some successfully treated patients might have improved without implantation of a SCS system. Four patients made 'improved' or 'much improved' recoveries, although their pain had worsened or had scarcely improved $(<1$ on VAS). Clinical status in two other patients was 'worse', although their pain had improved. The observation that the GPE and pain scores do not completely correlate, underscores the need to conduct a prospective study when evaluating SCS in a variable disorder such as RSD. ${ }^{13}$

Although functional status was not recorded prospectively in the present study, some data may be of interest. Pretreatment, two patients were wheelchair dependent, and two others could walk with the aid of crutches. Posttreatment, these four patients are walking without aid. Three patients who were unable to use their hand pretreatment have regained its use. They are able, for example, to drive a car. Thus, the SCS system provided functional improvement in four (31 percent) of $13 \mathrm{pa}-$ tients with an affected leg and in three ( 30 percent) of 10 patients with an affected arm.

\section{Methodological Considerations}

In a study that evaluates the efficacy of SCS for the treatment of RSD several problems are encountered. First, because no objective measures are known with which to diagnose RSD, diagnosis is based on clinical criteria. All patients in this study fulfilled the International Association for the Study of Pain criteria for CRPS 1. All suffered severe pain, which was reflected by VAS pain scores of at least 6 . Second, assessment of the efficacy of SCS cannot be truly performed in a 'blinded' fashion because of the paresthesiae that accompany stimulation. Nevertheless, results of this retrospective study should be seen in light of the fact that no control group has been used. Third, to assess the results of SCS on the level of pain, we are always dependent on subjective measures, which make it difficult to differentiate between effect and placebo. We tried to meet this problem by questioning all patients in whom SCS was attempted, not only those in whom SCS was a success. 
One important feature of this study is the complete documentation of those patients nonsuccessfully treated. We believe that this is crucial for the evaluation of an expensive, demanding therapy used to treat a nonlife-threatening disorder. Until now studies have neglected to provide data on these failed cases. ${ }^{7,8,12}$ We found that the pretreatment degree of pain remained unchanged in patients who did not profit from SCS (eight patients), during a mean follow-up period of 32 months. This is an important observation, which suggests that whatever the outcome, SCS does not negatively affect the course of RSD.

\section{Treatment Complications}

Nine ( 39 percent) of the 23 patients suffered complications. In two patients the SCS system had to be removed due to a complication ( 9 percent). Based on findings from larger studies it is known that complications of various character necessitate removal of the system in 5 to 15 percent of cases. ${ }^{14,15}$ Technical defects are a substantial part of SCS management problems. In this study five ( 22 percent) of 23 patients suffered technical defects. Two of these defects (pulse-generator failure, pulse-generator disconnection) might be considered random events, whereas the risk of the lead shifting and breaking in vivo seems to be inherent in the treatment itself; there is a reported incidence of these defects in 3 to 5 percent of cases. ${ }^{14,16}$ Although complications affect treatment results, cause patient discomfort, and generate costs, these rarely cause permanent neurological deficits. ${ }^{14-16}$ For this reason, the relatively high complication rate of SCS should not be an obstacle in treatment consideration but must be well communicated to the future patient.

\section{Conclusions}

The findings in our study suggest that SCS is effective in the treatment of a majority of patients with RSD, although the incidence of complications is substantial. To prove unequivocally the clinical and cost-effectiveness of SCS for the treatment of patients with RSD, a randomized, prospective study is required, one that includes effective parameters such as pain scores, functional assessments, and quality of life measures. Currently we are conducting such a study.

\section{References}

1. Merskey H, Bogduk N. Classification of chronic pain: descriptions of chronic pain syndromes and definitions of pain terms. Seattle: IASP Press, 1994: 40-2.

2. Baron $\mathrm{R}$, Blumberg $\mathrm{H}$, Jänig W. Clinical characteristics of patients with complex regional pain syndrome in Germany with special emphasis on vasomotor function. In: Jänig W, Stanton-Hicks $M$, eds. Reflex sympathetic dystrophy: a reappraisal. Seattle: IASP Press, 1996: 25-48.

3. Schwartzman RJ, McLellan TL. Reflex sympathetic dystrophy: a review. Arch Neurol 1987; 55: 555-61. 
4. Ochoa JL. Guest editorial: essence, investigation, and management of 'neuropathic' pains: hopes from acknowledgment of chaos. Muscle \& Nerve 1993; 16: 9971008.

5. Verdugo RJ, Ochoa JL. 'Sympathetically maintained pain.' I. Phentolamine block questions the concept. Neurology 1994; 44: 1003-10.

6. Shealy CN, Mortimer JT, Reswick JB. Electrical inhibition of pain by stimulation of the dorsal columns: a preliminary report. Anesth Analg 1967; 46: 489-491.

7. Barolat G, Schwartzman R, Woo R. Epidural spinal cord stimulation in the management of reflex sympathetic dystrophy. Stereotact Funct Neurosurg 1989; 53: 29-39.

8. Robaina FJ, Rodriguez JL, de Vera JA, Martin MA. Transcutaneous electrical nerve stimulation and spinal cord stimulation for pain relief in reflex sympathetic dystrophy. Stereotact Funct Neurosurg 1989; 52: 53-62.

9. Jensen MP, McFarland CA. Increasing the reliability and validity of pain intensity measurement in chronic pain patients. Pain 1993; 55: 195-203.

10. Goris RJA. Treatment of reflex sympathetic dystrophy with hydroxyl radical scavengers. Unfallchirurg 1985; 88: 330-2.

11. Zuurmond WWA, Langendijk PNJ, Bezemer PD, Brink HEJ, de Lange JJ, van Loenen AC. Treatment of acute reflex sympathetic dystrophy with DMSO $50 \%$ in a fatty cream. Acta Anaesthesiol Scand 1996; 40: 364-7.

12. Kumar K, Nath RK, Toth C. Spinal cord stimulation is effective in the management of reflex sympathetic dystrophy. Neurosurgery 1997; 40: 503-8.

13. Veldman PHJM, Goris RJA. Multiple reflex sympathetic dystrophy: which patients are at risk for developing a recurrence of reflex sympathetic dystrophy in the same or another limb. Pain 1996; 64: 463-6.

14. Meglio M, Cioni B, Rossi GF. Spinal cord stimulation in management of chronic pain. J Neurosurg 1989; 70: 519-24.

15. North RB, Kidd DH, Zahurak M, James CS, Long DM. Spinal cord stimulation for chronic, intractable pain: experience over two decades. Neurosurgery 1993; 32: 384-94.

16. Broggi G, Servello D, Dones I, Carbone G. Italian multicentric study on pain treatment with epidural spinal cord stimulation. Stereotact Funct Neurosurg 1994; 62: 273-8. 


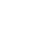


CHAPTER 3

Health-Related Quality of Life in

Chronic Refractory Reflex

Sympathetic Dystrophy

Marius A. Kemler and Henrica C.W. de Vet 


\section{Introduction}

The great demand for health care and the scarcity of means obliges health care providers to demonstrate objectively the improvements in health resulting from their activities. As long as treatments are able to achieve total cure, morbidity and mortality rates are adequate outcome measures. Nowadays, our health care often is aimed at (marginal) improvement in chronic disease status. Therefore, healthrelated quality of life (HRQL) is becoming an important issue.

No single universally accepted definition exists for HRQL. The definition used in the present study is that proposed by Schipper et al.: 'Quality of life represents the functional effect of an illness and its consequent therapy upon a patient, as perceived by the patient. Four broad domains contribute to the overall effect: physical and occupational function; psychologic state; social interaction and somatic sensation. This definition is based on the premise that the goal of medicine is to make the morbidity and mortality of a particular disease disappear. We seek to take away the disease and its consequences, and leave the patient as if untouched by the illness.'

There are two types of HRQL measures: generic instruments and specific instruments. ${ }^{2}$ Generic instruments attempt to measure all important aspects of HRQL and thus detect differential effects on different aspects of health status. They can be used in any population, regardless of the underlying condition. In addition, they are highly suitable for comparison of the impact of different diseases on HRQL. One of the disadvantages is that the instrument may not focus adequately on the area of interest, i.e. the aspects of $\mathrm{HRQL}$ affected by specific disease, and that it may not be optimally responsive. Specific instruments focus only on aspects of health that are relevant to the patients being studied. Therefore, these instruments have a higher responsiveness than generic instruments which include all aspects of health. As a consequence of their approach to improving responsiveness, however, specific instruments narrow the field of vision. As a result, consequences of disease which do not spontaneously come to mind when patients are asked to define the impact of their disease, could remain unobserved. The use of generic instruments reveals the complete variety of aspects that are included in HRQL.

Considering these advantages and disadvantages we propose the use of generic instruments, and to focus treatment especially on aspects that appear relevant. For that purpose, prior to therapy several instruments measuring as many different aspects of $H R Q L$ as possible, should be completed by a large enough group of patients suffering the disease to be evaluated. Comparing the outcomes with those of the normal population will show which aspects are the most important cause of the affected HRQL. On these aspects the most important gains in health are to be expected.

In the present study, using generic instruments, we provide important data on which aspects affect $H R Q L$ in patients with chronic refractory reflex sympathetic dystrophy (RSD), a condition that causes pain and impairs function in the affected 
arm or leg. It nearly always starts suddenly after a noxious event, like a trauma or an operation. ${ }^{3}$ The pathogenesis of RSD is only partly understood, ${ }^{4}$ and there are no treatments that can guarantee improvement; improvement following treatment is rare. As a consequence only $20-30$ percent of RSD patients return full-time to their previous employment. ${ }^{5}$ Most patients have never heard of RSD until they become affected. Usually, the sudden unexpected start of this painful handicap causes anger and incomprehension. All subjects in this study had one affected arm or leg of which they suffered severe pain and functional impairment which made them unfit for work.

To our knowledge, HRQL measurements have not been performed in RSD patients previously. In addition, it is conceivable that patients with an affected arm differ in HRQL compared to patients with an affected leg. Sickness Impact Profile (SIP), Nottingham Health Profile (NHP) and Euroqol (EQ-5D) are all well known generic HRQL instruments, each having its own specific purpose and interest. ${ }^{6-8}$

This study was aimed to find out which aspects, as measured by SIP, NHP and EQ-5D are of particular importance to HRQL reduction in RSD patients, either with an affected arm or with an affected leg. In this way we will enable investigators and clinicians to focus research and treatment directly on the main aspects affecting HRQL in RSD.

\section{Methods}

\section{Sample and Data Collection}

All medical specialists known to treat RSD patients (such as anesthesiologists, surgeons, neurologists, and others) working in hospitals in the south of the Netherlands were asked to refer patients fulfilling the standardized diagnostic algorithm (Table 3.1) to the department of Surgery of the Maastricht University Hospital. The algorithm closely resembles the criteria for Complex Regional Pain Syndrome type I, as stated by the International Association for the Study of Pain (IASP). ${ }^{9}$ Upon arrival in our institution the final decision whether patients could enroll the study was based on re-checking the diagnostic criteria-a physical examination was conducted by two physicians separately-and a psychological test (SCL-90). ${ }^{10}$ In addition, patients should had suffered from RSD for at least six months, during which period the symptoms had been unresponsive to all conventional treatments, such as nonsteroidal antiinflammatory drugs, opioids, antidepressants, anticonvulsants, sympathetic blocks, transcutaneous electrical nerve stimulation and physical therapy. Pain as measured on a $10 \mathrm{~cm}$ visual analog scale had to be at least $5 \mathrm{~cm}$. Patients with other conditions affecting function were not included in the study. Informed consent was obtained from all patients according to the Declaration of Helsinki. The study protocol had been approved by the Ethical Committee of our institution.

Eventually, 54 patients were considered eligible for the study while 56 were ex- 
TABLE 3.1. Diagnostic algorithm for RSD*

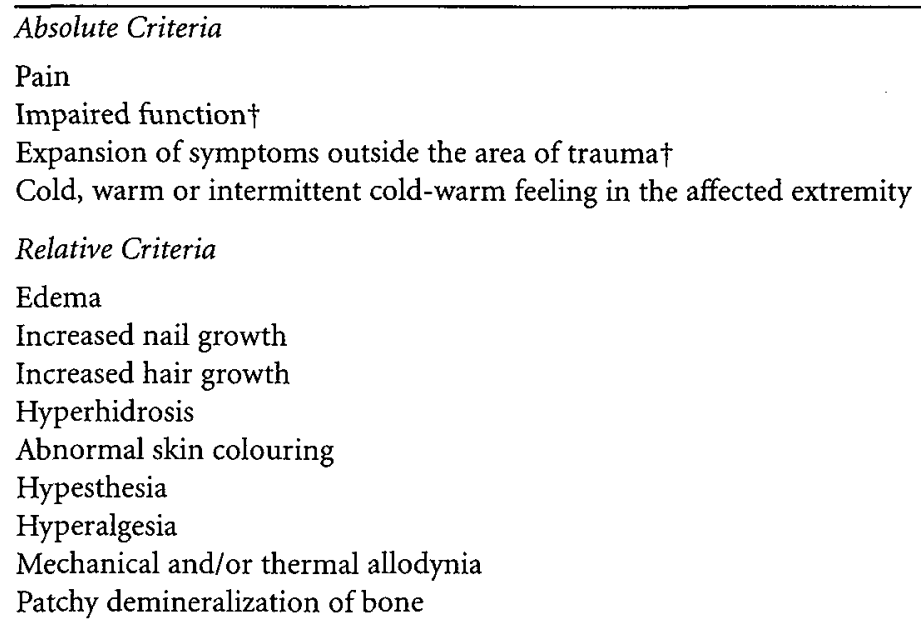

${ }^{*}$ All absolute criteria together with at least three relative criteria were needed for the diagnosis RSD. IIndicates criteria additional to those of the International Association for the Study of Pain.

cluded-40 were not eligible and 16 refused to participate. All included patients were white, Dutch-speaking adults (18 to 65 years) suffering from severe RSD affecting either one arm $(n=33)$ or one leg $(n=21)$. Sociodemographic characteristics of both groups have been summarized in Table 3.2. All these characteristics were not significantly different between the groups $(p>0.10)$. After inclusion in the study, a questionnaire that among others contained the Dutch versions of the EQ5D, the SIP68 and the NHP, in this order, was self administered by the patients. These instruments have been validated and translated into Dutch. ${ }^{8,11,12}$ One physician presented the instruments in all cases and was present to answer questions. EQ-5D and NHP will be presented together with normal values. Concerning EQ$5 \mathrm{D}$, these values are acquired from Essink-Bot. ${ }^{13}$ Normal values of the NHP are counted from the age groups from 20 to 64 years of the general population, presented by Hunt. ${ }^{14}$ The SIP68 is presented without normal values, since this instrument is purely aimed at the consequences of the disease investigated. The normal population does not suffer RSD and thus will always score 0 .

\section{The Nottingham Health Profile}

In accordance with its name, the NHP tries to measure a 'health profile'. In contrast to the SIP68, which is aimed purely at the consequences of the disease investigated, the NHP tries to present an image of the overall health status. Thus, problems unrelated to the disease investigated will also show up in the profile. The items of part 1 are limited to rather severe problems. This was found necessary in the development, in order to avoid picking up large numbers of false positives. However, it does mean that some milder forms of distress may not show up in the profile. The 
TABLE 3.2. Sociodemographic characteristics of the patient sample*

\begin{tabular}{|c|c|c|}
\hline & $\begin{array}{l}\text { Affected arm } \\
\quad(n=33)\end{array}$ & $\begin{array}{l}\text { Affected leg } \\
(n=21)\end{array}$ \\
\hline \multicolumn{3}{|l|}{ Age (years) } \\
\hline mean age $\pm S D$ & $38.3 \pm 10.7$ & $39.1 \pm 11.5$ \\
\hline $18-45(\%)$ & 75.8 & 66.7 \\
\hline $46-65(\%)$ & 24.2 & 33.3 \\
\hline \multicolumn{3}{|l|}{ Gender } \\
\hline Female (\%) & 63.6 & 76.2 \\
\hline Male (\%) & 36.4 & 23.8 \\
\hline \multicolumn{3}{|l|}{ Education } \\
\hline Elementary $\dagger(\leq 10$ years) $(\%)$ & 51.5 & 47.6 \\
\hline Vocational $\ddagger(>10$ years $)(\%)$ & 48.5 & 52.4 \\
\hline \multicolumn{3}{|l|}{ Net Income (Dutch guilders) ${ }^{* *}$} \\
\hline mean income $\pm S D$ & $1750 \pm 1545$ & $1295 \pm 1210$ \\
\hline $0-1500(\%)$ & 48.5 & 61.9 \\
\hline$>1500(\%)$ & 51.5 & 38.1 \\
\hline \multicolumn{3}{|c|}{$\begin{array}{l}\text { *None of the differences between both groups was significant }(p>0.10) \\
\dagger \text { Elementary means less than or equal to ten years of education. } \\
\ddagger \text { Vocational means more than } 10 \text { years education. } \\
{ }^{*} \text { Multiply } 1999 \text { Dutch guilders by } 0.47 \text { to calculate equivalent } 1999 \text { US dollars. }\end{array}$} \\
\hline
\end{tabular}

NHP was developed at Nottingham University in the United Kingdom. The final edition has been in use since 1981 . $^{7}$

The profile consists of two parts. In both parts of the profile, respondents are required to answer 'yes' if the statement applies to them and 'no' if it does not. Part 1 comprises 38 statements, divided over six dimensions (mobility, pain, sleep, energy, social isolation, emotional reaction). Within each dimension in part 1 , statements have been weighted for severity. Positive answers are given the appropriate weight and the score on any section becomes a measure of the number and severity of perceived problems for that dimension. The maximum score on any dimension in part 1 is 100 , the minimum score is 0 . Part 2 of the profile consists of seven statements relating to those areas of daily life most often affected by health: paid employment, jobs around the house, social life, personal relationships, sex life, hobbies and interests, and holidays.In part 2, the scores range from 7 (no problems) to 21 (many problems).

\section{The EuroQol-5D}

The EuroQol instrument is a multidimensional measure of HRQL, capable of being expressed as a single index value. It is not disease specific. The present five-dimensional instrument (EQ-5D) has been in use since 1991 and was developed by an international, multidisciplinary group of researchers from seven centres in England, Finland, the Netherlands, Norway and Sweden. ${ }^{15}$

For each of the five dimensions (mobility, self-care, usual activities, pain/ 
discomfort, anxiety/depression) three levels of increasing difficulty can be scored, i.e., level 1: no problem; level 2: some or moderate problems; level 3: complete inability or extreme problems. Finally, a vertical $20 \mathrm{~cm}$ visual analog scale is applied to obtain a self-rating health state score with endpoints of 100 (best imaginable health state) at the top and 0 (worst imaginable health state) at the bottom end.

\section{The Sickness Impact Profile}

The SIP includes 136 statements about health-related dysfunction in twelve areas of activity. In completing the SIP, the subject is asked to check only those statements that definitely describe his situation on a given day and are related to his health. Thus, the instrument concentrates purely on the consequences of the disease investigated rather than on other reasons affecting a person's health. The scale values of all items endorsed within a dimension are summed, then divided by the sum of the values of all items in that particular dimension, and finally multiplied by 100 . This means that the score within each dimension ranges from 0 to 100 . The SIP was developed at the University of Washington in Seattle and has been in use since $1976 .^{6}$

A major disadvantage of the SIP is its length. Therefore a shortened version, the SIP68, was developed in the Netherlands. The SIP68 includes 68 items selected from the original instrument, grouped into six dimensions (somatic autonomy, mobility control, psychologic autonomy, social behavior, emotional stability, mobility range). The SIP68 meets the same high standards as the SIP136 as far as reliability, validity and responsiveness are concerned. ${ }^{12,16,17}$

\section{Statistics}

A series statistical tests was carried out to evaluate the differences between patients with an affected arm and patients with an affected leg. Concerning sociodemographic characteristics, the $\chi^{2}$ test was used, while concerning differences of HRQL scores the Mann-Whitney U test was employed. Two-tailed $p$-values $<0.05$ were considered to indicate statistical significance.

\section{Results}

The Nottingham Health Profile, Part 1

The outcomes of the first part of the NHP for RSD patients, compared to those of the general population, are presented in Figure 3.1.

For patients with an affected leg the most important dimension is pain, followed by mobility, energy, and sleep. For patients with an affected arm again pain is the most important dimension. Sleep and energy also are of importance to patients with an affected arm, while mobility is not. Scores on the dimensions pain and mobility are significantly higher for patients with an affected leg $(p<0.001)$. The dimensions social isolation and emotional reaction are of marginal importance to both patients with an affected leg and patients with an affected arm. 


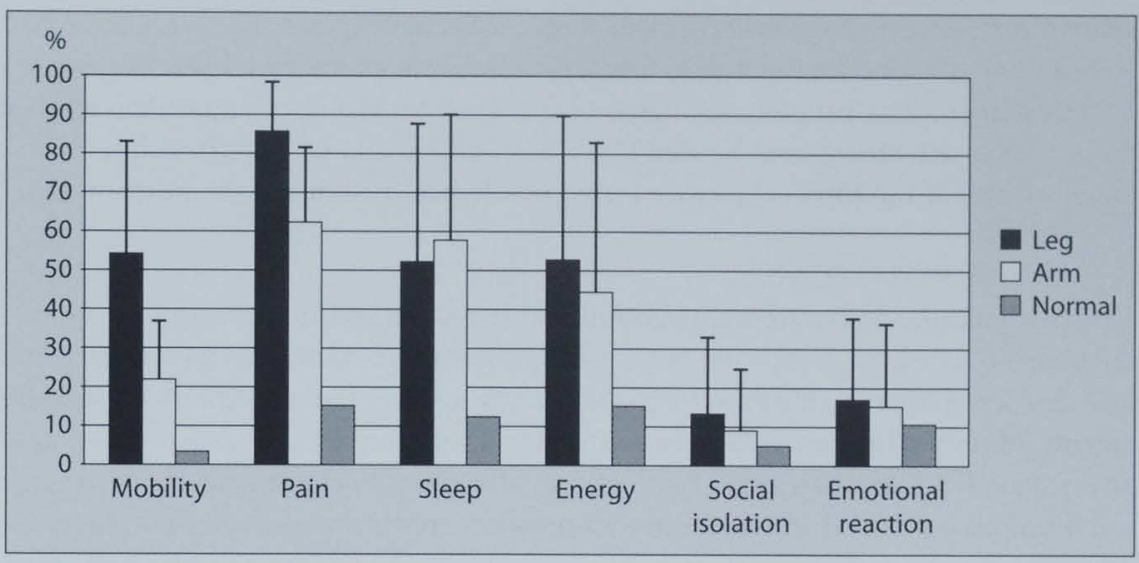

Figure 3.1. Outcomes of the dimensions of the first part of the Nottingham Health Profile for patients with RSD of the arm or leg and for the general population in percentages (SD).

\section{The Nottingham Health Profile, Part 2}

The outcomes of the second part of the NHP for RSD patients, compared to those of the general population, are presented in Figure 3.2.

For patients with RSD of the leg, the order of most affected life areas is: jobs around the house, work, holidays, hobbies, social life, and sex life. Home life is

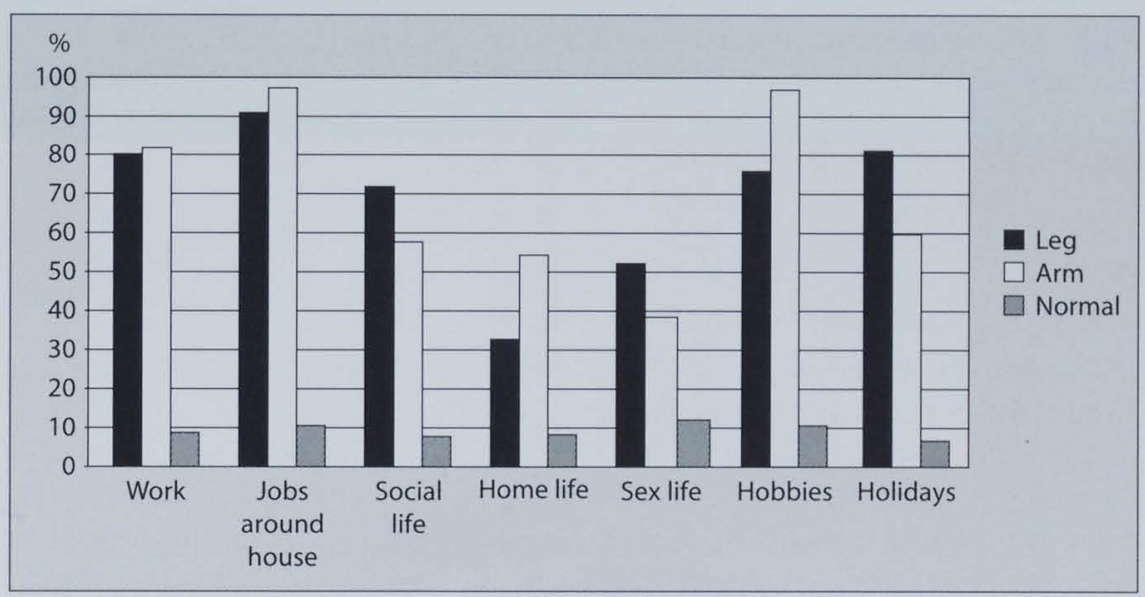

Figure 3.2. Outcomes of the dimensions of the second part of the Nottingham Health Profile for patients with RSD of the arm or leg and for the general population in percentages. 
scored in less than 50 percent of cases. For patients with RSD of the arm, this order is: hobbies, jobs around the house, work, holidays, social life, and home life. Sex life is scored in less than 50 percent of cases. Hobbies is scored significantly more often by patients with an affected $\operatorname{arm}(p<0.02)$.

\section{The EuroQol-5D}

Figure 3.3 presents the frequency distribution of the EQ-5D for the general population, for patients with RSD of the arm and for patients with RSD of the leg.

Mobility affects significantly more patients with an affected leg $(p<0.001)$, but also one third of the patients with an affected arm. Concerning self care the reverse is true: 80 percent of patients with an affected arm are having problems compared to one third of patients with an affected leg $(p=0.001)$. Frequency distributions for the dimensions usual activities, pain/discomfort and anxiety/depression are more or less equally divided in patients with RSD of the arm or leg. Almost all RSD patients are having problems with usual activities and suffer pain/discomfort. Anxiety/ depression occurs in 50 percent of RSD patients.

The Sickness Impact Profile

The outcomes of the SIP68 are presented in Figure 3.4. With about 50 percent of items marked, the only important SIP68 dimension for RSD patients is social behavior. All other SIP68 dimensions are scored by less than 50 percent of RSD patients.

The dimension mobility control is of greater importance to patients with an affected leg, compared to patients with an affected arm $(p<0.001)$, but even pa-

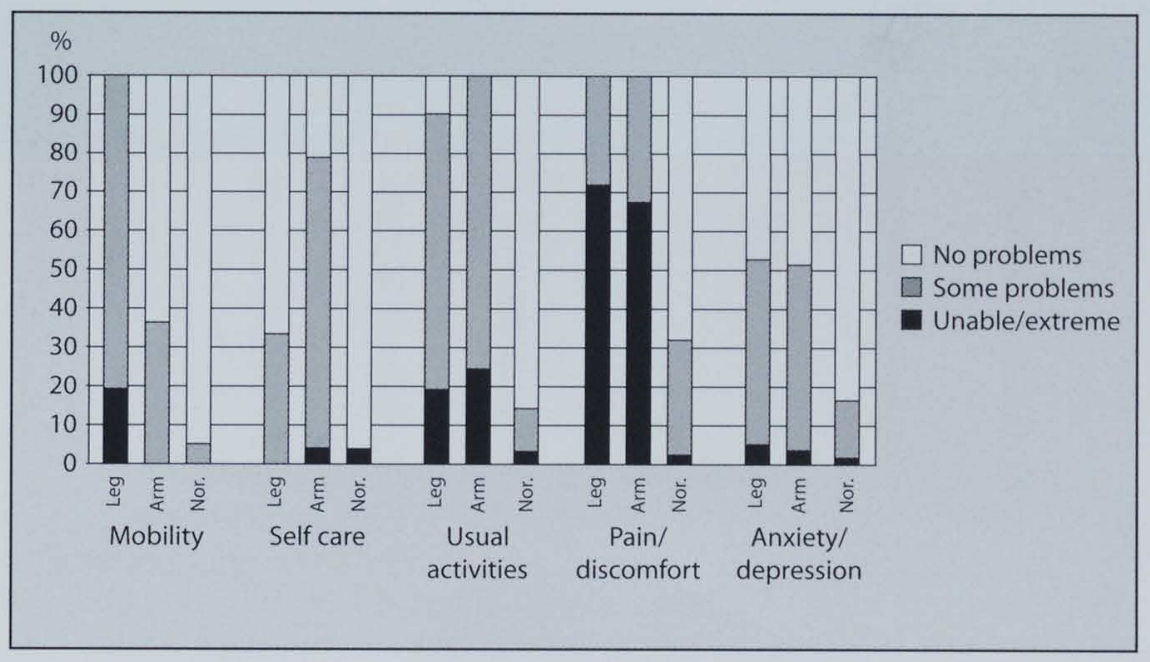

Figure 3.3. Outcomes of the dimensions of the EQ-5D for patients with RSD of the arm or leg and for the general population in percentages. 


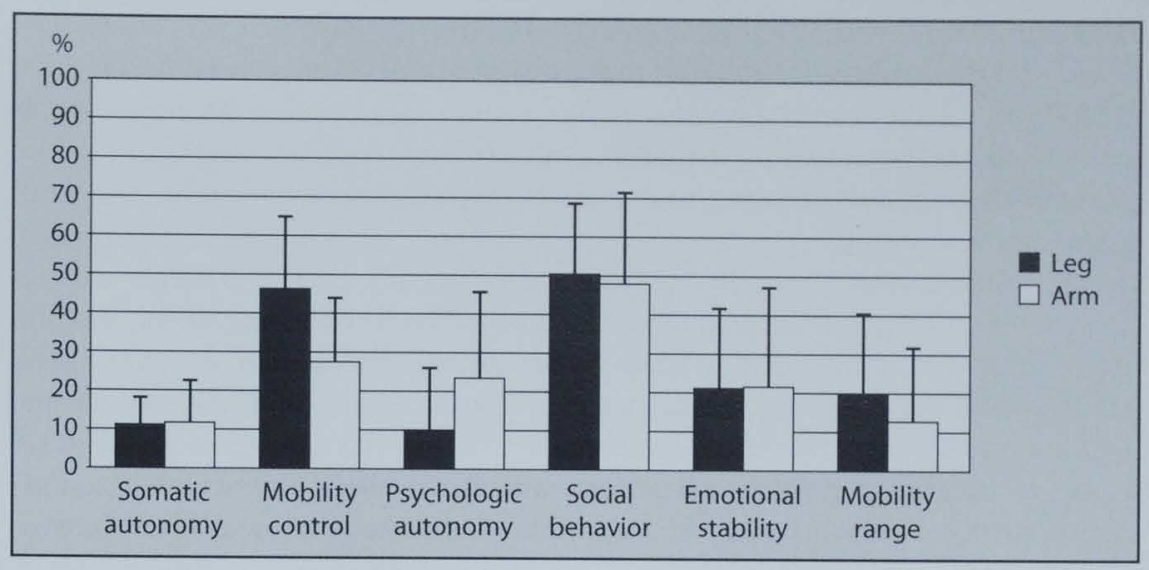

Figure 3.4. Outcomes of the dimensions of the Sickness Impact Profile 68 for patients with RSD of the arm or leg in percentages (SD).

tients with an affected leg score less than 50 percent of items in this dimension. The dimensions somatic autonomy, emotional stability and mobility range are of very low importance to RSD patients. The same holds true for the dimension psychologic autonomy, that is scored more often by patients with an affected arm $(p=0.002)$. This could be explained by the statement 'I am having trouble typing or writing'.

\section{Discussion}

We advocate the use of generic instruments in assessments of the effect of treatment. Unlike specific instruments, generic instruments contain dimensions that are generally accepted of importance to well-being. Their use sheds light on the importance of a disease in affecting general well-being and also enables comparison between otherwise unrelated diseases. Offering different instruments to a group of patients with a specific disease, allows for extraction of HRQL dimensions which are important (i.e. responsive) to these patients. Improvement of these dimensions following treatment will clearly prove the treatment's effect. This approach is comparable to the development of a specific instrument, with the difference being that the generic instruments used will remain intact hence still supplying information on dimensions that are not maximally responsive to a specific disease. It is conceivable that this approach may not reveal small differences in HRQL, while the most responsive technique (using a specific instrument) will. When trying to measure treatment effect, however, one might question whether such small differences are clinically relevant.

In the present study relevant aspects of three generic questionnaires were assessed for patients with RSD. To ensure the representativeness and generalizability 
of the sample we used rigid diagnostic criteria, selected chronic cases (more than six months RSD) only and enrolled randomly selected consecutive subjects whose function was not affected by other conditions. Outcomes were divided for patients with an affected leg and patients with an affected arm. Sociodemographic differences between the two patient groups, which might have influenced the study outcome were not found.

The study showed that HRQL is affected differently in RSD patients with an affected leg and with an affected arm. Patients with RSD of the leg suffer pain and their mobility is impaired. The generic instruments brought to light that these handicaps caused diminished social activity and problems with work, jobs around the house, hobbies and holidays. Patients with RSD of the arm suffer pain and are unable to use their hand properly. The generic instruments also revealed that life aspects such as hobbies, sleep, jobs around the house, self care, and work were influenced.

Consequently, different (parts of) HRQL instruments are appropriate to evaluate treatment effects in each group. The SIP68 has little value to patients with RSD of the arm. Only the dimension social behavior is affected to some extent. The NHP 1 dimensions pain, sleep and energy and the EQ-5D dimensions pain, usual activities and self care are of importance. RSD patients with an affected leg are best evaluated with the SIP68 dimensions social behavior and mobility control, the NHP 1 dimensions pain, mobility, sleep and energy and the EQ-5D dimensions mobility, pain and usual activities.

The extent of impairment can be illustrated by comparing HRQL results of chronic RSD patients with results of patients suffering from other chronic conditions. For diabetics, it is known that HRQL scores are all significantly lower than those of the general population. ${ }^{18,19}$ Nevertheless, their worst scores-NHP-energy: 35 percent; SIP-mobility range: 11 percent-are still better than scores of chronic RSD patients. Migraine patients obtain the highest NHP scores at energy (42 percent) and sleep (39 percent) ${ }^{20}$ and the highest EQ5D scores at pain (47 percent some), usual activities (26 percent some problems) and anxiety/depression (25 percent some problems); ${ }^{21}$ all scores are worse in chronic RSD patients. The same is true when comparing HRQL of RSD patients with HRQL of chronic nonspecific lung disease patients. ${ }^{22,23}$ The comparisons with other chronic diseases demonstrate how severely HRQL is affected in patients with chronic RSD. However, we emphasize that our results are solely applicable to the specific group of chronic RSD patients and thus not to all RSD patients.

Although the SIP68 is intended to pick up small sickness impacts, while the NHP tries to measure more severe problems, RSD patients are scoring higher on NHP than on SIP68. Possible reasons for the low scores on the SIP68 are the following. The SIP68 items are not yes/no statements, but have to be checked. This makes them more liable to be overseen. Many SIP68 statements are stated absolutely, i.e. although the problem described may be small, it has to be present always, and therefore it does apply to few patients. In addition, the SIP68 is not always clear in 
what is expected from the respondent. For example, should a patient who is unable to walk check all the items concerning walking in 'mobility control' (I walk shorter distances, I walk more slowly, etc.) or should he not. Some patients do, but others decide to check none of these items because they cannot walk at all. Therefore, the patient's interpretation is an important factor in SIP68 outcome and it seems that the goal of the SIP68 to pick up small sickness impacts is not achieved. The NHP mostly includes relative instead of absolute statements. Besides, the NHP has dimensions (especially pain and sleep) that appeared highly applicable to RSD patients and which are not included in the SIP68.

In conclusion, before evaluating treatment, testing generic instruments on the specific patient population reveals whether the instruments are potentially responsive in total and whether subcategories (dimensions) are especially responsive. In this way generic instruments have the advantages of specific instruments, while still giving broad information on HRQL. Using this approach in patients with RSD showed that the NHP and EQ-5D are good instruments to assess HRQL in both patients with an affected arm or leg, while the SIP68 is of importance to patients with an affected leg only. Some dimensions which, on the basis of their label, might be expected to be important, were found not to be so. Chronic RSD severely affects HRQL, although the reasons for this differ between patients with an affected arm or leg. This study improves our understanding of these differences, hence helping to focus treatment on the needs of the individual patients.

\section{References}

1. Schipper H, Clinch J, Powell V. Definitions and conceptual issues. In: Spilker B, ed. Quality of life assessments in clinical trials. New York: Raven Press, 1990: 11-24.

2. Guyatt GH, Feeny DH, Patrick DL. Measuring health-related quality of life. Ann Intern Med 1993; 118: 622-9.

3. Veldman PHIM, Reynen HM, Arntz IE, Gor is RJA. Signs and symptoms of reflex sympathetic dystrophy: prospective study of 829 patients. Lancet 1993; 342: 1012-16.

4. Schwartzman RJ, McLellan TL. Reflex sympathetic dystrophy: a review. Arch Neurol 1987; 55: 555-61.

5. Poplawski ZJ, Wiley AM, Murray JF. Post-traumatic dystrophy of the extremities. J Bone Joint Surg 1983; 65A: 642-55.

6. Bergner M, Bobbitt RA, Carter WB, Gilson BS. The sickness impact profile: development and final revision of a health status measure. Med Care 1981; 19: 787-805.

7. Hunt SM, McEwen J, McKenna SP. Measuring health status: a new tool for clinicians and epidemiologists. J Royal Coll Gen Practit 1985; 35: 185-8.

8. Euroqol-Group. EuroQol-a new facility for the measurement of health-related quality of life. Health Policy 1990; 16: 199-208.

9. Merskey H, Bogduk N. Classification of chronic pain: descriptions of chronic pain syndromes and definitions of pain terms. Seattle: IASP Press, 1994: 40-2.

10. Arrindell WA, Ettema JHM. SCL90 Handleiding bij een multidimensionele psychopathologie-indicator. Lisse: Swets \& Zeitlinger, 1986. 
11. van Eijk JTM, Smits A, Meyboom W, Mokkink H, van Son J. Reliability and validity of the Nottingham Health Profile in the Dutch situation (internal report). Nijmegen: NUHI, 1987.

12. de Bruin AF, Buys M, de Witte LP, Diederiks JPM. The sickness impact profile: SIP68, a short generic version. First evaluation of the reliability and reproducability. J Clin Epidemiol 1994; 47: 863-71.

13. Essink-Bot ML, Stouthard M, Bonsel GJ. Generalizability of valuations on health states collected with the euroqol questionnaire. Health Econ 1993; 2: 237-46.

14. Hunt SM, McEwen J, McKenna SP. Perceived health: age and sex comparisons in a community. J Epidemiol Comm Health 1984; 38: 156-60.

15. Euroqol-Group. EQ-5D user guide. Rotterdam: The Euroqol Group, 1996.

16. de Bruin AF, Diederiks JPM, de Witte LP, Stevens FCJ, Philipsen H. The development of a short generic version of the sickness impact profile. J Clin Epidemiol 1994; 47: 407-18.

17. de Bruin AF, Diederiks JPM, de Witte LP, Stevens FCJ, Philipsen H. Assessing the responsiveness of a functional status measure: the sickness impact profile versus the SIP68. J Clin Epidemiol 1997; 50: 529-40.

18. Keinänen-Kiukaanniemi $S$, Ohinmaa A, Pajunpää $H$, Koivukangas $P$. Health related quality of life in diabetic patients measured by the Nottingham Health Profile. Diabet Med 1996; 13: 382-8.

19. de Grauw WJC, van de Lisdonk EH, Behr RRA, van Gerwen WHEM, van den Hoogen HJM, van Weel C. The impact of type 2 diabetes mellitus on daily functioning. Fam Pract 1999; 16: 133-9.

20. Jenkinson C. Health status and mood state in a migraine sample. Int J Soc Psychiat 1990; 36: $42-8$.

21. Essink-Bot ML, van Royen L, Krabbe P, Bonsel GJ, Rutten FFH. The impact of migraine on health status. Headache 1995; 35: 200-6.

22. Schrier AC, Dekker FW, Kaptein AA, Dijkman JH. Quality of life in elderly patients with chronic nonspecific lung disease seen in family practice. Chest 1990; 98: 894-9.

23. Tsukino M, Nishimura K, Ikeda A, Koyama H, Mishima M, Izumi T. Physiologic factors that determine the health-related quality of life in patients with COPD. Chest 1996; 110: 896-903. 
CHAPTER 4

\section{An Objective and Standardized Test of Foot Function: Normative Values and Validation in Patients With Reflex Sympathetic Dystrophy}

Marius A. Kemler and Henrica C.W. de Vet 


\section{Introduction}

Currently, two types of clinical tests to assess function of the lower extremities are available: performance tests and self-report tests. Hoeymans and colleagues have demonstrated that the two measures are complementary, but do not measure the same construct, ${ }^{1}$ and that therefore both are necessary to improve our understanding of the functional capacity of a patient. While self-report tests are widely used, performance tests are mainly applied to assess mobility in patients with a systemic disease. The timed 'up \& go' test was developed to measure basic functional mobility in frail elderly persons, ${ }^{2}$ while the six-minute walk test is applied in patients with peripheral arterial occlusive disease, ${ }^{3}$ chronic obstructive pulmonary disease, ${ }^{4}$ or chronic heart failure. ${ }^{5}$ Although the tests are valuable for assessing overall functional capacity, they do not supply information about the function of each individual foot and therefore their significance in patients with a non-systemic functional impairment of the lower extremities seems small.

There is lack of a measure that can objectively assess the functional status of patients with motor deficiencies of the lower extremities, like those suffering from stroke, spinal cord injury, lower extremity fractures, arthrosis, etc. The existing performance and self-report tests evaluate mobility as an indicator of endurance but do not test the actual functional capacity of each leg. Especially in the rehabilitation practice, in order to determine the present functional status or the effect of treatment in patients with impaired leg function, a new tool is required. Function of the lower extremities comprises more than walking so, in patients with a non-systemic functional impairment of the lower extremities, this should be tested by tasks representative of everyday foot function, like driving a car, playing the piano, or depressing a lever with the foot to open a trash can. An objective test of foot function that enables comparison of both feet is of interest since disease and trauma to the lower extremities often only affect the function of one foot. In addition, such a test could provide objective information on footedness, which has been reported being a better predictor of lateralization than handedness. ${ }^{6,7}$

We have developed a test of foot function that provides objective measurements of standardized tasks that simulate common activities in daily living. Instead of evaluating whether a patient is in good general health and has an adequate walking performance, this measure can potentially assess the specific functional status of each leg, thus providing the missing link in the rehabilitation practice. In this study the test was performed on 100 healthy subjects. Apart from normative values, information will be given on test-retest reliability, inter-rater reliability, and influences on the results of age, dominance, gender, height, weight, shoe size and leisure activities involving foot function. In order to validate the test it was also performed by 20 patients suffering from reflex sympathetic dystrophy of one lower extremity. Reflex sympathetic dystrophy is a neuropathic pain syndrome of unknown pathophysiology, that results from minor trauma or operation to a limb; it is always characterized by an excruciating burning pain and functional impairment. The results 
of these patients on the footboard were compared with the normative values. In addition, correlations have been obtained between the results of these patients on the footboard and their results on the timed 'up \& go' test, a three-minute walk test, and on the mobility dimensions of the Sickness Impact Profile 68 (SIP68) and the Nottingham Health Profile (NHP) ${ }^{8,9}$ Finally, we looked at the ability of the instruments to distinguish between crutch-dependent patients and non-crutch-dependent patients.

\section{Subjects and Methods}

\section{Healthy Subjects}

The test was administered to 10 male and 10 female subjects in each of the following age groups: $20-29$ years, 30-39 years, $40-49$ years, $50-59$ years, and 60-69 years (total 100 subjects). Exclusion criteria were disorders affecting foot function (e.g., arthrosis, rheumatoid arthritis, major lower extremity trauma in history, etc.), use of medication, and extraproportional physical dimensions (e.g., height in excess of two meters or less than 1.5 meters, body mass index greater than 30 , shoe size larger than 11.5). The subjects showed no clinical evidence of abnormality of lower extremity structure, mobility, strength, sensation or coordination. After a five minutes period of rest, tests were performed in the following order: forward and backward shifting, lateral shifting, touching bells and depressing the pedal (see below for detailed description). In all cases, tests were rated by a single person and the nondominant foot was tested first. To provide information on test-retest reliability and inter-rater reliability, all subjects $(n=100)$ were tested twice with a resting period between the two tests of approximately five minutes (M1 and M2). In addition, half of the subjects $(\mathbf{n}=50)$ (equally divided among the age groups) were retested after an interval of one week, at a time of day different from that of the first test (M3). Finally, half of the subjects $(n=50)$ (equally divided over the age groups) were scored simultaneously by two raters. The following details were obtained from each subject: height, weight, shoe size, dominant side and performance of leisure activities involving foot function.

\section{Patients}

The test involved 20 patients, five male and 15 female, with a mean age of 39 years, all of whom suffered from reflex sympathetic dystrophy. Eleven of these patients were unable to stand on their affected foot, and were consequently crutchdependent; the remainder were not. The diagnosis of reflex sympathetic dystrophy was performed in accordance with the criteria of the International Association for the Study of Pain for complex regional pain syndrome type $\mathrm{I} .{ }^{10}$ Exclusion criteria for patients regarding use of medication and extraproportional physical dimensions were similar to the aforementioned criteria for healthy subjects. In addition to using the footboard, strength of both foot dorsiflexors and plantarflexors was measured, 
using hand-held myometry. These patients also performed two other tests, and completed two questionnaires.

The three-minute walk test measured the distance covered by patients in three minutes. Patients were instructed to attempt to complete the greatest distance possible during the allotted time, at a self-determined speed, walking along the outer boundary lines of a gymnasium (twelve by twenty meters). They were allowed to pause for rest whenever they felt it necessary. Patients unable to walk without a walking aid were allowed to use this.

The timed 'up \& go' test measured, in seconds, the time taken to stand up from a standard arm chair, walk a distance of three meters, turn, walk back to the chair, and sit down again. ${ }^{2}$ The subjects started sitting, with their backs against the chair, their arms resting on the arms of the chair and their walking aid to hand.

The entire SIP68 and NHP were completed by the patients, ${ }^{8,9}$ but for this study only results from the dimensions Mobility Control and Mobility Range (SIP68) and Mobility (NHP) were used.

\section{The Board}

The footboard consists of three parts: the board itself, the foot panel, and the pedal panel (Figure 4.1). The board is made out of wood and is 1.10 by 0.60 meters in

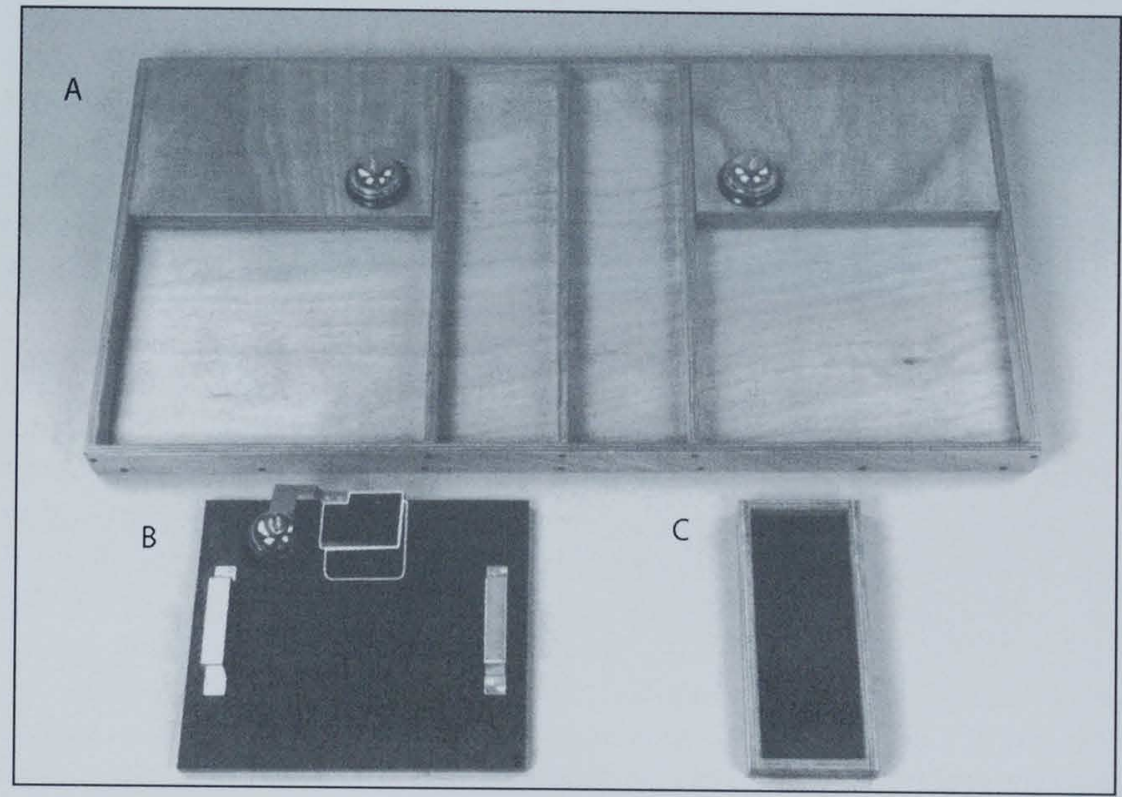

Figure 4.1. Photograph showing the footboard (part A), the pedal panel (part B) and the foot panel (part C). 
size. It is constructed symmetrically having on each side a transverse compartment measuring 40 by $35 \mathrm{~cm}$, a longitudinal compartment measuring 15 by $60 \mathrm{~cm}$ and a raised section measuring 40 by $25 \mathrm{~cm}$. A bell is attached to a point five $\mathrm{cm}$ from the lower limitation and $7.5 \mathrm{~cm}$ from the medial limitation of each raised part. The symmetrical construction allowes an identical test for both legs. Coefficients of friction and difficulties relating to body position are of no importance since these similarly occur for left and right feet.

The foot panel has surface dimensions of 15 by $35 \mathrm{~cm}$ which means that it is just long enough to fit exactly into the transverse compartment and broad enough to fit into the longitudinal compartment. To prevent the shoe slipping, the surface of the panel was covered with a layer of rubber.

The pedal panel has surface dimensions of 40 by $35 \mathrm{~cm}$ and fits exactly into the transverse compartments. On the panel, a perforator and a bell are screwed in adjacent to each other. They are connected by a metal plate in such a way that when the pedal (i.e. the perforator) is sufficiently depressed, the bell rings. Again, to prevent the shoe slipping, the surface of the panel was covered with a layer of rubber.

\section{Subtests}

Four subtests were chosen to provide a broad sampling of foot function:

1. Forward and backward shifting (FBS)-measures mobility.

2. Lateral shifting (LS)-measures mobility.

3. Touching bells (TB)-measures coordination and mobility.

4. Depressing the pedal (DP) - measures strength and mobility.

Each of the subtests was designed to be administered in precisely the same manner to each subject. The results were measured objectively using a stopwatch; this allowed for a continuum of scores. The mean of three administrations of each subtest was recorded as the final measure. The board was placed on the floor in front of the subject's chair and, to avoid slippage, was jammed firmly in between a heavy piece of furniture on both sides, and between the legs of the chair and the wall at the rear. Each subject was tested using the same chair (height and depth $45 \mathrm{~cm}$ ). Subjects were allowed to change position in the chair, but not to change the position of the chair itself. After the instructions had been given, a check was made on whether these had been fully understood. Subjects were required to practice each subtest before the subtest was actually performed. The subtests were always presented in the same sequence and were first performed with the nondominant foot (defined as the foot contralateral to the side of the writing hand). The subtest descriptions below concern the right foot tests.

Subtest 1: Forward and Backward Shifting (FBS)

Procedure. The left foot was placed in the lower medial corner of the left transverse compartment, while the right foot was placed in the foot panel, which was situated low in the right longitudinal compartment. The subject was instructed to shift the foot panel three times to and fro as quickly as possible (Figure $4.2 a$ ). The procedure 
was timed from the word 'go' until the foot panel struck the rearmost edge of the compartment for the third time.

Subtest 2: Lateral Shifting (LS)

Procedure. The left foot was placed in the lower medial corner of the left transverse compartment, while the right foot was placed in the foot panel, which was situated medial in the right transverse compartment. The subject was instructed to shift the foot panel from the middle to the side and back three times as rapidly as possible (Figure $4.2 b$ ). The procedure was timed from the word 'go' until the foot panel struck the middle division of the compartment for the third time.

Subtest 3: Touching Bells (TB)

Procedure. The left foot was placed in the lower medial corner of the left transverse compartment, while the right foot was placed in the lower medial corner of the right transverse compartment. The subject was instructed to tap the bells alternately three times as quickly as possible, starting with the opposite (left) bell (Figure 4.2c). The procedure was timed from the word 'go' until the sixth ring of a bell was heard. Should the subject miss out one of the bells, the whole procedure was required to be gone through again.

Subtest 4: Depressing the pedal (DP)

Procedure. The left foot was placed in the lower medial corner of the left transverse compartment. The pedal panel was situated in the right transverse compartment
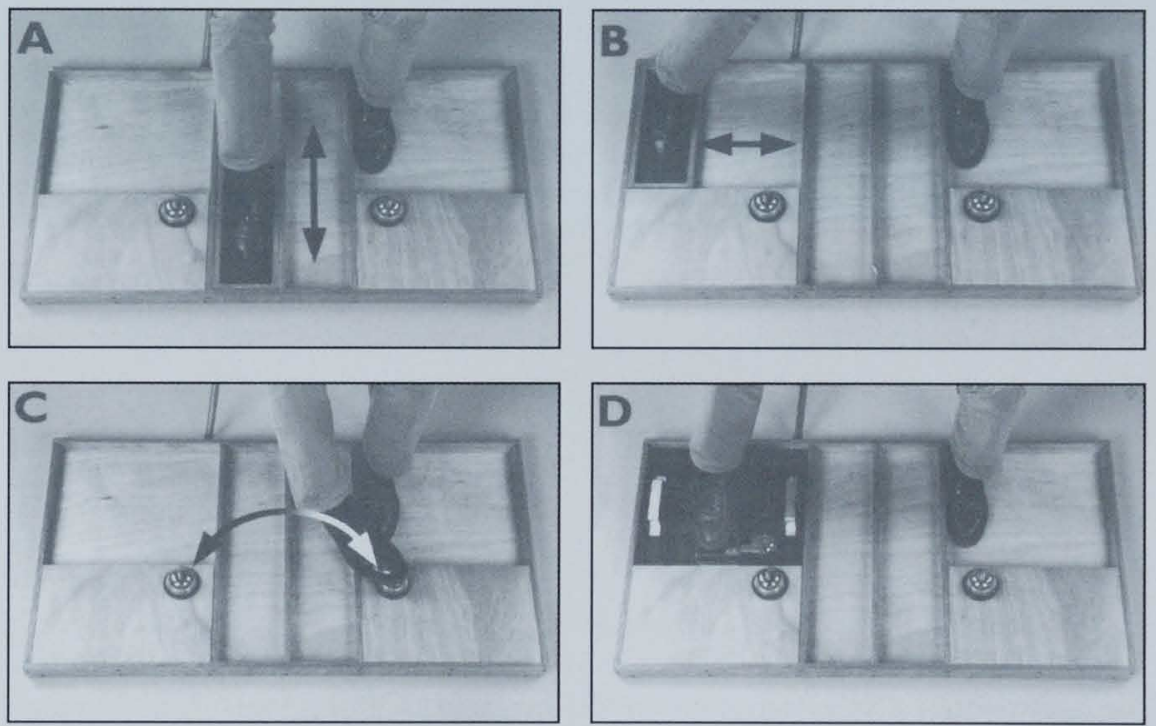

Figure 4.2. The footboard subtests: (a) 'forward and backward shifting', (b) 'lateral shifting', (c) 'touching bells', and (d) 'depressing the pedal'. 
and the front portion of the right foot was placed on the pedal with the heel in contact with the bottom of the panel. Whenever the pedal was depressed sufficiently, a bell would ring (Figure $4.2 d$ ). The subject was instructed to depress the pedal ten times as quickly as possible, and each time allow it to return completely to the raised position. The procedure was timed from the word 'go' until the tenth ring of the bell was heard.

\section{Aims and Hypotheses}

In order to determine the value of the footboard as a reliable measure of foot function, the following aspects were studied.

1. Normal scores on the footboard were measured.

2. The inter-rater and intra-rater (test-retest) reliability of the measurement were determined.

3. The influence by the factors age, dominance, gender, height, weight, shoe size and leisure activities involving foot function on results of the footboard was assessed.

4. The test was validated by applying it to reflex sympathetic dystrophy patients with definite functional impairment of one lower extremity.

5. Footboard results were compared with results on a battery of performance and self-report tests by obtaining correlation coefficients and by finding the ability of each test to differentiate between patients who are crutch-dependent and those who are not.

We hypothesized (1) that the inter-rater and intra-rater reliabilities of the footboard are high, (2) that its results might be influenced by any of the mentioned factors, (3) that the test is capable of discerning patients from controls, (4) that its results do not, or only to a limited extent, correlate with results of other tests, since we expect the footboard to measure another phenomenon than existing tests and (5) that it is able to distinguish between crutch-dependent patients and non-crutchdependent patients.

\section{Statistical procedure}

Healthy subjects For each age group, means and standard deviations were calculated per gender. The intra-rater and inter-rater reliability were analyzed by obtaining Pearson correlation coefficients. In addition, the test-retest reliability was calculated with the $t$-test for paired samples to detect systematic differences. Statistical differences between the mean subtest scores of each age group were tested with analysis of variance (ANOVA). Differences between dominant and nondominant side were analyzed using a $t$-test for paired samples. By means of a linear regression analysis, the influence of the factors of age, gender, height, weight, shoe size and leisure activities was examined. The influence of gender and leisure activities was also analyzed using a $t$-test for independent samples. 
Patients The mean results for the patients were compared to normative values, using a $t$-test for independent samples, after the normative values had been corrected for gender and dominance, and, in the case of DP, also for age. The relationship between results of the affected leg on the footboard (expressed as the sum on the four subtests, divided by four) and on the other tests and questionnaires were analyzed by obtaining Pearson correlation coefficients. The ability of the instruments to distinguish between crutch-dependent patients and non-crutch-dependent patients was determined by comparing the means of both groups with a $t$-test for independent samples.

\section{Results}

\section{Characteristics of Normal Subjects}

The mean age (SD) of the subjects was $45 \pm 14$ years for men and $44 \pm 15$ years for women. Men had a mean height of $1.81 \pm 0.07 \mathrm{~m}$, a mean weight of $80 \pm 10 \mathrm{~kg}$, and a mean shoe size of 9.5 , whereas women had a mean height of $1.67 \pm 0.07 \mathrm{~m}$, a mean weight of $63 \pm 8 \mathrm{~kg}$, and a mean shoe size of 6 . Forty men $(80 \%)$ and 46 women (92\%) were right-handed. Twenty-seven men (54\%) and 22 women (44\%) had leisure activities involving foot function.

\section{Performance of Normal Subjects}

Mean subtest results on M1, M2 and M3 for left and right sides in each age group are presented in Table 4.1 (men) and Table 4.2 (women).

Inter-rater and intra-rater reliability High correlation coefficients were obtained between results of the first and second raters, ranging from 0.85 (LS, nondominant leg) to 0.99 (DP, nondominant leg). Similarly high correlation coefficients were obtained between the results of $M 1$ and $M 2$, and the results of $\mathrm{M} 2$ and $M 3$, ranging from 0.74 (FBS, nondominant leg, M2-M3) to 0.93 (DP, dominant leg, M1-M2). Despite high correlation coefficients, systematic differences occurred: all tests were performed significantly faster on M2 as compared to M1 (all $p$ 's $<0.0001$ ). Results of LS $(p<0.05)$ and TB $(p<0.0001)$ on M3 were also significantly faster than on M2. Results of FBS and DP were not statistically significant for M2 and M3.

Influencing factors The extent of differences between age groups, detected by ANOVA, differed from test to test, but appeared only of significant influence to performance on the pedal; younger subjects were faster $(p=0.001)$. Because of the small influence of age on results of FBS, LS, and TB, the mean value of the complete group can be used as the normative value; for DP, we present a normative value for younger (20-40 years) and older (above 40 years) age categories. These normative values against which patient performance can be compared are presented in Table 4.3. On all tests, in all three assessments, the dominant side was significantly faster than the nondominant side (all $p$ 's $<0.0001$ ), but the extent of difference between both sides decreased from M1 to M3. Linear regression analysis revealed 
that gender is of influence to all subtest results, except FBS, and age and leisure activity influence DP. Thus, the factors height, weight and shoe size have no influence on the results. The $t$-test analysis showed that males performed the subtests

TABLE 4.1. Subtest results of each age group for male subjects on $M 1, M 2$ and M3

\begin{tabular}{|c|c|c|c|c|c|c|c|c|c|}
\hline & & \multicolumn{2}{|c|}{$\begin{array}{l}\text { Forward backward } \\
\text { shifting }\end{array}$} & \multicolumn{2}{|c|}{ Lateral shifting } & \multicolumn{2}{|c|}{ Touching bells } & \multicolumn{2}{|c|}{ Depressing the pedal } \\
\hline & & DS & NDS & DS & NDS & DS & NDS & DS & NDS \\
\hline \multirow{3}{*}{$20-29$ yrs } & M1 & $1.64(.28)$ & $1.74(.27)$ & $1.88(.25)$ & $1.87(.20)$ & $2.25(.31)$ & $2.33(.31)$ & $2.68(.40)$ & $2.88(.49)$ \\
\hline & M2 & $1.64(.30)$ & $1.64(.22)$ & $1.75(.29)$ & $1.84(.27)$ & $2.13(.34)$ & $2.25(.38)$ & $2.68(.33)$ & $2.78(.35)$ \\
\hline & M3 & $1.60(.19)$ & $1.56(.17)$ & $1.68(.17)$ & $1.74(.20)$ & $1.98(.16)$ & $2.06(.24)$ & $2.54(.13)$ & $2.51(.17)$ \\
\hline \multirow{3}{*}{$30-39$ yrs } & M1 & $1.68(.14)$ & $1.73(.12)$ & $1.84(.28)$ & $1.96(.19)$ & $2.28(.27)$ & $2.38(.33)$ & $2.61(.26)$ & $3.06(.36)$ \\
\hline & M2 & $1.56(.12)$ & $1.61(.15)$ & $1.63(.20)$ & $1.77(.26)$ & $2.13(.23)$ & $2.24(.26)$ & $2.51(.24)$ & $2.75(.28)$ \\
\hline & M3 & $1.51(.14)$ & $1.65(.18)$ & $1.66(.10)$ & $1.79(.27)$ & $2.13(.22)$ & $2.26(.30)$ & $2.34(.30)$ & $2.60(.29)$ \\
\hline \multirow{3}{*}{$40-49$ yrs } & M1 & $1.67(.15)$ & $1.82(.23)$ & $1.80(.19)$ & $1.91(.18)$ & $2.44(.21)$ & $2.63(.27)$ & $3.17(.38)$ & $3.39(.38)$ \\
\hline & M2 & $1.63(.13)$ & $1.74(.13)$ & $1.70(.15)$ & $1.83(.13)$ & $2.32(.28)$ & $2.55(.21)$ & $2.93(.22)$ & $3.03(.29)$ \\
\hline & M3 & $1.59(.07)$ & $1.66(.09)$ & $1.66(.10)$ & $1.74(.10)$ & $2.18(.15)$ & $2.39(.17)$ & $2.87(.28)$ & $3.04(.29)$ \\
\hline \multirow{3}{*}{$50-59$ yrs } & Ml & $1.73(.22)$ & $1.89(.21)$ & $1.84(.27)$ & $1.95(.26)$ & $2.37(.39)$ & $2.51(.25)$ & $3.13(.30)$ & $3.64(.58)$ \\
\hline & M2 & $1.61(.24)$ & $1.68(.22)$ & $1.70(.24)$ & $1.74(.25)$ & $2.27(.35)$ & $2.42(.29)$ & $2.85(.30)$ & $3.21(.28)$ \\
\hline & M3 & $1.77(.31)$ & $1.82(.28)$ & $1.74(.30)$ & $1.87(.34)$ & $2.27(.31)$ & $2.44(.34)$ & $2.86(.31)$ & $3.08(.32)$ \\
\hline \multirow{3}{*}{$60-69$ yrs } & M1 & $1.73(.14)$ & $1.81(.19)$ & $1.81(.19)$ & $1.97(.24)$ & $2.34(.25)$ & $2.48(.19)$ & $3.25(.22)$ & $3.53(.29)$ \\
\hline & M2 & $1.64(.14)$ & $1.69(.14)$ & $1.73(.23)$ & $1.78(.17)$ & $2.26(.23)$ & $2.41(.24)$ & $3.00(.26)$ & $3.12(.11)$ \\
\hline & M3 & $1.61(.13)$ & $1.70(.20)$ & $1.65(.17)$ & $1.72(.15)$ & $2.15(.10)$ & $2.28(.17)$ & $2.94(.20)$ & $3.10(.05)$ \\
\hline
\end{tabular}

TABLE 4.2. Subtest results of each age group for female subjects on M1, M2 and M3

\begin{tabular}{|c|c|c|c|c|c|c|c|c|c|}
\hline & & \multicolumn{2}{|c|}{$\begin{array}{l}\text { Forward backward } \\
\text { shifting }\end{array}$} & \multicolumn{2}{|c|}{ Lateral shifting } & \multicolumn{2}{|c|}{ Touching bells } & \multicolumn{2}{|c|}{ Depressing the pedal } \\
\hline & & DS & NDS & DS & NDS & DS & NDS & DS & NDS \\
\hline \multirow{3}{*}{$20-29$ yrs } & M1 & $1.90(.30)$ & $2.00(.24)$ & $1.99(.27)$ & $2.14(.33)$ & $2.49(.42)$ & $2.60(.46)$ & $3.02(.49)$ & $3.36(.53)$ \\
\hline & M2 & $1.82(.30)$ & $1.87(.31)$ & $1.9](.35)$ & $2.05(.40)$ & $2.42(.46)$ & $2.59(.53)$ & $2.82(.38)$ & $2.98(.45)$ \\
\hline & M3 & $1.74(.24)$ & $1.78(.35)$ & $1.74(.29)$ & $1.82(.28)$ & $2.19(.33)$ & $2.26(.38)$ & $2.67(.24)$ & $2.67(.15)$ \\
\hline \multirow{3}{*}{$30-39$ yrs } & M1 & $1.82(.30)$ & $1.91(.24)$ & $1.90(.31)$ & $1.99(.36)$ & $2.45(.41)$ & $2.66(.46)$ & $3.13(.48)$ & $3.58(.71)$ \\
\hline & M2 & $1.72(.30)$ & $1.82(.25)$ & $1.79(.30)$ & $1.87(.31)$ & $2.31(.41)$ & $2.47(.48)$ & $2.92(.58)$ & $3.04(.44)$ \\
\hline & M3 & $1.70(.26)$ & $1.81(.27)$ & $1.77(.29)$ & $1.81(.24)$ & $2.14(.40)$ & $2.28(.38)$ & $2.70(.44)$ & $2.75(.48)$ \\
\hline \multirow{3}{*}{$40-49$ yrs } & $\mathrm{Ml}$ & $2.00(.29)$ & $2.09(.30)$ & $2.01(.36)$ & $2.22(.34)$ & $2.66(.45)$ & $2.81(.39)$ & $3.76(.84)$ & $4.28(1.08)$ \\
\hline & M2 & $1.93(.25)$ & $1.99(.27)$ & $1.95(.32)$ & $2.06(.34)$ & $2.50(.37)$ & $2.62(.39)$ & $3.42(.70)$ & $3.67(.79)$ \\
\hline & M3 & $1.78(.14)$ & $1.88(.24)$ & $1.82(.16)$ & $1.97(.20)$ & $2.62(.52)$ & $2.68(.41)$ & $3.53(.65)$ & $3.99(.98)$ \\
\hline \multirow{3}{*}{$50-59$ yrs } & M1 & $1.89(.19)$ & $1.99(.17)$ & $1.98(.17)$ & $2.00(.20)$ & $2.64(.34)$ & $2.78(.39)$ & $3.28(.59)$ & $3.67(.68)$ \\
\hline & M2 & $1.75(.22)$ & $1.84(.16)$ & $1.85(.24)$ & $1.86(.23)$ & $2.47(.34)$ & $2.57(.42)$ & $2.97(.49)$ & $3.22(.58)$ \\
\hline & M3 & $1.73(.23)$ & $1.79(.30)$ & $1.76(.30)$ & $1.84(.24)$ & $2.43(.65)$ & $2.48(.65)$ & $3.05(.66)$ & $3.49(.95)$ \\
\hline \multirow{3}{*}{$60-69$ yrs } & M1 & $2.07(.28)$ & $2.26(.33)$ & $2.17(.38)$ & $2.28(.29)$ & $2.96(.54)$ & $3.16(.67)$ & $4.19(1.27)$ & $4.50(1.05)$ \\
\hline & M2 & $1.94(.31)$ & $2.01(.33)$ & $2.13(.43)$ & $2.09(.38)$ & $2.85(.53)$ & $3.06(.66)$ & $3.68(1.07)$ & $3.80(.93)$ \\
\hline & M3 & $1.85(.18)$ & $1.96(.14)$ & $2.03(.15)$ & $1.90(.17)$ & $2.73(.29)$ & $2.87(.40)$ & $3.19(.36)$ & $3.42(.43)$ \\
\hline
\end{tabular}


significantly faster than females $(p<0.05)$, the order of magnitude of difference being: DP, TB, FBS, LS ( $p<0.05$ in all cases). Subjects with leisure activities involving foot function $(n=49)$ were on all three assessments significantly faster on the pedal than those without such a pastime $(n=51)(p<0.05)$. On M3, all subtests were performed significantly faster by subjects with this kind of leisure activity $(n=28)$ as compared to those without $(n=22)(p<0.05)$.

\section{Performance of Patients}

The mean M2 results on the footboard of the affected and unaffected sides of 20 patients with reflex sympathetic dystrophy were $11.21 \pm 5.38 \mathrm{~s}$ and $2.82 \pm 0.97 \mathrm{~s}$ on FBS, $11.76 \pm 6.04 s$ and $2.90 \pm 1.03 s$ on LS, $7.83 \pm 3.38 s$ and $3.38 \pm 1.14 s$ on TB, and $16.89 \pm 7.77 \mathrm{~s}$ and $4.24 \pm 1.24 \mathrm{~s}$ on DP. The results on the footboard compared to normative values are presented in Figure 4.3 (for each patient the normative value was obtained from Table 4.3; the mean \pm SD was then calculated for each subtest). On the affected side, patients performed the subtests FBS, LS and TB significantly more slowly than controls $(p<0.0001)$, while for DP the difference between patients and controls was somewhat less clear for older patients $(\leq 40$ years: $p<0.0001 ;>40$ years: $p=0.002)$. On the unaffected side the differences were smaller, but still significant (FBS and LS: $p<0.0001$; TB: $p=0.003$ ). Concerning DP, again, the difference between patients and controls was less clear for older patients ( $\leq 40$ years: $p=0.001 ;>40$ years: $p=0.02$ ).

Correlation with other tests Correlation coefficients between results on the footboard and on the other performance tests and questionnaires are presented in Table 4.4. On the affected side, only strength of foot dorsiflexors and plantarflexors correlated with the footboard $(p<0.0001)$. Correlation coefficients between the footboard and foot dorsiflexors $(-0.50)$ and plantarflexors $(-0.48)$ on the unaffected side were less robust, referring to the difference in correlation coefficients rather than to $p$ values $(p<0.05)$. Correlation coefficients between the three-minute walk test and the timed 'up \& go' test $(p<0.05)$, between the mobility dimensions of the SIP68 (Mobility Range) and NHP ( $p<0.05$ ), and between strength of affected foot dorsiflexors and plantarflexors were significant $(p<0.0001)$.

TABLE 4.3. Normative values

\begin{tabular}{llllll}
\hline & $\begin{array}{l}\text { Forward- } \\
\text { backward } \\
\text { shifting }\end{array}$ & $\begin{array}{l}\text { Lateral } \\
\text { shifting }\end{array}$ & $\begin{array}{l}\text { Touching } \\
\text { bells }\end{array}$ & $\begin{array}{l}\text { Depressing } \\
\text { the pedal } \\
(20-40 \mathrm{yrs})\end{array}$ & $\begin{array}{l}\text { Depressing } \\
\text { the pedal } \\
(>40 \mathrm{yrs})\end{array}$ \\
\hline Male dominant & $1.62(.19)$ & $1.70(.22)$ & $2.22(.29)$ & $2.60(.29)$ & $2.93(.26)$ \\
Male nondominant & $1.67(.17)$ & $1.79(.22)$ & $2.37(.29)$ & $2.77(.31)$ & $3.12(.24)$ \\
Female dominant & $1.83(.28)$ & $1.92(.33)$ & $2.51(.45)$ & $2.88(.47)$ & $3.38(.84)$ \\
Female nondominant & $1.91(.27)$ & $1.99(.35)$ & $2.66(.53)$ & $3.04(.43)$ & $3.58(.82)$ \\
\hline
\end{tabular}

Mean subtest scores in seconds (SD) of 50 (FBS, LS, TB), 30 (DP; 20-40 yrs), and 20 (DP; $>40$ yrs) male and 50 (FBS, LS, TB), 28 (DP; 20-40 yrs), and 22 (DP; $>40$ yrs) female healthy subjects. 


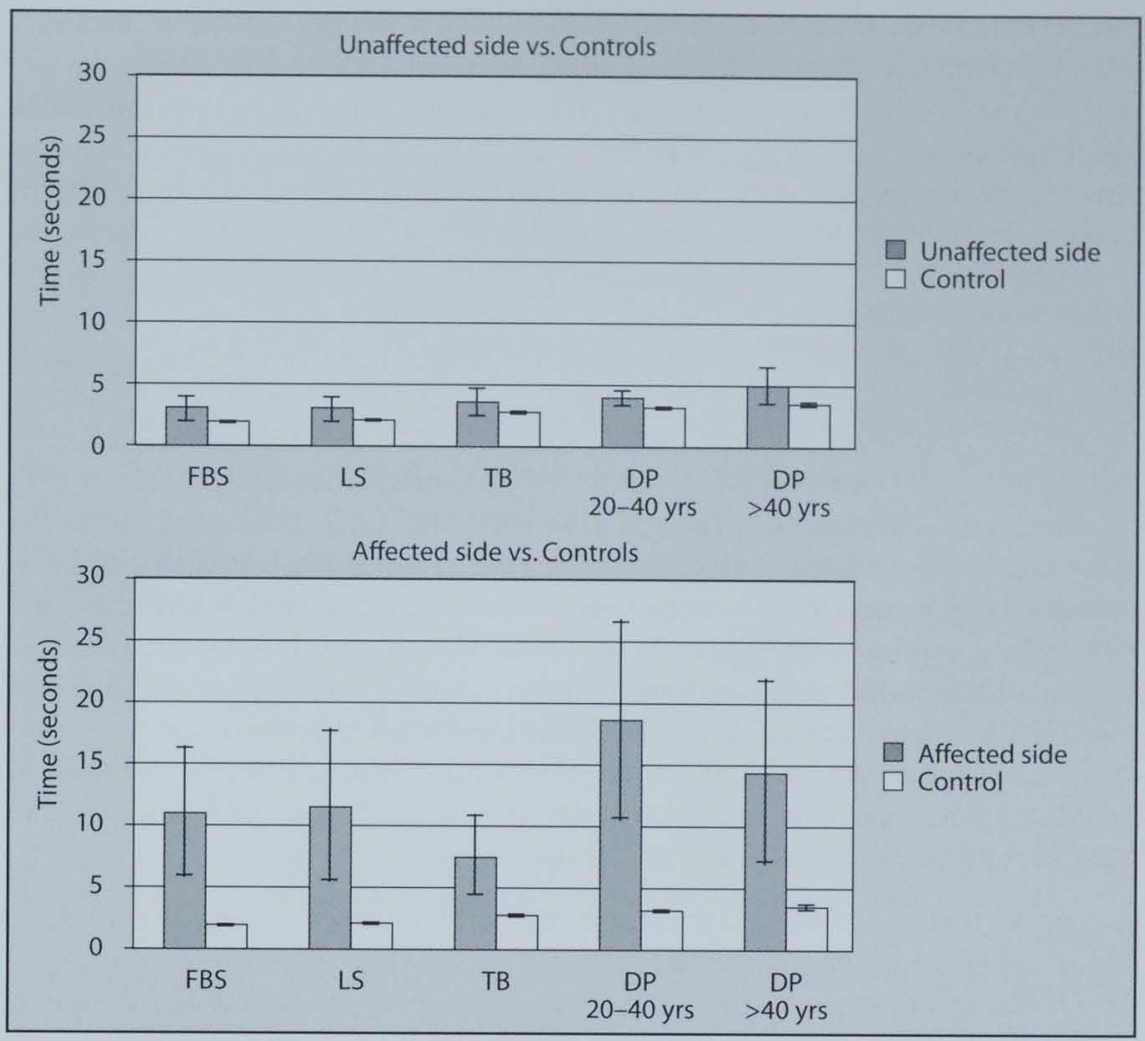

Figure 4.3. Mean results ( \pm SD) of the unaffected and affected feet of 20 reflex sympathetic dystrophy patients compared with gender and dominance corrected control values on footboard subtests 'forward and backward shifting' (FBS), 'lateral shifting' (LS), 'touching bells' (TB), and 'depressing the pedal' (DP). DP results are presented for the age groups of 20 to 40 years $(n=11)$ and above 40 years $(n=9)$. All differences between patients and controls are significant $(p<0.05)$.

Measuring crutch-dependency of the seven instruments, only the footboard $(p=0.001)$ and the myometry of foot dorsiflexors $(p=0.004)$ and plantarflexors $(p=0.005)$ measured a significant difference ( $t$-test for independent samples) between crutch-dependent patients and non-crutch-dependent patients.

\section{Discussion}

The footboard is clearly a valuable and reliable tool for assessing foot function: the principle is easy to comprehend, and the construction of the apparatus is simple; the inter-rater and intra-rater reliabilities are high. However, a substantial learning 
$T_{A B L E}$ 4.4. Correlation coefficients between results of the affected foot on the footboard and on the other performance tests and questionnaires

\begin{tabular}{lrrrrrrrr}
\hline & \multicolumn{1}{c}{ FB } & TUG & TMW & NM & SMR & SMC FDF & FPF \\
\hline Footboard (FB) & 1.00 & & & & & & & \\
Timed 'up \& go' (TUG) & 0.30 & 1.00 & & & & & & \\
Three-minute walk (TMW) & -0.01 & $-0.47^{*}$ & 1.00 & & & & & \\
NHP 'mobility' (NM) & 0.28 & 0.35 & -0.40 & 1.00 & & & & \\
SIP68 'mobility range' (SMR) & 0.11 & -0.13 & -0.17 & $0.47^{*}$ & 1.00 & & & \\
SIP68 'mobility control' (SMC) & -0.02 & 0.06 & -0.29 & 0.02 & 0.24 & 1.00 & & \\
Foot dorsiflexors (FDF) & $-0.77^{* *}$ & -0.20 & -0.04 & -0.37 & -0.17 & 0.17 & 1.00 & \\
Foot plantarflexors (FPF) & $-0.73^{* *}$ & -0.21 & -0.08 & -0.43 & -0.22 & 0.16 & $0.89^{* *}$ & 1.00 \\
\hline
\end{tabular}

Asterisks indicate significant correlation coefficients at the $p<0.05$ level $^{*}$ or at the $p<0.0001$ level $^{* *}$.

effect is present, with the difference being especially high between M1 and M2. Therefore, we suggest that the first measurement session always be preceded by a full practice session. Although results of LS and TB also slightly improved from M2 to $M 3$, we regard M2 values as baseline values. With the exception of DP, results were not influenced by age. The demonstrated relationship between age and results on DP is evidence for this being the most demanding subtest. The fact that results were not influenced by age implies that the test is equally easily performed by both young and old subjects. Because the test is carried out while seated, it is also suitable for frail elderly and wheelchair dependent persons, which is a great advantage over walking distance tests.

The dominant foot, defined as the foot ipsilateral to the side of the writing hand, was on all tests significantly faster than the nondominant foot. Recent evidence shows that lateralization of language and emotion varies with preferred foot but not with preferred hand ${ }^{6,7}$ and in consequence there is increasing interest nowadays in tests to assess footedness. There is, however, ongoing discussion on which foot should be considered the dominant one. Peters proposed defining the foot that is used to manipulate an object as the preferred foot, while the foot that is used to support the activities of the preferred foot by lending postural and stabilizing support should be considered to be the nonpreferred foot. "Gabbard and Hart, on the other hand, feel that the mobilizing limb is dominant for mobility but not for stability. ${ }^{12}$ The footboard tests both legs in a similar way and eliminates the skill of a stabilizing leg, because mobilization is tested while seated. Assessment of footedness is therefore maximally objective and further studies should demonstrate whether the mobilizing foot actually is the fastest foot on the board.

Men performed all subtests faster than women. Clearly, this was not the result of differences in height, weight or shoe size between the genders. Notwithstanding the fact that the test requires little effort, it appears to be sensitive to physical strength. Interestingly, the largest difference between male and female subjects was measured on DP, which is additional evidence for this being the most demanding subtest. Technically, DP seems also to be the most difficult subtest since subjects 
with leisure activities involving foot function were significantly faster on DP than those without. A leisure activity involving foot function additionally favoured learning capacity; on M3, subjects with such a pastime were significantly faster on all subtests than those without.

Patients experiencing reflex sympathetic dystrophy scored significantly worse than controls with their affected foot, supporting the validity of the footboard procedure. To a much lesser extent, the same was true for the unaffected foot. This can be explained by the fact that patients cannot give support to the leg being tested with their affected leg, as can healthy subjects. Therefore, normative values are to be preferred as controls over unaffected-side values.

A drawback of mobility tests is their inability to test subjects who are non-ambulant. The footboard is suitable for such patients, because its subtests are easy to perform and subjects are seated during the test. In the present study, patients unable to walk unaided performed the three-minute walk test and the timed 'up \& go' test while using their crutches. Although their functional ability is worse, it is possible for such patients to obtain better scores than those who walk without such assistance. Indeed, both the timed 'up \& go' and the three-minute walk test were unable to distinguish between those patients of the RSD group who were, and those who were not crutch-dependent. The mobility dimensions of the SIP68 and NHP were also unable to distinguish between these groups, which supports the hypothesis that the questionnaires do not request information about the function of each individual foot. When patients with reflex sympathetic dystrophy become crutchdependent this means that, because of severe pain, they cannot stand on the affected leg. In other words, clinically there is a great difference between those patients with this disease who are crutch-dependent and those who are not. That a battery of performance and self-report tests was unable to distinguish crutchdependency, while the footboard and myometry were indeed able to do so, underlines the fact that most available instruments are unsuitable for evaluating nonsystemic functional impairment of the lower extremities.

In line with Hoeymans' hypothesis that performance and self-report tests do not measure the same construct, ${ }^{1}$ the timed 'up \& go' and the three-minute walk test showed no correlation with the mobility dimensions of the SIP68 and NHP. The performance tests, however, correlated well with each other, as did the self-report tests. The footboard, on the other hand, correlates neither with the performance tests nor with the self-report tests, suggesting that it provides additional information. The footboard did however correlate well with hand-held myometry. Because in order to measure the strength by myometry patients are required to push against a dynamometer, the results are heavily influenced by the painful sensitivity to touch that many RSD patients experience. ${ }^{13}$ On the unaffected side, we found a moderate correlation between the footboard and myometry results, again showing the footboard to be sensitive to physical strength. On the affected side, this correlation was both stronger and more significant, indicating that after strength, painful sensitivity to touch has an important influence on footboard results. 
The additional information that is provided by the footboard is of great relevance to rehabilitation practices. The goal of rehabilitation of patients with a nonsystemic functional impairment of the lower extremities, like those suffering from stroke, spinal cord injury, lower extremity fractures, arthrosis, or reflex sympathetic dystrophy, is to improve the functional status of these extremities. Therefore, the evaluation of the functional status and of the effect of treatments, like physical therapy, taping, surgery or medication, should be measured directly by assessment of the lower extremity function itself. The footboard potentially provides this objective evaluation of the functional status and may be used for research purposes as a direct outcome measure of foot function.

\section{Conclusion}

In summary, we can conclude that the footboard is a simple and convenient device that objectively assesses foot function by testing separate tasks for each foot. The test distinguishes healthy individuals from those with impaired function of the lower extremities. Unlike other performance tests, it is applicable to non-ambulant patients. The footboard was perfectly capable to distinguish crutch-dependent from non-crutch-dependent patients; out of a battery of performance and self-report tests, only myometry could distinguish between these groups. In addition to a clinical role as a means of describing current level of function, and a research role as an outcome indicator, this test is an interesting alternative means of assessing footedness. For these reasons, the footboard should prove a valuable addition to the available tests for assessing foot function.

\section{References}

1. Hoeymans N, Feskens EJM, van den Bos GAM, Kromhout D. Measuring functional status: cross-sectional and longitudinal associations between performance and self-report (Zutphen Elderly Study 1990-1993). J Clin Epidemiol 1996; 49: 1103-10.

2. Podsiadlo D, Richardson S. The timed 'up \& go': a test of basic functional mobility for frail elderly persons. J Am Geriatr Soc 1991; 39: 142-8.

3. Montgomery PS, Gardner AW. The clinical utility of a six-minute walk test in peripheral arterial occlusive disease patients. J Am Geriatr Soc 1998; 46: 706-11.

4. Borak J, Chodosowska E, Matuszewski A, Zielinski J. Emotional status does not alter exercise tolerance in patients with chronic obstructive pulmonary disease. Eur Respir ) 1998; 12: 370-3.

5. Roul G, Germain P, Bareiss P. Does the 6-minute walk test predict the prognosis in patients with NYHA class II or III chronic heart failure? Am Heart J 1998; 36: 449-57.

6. Day LB, MacNeilage PF. Postural assymmetries and language lateralization in humans (homo sapiens). J Comp Psychol 1996; 110: 88-96.

7. Elias LJ, Bryden MP, Bulman-Fleming MB. Footedness is a better predictor than handedness of emotional lateralization. Neuropsychologia 1998; 36: 37-43. 
8. De Bruin AF, Buys M, De Witte LP, Diederiks JPM. The sickness impact profile: SIP68, a short generic version. First evaluation of the reliability and reproducability. J Clin Epidemiol 1994; 47: 863-71.

9. Hunt SM, McEwen J, McKenna SP. Measuring health status: a new tool for clinicians and epidemiologists. J Royal Coll Gen Practit 1985; 35: 185-8.

10. Merskey H, Bogduk N, editors. Classification of chronic pain: descriptions of chronic pain syndromes and definitions of pain terms. Seattle: IASP Press, 1994, pp. 41-2.

11. Peters $M$. Footedness: asymmetries in foot preference and skill and neuropsychological assessment of foot preference. Psychol Bull 1988; 103: 179-92.

12. Gabbard C, Hart S. A question of foot dominance. J Gen Psychol 1996; 123: 289-96.

13. Veldman PHJM, Reynen HM, Arntz IE, Goris RJA. Signs and symptoms of reflex sympathetic dystrophy: prospective study of 829 patients. Lancet 1993; 342: 1012-6. 

CHAPTER 5

Thermal Thresholds in Reflex

Sympathetic Dystrophy: Sensitivity

and Repeatability of the Methods of Limits and Levels

Marius A. Kemler, Jos P.H. Reulen, Maarten van Kleef, Gerard A.M. Barendse, Frans A.J.M. van den Wildenberg, and Frank Spaans 


\section{Introduction}

Assessment of thermal sensory detection thresholds increases our understanding of the function of small myelinated (A $\delta$ ) and unmyelinated (C) nerve fibers. ${ }^{1,2}$ In reflex sympathetic dystrophy (RSD), a syndrome of unknown pathophysiology causing pain and impairing function in the affected extremity, abnormal function of small sensory fibers is likely for several reasons. Hypoesthesia and allodynia are frequently present, ${ }^{3}$ and are among the diagnostic criteria. ${ }^{4}$ Histological analysis of nerves from amputated legs suffering from RSD has revealed C-fiber pathology, ${ }^{5}$ and in patients suffering from RSD occurrence of several abnormal thermal threshold patterns has been described. Pure warm hypoesthesia, pure cold hypoesthesia, thermal hyperalgesia as well as combinations of these disturbances are possible. ${ }^{6}$ Patterns with an organic basis tend to be stereotyped in different individuals with similar pathophysiological states and tend to be consistent over time. They also tend to evolve into other predictable patterns as the underlying neurological disease repairs or worsens. ${ }^{6}$ For these reasons, evaluation of the thermal sensory pattern in RSD patients might improve our understanding of peripheral nerve function in these patients, and might be used in the assessment of therapy.

Presently, no objective tests are available to test thermal sensory thresholds and thus psychophysical methods have to be used. Over a hundred years ago James had already noted these methods as measuring more than merely sensory factors: 'Whilst part of what we perceive comes through our senses from the object before us, another part (and it may be the larger part) always comes...out of our own head'.' Classical psychophysical methods such as the method of constant stimuli, also known as the 'Method of Levels' (MLE), and the Method of Limits (MLI) produce estimates of thresholds that are potentially contaminated by nonsensory factors. ${ }^{8}$

Apart from the fundamental problem with psychophysical methods as described above, there is ongoing discussion about which of these two most frequently used methods is to be preferred. The MLI, in which the subject is exposed to a stimulus of increasing intensity and then asked to indicate the first onset of sensation, includes a reaction time artefact which is especially important when slower conducted sensations, such as warm sensation, are measured. ${ }^{9}$ In the MLE a stimulus of predetermined intensity and duration is delivered to the subject who responds post factum. A series of constant stimuli is needed to estimate the threshold, which causes this method inevitably to take longer than the MLI. Because the MLE lacks a reaction time artefact, an increased accuracy in threshold detection is gained in return for the longer duration. ${ }^{9}$ Several investigators, however, have been unable to find an increased sensitivity for disease detection, ${ }^{10}$ or an improvement in repeatability of the MLE compared to the MLI, ${ }^{11,12}$ therefore, most investigators tend to use the time-saving MLI. A recent textbook states: 'Considering the intensity with which the question MLI or MLE has been discussed, it is surprising that so few studies have been carried out to compare the methods using the same type of stimulus'. ${ }^{13}$ 
Indeed, knowing and using the best method would simplify research and improve the comparison between different studies.

In the present study we will compare the MLE and the MLI in patients with RSD with regard to sensitivity in detection of thermal sensory pathology, sensory threshold agreement, and sensory threshold repeatability. Thermal pain thresholds, although frequently abnormal in RSD patients, ${ }^{6}$ are beyond the scope of this study since their assessment is possible with only one method: the MLI.

\section{Patients and Methods}

Subjects

Fifty-three patients suffering from RSD ( 37 females and 16 males), with a mean age of 38.6 years (range: 21 to 65 years) were studied; 33 patients had RSD of an arm while 20 had RSD of a leg. The mean duration of RSD was 38.2 months (range: 9-120 months). Perception thresholds for warmth and cold were assessed twice, at an interval of one month. During this month the patients did not receive any treatment. The patient's clinical signs had to fulfil a minimum of four absolute criteria and three out of nine relative criteria before the diagnosis of RSD was made; these diagnostic criteria are detailed in Table 5.1. The criteria are in accordance with those stated by the International Association for the Study of Pain (IASP). ${ }^{4}$ All patients had RSD with severe pain (i.e. at least 5 out of 10 centimeters on a visual analog scale) which was unresponsive to conventional treatments. Consequently, none of the patients used pain medication. Informed consent was obtained from

TABLE 5.1. Diagnostic algorithm for RSD*

Absolute criteria

Pain

Impaired function

Expansion of symptoms outside the area of trauma

Cold, warm or intermittent cold-warm feeling in the affected extremity

Relative criteria

Edema

Increased nail growth

Increased hair growth

Hyperhidrosis

Abnormal skin coloring

Hypoesthesia

Hyperalgesia

Mechanical and/or thermal allodynia

Patchy demineralization of bone

*All absolute and at least three relative criteria are needed for RSD to be diagnosed in a patient. 
all patients according to the Declaration of Helsinki. The study protocol was approved by the Ethical Committee of Maastricht University Hospital, where the research took place.

\section{Equipment}

All tests were performed using a TSA 2001 (Medoc, Ramat Yishai, Israel), which operates on the Peltier principle. Passing an electrical current through two dissimilar semiconductors displaces heat in the direction of the current. If a good heat conductor, such as a metallic plate, is juxtaposed to one side of the semiconductor system, it will be heated or cooled depending on the direction of the current. The plate increases in temperature when the current flows toward it and decreases when the current flows away. The opposite side of the system is buffered by water at a temperature of $20^{\circ} \mathrm{C}$, which acts as a heat sink or heat source depending on the direction of current. The temperature at the surface of the stimulator probe (thermode) is measured through a built-in thermocouple made of dissimilar wires (copper and constantin) whose voltage difference varies in response to change in temperature. A rectangular thermode with a surface of $5 \mathrm{~cm}$ by $2.5 \mathrm{~cm}$ was used for cutaneous stimulation. This was applied at a standard baseline temperature of $32^{\circ} \mathrm{C}$. In order to prevent thermal injury, and to protect the Peltier instrument, the high temperature limit was set at $50^{\circ} \mathrm{C}$ and the low at $0^{\circ} \mathrm{C}$. When these temperatures were reached, the direction of current was automatically reversed, thus driving the stimulator to the baseline.

\section{Test algorithms}

For the MLE, subjects were asked to press YES on a switch held in the free hand if a thermal sensation was perceived, and NO if this was not the case. For warmth, there was an initial temperature interval of $2^{\circ} \mathrm{C}$, with the temperature returning to adaptation immediately upon stimulus termination. After the first YES response, the stimulus decreased by one half of the initial step until a NO was given. Subsequently, the step was halved for each successive stimulus, and the direction changed according to the response: increase for NO, decrease for YES. The procedure was continued until step size reached $0.1^{\circ} \mathrm{C}$. For cold, an initial temperature step of $1^{\circ} \mathrm{C}$ was given, this being the only difference compared with the procedure to assess the warm perception threshold. Time between subject response and the subsequent stimulus was 6 seconds. To optimize alertness, an auditory cue was given to the subject at stimulus onset. The MLE was performed twice for warmth and twice for cold and the two results were averaged to obtain a single threshold score.

The MLI was performed with a rate of temperature change of $1^{\circ} \mathrm{C} / \mathrm{s}$. Subjects were asked to depress a switch held in the free hand the instant a thermal sensation was perceived. Five readings at each site were obtained for each thermal sensation, and results were averaged to obtain a single threshold score. Interstimulus intervals were 6 seconds, with an auditory cue at stimulus onset to optimize alertness. Patients were told in advance whether a low or high temperature stimulus was to be given and 
were instructed not to react until an obvious thermal sensation was perceived.

The order of tests was in all cases as follows: MLE for warmth, MLE for cold, MLI for warmth, MLI for cold, MLE for warmth, MLE for cold. The unaffected side was tested first. If patients were unable to press the switch with their affected hand, the physician pressed the button for both sides as soon as the patient reported perceiving a thermal sensation. Results of the MLI could be influenced by the physician's reaction time and were corrected for the interference (see below). Thermal pain thresholds were assessed following measurement of the thermal perception thresholds. (These results will be reported separately since they are beyond the scope of this study.) The tests were performed in a draught-free, silent room suitable for psychophysical studies, at a temperature of $20^{\circ} \mathrm{C}$. The patient relaxed on a recliner, without visual access to the display screen. A single physician (M.A.K.) performed the tests on all patients throughout.

\section{Test sites}

Thresholds for patients with an affected leg were assessed at the dorsal aspects of both feet, immediately proximal to the basis of the second and third toe. Thresholds for patients with an affected arm were assessed at the volar aspects of both wrists, immediately proximal to the base of the hand. The thermode was attached to the skin by means of an elastic Velcro tape. Care was taken to minimize variation of thermode application pressure.

\section{Calculations and statistical analysis}

Reference ranges for the warm and cold perception thresholds were obtained from Yarnitsky and Sprecher. ${ }^{14}$ These authors applied the same apparatus, using a thermode size, a baseline temperature and a rate of stimulus rise, similar to the present study. Warm hypoesthesia was diagnosed when the measured value was 3SD higher than the mean warm threshold at that location for the same sex/age group. Cold hypoesthesia was diagnosed when the measured value was $3 \mathrm{SD}$ lower than the mean cold threshold at that location for the same sex/age group.

The physician's reaction time was assessed in 10 healthy volunteers who alternately pressed the switch themselves or had the physician press the switch for them in four successive MLI sessions of their wrists. The mean addition to the results caused by the physician was found to be $0.03^{\circ} \mathrm{C}$ for cold and $0.12^{\circ} \mathrm{C}$ for warmth. All results of patients who had been unable to press the switch themselves were corrected for this interference by subtracting the mean addition.

The degree of agreement between thresholds determined by the MLE and the MLI was assessed for the data provided by both measurement sessions (T1 and T2). Firstly, the data were examined by plotting the difference between the methods against their mean. Lack of agreement can be summarized by calculating the bias, estimated by the mean difference (MD) and the standard deviation of the differences (SDD).$^{15}$ About 95 percent of the differences lie between $\mathrm{MD}-2 \mathrm{SDD}$ and $\mathrm{MD}+2 \mathrm{SDD}$. These limits are referred to as the 'limits of agreement'. 
The coefficient of repeatability (CR) is defined here in such a way that there can be 95 percent confidence that results of two determinations made on the same subject under the same circumstances would differ by less than CR. Calculation of $\mathrm{CR}$ was as follows: the differences between the two measurements ( $\mathrm{T} 1$ and $\mathrm{T} 2$ ) were squared, added together, and divided by $n$; the square root was then calculated to obtain the standard deviation of the differences (SDD). The coefficient of repeatability is twice this figure $(\mathrm{CR}=2 \mathrm{SDD}) .^{15}$

The Wilcoxon Signed Ranks Test for paired samples or the $\chi^{2}$ test were applied as appropriate, with $p$-values $<0.05$ considered statistically significant.

\section{Results}

\section{Sensitivity for pathology}

Table 5.2 presents the numbers of patients with an abnormal threshold on both assessments, on one assessment only, and on neither assessment. There was no significant difference in prevalence of abnormality detected by the MLE and the MLI, nor was there a significant difference between abnormality prevalences at the wrist and the foot. The frequencies of hypoesthesia at the wrist, detected in any test (i.e. MLE and/or MLI at T1 and/or T2), were 36 percent (warm) and 24 percent (cold) on the affected side, and 15 percent (warm) and 3 percent (cold) on the unaffected side. Thus, at the wrist, warm hypoesthesia was observed more frequently than cold hypoesthesia. At the foot, these frequencies were 15 percent

TABLE 5.2. Sensitivity in detection of pathology of the MLE and the MLI

\begin{tabular}{|c|c|c|c|c|c|c|}
\hline & & & & $\mathrm{T} 1$ and $\mathrm{T} 2$ & $\mathrm{~T} 1$ or $\mathrm{T} 2$ & $\mathrm{~T} 1$ nor $\mathrm{T} 2$ \\
\hline \multirow[t]{8}{*}{ Wrist } & \multirow[t]{4}{*}{ MLE } & Affected & Warm hypoesthesia & 4 & 8 & 21 \\
\hline & & Unaffected & Warm hypoesthesia & 1 & 3 & 29 \\
\hline & & Affected & Cold hypoesthesia & 1 & 4 & 28 \\
\hline & & Unaffected & Cold hypoesthesia & - & 1 & 32 \\
\hline & \multirow[t]{4}{*}{ MLI } & Affected & Warm hypoesthesia & 1 & 8 & 24 \\
\hline & & Unaffected & Warm hypoesthesia & - & 3 & 30 \\
\hline & & Affected & Cold hypoesthesia & 1 & 4 & 28 \\
\hline & & Unaffected & Cold hypoesthesia & - & 1 & 32 \\
\hline \multirow[t]{8}{*}{ Foot } & \multirow[t]{4}{*}{ MLE } & Affected & Warm hypoesthesia & 3 & - & 17 \\
\hline & & Unaffected & Warm hypoesthesia & 2 & 1 & 17 \\
\hline & & Affected & Cold hypoesthesia & 2 & 1 & 17 \\
\hline & & Unaffected & Cold hypoesthesia & - & 2 & 18 \\
\hline & \multirow[t]{4}{*}{ MLI } & Affected & Warm hypoesthesia & 2 & 1 & 17 \\
\hline & & Unaffected & Warm hypoesthesia & 1 & - & 19 \\
\hline & & Affected & Cold hypoesthesia & 3 & 1 & 16 \\
\hline & & Unaffected & Cold hypoesthesia & 1 & 2 & 17 \\
\hline
\end{tabular}

Numbers of patients with an abnormal threshold on both assessments, on one assessment only, and on neither assessment, for patients with an affected wrist $(n=33)$ or an affected foot $(n=20)$. 
(warm) and 20 percent (cold) on the affected side, and 15 percent (warm) and 15 percent (cold) on the unaffected side. Clinical characteristics, like oedema, hyperhidrosis, abnormal skin colouring, increased nail growth or increased hair growth showed no statistically significant relationship with presence or absence of either warm or cold hypoesthesia.

\section{Agreement of thresholds}

Table 5.3 presents the mean differences between the thresholds of the MLE and the MLI, and the limits of agreement for the first assessment (T1); the results for the second assessment (T2) were in line with those of the first. The extremes from Table 5.3 have been depicted in Figure 5.1, containing data from all individual subjects. The smallest limits of agreement were found for the warm threshold of the unaffected wrist: the threshold of the MLI may be $0.4^{\circ} \mathrm{C}$ below or $2.3^{\circ} \mathrm{C}$ above the threshold of the MLE ( $M D \pm 2 S D D$ ). Lack of agreement between the two methods is especially noticable for the cold threshold of the affected foot. Here, the threshold of the MLI may be as much as $4.1^{\circ} \mathrm{C}$ below, or $10.2^{\circ} \mathrm{C}$ above, the threshold of the MLE.

The difference between the thresholds of the MLE and the MLI may also be regarded as an equivalent of the neural conduction time (since this involves a $1^{\circ} \mathrm{C} / \mathrm{s}$ stimulus rise, it means that $1^{\circ} \mathrm{C}$ may be regarded also as 1 second), from which the afferent conduction time can be isolated by subtracting $200 \mathrm{~ms}$ for central processing and efferent conduction times ${ }^{9}$. In Yarnitsky and Ochoa's study, the mean conduction distance (i.e. the distance between stimulus site and spinal process of $\mathrm{C7}$ ) was found to be $0.716 \mathrm{~m}$. We did not measure this distance, but if Yarnitsky and Ochoa's value is applied to the unaffected wrist results of our patients, as presented in Tables 5.3 and 5.4, we arrive at the following mean conduction velocities: $0.9 \mathrm{~m} / \mathrm{s}$ at T1 and $1.0 \mathrm{~m} / \mathrm{s}$ at T2 (warmth, unaffected wrist); $0.5 \mathrm{~m} / \mathrm{s}$ at T1 and $1.4 \mathrm{~m} / \mathrm{s}$ at T2

TABLE 5.3. Degree of agreement between the thresholds of the MLE and the MLI

\begin{tabular}{lll}
\hline & Mean difference $\left({ }^{\circ} \mathrm{C}\right)$ & Limits of agreement $\left({ }^{\circ} \mathrm{C}\right)$ \\
\hline Warm perception threshold & & \\
Unaffected wrist & 1.0 & -0.4 and 2.3 \\
Affected wrist & 1.6 & -2.2 and 5.3 \\
Unaffected foot & 1.6 & -2.9 and 6.0 \\
Affected foot & 2.3 & -1.2 and 5.8 \\
Cold perception threshold & & \\
Unaffected wrist & 0.4 & -1.0 and 1.8 \\
Affected wrist & 1.0 & -2.6 and 4.6 \\
Unaffected foot & 1.6 & -3.3 and 6.4 \\
Affected foot & 3.1 & -4.1 and 10.2 \\
\hline
\end{tabular}

Mean differences $\left({ }^{\circ} \mathrm{C}\right)$ between the thresholds of the MLI and the MLE with the limits of agreement concerning the first measurement (T1) of patients with an affected wrist $(n=33)$ or an affected foot $(n=20)$. 


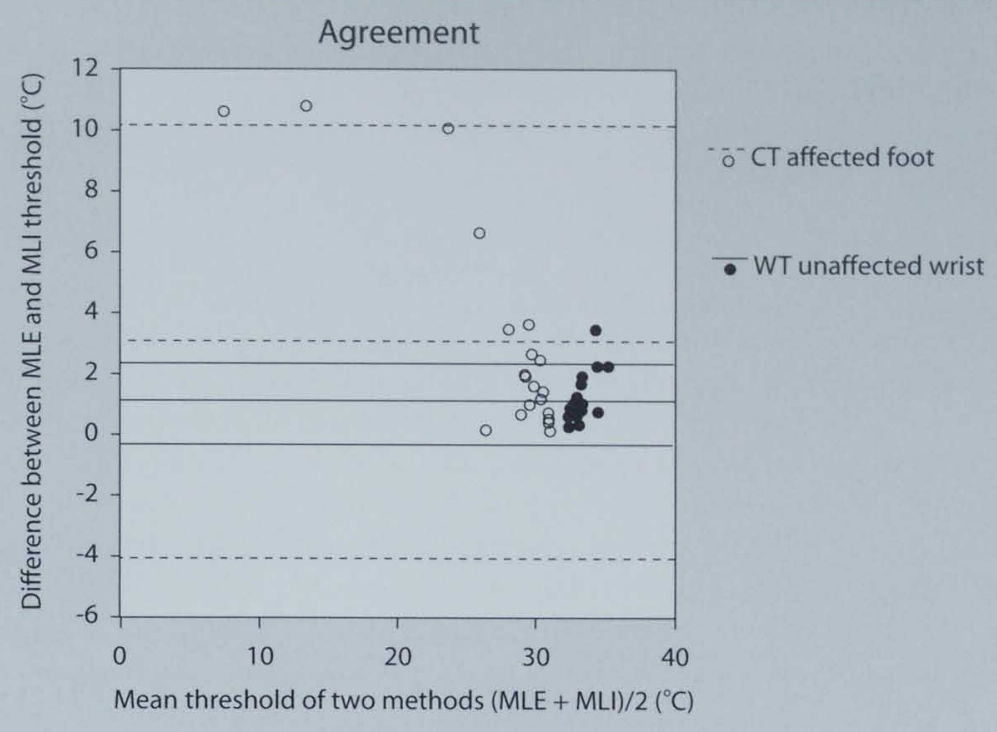

Figure 5.1. Difference between thresholds measured with the MLI and MLE against the mean threshold by both methods of the warm threshold (WT) of the unaffected wrist and of the cold threshold (CT) of the affected foot. The figure contains data from all individual subjects; lines refer to the means and the limits of agreement.

(warmth, affected wrist); $3.6 \mathrm{~m} / \mathrm{s}$ at T1 and $2.4 \mathrm{~m} / \mathrm{s}$ at T2 (cold, unaffected wrist) and; $0.9 \mathrm{~m} / \mathrm{s}$ at T1 and $2.4 \mathrm{~m} / \mathrm{s}$ at T2 (cold, affected wrist).

\section{Repeatability of thresholds}

Means of the thermal perception thresholds with their coefficients of repeatability for warmth and cold measured at the unaffected and affected wrists $(n=33)$ and at the unaffected and affected feet $(n=20)$ at a one month interval are presented in Table 5.4.The group data were reproducible, i.e. there were no statistically significant differences between mean values at T1 and T2 for both methods. Except for the warm perception threshold of the unaffected side, the coefficients of repeatability concerning the wrist were significantly better for the MLE than for the MLI $(p<0.05)$. The difference in repeatability of the two methods is illustrated in Figure 5.2. As far as measurements at the foot were concerned, the differences in coefficients of repeatability between the tests were not significant.

\section{Discussion}

General discussion

The present study shows that 15 percent (foot) to 36 percent (wrist) of RSD pa- 
TABLE 5.4. Repeatability of thermal perception threshold assessments in unaffected extremities and in extremities affected by RSD

\begin{tabular}{|c|c|c|c|c|c|c|c|}
\hline & $\begin{array}{l}\text { MLE-T1 } \\
\bar{x}(S D)\end{array}$ & $\begin{array}{l}\text { MLE-T2 } \\
\bar{x}(S D)\end{array}$ & $\mathrm{CR}$ & $\begin{array}{l}\text { MLI-T1 } \\
\bar{x}(S D)\end{array}$ & $\begin{array}{l}\text { MLI-T2 } \\
\bar{x}(\mathrm{SD})\end{array}$ & $\mathrm{CR}$ & $p$-values \\
\hline \multicolumn{8}{|l|}{$\begin{array}{l}\text { Warm perception } \\
\text { threshold }\end{array}$} \\
\hline Unaffected wrist & $32.7(0.5)$ & $32.7(0.5)$ & 1.0 & $33.7(0.9)$ & $33.6(0.8)$ & 1.7 & .091 \\
\hline Affected wrist & $33.1(1.0)$ & $33.0(1.0)$ & 2.0 & $34.7(2.6)$ & $33.8(1.1)$ & 5.0 & .014 \\
\hline Unaffected foot & $35.7(3.8)$ & $34.6(3.1)$ & 5.4 & $37.2(3.6)$ & $36.7(3.2)$ & 2.9 & .530 \\
\hline Affected foot & $36.5(4.2)$ & $35.9(4.2)$ & 40 & $38.8(4.2)$ & $37.9(4.1)$ & 4.4 & .590 \\
\hline \multicolumn{8}{|l|}{$\begin{array}{l}\text { Cold perception } \\
\text { threshold }\end{array}$} \\
\hline Unaffected wrist & $31.3(0.3)$ & $31.2(0.5)$ & 0.8 & $30.9(0.9)$ & $30.6(1.1)$ & 2.3 & .009 \\
\hline Affected wrist & $30.9(0.7)$ & $30.9(0.7)$ & 0.7 & $29.9(2.2)$ & $30.4(1.2)$ & 3.7 & $<.0001$ \\
\hline Unaffected foot & $30.0(2.9)$ & $30.0(2.0)$ & 4.1 & $28.4(4.9)$ & $28.4(3.9)$ & 5.3 & .184 \\
\hline Affected foot & $28.8(4.8)$ & $28.5(4.5)$ & 5.8 & $25.8(7.8)$ & $26.6(6.9)$ & 3.4 & .970 \\
\hline
\end{tabular}

Means $(\bar{x})$ of the thermal perception thresholds $\left({ }^{\circ} \mathrm{C}\right)(\mathrm{SD})$ with their coefficients of repeatability $(\mathrm{CR})$, together with the statistical differences between the coefficients of repeatability of patients with an affected wrist $(\mathrm{n}=33)$ or an affected foot $(\mathrm{n}=20)$. $\mathrm{T} 1=$ first assessment; $\mathrm{T} 2=$ second assessment.

tients suffered from hypoesthesia to warmth, and 20 percent (foot) to 24 percent (wrist) suffered from hypoesthesia to cold. Previously, similar frequencies of cold and warm hypoesthesia have been found in patients suffering from RSD. ${ }^{6}$ The higher sensory thresholds at the feet as compared with the hand are well-known, ${ }^{16,17}$ and may be due to differences in receptor type and properties, receptor density, receptor location, and conduction time and central processing. ${ }^{16}$ In general, cold hypoesthesia is regarded as $A \delta$ fiber dysfunction, while warm hypoesthesia is regarded as $\mathrm{C}$ fiber pathology, ${ }^{6}$ but some caution is appropriate since testing warm and cold sensation explores the status of somatosensory afferents all the way between cutaneous receptor and brain/mind, without providing clues as to the precise locus of dysfunction along the channels. Remarkably, abnormalities were also obtained on the clinically unaffected side. Involvement of a spinal component in RSD has been previously suggested, based on the existence of microcirculatory abnormalities in the clinically unaffected hand. ${ }^{18}$ Ours is the first study to report findings indicating that thermal perception may also be affected in the clinically unaffected extremity of RSD patients. However, apart from a possible spinal component, the sensory abnormalities of the unaffected side could also reflect impaired cooperation or attention in these patients with a disabling pain syndrome (false positives).

These findings underline that in order to improve our understanding of the pathophysiology of RSD, more studies of small caliber sensory fibers are needed. There is a great lack of histological research in RSD since additional injury by taking biopsies may trigger an increase of severity or recurrence of RSD. Recently, C fiber 


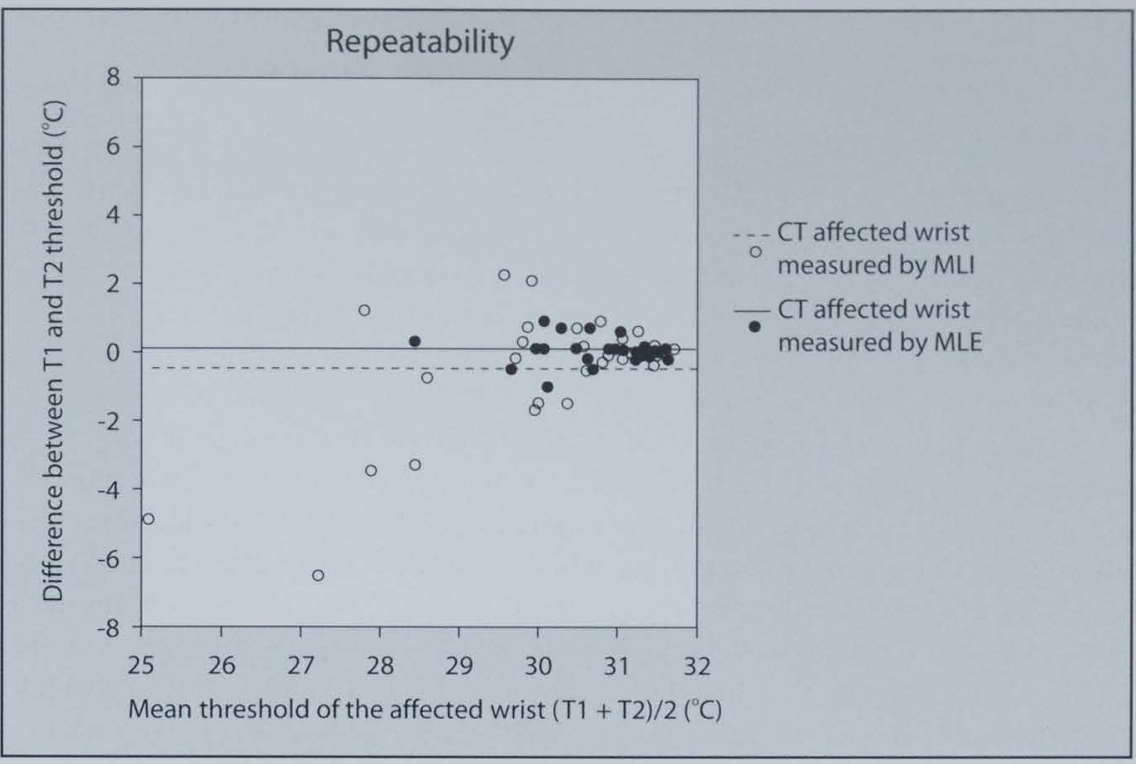

Figure 5.2. Difference between thresholds measured on $T 1$ and $T 2$, against the mean of the two measurements for the cold threshold $(C T)$ of the affected wrist, both for MLE and MLI. Lines refer to the mean differences.

pathology was observed in RSD tissue obtained by amputation while the other sensory fibers showed no abnormalities. ${ }^{5}$ Studies using microneurography, i.e. microelectrode recordings of impulses in single nerve fibers in awake human subjects, confirmed in one case with neuropathic pain that $\mathrm{C}$ polymodal nociceptors were sensitized and exhibited abnormally sustained after-discharges. ${ }^{19}$ Our finding that warm hypoesthesia was more frequently present than cold hypoesthesia is another argument for C fiber pathology in RSD. Since both histologic and microneurographic studies are prevented by the risk of nerve damage, in vivo studies of small caliber sensory fibers are dependent on the noninvasive quantitative thermal sensory analysis. In this study we tried to answer the question which psychophysical method-MLE or MLI-is best applied to perform the analysis.

Comparing previous studies that contrast the MLE and MLI is problematical since most of these used different stimuli (temperature, vibration) at different body locations (hand, foot). Most studies have used small samples of healthy subjects with a high level of educational attainment, but it is questionable whether results in such groups can be applied on the average patient population. In addition, it is debatable whether normal subjects who are willing to take part in a study comparing the quality of two tests have the same level of motivation as patients who undergo such tests. A good quality evaluation of a procedure might be better per- 
formed on those subjects for whom the procedure is intended. The preferred method should be the best for both healthy persons and patients.

\section{Methodological considerations}

The test procedure was performed under the most constant conditions possible. Slight variations could have taken place in thermode application pressure, but thermoreceptors are not activated by tactile or vibratory stimuli within a physiological temperature range. ${ }^{20}$ Variations in thermode position are not likely since the positions were well described and all experiments were performed by a single physician.

Results of the MLI may be influenced by the rate of warming or cooling: the threshold increases with increasing rate of temperature change. This artefact is significantly larger for the warm as compared with the cold threshold. ${ }^{9}$ A relatively slow $\left(1^{\circ} \mathrm{C} / \mathrm{s}\right)$ temperature change rate, which diminishes the reaction time artefact, ${ }^{13}$ was used both for warming and cooling in the present study. In addition, results are dependent on the alertness and cooperation of the subject. ${ }^{21}$ Although without a reaction time artefact it is also unlikely that the MLE is capable of measuring the true detection threshold, since the method is potentially sensitive to subject criterion changes. ${ }^{22}$ To improve patient alertness, all sessions were started with a standard explanation and an auditory cue preceded each stimulus.

If patients were unable to press the switch with their affected hand because of severe allodynia and/or functional disability, the physician pressed the button in these cases for both sides, dividing his reaction time variations equally over the two. This is a drawback in experiment design which cannot be avoided with the present equipment when testing a population patients with RSD of the hand. Replacing the switch by a speech recognizer system might be a solution. The variation was corrected by subtracting the addition to the results caused by the physician's reaction time.

The normal control values applied in this study were obtained from Yarnitsky and Sprecher.${ }^{14}$ These values were valid as a reference to our evaluation since the same apparatus, the same methods, and the same sites were used, although one might argue that the wrist differs from the thenar. Factors in our method which might influence the results, like the area of stimulation by virtue of the spatial summation factor, the rate of stimulus rise by affecting temporal summation, and baseline temperature by differentially influencing the ability to discriminate a rise or fall in temperature, were similar to the factors used in the study providing the control values. ${ }^{14}$

The diagnosis of RSD was in accordance with well-described IASP criteria. ${ }^{4}$ Only patients with RSD in one entire hand or foot were included in the study and patients with any symptoms relating to the contralateral extremity were excluded. Consequently, we could realistically compare a clinically unaffected and an affected side within one subject. The patients had suffered from RSD for at least six months, during which period the course of the disease had not altered. Sensory profiles of these patients have been shown to remain unchanged even over a decade ${ }^{23}$ thus, an 
alteration during the 1 month test interval is unlikely and was reported by not one single patient: the results of the two tests should have coincided.

\section{Sensitivity for pathology}

In the present study, there was no significant difference in prevalence of abnormality detected by the MLE and the MLI. Although a stringent criterion for abnormality was set (i.e. 3 instead of 2 SD away from the population mean), abnormality was mostly demonstrated in one assessment only-in 7 of 16 cases predominantly the first assessment. It is not clear whether this might be an indication of some learning effect. With no gold standard available it remains unclear whether patients with abnormal thresholds in one of two assessments are false positive or false negative. In order to compare both methods equally, patients with abnormal thresholds in any session were regarded as abnormal. In diabetics, sensitivity of the MLE and the MLI in detection of neuropathy has also been shown to be similar. ${ }^{10}$

\section{Agreement and repeatability of thresholds}

For determination of thresholds, a consensus report from the Peripheral Neuropathy Association recommends for research purposes the use of a validated forcedchoice algorithm. ${ }^{24}$ This recommendation, however, was not arrived at as a consequence of a forced-choice algorithm being clearly superior to the alternative. Dyck et al compared thresholds obtained by both the MLE and MLI and found the latter much speedier than the former. The present study did not measure test duration but, beyond doubt, the MLI is less time consuming than the MLE; the latter may take up to six times longer. ${ }^{25}$ Dyck et al also concluded that both methods were comparable in accuracy and repeatability. ${ }^{26}$ Other studies have shown significantly higher thresholds for the MLI. ${ }^{9-12,14}$ On the other hand, in several studies no better repeatability was found for the MLE. ${ }^{10-12}$

The MLI threshold includes a reaction time artefact, so that in principle the MLE threshold is the most correct of the two approaches. In order to answer the question which of the two methods is to be preferred from a practical point of view, thresholds measured with the MLI have to be compared with those measured with the MLE. Should neither method provide an unequivocally correct measurement, as is the case with psychophysical methods, the next step is to assess the degree of agreement. ${ }^{15}$ If the two methods show sufficient agreement, they could be used interchangeably. This is the case when differences within $\mathrm{MD} \pm 2 \mathrm{SD}$ are not clinically significant. The decision on whether such differences are clinically acceptable does not depend on a statistical test, but is one of medical common sense. ${ }^{15}$ In previous studies, the conclusion as to which method is to be preferred has always been based on the repeatability of each method, ${ }^{9-12,14,26}$ and the higher threshold obtained with the MLI - which lies further from the true threshold- has apparently been considered of minor relevance. In our opinion, only the differences between the two methods in the unaffected wrist as found in the present study are acceptable: the 
threshold of the MLI may vary from $0.4^{\circ} \mathrm{C}$ below to $2.3^{\circ} \mathrm{C}$ above that of the MLE. In the affected wrist, however, the threshold of the MLI may vary from $2.2^{\circ} \mathrm{C}$ below to $5.3^{\circ} \mathrm{C}$ above that of the MLE, and in the foot these findings vary from $1.2^{\circ} \mathrm{C}$ below in the affected foot for warm perception to $10.2^{\circ} \mathrm{C}$ above in the affected foot for cold perception. In future studies, it should be decided what degree of difference between the two methods is acceptable. For clinical purposes, we argue that differences as observed in the affected wrist or in the foot make the MLI inappropriate for accurate assessment.

Calculation of the conduction velocity for the primary afferents mediating the sensations of warmth and cold, on the basis of reaction time (the difference between results of the MLE and the MLI) and conduction distance, ${ }^{9}$ gave the following results. At the unaffected wrist the calculated conduction velocity of fibres conducting warmth was in line with values from neurophysiological textbooks, ${ }^{13}$ and was also reproducible. At $\mathrm{T} 1$, the calculated conduction velocity of fibres conducting cold was in accordance with known values, ${ }^{13}$ but at $\mathrm{T} 2$ it was only two-thirds of the value at $\mathrm{T} 1$. At the affected wrist, the calculated values were not reproducible. Considering the poor repeatability of both MLE and MLI at the foot, there can be no value to conduction velocity calculation at that location.

Another basic element of the study of method comparison is the assessment of repeatability of the two methods. If one method has poor repeatability, the agreement between the two methods is likely to be poor as well. In the present study, the MLE appeared to be the better test for measurements of the thermal perception threshold of the wrist, in line with the findings of Yarnitsky and Sprecher. ${ }^{14}$ The superiority of the MLE was especially noticeable in the affected wrist, where the CR's of the MLI were approximately twice as large as those of the MLE. As far as measurements at the foot were concerned, the differences between the tests were less clear and a preference for the MLE, as recommended by Yarnitsky and Sprecher, ${ }^{14}$ could not be demonstrated. The coefficients of repeatability of the MLE and MLI did not differ significantly, implying that both methods appear to have poor repeatabilities at that location. Poorer repeatability coefficients of threshold measurements at the foot, as compared to those at the hand, have been previously reported. ${ }^{14}$

In summary, sensitivity for pathology of the MLE and the MLI is similar. Both at the affected ( 20 percent foot, 36 percent wrist) and unaffected ( 15 percent foot, wrist) side, abnormal thresholds are detected by either method. The degree of agreement between the methods at the healthy wrist as acceptable, while the repeatability of the MLE is significantly better at both the healthy and the affected wrist. The lack of agreement between the methods at the foot is to the disadvantage of the MLI. The repeatability, however, is poor for both methods at the foot. For these reasons the MLE is regarded the better test for both locations. Taken together, this study demonstrates that for assessing thermal sensory thresholds, the MLE is to be preferred. 


\section{References}

1. Dotson RM. Clinical neurophysiology laboratory tests to assess the nociceptive system in humans. J Clin Neurophysiol 1997; 14: 32-45.

2. Yarnitsky D. Quantitative sensory testing. Muscle Nerve 1997; 20: 198-204.

3. Veldman PHJM, Reynen HM, Arntz IE, Goris RJA. Signs and symptoms of reflex sympathetic dystrophy: prospective study of 829 patients. Lancet 1993; 342: 1012-16.

4. Merskey H, Bogduk N, eds. Classification of chronic pain: descriptions of chronic pain syndromes and definitions of pain terms. 2nd ed. Seattle: IASP Press, 1994.

5. van der Laan L, ter Laak HJ, Gabreëls-Festen AAWM, Gabrëls FJM, Goris RJA. Histopathological findings in chronic reflex sympathetic dystrophy. Neurology 1998; 51:20-5.

6. Verdugo R, Ochoa JL. Quantitative somatosensory thermotest - a key method for functional evaluation of small calibre afferent channels. Brain 1992; 115: 893-913.

7. James W. The principles of psychology. Cambridge, MA: Harvard University Press, 1890.

8. Gardner RM. Misconceptions about classical psychophysics and the measurement of response bias. Percept Mot Skills 1997; 84: 587-94.

9. Yarnitsky D, Ochoa JL. Warm and cold specific somatosensory systems. Psychophysical thresholds, reaction times and peripheral conduction velocities. Brain 1991; 114: 1819-26.

10. Levy D, Abraham R, Reid G. A comparison of two methods for measuring thermal thresholds in diabetic neuropathy. J Neurol Neurosurg Psychiatry 1989; 52: 1072-7.

11. Muijser $\mathrm{H}$, Hooisma J, Hoogendijk EM, Twisk DA. Vibration sensitivity as a parameter for detecting peripheral neuropathy. I.Results in healthy workers. Int Arch Occup Environ Health 1986; 58: 287-99.

12. Gerr FE, Letz R. Reliability of a widely used test of peripheral cutaneous vibration sensitivity and a comparison of two testing protocols. $\mathrm{Br}$ J Ind Med 1988; 45: 635-9.

13. Osselton JW, ed. Clinical neurophysiology. Oxford: Butterworth-Heinemann, 1995.

14. Yarnitsky D, Sprecher E. Thermal testing: normative data and repeatability for various test algorithms. J Neurol Sci 1994; 125: 39-45.

15. Bland JM, Altman DG. Statistical methods for assessing agreement between methods of clinical measurement. Lancet 1986; i: 307-10.

16. Dyck PJ, Karnes J, O'Brien PC, Zimmerman IR. Detection thresholds of cutaneous sensation in humans. In: Dyck PJ, Thomas PK, Griffin JW, Low PA, Poduslo JF, eds. Peripheral Neuropathy. 3rd ed. Philadelphia: WB Saunders Company, 1993: 706-28.

17. Hagander LG, Midani HA, Kuskowski MA, Parry GJ. Quantitative sensory testing: effect of site and skin temperature on thermal thresholds. Clin Neurophysiol 2000; 111:17-22.

18. Kurvers HAJM, Jacobs MJHM, Beuk RJ, et al. Reflex sympathetic dystrophy: the spinal component to skin blood flow abnormalities. Arch Neurol 1996; 53: 58-65.

19. Cline MA, Ochoa JL, Torebjörk HE. Chronic hyperalgesia and skin warming caused by sensitized C nociceptors. Brain 1989; 112: 621-47.

20. Konietzny F, Hensel H. Warm fiber activity in human skin nerves. Pflügers Arch 1975; 359: 265-7.

21. Yarnitsky D, Sprecher E, Tamir A, Zaslansky R, Hemli JA. Variance of sensory threshold measurements: discrimination of feigners from trustworthy performers. J Neurol Sci 1994; 125: 186-9.

22. Kershaw $C D$. Statistical properties of staircase estimates from two interval forced choice experiments. Br J Math Stat Psy 1985; 38: 35-43. 
23. Wahren LK, Torebjörk E. Quantitative sensory tests in patients with neuralgia 11 to 25 years after injury. Pain 1992; 48: 237-44.

24. Dyck PJ. Quantitative sensory testing: a consensus report from the Peripheral Neuropathy Association. Neurology 1993; 43: 1050-2.

25. Claus D, Hilz MJ, Neundorfer B. Thermal discrimination thresholds: a comparison of different methods. Acta Neurol Scand 1990; 81: 533-40.

26. Dyck PJ, Karnes JL, Gillen DA, O’Brien PC, Zimmerman IR, Johnson DM. Comparison of algorithms of testing for use in automated evaluation of sensation. Neurology 1990; 40: 1607-13. 



\section{CHAPTER 6}

\section{Does Randomization Introduce Bias in Unblinded Trials?}

Marius A. Kemler and Henrica C.W. de Vet 
Nowadays, many clinical trials use health-related quality of life (HRQL) to assess treatment effects. In unblinded trials, this subjective outcome measure may be susceptible to bias. We have noticed in a randomized clinical trial on the effect of spinal cord stimulation (SCS) on reflex sympathetic dystrophy an improvement in HRQL even before the start of treatment.

Patients in this study were suffering from chronic reflex sympathetic dystrophy, a disabling disease of unknown pathophysiology, characterized by pain and impaired function. They had not responded to any previous treatment, so their last hope was the pain-relieving effect of SCS. In this procedure, an electrode is positioned in the epidural space on the dorsal aspect of the spinal cord at the level of the nerve roots innervating the painful area; electrical current from the electrode brings about paresthesiae, a sensation that suppresses the pain. The patients were randomized into two groups: one group to receive SCS and physical therapy (SCS group; $n=36$ ) and one group to receive physical therapy alone (control group; $\mathrm{n}=17$ ). The SCS group underwent a testing period of 7 days, using a test electrode. A complete SCS system was implanted only when the patient reported $\geq 50$ percent reduction in pain during the testing period ( $S C S+, n=24 ; S_{-}-, n=12$ ). Among other parameters, HRQL, by means of a 'thermometer' from 0 (worst imaginable health state) to 100 (perfect health), and pain, using a visual analog scale from 0 (no pain) to 10 (worst imaginable pain) were measured, both before randomization (T0) and then again one month later (T1). For SCS+ patients, T1 was the day before implantation, while SCS- patients knew at that point that they would not receive a SCS system. Between T0 and T1, the HRQL and pain scores of the total SCS group improved compared with the control group (Table 6.1). Trials on SCS cannot be blinded because of the paresthesiae and, therefore, patients know immediately after randomization what treatment they will be receiving. Merely the fact of being assigned to the SCS group was enough to cause an improvement in HRQL and pain intensity. As might be expected, the HRQL improvement was higher in SCS+ patients than in SCS- patients. On the other hand, for pain intensity this

TABLE 6.1. Differences in scores on health-related quality of life and pain intensity between T0 and T1

\begin{tabular}{|c|c|c|c|c|c|}
\hline & & $\begin{array}{l}\text { T0 values } \\
\text { mean }(95 \% \mathrm{CL})\end{array}$ & $\begin{array}{l}\text { TI values } \\
\text { mean (95\% CL) }\end{array}$ & $\begin{array}{l}\mathrm{Tl}-\mathrm{T} 0 \text { values } \\
\text { mean }(95 \% \mathrm{CL})\end{array}$ & $\begin{array}{l}\triangle \mathrm{SCS} \text { versus } \triangle \text { Controls } \\
\text { Difference of means } \\
(95 \% \mathrm{CL})\end{array}$ \\
\hline HRQL & $\begin{array}{l}\text { Controls } \\
\text { SCS } \\
\text { SCS+ } \\
\text { SCS- }\end{array}$ & $\begin{array}{l}42.5(32.7,52.4) \\
44.2(32.7,55.8) \\
47.7(39.2,56.2) \\
44.4(33.1,55.7)\end{array}$ & $\begin{array}{l}39.6(28.4,50.8) \\
53.3(43.6,63.0) \\
56.0(49.5,62.5) \\
50.0(41.3,58.7)\end{array}$ & $\begin{array}{c}-2.9(-9.2,3.4) \\
7.4(1.5,13.3) \\
8.3(2.0,14.7) \\
5.6(-8.5,19.6)\end{array}$ & $-10.2(-18.7,-1.9)$ \\
\hline $\begin{array}{l}\text { Pain } \\
\text { intensity }\end{array}$ & $\begin{array}{l}\text { Controls } \\
\text { SCS } \\
\text { SCS+ } \\
\text { SCS- }\end{array}$ & $\begin{array}{l}6.8(6.2,7.4) \\
7.2(6.4,8.1) \\
7.1(6.4,7.8) \\
7.2(6.5,8.0)\end{array}$ & $\begin{array}{l}7.3(6.5,8.1) \\
6.4(5.3,7.5) \\
6.6(5.7,7.5) \\
6.7(5.5,7.8)\end{array}$ & $\begin{array}{c}0.5(-0.1,1.0) \\
-0.5(-0.9,-0.1) \\
-0.5(-1.0,0.0) \\
-0.6(-1.3,0.2)\end{array}$ & $1.0(0.4,1.7)$ \\
\hline
\end{tabular}


difference was not found. Therefore, we argue that the effect of randomization is due to bias rather than to chance. Olsson and collegues also showed that a deliberate attempt to maximize the expectation effect can influence the perceived clinical course. ${ }^{1}$ This finding raises the question of whether pre-randomization values are valid as baseline values in unblinded studies. If, for example, HRQL remains stable at the T1 level following treatment, despite the difference between the SCS group and the control group, it is questionable whether SCS improves HRQL. While T0 values (pre-randomization) are necessary to ensure prognostic similarities between study groups, $\mathrm{Tl}$ values (pre-treatment) are more appropriate as baseline values in unblinded trials.

\section{Reference}

1. Olsson B, Olsson B, Tibblin G. Effect of patients' expectations on recovery from acute tonsillitis. Fam Pract 1989; 6: 188-92. 



\section{CHAPTER 7}

\section{The Effect of Spinal Cord Stimulation in Patients With Chronic Reflex Sympathetic Dystrophy- A Randomized Controlled Trial}

Marius A. Kemler, Gerard A.M. Barendse, Maarten van Kleef, Henrica C.W. de Vet, Coen P.M. Rijks, Carina A. Furnée, and Frans A.J.M. van den Wildenberg 


\section{Introduction}

Reflex sympathetic dystrophy(RSD) is a pain syndrome of unknown pathophysiology, resulting from trauma or operation to a limb. Excruciating burning pain and functional impairment are the most disabling characteristics of RSD, together with other signs outlined in Table 7.1. Only one in five patients is able fully to resume prior activities. ${ }^{1}$ Since in the past many different diagnostic criteria have been used, the exact incidence is unknown, but has been assumed to be one case in every 2,000 accidents. ${ }^{2}$ In 1994, the International Association for the Study of Pain proposed stringent diagnostic criteria and introduced the new name: complex regional pain syndrome type $1 .^{3}$ In this paper we use the more common term RSD.

Many methods have been used to reduce the pain intensity in RSD, e.g. conventional pain medication, physical therapy, sympathetic blocks and transcutaneous electrical nerve stimulation, but all with mainly unfavourable results. ${ }^{4,5}$ Spinal cord stimulation (SCS) was introduced in $1967,{ }^{6}$ and has been reported effective for pain complaints in RSD in several retrospective analyses. ${ }^{7-10}$ In this procedure, an electrode is positioned in the epidural space on the dorsal aspect of the spinal cord at the level of the nerve roots innervating the painful area; electrical current from the electrode brings about paresthesiae, a sensation that suppresses the pain. The current is supplied by a pulse generator, positioned subcutaneously in the anterior abdominal wall, and connected to the electrode by an extension lead. Patients are able to reduce or increase the intensity of the current supplied by the pulse generator by means of a patient programmer using radiofrequency transmission. Because SCS is expensive-a complete system costs at least $\$ 8,500$, in some countries far

TABLE 7.1. Diagnostic algorithm for RSD*

\begin{tabular}{l} 
Absolute Criteria \\
Pain \\
Impaired function $\dagger$ \\
Expansion of symptoms outside the area of trauma $\dagger$ \\
Cold, warm or intermittent cold-warm feeling in the affected extremity \\
Relative Criteria \\
Edema \\
Increased nail growth \\
Increased hair growth \\
Hyperhidrosis \\
Abnormal skin colouring \\
Hypesthesia \\
Hyperalgesia \\
Mechanical and/or thermal allodynia \\
Patchy demineralization of bone \\
${ }^{*}$ All absolute criteria together with at least three relative criteria were needed for the diagnosis RSD. \\
$\dagger$ Indicates criteria additional to those of the International Association for the Study of Pain. \\
\hline
\end{tabular}


more-and also has drawbacks, ${ }^{10}$ there is great need for prospective studies.

In a prospective randomized controlled study, we investigated whether treatment of chronic RSD with SCS and physical therapy is more effective than treatment with physical therapy alone. We assessed influences of treatment on pain intensity, global perceived effect, functional status and health-related quality of life (HRQL).

\section{Methods}

\section{Selection of Patients}

Study inclusion was considered for patients meeting the International Association for the Study of Pain criteria for complex regional pain syndrome type $1 .{ }^{3}$ In addition, patients had to show impaired function and extension of symptoms outside the area of trauma (Table 7.1). Further inclusion criteria were: age 18-65; disease clinically restricted to one extremity, but affecting the whole hand or foot; disease duration of at least six months; no lasting success with standard therapy, including six months physical therapy, sympathetic blocks, transcutaneous electrical nerve stimulation and medication; and a mean pain intensity of at least $5 \mathrm{~cm}$, measured on a visual analog scale from 0 (no pain) to $10 \mathrm{~cm}$ (very severe pain), according to Jensen. ${ }^{11}$ Exclusion criteria were presence of Raynaud's disease; presence, or previous history, of neurological abnormalities not related to RSD; conditions affecting function of diseased or contralateral extremities, other than RSD itself; blood clotting disturbances or anticoagulant drug therapy; and cardiac pacemaker use. All patients completed the Symptom Check List- $90,{ }^{12}$ a standardized psychological test. Patients scoring 200 or more, underwent a full examination by a psychologist in order to rule out significant drug habituation problems, major psychiatric diagnoses or significant personality disorders, and to address issues of secondary gain. Patients who were considered on the basis of the examination to have substantial psychopathology were to be excluded. The study complied with the Declaration of Helsinki regarding investigations in humans and was approved by the medical ethics committee of Maastricht University Hospital. All patients gave written informed consent.

\section{Randomization and Power Calculation}

Patients were assigned through randomization to a group with SCS and a standardized physical therapy program (SCS+PT group), or to a group with the standardized physical therapy program alone (PT group). At the end of the baseline assessment, a concealed randomization procedure was applied with a prestratification for location of RSD (upper or lower extremity), using a computer-generated table of random numbers. All patients assigned to SCS+PT underwent test stimulation; those not successfully responding did not receive the SCS-system. The patient was assigned through a telephone call by an independent person using the table, either to SCS+PT or PT. The randomization used a 2:1 ratio in favour of the SCS+PT group. To estimate the required sample size, pilot study data were used. ${ }^{10}$ The 
prespecified study aim was to detect significant pain relief of $3.5 \mathrm{~cm}$ at $\mathrm{T} 4$ for patients with an implanted spinal cord stimulator. Since 33 percent of patients allocated to SCS+PT were expected not to react to test stimulation (improvement zero), the pain reduction in the SCS $+\mathrm{PT}$ group which this study aimed to detect was $2.3 \mathrm{~cm}(0.66 \times 3.5+0.33 \times 0)$. Using the SD $(2.34)$ of the pilot study, 51 $(34+17)$ patients are needed in a $2: 1$ randomization scheme in order to detect a $2.3 \mathrm{~cm}$ difference between the study groups at a two-tailed significance $(\alpha)$ level of 0.05 and a power of 0.90 .

\section{Test Stimulation and Implantation Criteria}

Test stimulation was performed in order to assess whether patients respond to SCS positively. After administration of antibiotic prophylaxis (1500 $\mathrm{mg}$ cefuroxim, intravenously), the patient was placed in prone position and the epidural space was localized with a Tuohy needle. Using direct fluoroscopy, a temporary lead (model 3861, Medtronic, Minneapolis, MA) was advanced through the needle in the posterior epidural space until the electrode tip was at the required level-normally $\mathrm{C4}$ for upper extremities and Th12 for lower extremities-connected to an external screener (model 3625, Medtronic) and positioned until the patient reported that stimulation paresthesiae completely overlapped the topography of their usual pain. The needle was then withdrawn, the electrode was stitched to the skin and connected to the external screener. During a home-testing period of at least seven days, as is consistent with conventional practice, ${ }^{13,14}$ patients were advised to perform normal daily activities. After the testing period, the temporary lead was removed.

The decision to implant the permanent SCS-system was made when pain intensity measured during the last four days of the testing period was at least 50 percent lower as compared with the original ( $\mathrm{T} 0$ ) visual analog score, or if 'much improvement' was reported on a seven-point global perceived effect scale (see below). Patients not meeting these criteria continued the study with physical therapy alone.

\section{Implantation SCS System}

After administration of antibiotic prophylaxis ( $1500 \mathrm{mg}$ cefuroxim, intravenously), the patient was placed in prone position and a $5 \mathrm{~cm}$ vertical midline incision was made in the skin overlying the thoracic (upper extremity) or lumbar (lower extremity) spine. The SCS electrode (model 3487A, Medtronic) was implanted in a similar fashion as the temporary lead and fixed with special clips. After lead positioning, patients were placed in lateral position and received propofol ( $1 \mathrm{mg} / \mathrm{kilogram}$ ) as a sedative. A pulse generator (Itrel 3, model 7425, Medtronic) was implanted subcutaneously in the left lower anterior abdominal wall and connected to the electrode by a tunneled extension lead (model 7495-51/66, Medtronic). After closing the skin, the pulse generator was activated (rate: $85 \mathrm{~Hz}$; pulse width: $210 \mu \mathrm{s}$ ) using a console programmer (model 7432, Medtronic). Patients could control stimulation intensity by adjusting the amplitude from 0 to $10 \mathrm{~V}$ with a patient programmer (model 7434-NL, Medtronic). After implantation, patients remained in the hospital 
for 24 hours, during which time they received two doses of cefuroxim (750 $\mathrm{mg}$ ) intravenously. If on the following day no change in electrode position was evident on an $\mathrm{x}$-ray film, the patient was discharged.

\section{Physical Therapy Program}

The physical therapy program was offered to all patients in the study and consisted of excercises using a graded activity approach, aimed to improve endurance, mobility and function of the affected extremity. Pain during excercises was considered acceptable, but had to return to its original level within 24 hours, otherwise the intensity of the excercises was reduced. The frequency of therapy was 30 minutes, twice a week, with a minimum of two days between two sessions. Total duration of the physical therapy was six months, starting at $\mathrm{T} 1$. To ensure standardization, therapy was given by selected physical therapists, who had reveived previous training. The coordinating physical therapist from our institute visited the other therapists regularly to guarantee uniformity in treatment.

\section{Data Collection and Follow-up}

The patients were assessed before randomization (T0) and on the day prior to implantation (T1). ( $\mathrm{T} 1$ of patients not receiving an implant was planned close to T1 of implant patients). Further assessments were made at one month (T2), three months (T3) and six months (T4) after T1. Outcome measures were grouped into five categories. Firstly, pain was assessed using a visual analog scale according to Jensen, and the McGill pain questionnaire, expressed as the number of words chosen and the pain rating index. ${ }^{15}$ Secondly, patients rated global perceived effect on a seven-point scale, indicating: worst ever; much worse; worse; not improved/not worse; improved; much improved; and best ever. ${ }^{16}$ Thirdly, we measured functional status, using the test by Jebsen et al. ${ }^{17}$ for the upper extremity, or a specially devised foot function test for the lower extremity. ${ }^{18}$ For both procedures, the time necessary to perform a subtest is measured in seconds using a stopwatch; the mean of the subtest times provides the final result. Using goniometry, the range of motion of either both ankles (foot patients), or of both wrists, and the sum of all finger joints (hand patients) was measured. Either grip strength (Jamar dynamometer) ${ }^{19}$ or strength of foot dorsiflexors and plantarflexors (hand-held myometry) ${ }^{20}$ was assessed, employing myometry. Fourthly, HRQL was evaluated using the Nottingham Health Profile, ${ }^{21}$ the EuroQol 5D, ${ }^{22}$ the Sickness Impact Profile $68,{ }^{23}$ and the Selfrating Depression scale. ${ }^{24}$ These questionnaires had previously been validated and translated into Dutch. ${ }^{25-27}$ Fifthly, we listed technical and surgical complications.

\section{Statistical Analysis}

The statistical analysis was carried out according to the 'intention to treat' principle.

For all outcome measures, differences between T1 and T4 values for each individual were calculated and compared between both groups using independent samples $t$-tests or, if the results were not normally distributed, nonparametric tests. 
Fisher's exact tests were used to compare proportions. For global perceived effect (dichotomized in $\geq$ 'much improved' and in $\leq$ 'improved'), there is no baseline information; consequently, only differences between the two groups were calculated. Multivariate regression analysis was performed to assess potential influences of baseline differences and outcome variables on effect size. Two-tailed $p$ values $<0.05$ were considered to indicate statistical significance.

\section{Results}

Between March 1997 and July 1998, 110 potential candidates were referred to our department. We included 54 patients, while 56 patients were excluded: 40 were not eligible, 16 refused to participate. Eight of 77 patients completing the Symptom Check List-90 scored 200 or more; one of them entered the study after psychological examination. The RSD was precipitated by trauma in 26 patients, by surgery in 24 patients and had started spontaneously in the last four patients. All patients suffered severe pain and functional impairment which made them unfit for work. Of 33 patients with an affected hand, 20 were unable to use their hand for any daily activity; 13 of them were using a splint. Of 21 patients with an affected foot, 10 were wheelchair dependent and 8 were using crutches. Of the 54 patients taking part, one (assigned to PT) refused to undergo any physical test after T0. Randomization was successful and the two groups were statistically comparable at baseline regarding all prognostic variables and outcome measures (Table 7.2).

\section{Results Test Stimulation}

Test stimulation was complicated by a spinal tap in four cases, causing a spontaneous resolving postspinal headache in two cases. In one case it was impossible to enter the epidural space with the Tuohy needle; this patient received no implant.

TABLE 7.2. Baseline (T0) characteristics

\begin{tabular}{lll}
\hline & Physical therapy and SCS & Physical therapy alone \\
\hline Characteristic & $(\mathrm{N}=36)$ & $(\mathrm{N}=18)$ \\
Age-yr & $40 \pm 12^{*}$ & $35 \pm 8$ \\
Sex-no. (\%) & & \\
$\quad$ Male & $14(39)$ & $3(17)$ \\
Female & $22(61)$ & $15(83)$ \\
Duration-months & $40 \pm 28$ & $34 \pm 22$ \\
Location-no. (\%) & & \\
Upper extremity & $22(61)$ & $11(61)$ \\
Lower extremity & $14(39)$ & $7(39)$ \\
SCL90 score & $143 \pm 28$ & $6.7 \pm 1.2$ \\
Visual analog pain score $-\mathrm{cm}$ & $7.1 \pm 1.5$ & $42 \pm 19$ \\
Health-related quality of life-\% & $47 \pm 19$ & \\
*Plus-minus values are means \pm SD. & & \\
\hline
\end{tabular}


Test stimulation was successful in 24 of 36 patients (67 percent): all reported 'much improvement' on the global perceived effect scale, in 19 patients a 50 percent decrease in original visual analog score was measured.

\section{Results at Six Months}

Only six months (T4) results are reported, but, except for data on functional status, similar changes were obtained at one month and three months (T2, T3). After six months (results at $\mathrm{T} 4$ minus results at $\mathrm{T} 1$ ), the mean pain intensity with SCS+PT was reduced by $2.4 \mathrm{~cm}$ (Figure 7.1 ), compared to a $0.2 \mathrm{~cm}$ rise with PT $(p<0.001)$ (Table 7.3). The extent of pain relief was similar for upper and lower extremity patients. Of $36 \mathrm{SCS}+\mathrm{PT}$ patients, 14 (39 percent) reported 'much improvement' (Figure 7.2), compared with one (6 percent) of $18 \mathrm{PT}$ patients $(p=0.01)$. SCS was eventually successful in 20 of 36 patients ( 56 percent); 14 reported 'much improvement' on the global perceived effect scale, while 18 patients showed a 50 percent decrease of the T1 visual analog score. Multivariate regression analysis demonstrated that no baseline factor except treatment group influenced effect size. Other pain measures, functional status and HRQL showed non-statistically significant changes.

The mean pain relief of 24 patients with SCS was $3.6 \mathrm{~cm}$, as compared with

TABLE 7.3. Outcomes of treatment evaluated after six months

\begin{tabular}{|c|c|c|c|c|c|}
\hline \multirow{3}{*}{ Characteristic } & \multirow{2}{*}{\multicolumn{2}{|c|}{ SCS+PT subgroups }} & \multicolumn{2}{|c|}{ Intention to treat } & \multirow[t]{3}{*}{$p$-values* } \\
\hline & & & \multirow{2}{*}{$\begin{array}{l}\text { SCS }+ \text { PT } \\
\text { Total } \\
\text { group }\end{array}$} & \multirow[t]{2}{*}{$\mathrm{PT}$} & \\
\hline & $\begin{array}{l}\text { With } \\
\text { implant }\end{array}$ & $\begin{array}{l}\text { Without } \\
\text { implant }\end{array}$ & & & \\
\hline & $(\mathrm{n}=24)$ & $(\mathrm{n}=12)$ & $(\mathrm{n}=36)$ & $(n=18)$ & \\
\hline $\begin{array}{l}\text { Visual analog pain score }-\mathrm{cm} \\
\text { Global perceived effect-no. }(\%) \ddagger\end{array}$ & $\begin{array}{l}-3.6 \pm 2.0 \dagger \\
14(58)\end{array}$ & $\begin{array}{l}0.2 \pm 0.9 \\
0(0)\end{array}$ & $\begin{array}{l}-2.4 \pm 2.5 \\
14(39)\end{array}$ & $\begin{array}{l}0.2 \pm 1.6 \\
1(6)\end{array}$ & $\begin{array}{l}<.0001 \\
0.01\end{array}$ \\
\hline Functional score & $(\mathrm{n}=15)$ & $(n=7)$ & $(n=22)$ & $(n=11)$ & \\
\hline Upper extr. (function)-sec & $0 \pm 6$ & $6 \pm 14$ & $2 \pm 10$ & $-1 \pm 5$ & 0.21 \\
\hline Upper extr. (strength) - kg & $5 \pm 9$ & $-1 \pm 4$ & $3 \pm 8$ & $1 \pm 3$ & 0.44 \\
\hline Upper extr. (ROM-wrist) - ${ }^{\circ}$ & $7 \pm 35$ & $-7 \pm 15$ & $2 \pm 30$ & $-3 \pm 30$ & 0.61 \\
\hline Upper extr. (ROM-hand)- ${ }^{\circ}$ & $\begin{array}{l}76 \pm 160 \\
(n=9)\end{array}$ & $\begin{array}{l}-92 \pm 179 \\
(n=5)\end{array}$ & $\begin{array}{l}23 \pm 181 \\
(n=14)\end{array}$ & $\begin{array}{l}-39 \pm 190 \\
(n=6)\end{array}$ & 0.38 \\
\hline Lower extr. (function)- $-\mathrm{sec}$ & $-1 \pm 2$ & $-1 \pm 5$ & $-1 \pm 3$ & $-1 \pm 3$ & 0.96 \\
\hline Lower extr. (dorsiflexors) $-\mathrm{N}$ & $24 \pm 31$ & $-4 \pm 8$ & $14 \pm 28$ & $3 \pm 4$ & 0.16 \\
\hline Lower extr. (plantarflexors) $-\mathrm{N}$ & $38 \pm 76$ & $-4 \pm 5$ & $23 \pm 63$ & $40 \pm 51$ & 0.54 \\
\hline Lower extr. (ROM-ankle) $-^{\circ}$ & $18 \pm 19$ & $-2 \pm 2$ & $11 \pm 18$ & $8 \pm 10$ & 0.71 \\
\hline Health-related quality of life-\% & $11 \pm 23$ & $-5 \pm 15$ & $6 \pm 22$ & $3 \pm 18$ & 0.58 \\
\hline
\end{tabular}

${ }^{*} p$ values of intention to treat analysis (SCS+PT versus PT).

$\dagger$ Plus-minus values are means $\pm \mathrm{SD}$.

$\ddagger$ Number (\%) of patients reporting at least 'much improved' on global perceived effect. 


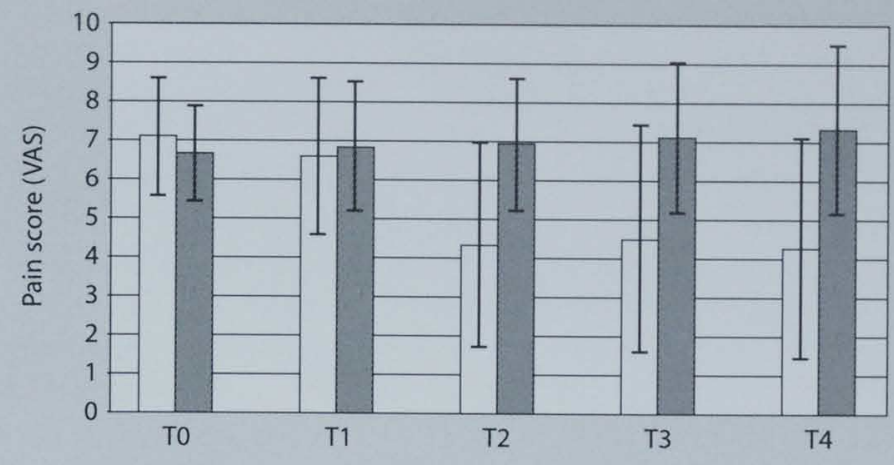

$\square$ SCS+PT

$\square$ PT

Figure 7.1. Mean $( \pm \mathrm{SD})$ visual analog pain scores in centimeters of reflex sympathetic dystrophy patients treated with spinal cord stimulation and physical therapy (white) or with physical therapy alone (shaded). $\mathrm{T} 0=$ baseline; $\mathrm{T} 1=$ before implantation; $\mathrm{T} 2=$ one month after $\mathrm{T} 1$; $\mathrm{T} 3=$ three months after $\mathrm{T} 1$; and $\mathrm{T} 4=$ six months after $\mathrm{T} 1$.

$0.2 \mathrm{~cm}$ increase among 18 patients receiving physical therapy $(p<0.001)$ (Table 7.3 ). Fourteen out of 24 patients ( 58 percent) with SCS reported 'much improvement', compared with one of 18 patients ( 6 percent) receiving physical therapy ( $p$ $<0.001)$. SCS also improved the pain rating index $(p=0.02)$ and the health-related

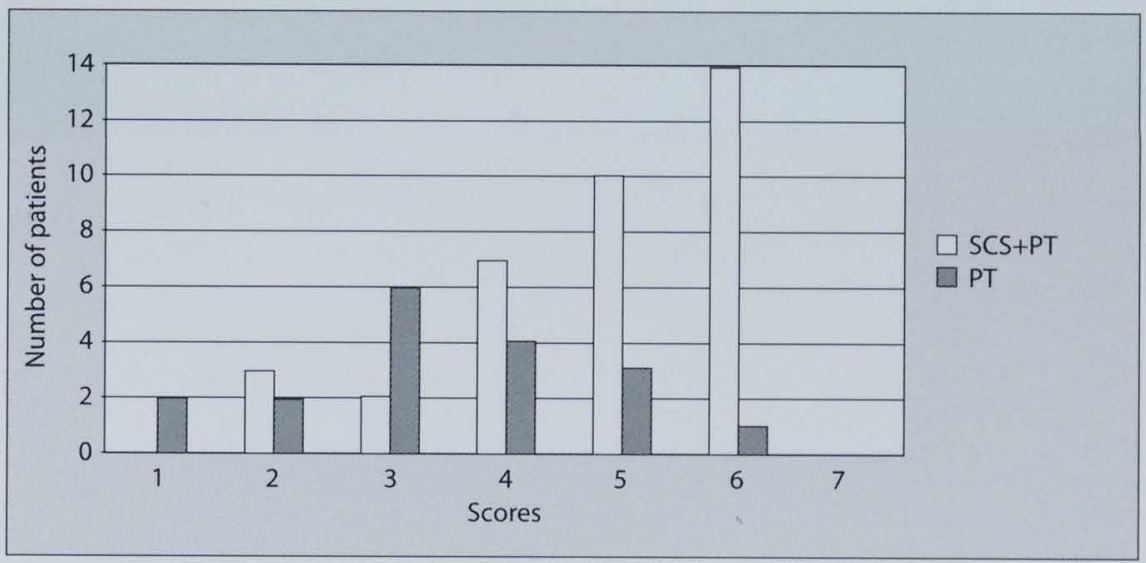

Figure 7.2. Global perceived effect scores at six months in number of patients. White: spinal cord stimulation and physical therapy $(n=36)$. Shaded: physical therapy alone $(n=18) .1=$ worst ever; $2=$ much worse; $3=$ worse; $4=$ not improved/not worse; $5=$ improved; $6=$ much improved; $7=$ best ever. 
quality of life dimension 'Pain' (Nottingham Health Profile) for both upper $(p=0.02)$ and lower extremities $(p=0.008)$. The treatment did not result in any functional improvement.

\section{Complications}

Implantation of the permanent SCS-system was complicated by a spinal tap in two subjects (postspinal headache in one case). In total, six out of 24 patients (25 percent) suffered 11 other complications during six months after implantation. Longterm complications occurred in four patients, including removal of the system on the grounds of clinical signs of infection ( 1 case), revision of a painful pulse generator pocket ( 2 cases), and replacement of a defective lead ( 1 case). The infection was not confirmed by bacteriological culture and after clinical improvement this patient underwent a reimplantation. Complications related to unsatisfactory position of the electrode occurred in five patients. Single operative reposition was successful in four cases; one patient needed three repositions.

\section{Discussion}

Our study - the first randomized controlled trial on SCS for RSD-provides evidence that SCS reduces pain intensity of RSD when all conventional treatments have failed. Several consecutive patient series have demonstrated the safety and effectiveness of SCS for the treatment of chronic pain. ${ }^{28-30}$ Complications, generally of minor character, have been reported to occur in 20 to 75 percent of patients. ${ }^{31}$ During a period of six months after implantation, we noticed complications in six of $24 \mathrm{pa}-$ tients ( 25 percent), mostly related to unsatisfactory position of the electrode. Success in treatment is dependent on strict inclusion criteria, ${ }^{32}$ excluded psychopathology, ${ }^{33,34}$ and full coverage of the painful area by paraesthesiae, ${ }^{35}$ and we were careful taking all these matters into account. Because of the paraesthesiae that accompany stimulation, studies on SCS cannot be blinded, but a placebo response is thought unlikely for two reasons. Firstly, results at one month and six months were similar, and sustained benefit has previously been described. ${ }^{30}$ Secondly, pain relief is not achieved unless the complete pain area is covered by paraesthesiae, and is lost immediately after lead displacement. ${ }^{30}$

It appeared from our data that between $\mathrm{T} 0$ and $\mathrm{T} 1$, i.e. when the patients were aware of the randomization code and the test stimulation result, but actual implantation had not yet been performed, HRQL and pain intensity in the SCS+PT group improved significantly compared with the PT group. ${ }^{36}$ In order to evaluate the true outcome of treatment, we therefore compared the six month effects to $\mathrm{T} 1$, instead of to $\mathrm{T} 0$, values.

Because of the risks and high costs, SCS is presently reserved for severely disabled patients, and the present study was restricted to patients who, for at least six months, had suffered from RSD that was unresponsive to conventional treatments, and was characterized by severe pain. Therefore, results of our study cannot be generalized 
to all RSD patients. The intention to treat analysis revealed significant improvements achieved through SCS for pain intensity and global perceived effect, even while one third of patients in the SCS+PT group had not successfully responded to test stimulation. If RSD patients do successfully respond to test stimulation, SCS was found to improve pain intensity, the pain rating index, global perceived effect and HRQL.

Even in patients who received an implant, functional status did not improve. At baseline, most patients were severely disabled, often being wheelchair or splint dependent. At that stage, contractures and muscle atrophy are already too far advanced for functional progress reasonably to be anticipated in the future. However, in our study we found no indication that applying SCS in early RSD would yield more functional improvement, because there was no correlation between disease duration or functional status at baseline, and improvement in function at six months. SCS treats pain but not the disease itself, and consequently pain reduction finds no expression in function.

The implant led to an 11 percent improvement of the overall HRQL. Generic questionnaires demonstrated that this effect derives chiefly from pain alleviation. For our particular study population, pain is the far and away the most critical source of distress. Therefore, despite the lack of effect on other HRQL aspects, SCS offers an important improvement for the management of chronic RSD patients. Whether the improvements balance the high costs has to be determined in a costeffectiveness analysis.

We conclude that after careful selection and successful test stimulation, SCS is safe, reduces pain and leads to a better HRQL in chronic RSD.

\section{References}

1. Subbarao J, Stillwell GK. Reflex sympathetic dystrophy syndrome of the upper extremity: analysis of total outcome of management of 125 cases. Arch Phys Med Rehabil 1981;62: 549-54.

2. Plewes LW. Sudeck's atrophy in the hand. J Bone Joint Surg 1956; 38B: 195-203.

3. Merskey $\mathrm{H}$, Bogduk N. Classification of chronic pain: descriptions of chronic pain syndromes and definitions of pain terms. Seattle: IASP Press, 1994: 40-2.

4. Schwartzman RJ, McLellan TL. Reflex sympathetic dystrophy: a review. Arch Neurol 1987; 55: 555-61.

5. Ochoa JL. Guest editorial: essence, investigation, and management of "neuropathic" pains: hopes from acknowledgment of chaos. Muscle \& Nerve 1993; 16: 997-1008.

6. Shealy CN, Mortimer JT, Reswick JB. Electrical inhibition of pain by stimulation of the dorsal columns: a preliminary report. Anesth Analg 1967; 46: 489-91.

7. Barolat G, Schwartzman R, Woo R. Epidural spinal cord stimulation in the management of reflex sympathetic dystrophy. Stereotact Funct Neurosurg 1989; 53: 29-39.

8. Robaina FJ, Rodriguez JL, de Vera JA, Martin MA. Transcutaneous electrical nerve stimulation and spinal cord stimulation for pain relief in reflex sympathetic dystrophy. Stereotact Funct Neurosurg 1989; 52: 53-62. 
9. Kumar K, Nath RK, Toth C. Spinal cord stimulation is effective in the management of reflex sympathetic dystrophy. Neurosurgery 1997; 40: 503-8.

10. Kemler MA, Barendse GAM, van Kleef M, van den Wildenberg FAJM, Weber WEJ. Electrical spinal cord stimulation in reflex sympathetic dystrophy: retrospective analysis of 23 patients. J Neurosurg 1999; 90 (Spine 1): 79-83.

11. Jensen MP, McFarland CA. Increasing the reliability and validity of pain intensity measurement in chronic pain patients. Pain 1993; 55: 195-203.

12. Arrindell WA, Ettema JHM. SCL90 Handleiding bij een multidimensionele psychopathologie-indicator. Lisse: Swets \& Zeitlinger, 1986.

13. Meyerson BA. Electric stimulation of the spinal cord and brain. In: Bonica JJ, ed. The management of pain. Malvern, PA: Lea \& Febiger, 1990: 1862-77.

14. North RB. Spinal cord stimulation. In: North RB, Levy RM, eds. Neurosurgical management of pain. New York: Springer-Verlag, 1997: 271-82.

15. Melzack R. The McGill pain questionnaire: major properties and scoring methods. Pain 1975; 1: 277-99.

16. Feinstein AR. Clinimetrics. New Haven: Yale University Press, 1987: 91-103.

17. Jebsen RH, Taylor N, Trieschmann RB, Trotter MJ, Howard LA. An objective and standardized test of hand function. Arch Phys Med Rehab 1969; 50: 311-19.

18. Kemler MA, de Vet HCW. An objective and standardized test for foot function: normative values and validation in patients with reflex sympathetic dystrophy. Arch Phys Med Rehabil 2000; in press.

19. Crosby CA, Wehbé MA, Mawr B. Hand strength: normative values. J Hand Surg 1994; 19A: $665-70$.

20. van der Ploeg RJO, Fidler V, Oosterhuis HJGH. Hand-held myometry: reference values. J Neurol Neurosurg Psychiatry 1991; 54: 244-7.

21. Hunt SM, McEwen J, McKenna SP. Measuring health status: a new tool for clinicians and epidemiologists. J Royal Coll Gen Practit 1985; 35: 185-8.

22. Euroqol-Group. EuroQol-a new facility for the measurement of health-related quality of life. Health Policy 1990; 16: 199-208.

23. de Bruin AF, Diederiks JPM, de Witte LP, Stevens FCJ, Philipsen H. The development of a short generic version of the sickness impact profile. J Clin Epidemiol 1994; 47: 407-18.

24. Zung WWK. A self-rating depression scale. Arch Gen Psychiat 1965; 12: 63-70.

25. van Eijk JTM, Smits A, Meyboom W, Mokkink H, van Son J. Reliability and validity of the Nottingham Health Profile in the Dutch situation (internal report). Nijmegen: NUHI, 1987.

26. de Bruin AF, Buys M, de Witte LP, Diederiks JPM. The sickness impact profile: SIP68, a short generic version. First evaluation of the reliability and reproducability. J Clin Epidemiol 1994; 47: 863-71.

27. Dijkstra P. De zelfbeoordelingsschaal voor depressie van Zung. In: van Praag HM, Rooymans HGM, eds. Stemming en ontstemming. Amsterdam: De Erven Bohn, 1974: 98-120.

28. Broggi G, Servello D, Dones I, Carbone G. Italian multicentric study on pain treatment with epidural spinal cord stimulation. Stereotact Funct Neurosurg 1994; 62: 273-8.

29. Meglio M, Cioni B, Rossi GF. Spinal cord stimulation in management of chronic pain. J Neurosurg 1989; 70: 519-24. 
30. North RB, Kidd DH, Zahurak M, James CS, Long DM. Spinal cord stimulation for chronic, intractable pain: experience over two decades. Neurosurgery 1993; 32: 384-94.

31. Turner JA, Loeser JD, Bell KG. Spinal cord stimulation for chronic low back pain: a systematic literature synthesis. Neurosurgery 1995; 37: 1088-95.

32. Simpson BA. Spinal cord stimulation. Pain Rev 1994; 1: 199-230.

33. Kupers RC, Van den Oever R, Van Houdenhove B, et al. Spinal cord stimulation in Belgium: a nation-wide survey on the incidence, indications and therapeutic efficacy by the health insurer. Pain 1994; 56: 211-16.

34. North RB, Kidd DH, Wimberly RL, Edwin D. Prognostic value of psychological testing in patients undergoing spinal cord stimulation: a prospective study. Neurosurgery 1996; 39: 30l-10.

35. Holsheimer J. Effectiveness of spinal cord stimulation in the management of chronic pain: analysis of technical drawbacks and solutions. Neurosurgery 1997; 40: 990-6.

36. Kemler MA, de Vet HCW. Does randomization introduce bias in unblinded trials? Epidemiology 2000; 11: 228. 
CHAPTER 8

Economic Evaluation of Spinal Cord Stimulation for Chronic Reflex Sympathetic Dystrophy

Marius A. Kemler and Carina A. Furnée 


\section{Introduction}

Reflex sympathetic dystrophy (RSD) is a neuropathic pain syndrome that starts after trauma or operation to a limb. The incidence of RSD is not precisely known, but has been assumed to be one case in every 2,000 accidents. ${ }^{1}$ While in most patients symptoms will subside after some years, a smaller percentage-again the incidence is unknown-will chronically suffer from RSD. Chronic RSD is a tremendous problem for both patients and physicians. The syndrome has an unknown pathophysiology, and results in functional disability and severe pain in affected arms or legs. Conventional treatments-consisting of pain medication, physical therapy (PT), sympathetic blocks, and transcutaneous electrical nerve stimulation -are recommended by expert panels, ${ }^{2}$ but are largely ineffective. ${ }^{3,4}$ Spinal cord stimulation (SCS) on the other hand has been shown to relieve pain, but not to improve function in chronic RSD patients (Chapter 7). The costs of this treatment are however prohibitive. Nevertheless, no economic evaluation, in which the increment in health benefits resulting from SCS is related to the increment in cost, has yet been reported.

Alongside a randomized controlled trial on the effectiveness of SCS in chronic RSD, we did perform an economic evaluation. We adopted the societal perspective-i.e. measuring all the costs and benefits of providing SCS, regardless of who pays or who benefits. In addition, we projected the long-term benefits and costs for the entire life of the patients in the cohorts. The comparisons were made from inclusion to one year following implantation of a SCS-system, and up to the predicted date of death.

The aim of this study was to answer the question of whether from the viewpoint of $(a)$ the budget of the Sickness Funds and $(b)$ society, treatment of chronic RSD patients by SCS in addition to conventional treatments is preferable to the existing treatment with conventional procedures alone.

\section{Methods}

Our analysis used data from a randomized controlled trial (Chapter 7). For details on study characteristics, surgical procedures, and study outcomes, we will make reference henceforth to the report of the clinical trial. In brief, 54 patients with chronic RSD of one extremity, referred to our department during the period March 1997 to July 1998, were included in the study. In 33 cases, the arm was the affected limb, while in 21 cases it was the leg. Patients were assigned by randomization to a group with SCS and a standardized PT program (SCS+PT group), or to a group with the standardized PT program alone (PT group). All patients assigned to SCS+PT underwent test stimulation; those not successfully responding did not receive the SCS-system. The randomization used a 2:1 ratio in favour of the SCS+PT group, and thus 36 patients were allocated to SCS+PT, and 18 were allocated to PT. Of the 36 patients allocated to SCS $+\mathrm{PT}, 24$ responded to test stimulation successfully and underwent implantation of a SCS-system (Figure 8.1). 


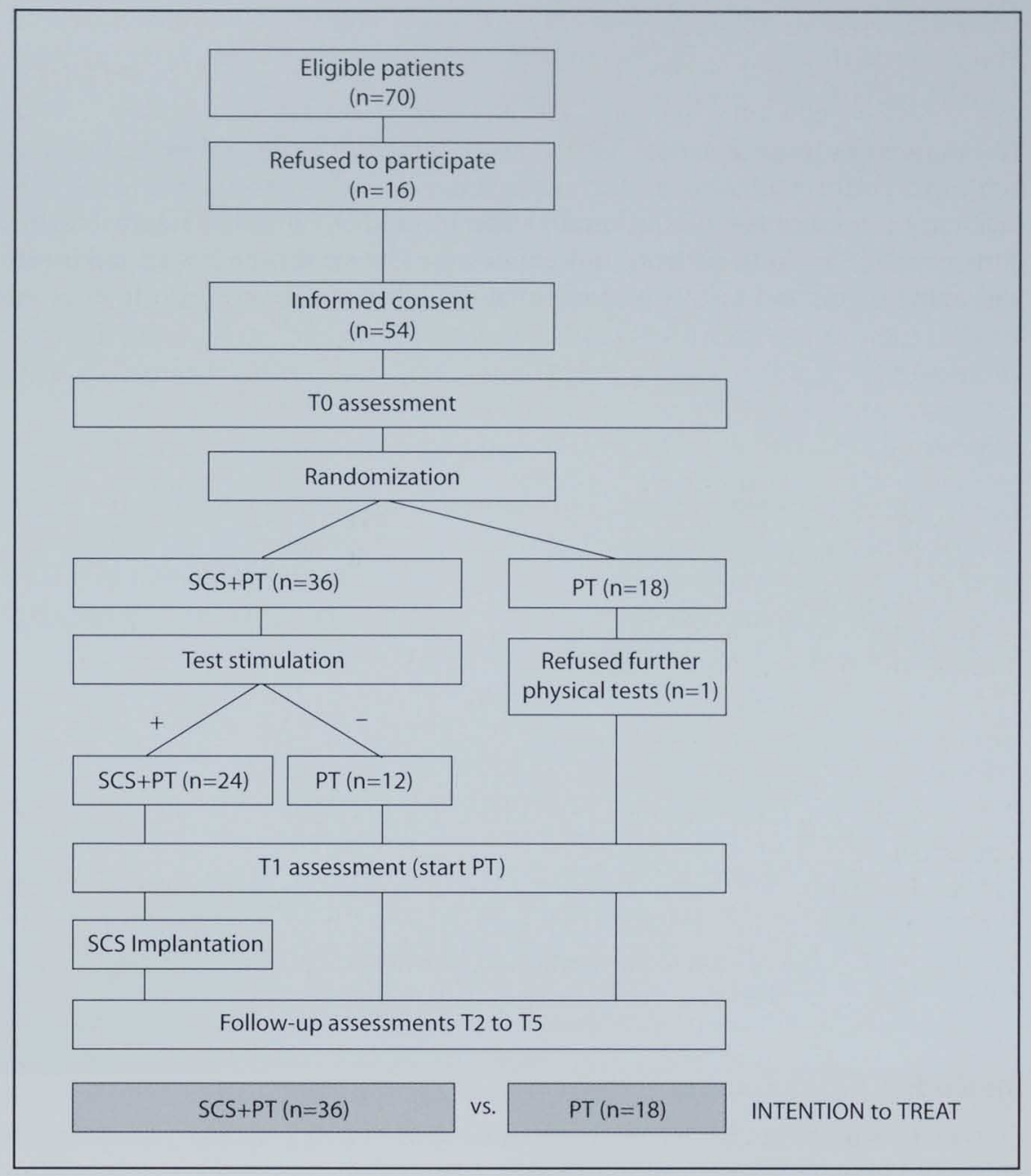

Figure 8.1. Flow chart illustrating the study protocol, and indicating the groups compared in the Intention to Treat Analysis.

\section{Health Outcomes}

Both pain and health-related quality of life were assessed on six occasions during the first year. These included baseline ( $\mathrm{T} 0$ ), one day prior to implantation of the SCS-system (T1), and one (T2), three (T3), six (T4), and twelve (T5) months following T1.

Pain Pain intensity was measured using a $10 \mathrm{~cm}$ visual analog scale $-0 \mathrm{~cm}$ repre- 
senting no pain, $10 \mathrm{~cm}$ the most extreme pain-on which patients rated their pain at three fixed time-points per day for four consecutive days. The average of these samples indicated the mean pain intensity. ${ }^{5}$

Health state Patients rated their health-related quality of life in relation to mobility, self-care, usual activities, pain/discomfort and anxiety/depression, using the EQ$5 \mathrm{D} .{ }^{6,7}$ In the societal perspective, patients' health states have to be evaluated by the general public, because everyone is not only a potential patient but also a taxpayer. The relative evaluations of members of the general public of different states of health were derived from Dolan et al. ${ }^{8}$ and have been elicited by using the time trade-off. ${ }^{9}$

Costs

Spinal cord Stimulation All costs were expressed in 1998 Dutch guilders (NLG). The costs of SCS were calculated by estimating each component of resource use. Applying 1998 financial and service data resulted in the determination of a fully allocated unit price for each service (micro-costing). The actual cost for each patient was determined by recording the quantity of services used, multiplying the quantity by the unit price of the service, and then calculating the totals for all services. Unit prices not only reflect the direct costs of care (e.g. salaries, wages and supplies), but also the costs of support departments (e.g. administration and housekeeping) and overhead items (e.g. employee benefits and equipment depreciation).

SCS costs for the predicted life span were calculated as follows. Life expectancy of each patient at the start of the study was calculated from age and sex specific life expectancies for the Dutch population..$^{10}$ In this way we obtained a mean residual life expectancy of 41 years (range 15 to 60 years). Longevity of the pulse-generator was estimated on all hospital visits of patients with an implanted SCS-system $(n=24)$ with the console programmer, using pulse-generator settings (number of hours use per day, amplitude, rate, pulse width) of each patient. The console programmer applied Medtronic longevity tables and estimated a mean battery life of 5.8 years (range 0.6 to 9.8 years). The frequency of each type of complication (e.g. infection, other biological complication, electrode defect, electrode displacement, pulse-generator defect) was acquired from a systemic literature synthesis of SCS." By linking the cost per complication type in our study to these frequencies, a total cost for any complication was obtained. Turner et al reported a mean percentage of patients suffering from any complication of 42 percent." All patients in Turner's study had an implanted SCS-system, while in our study only two thirds of patients in the SCS+PT group had an implanted SCS-system. Therefore, 28 percent of patients in the SCS+PT group $(2 / 3 \times 42 \%)$ could be expected to suffer from any complication each year. By multiplying the total cost for any complication by the percentage of patients suffering from any complication, the complication costs per patient per year were calculated. 
Conventional Approach Conventional approach costs are the costs of resources that are generally consumed by RSD patients. The costs are divided into five categories: medical care (e.g. hospital treatments, general practitioner visits, out-patient attendances, bed days, etc.); physical therapy; transport (e.g. journeys to and from the hospital by taxi, car, train or ambulance); medication; and aids (e.g. splints, crutches, special chairs, etc.). In the Netherlands, health insurance is a legal requirement for all citizens. ${ }^{12}$ As a consequence, health care expenses of the inhabitants of the country are precisely known and registered. We gathered this information for all patients from the authorities concerned, and calculated mean annual conventional approach costs before and after the intervention. Costs of PT were disregarded in the analysis, since these costs were a consequence of the study protocol and were generated equally in both groups.

Patient and Family Resources In order to estimate patient and family resources, patients were required to complete seven cost diaries during the first half year of the study (one in each month). The diaries provided information on how patients spent their time and their out-of-pocket expenses. We compared information from Diary 1 (before intervention) with the mean of Diaries 2 to 7 (after intervention). Since virtually all patients in both groups were unfit for work before and after the intervention, no actual working hours were lost by the patients. The opportunity costs of leisure time were disregarded in the analysis: the costs are low and do not differ as between both groups. For out-of-pocket expenses, the exact financial expenditures as reported by the patients were used. Journeys made were rated at NLG 0.60 per kilometer, as is normal practice in the Netherlands. ${ }^{13}$

\section{Analyses}

Analyses were done up to one year after implantation of the SCS-system, and up to the predicted death date. Costs included SCS costs and conventional approach costs. Since costs to patients (out-of-pocket expenses) did not differ between the groups, these were omitted in the analysis. Effects included $\mathrm{cm}$ pain intensity reduced and quality-adjusted life-years (QALYs) gained. We undertook two types of analysis: (1) a cost-effectiveness analysis, which investigates the additional cost and the additional net economic cost per $\mathrm{cm}$ pain intensity reduced; and (2) a costutility analysis, which investigates the additional cost and the additional net economic cost per QALY gained. ${ }^{14}$

In the analysis up to predicted time of death the incremental costs of SCS appeared to be negative, meaning that SCS is less costly than the conventional treatment protocol. In addition, the effectiveness appeared to be better for SCS than for the alternative. Because of this 'win-win' result-SCS comes out best both on costs and on effectiveness-the long-term result cannot be presented as a costeffectiveness analysis or cost-utility analysis. ${ }^{15}$ Treatment with SCS requires the early expenditure of large amounts of money to achieve later gains. Therefore, in the reference case analysis, both costs and health effects were discounted at a rate of 
3 percent per annum to convert the future values to their equivalent present value, as recommended by the U.S. Panel on Cost-Effectiveness in Health and Medicine. ${ }^{16}$ In the reference case analysis, life expectancy was set at 40 years, longevity of the pulse-generator at 5 years and the annual complication rate at 30 percent.

Sensitivity analyses were performed in order to determine the robustness of the findings in the presence of major changes in key factors. The following factors were varied: the discount rate ( 0 to $10 \%$ ); success of test stimulation (67 to $100 \%$ ); life expectancy ( 2 to 50 years); longevity of the pulse-generator ( 1 to 7 years); and complication rate ( 30 to $50 \%$ ).

\section{Statistical analysis}

The statistical analysis was carried out according to the 'intention to treat' principle: all patients, including withdrawals from treatment, remained in the group to which they had been assigned by randomization. For both health outcomes and costs, mean results at $\mathrm{T} 0$ and $\mathrm{T} 5$ were calculated and compared for each group using paired $t$-tests. Differences between patients with an affected arm or leg were assessed using independent sample $t$-tests. Linear regression analysis was performed to assess potential influences of age, gender or location of RSD on effect size. Twotailed $p$ values $<0.05$ indicated statistical significance.

\section{Results}

Two patients in the PT group who had had constant scores, were lost to follow-up after the six month assessment (T4). In order to prevent loss of information, their $\mathrm{T} 4$ scores were also used in the $\mathrm{T} 5$ analysis.

\section{Health Outcomes}

Mean pain intensity changed from 7.1 (baseline) to 4.3 (one year) in the SCS+PT

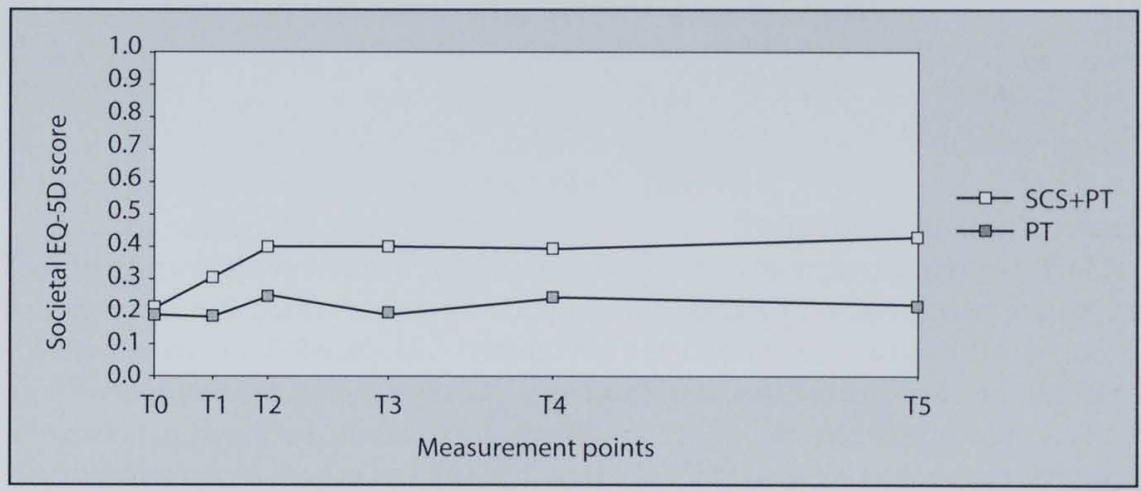

Figure 8.2. Societal EQ-5D scores of SCS+PT and PT. The area between both lines represents the quality-adjusted life years gained by spinal cord stimulation. 
group ( $p<0.001$ ), and from 6.7 (baseline) to 7.0 (one year) in the PT group. The mean health-related quality of life score in the SCS+PT group improved from 0.21 (baseline) to 0.43 (one year) $(p<0.002)$. In the PT group these numbers were 0.19 (baseline) and 0.22 (one year). Graphical presentation of the course of healthrelated quality of life is provided in Figure 8.2. Regression analysis revealed no relationship between effect of treatment and age, gender, or location of RSD. The incremental health improvements by SCS in Year 1 were calculated from the area between the curves of SCS+PT and PT, and were found to be 0.18 QALY and $-2.7 \mathrm{~cm}$ VAS per year. The incremental health improvement by SCS to death was calculated as follows:

Pain change in SCS group:

Pain change in PT group:

Incremental difference:

$E Q 5 D$ change in SCS group:

EQ5D change in PT group:

Incremental difference:

$$
\begin{aligned}
& 4.3-7.1=-2.8 \\
& 7.0-6.7=0.3 \\
&-2.8-0.3=-3.1
\end{aligned}
$$

Complications requiring reinterventions did not occur during test stimulation. Of the 24 patients who received an SCS-system, 17 complications in 9 patients during the first year could only be treated by means of an operation (complication percentage of $9 / 24$ equals $38 \%$ ). These included repositioning of a displaced electrode ( 8 actions in 6 patients), revision of a painful pulse-generator pocket or plug wound ('other biological'; 7 actions in 6 patients), removal and reimplantation of a SCSsystem after clinical signs of infection ( 1 action), and replacement of a defective lead (1 action).

\section{Costs}

Spinal Cord Stimulation The unit prices of the separate parts of treatment with SCS, and the subsequent total costs in this study are presented in Table 8.1. Costs are measured to one year and as projected to death. Costs of SCS in the first year consisted mainly of implantation costs (NLG 447,321.60;83\%). The remaining costs were generated by test stimulation (NLG 66,393.36;12\%) and complications (NLG 26,232.5; 5\%).

Conventional Approach Total conventional approach costs at baseline (mean NLG $1,054.22$ per month) did not show significant statistical differences between patients with an affected arm as opposed to patients with an affected leg, but these groups had a different distribution of costs over categories (Figure 8.3). The costs of aids $(p<0.03)$ and transport $(p<0.05)$ were significantly higher for patients with an affected leg. At baseline, there was no statistically significant difference in conventional approach costs between SCS+PT and PT. After treatment, mean annual costs in the SCS+PT group declined to NLG 550.79 per month ( $p<0.003$ ), while these remained constant in the PT group. The cost reduction was mainly caused by a 
TABLE 8.1. Costs to one year and to death in the SCS+PT and PT groups (undiscounted)

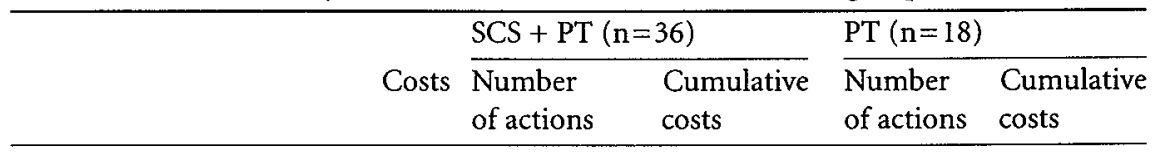

To One Year

Spinal cord stimulation

Outpatient visit 1

Implant test lead

Outpatient visit 2

$275.78 \quad 36$

$9,928.08$

$1,462.90 \quad 36 \quad 52,664.40$

$\begin{array}{lll}105.58 & 36 & 3,800.88\end{array}$

Implant SCS-system

Reposition lead

$18,638.40 \quad 24$

$447,321.60$

$800.35 \quad 8$

$6,402.80$

Replacement lead

$3,400.35$

$3,400.35$

Infection

$13,762.08$

$13,762.08$

(removal + reimplant)

Other biological

381.04

$13,381.04$

7

$2,667.28$

Replacement system

Conventional approach

SCS+PT group

$6,609.48$

36

18

$227,711.52$

$12,650.64$

$237,941.28$

PT group

$777,888.75$

$227,711.52$

$21,608.02$

$12,650.64$

Mean cost per patient

To death (projected)

Spinal cord stimulation

Conventional approach

$4,060,523.00$

$9,517,651.20$

$9,108,460.80$

$13,578,174.00$

$9,108,460.80$

$377,171.50$

$506,025.60$

Mean cost per patient

Values expressed in 1998 Dutch guilders. Multiply by 0.47 to calculate equivalent 1998 US dollars or by 0.45 to calculate equivalent in 1998 euros.

diminished requirement for medical care. Expenditure on transport, medication and aids remained constant.

Out-of-Pocket Expenses Only one patient refused to complete cost diaries. The mean baseline out-of-pocket cost of all other patients $(n=53)$ was NLG 232.66 per month. There were no statistically significant differences in out-of-pocket expenses between patients with an affected arm vis-à-vis patients with an affected leg. In both the SCS+PT and the PT group, the mean out-of-pocket expenses remained constant after treatment. Consequently, these were omitted from all further analyses.

Economic Evaluation Tables 8.2 and 8.3 present incremental costs and effects of SCS for chronic RSD. Table 8.3 differs from Table 8.2 in that future costs (those beyond the first year) and effects (pain intensity and QALYs) are discounted at rates of 3 and 5 percent per annum. In the reference case analysis, as a consequence of 


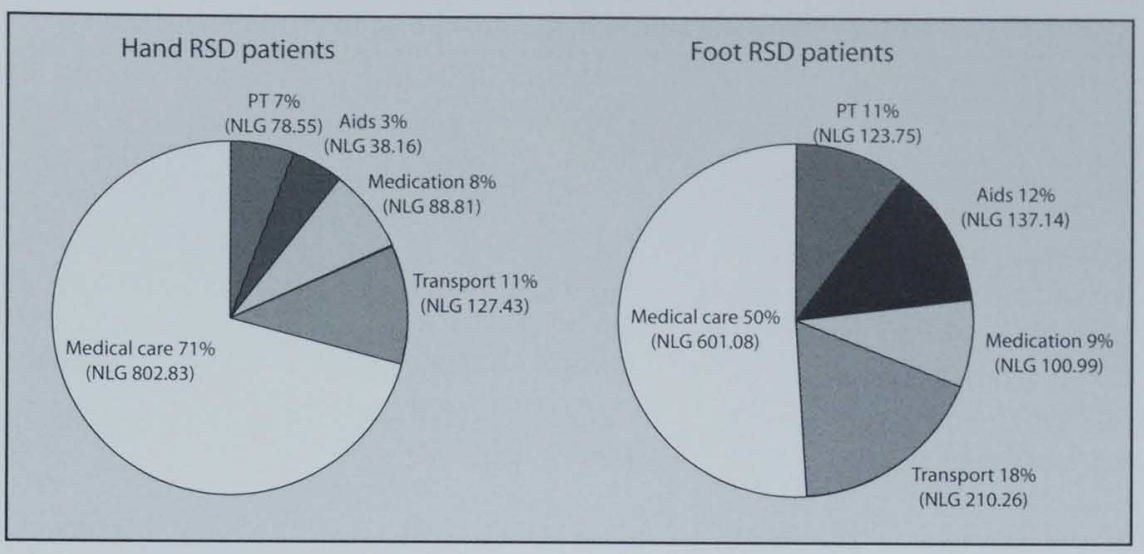

Figure 8.3. Mean monthly costs from the conventional approach in patients with RSD of the hand $(n=33)$ or foot $(n=21)$. Patients with an affected foot make significantly higher costs regarding aids and transport. PT refers to physical therapy. Values expressed in 1998 Dutch guilders. Multiply by 0.47 to calculate equivalent in 1998 U.S. dollars or by 0.45 to calculate equivalent in 1998 euros.

the reduction of conventional approach costs by SCS, after three years, costs in the PT group permanently exceed costs in the SCS+PT group (Figure 8.4).

Sensitivity Analyses Results of the sensitivity analyses are presented in Table 8.4. Incremental costs of SCS remained negative for all variants of discount rate, complication rate and success percentage of test stimulation. Only extreme values for mean longevity of the pulse-generator (1 year or below) and mean life expectancy (2 years or below) resulted in positive incremental costs. Even if a pulse-generator were to have a mean longevity of only one year, the incremental cost per QALY would nevertheless merely be NLG 20,606.35 (3 percent discount rate).

TABLE 8.2. Incremental costs and effects of SCS for chronic RSD (undiscounted)

\begin{tabular}{llr}
\hline To one year & Cost & $8,957.38$ \\
& Pain reduced $(\mathrm{cm})$ & 2.7 \\
& QALY's gained & 0.18 \\
& Cost/QALY gained & $49,763.22$ \\
To death (projected) & Cost & $-128,854.10$ \\
& Pain reduced $(\mathrm{cm})$ & 124 \\
& QALY's gained & 7.6 \\
& Cost/QALY gained & dominant
\end{tabular}

Costs expressed in 1998 Dutch guilders. Multiply by 0.47 to calculate equivalent 1998 US dollars or by 0.45 to calculate equivalent in 1998 euros. 
TABLE 8.3. Incremental costs and effects of SCS for chronic RSD (discounted)

\begin{tabular}{llr}
\hline To one year & Cost & $8,957.38$ \\
& Pain reduced $(\mathrm{cm})$ & 2.7 \\
& QALY's gained & 0.18 \\
& Cost/QALY gained & $49,763.22$ \\
To death (projected) & Cost & $-39,506.60$ \\
3 percent discount rate & Pain reduced $(\mathrm{cm})$ & 38.02 \\
& QALY's gained & 2.33 \\
& Cost/QALY gained & dominant \\
To Death (projected) & Cost & $-18,297.29$ \\
5 percent discount rate & Pain reduced (cm) & 17.61 \\
& QALY's gained & 1.08 \\
& Cost/QALY gained & dominant
\end{tabular}

Costs expressed in 1998 Dutch guilders. Multiply by 0.47 to calculate equivalent 1998 US dollars or by 0.45 to calculate equivalent in 1998 euros.

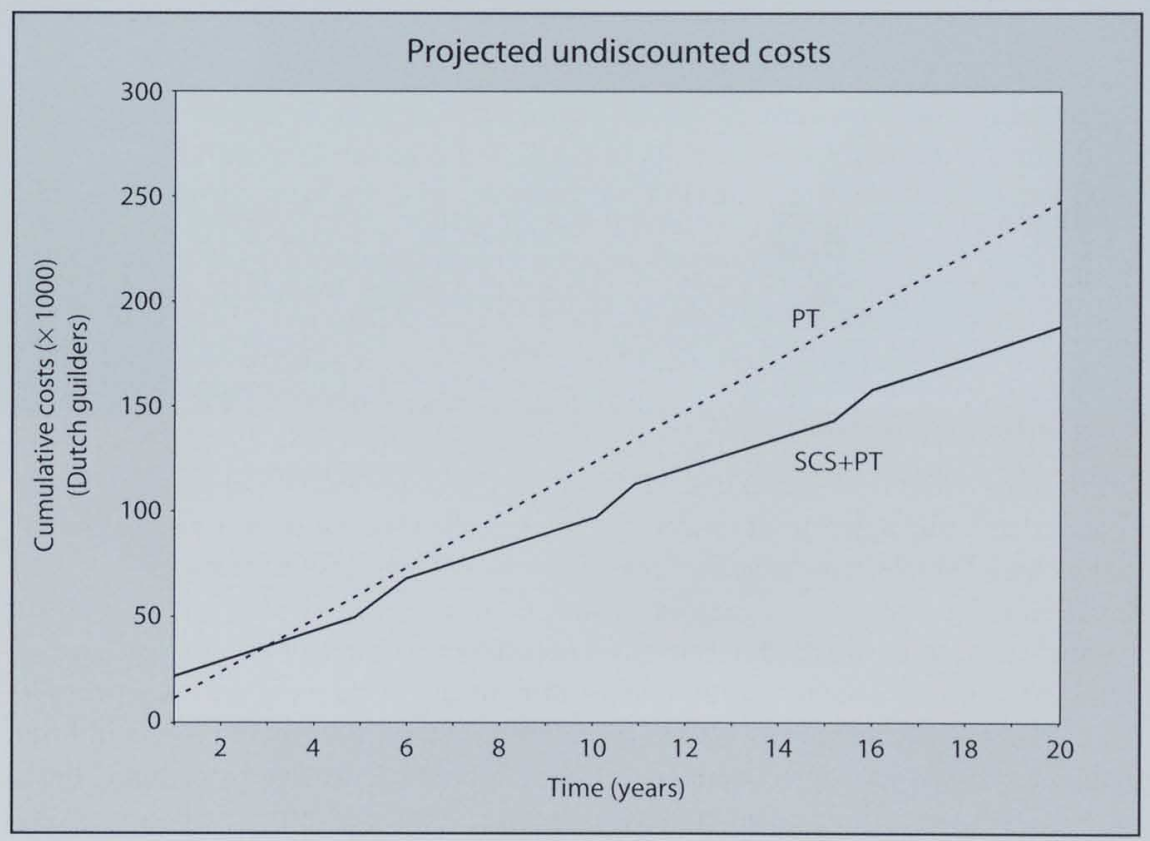

Figure 8.4. Projected undiscounted cumulative costs in the SCS+PT group and the PT group. PT costs go beyond SCS+PT costs after three years. Values expressed in 1998 Dutch guilders. Multiply by 0.47 to calculate equivalent in 1998 US dollars or by 0.45 to calculate equivalent in 1998 euros. 
TABLE 8.4. Sensitivity analysis on incremental costs of SCS for RSD (discounted at three percent)

\begin{tabular}{|c|c|c|c|c|}
\hline & Alternative & $\begin{array}{l}\text { Incremental } \\
\text { costs }\end{array}$ & $\begin{array}{l}\text { Delta } \\
\text { QALY }\end{array}$ & $\begin{array}{l}\text { Cost/QALY } \\
\text { gained }\end{array}$ \\
\hline Reference case & & $-39,506.60$ & 2.33 & dominant \\
\hline Discount rate & $\begin{array}{r}0 \% \\
10 \%\end{array}$ & $\begin{array}{c}-128,854.10 \\
-2,847.68\end{array}$ & $\begin{array}{l}7.60 \\
0.17\end{array}$ & $\begin{array}{l}\text { dominant } \\
\text { dominant }\end{array}$ \\
\hline Complication rate & $50 \%$ & $-32,280.20$ & 2.33 & dominant \\
\hline Longevity & $\begin{array}{l}1 \mathrm{yr} \\
2 \mathrm{yrs} \\
7 \mathrm{yrs}\end{array}$ & $\begin{array}{r}48,016.10 \\
-6,685.60 \\
-44,976.80\end{array}$ & $\begin{array}{l}2.33 \\
2.33 \\
2.33\end{array}$ & $\begin{array}{l}20,607.77 \\
\text { dominant } \\
\text { dominant }\end{array}$ \\
\hline Life expectancy & $\begin{array}{r}2 \text { yrs } \\
3 \text { yrs } \\
50 \text { yrs }\end{array}$ & $\begin{array}{r}3,661.27 \\
-1,201.95 \\
-37,034.30\end{array}$ & $\begin{array}{l}0.36 \\
0.52 \\
2.17\end{array}$ & $\begin{array}{l}10,170.19 \\
\text { dominant } \\
\text { dominant }\end{array}$ \\
\hline Success test stimulation & $100 \%$ & $-23,526.80$ & 2.33 & dominant \\
\hline
\end{tabular}

\section{Discussion}

The present study demonstrates that for patients suffering from chronic RSD, SCS is not only more effective but also less costly than the conventional treatment protocol. SCS can therefore be classified as a grade A technology, meaning that there is compelling evidence for adoption and appropriate utilization. ${ }^{15}$ Even in the worst case scenario - a mean battery life of one year - the incremental cost per QALY gained would be NLG 20,500, which is equivalent to CAN\$14,500/QALY gained (multiply 1998 Canadian dollars by 0.68 to calculate equivalent 1998 U.S. dollars). Technologies that cost less than CAN\$20,000/QALY gained are almost universally accepted as being appropriate ways of using the resources of society and the health care system. ${ }^{15}$ Note, however, that these criteria have no official status.

As stated earlier, a comparable economic evaluation of SCS has not to our knowledge been performed previously. Our study was carried out alongside a randomized controlled trial, resource use and clinical effects were assessed prospectively, and costs were valued via micro-costing. The only study that we could find in the literature-cost-effectiveness of SCS for failed back surgery syndrome-based costs and effects entirely on assumptions and estimates, and applied a five-year time horizon. ${ }^{17}$ Since SCS is dependent on expensive pulse-generator replacements throughout treatment, a short time horizon is a potential result-improving factor.

Total mean calculated costs in the first year were almost twice as high in the SCS+PT group as compared to those in the PT group (difference between mean 
costs per patient per year of NLG 9,000). The high initial expense of SCS was mainly due to the implantation itself, that formed 83 percent of the expenditure. Consequently, outgoings in the SCS+PT group after one year will be considerably lower. In fact, costs in the lifetime analysis for the reference case were lower for SCS than for the conventional treatment protocol. Consequently, we have been able to restrict the lifetime analysis to just a presentation of costs. Despite the high outlay in the first year, the expenses in the long run are lower than those in the conventional situation.

The results of the lifetime analysis were very robust. Whatever figure was chosen, discount rate, test stimulation success rate and complication rate did not influence the fact that conventional treatment costs outweighed those of SCS. Only in unrealistic situations - a mean longevity of the pulse-generator of one year, or a mean life expectancy for patients of two years-did SCS become more expensive than conventional treatment. In addition to reducing costs, however, SCS also results in diminished pain intensity and improved health-related quality of life (Chapter 7). Consequently, the results of SCS are even more favourable than the figures from this study would indicate.

We emphasize that our results are solely applicable to the specific category of chronic RSD patients. A characteristic of this type of patient is their intensive consumption of therapeutic resources due to unsatisfactory long-term relief of chronic pain. After treatment with SCS, demands for medical care made by chronic RSD patients appear to come down. The sum of costs of SCS treatment, plus the reduced medical costs caused by SCS, result in a lower total as compared to costs of the conventional treatment.

It appeared from our data that between $\mathrm{T} 0$ and $\mathrm{T} 1$ (i.e. when the patients were aware of the randomization code and the test stimulation result, but actual implantation had not yet been performed) health-related quality of life and pain intensity already clearly improved in the SCS+PT group, possibly indicating bias of randomization. ${ }^{18}$ In the clinical study, in order to evaluate the true outcome of treatment, we therefore compared final effects to $\mathrm{T} 1$, instead of to T0, values (Chapter 7). In the economic analysis, we are evaluating whether it is worthwile to try SCS for chronic RSD patients. In contrast to the clinical study, we thus compared final effects to TO.

In the reference case analysis, we applied a success rate of test stimulation of 67 percent, a life expectancy of 40 years, a longevity of the pulse-generator of 5 years, and a complication rate of 30 percent. These assumptions are based on the findings of the clinical study (Chapter 7) and are in line with figures reported in the literature. In both the pilot study ${ }^{19}$ and the clinical study (Chapter 7) we measured a 67 percent success rate of test stimulation in RSD. Data from Medtronic's SCS Multicenter Trial indicate that approximately 83 percent of all screened patients (i.e., not specifically RSD patients) will have a successful test stimulation. ${ }^{17}$ RSD is a chronic benign pain syndrome which does not affect life expectancy. Therefore, we could apply unmodified life expectancy tables for the Dutch population. The 
longevity of the pulse-generator has been found to be 65 months in Medtronic's SCS Multicenter Trial, ${ }^{17}$ comparable to the five years we calculated in the present study. The complication rate, and the cost for any complication finally, was (as explained previously) based on a systemic literature synthesis of SCS. "If we had used our own figures, the cost of any complication would have been NLG 1500 instead of NLG 3,000. We chose to apply Turner's figures, because these are least likely to be influenced by chance.

This study did take into account potential future developments that might influence the results. Once SCS becomes a more common treatment, this will reduce the costs. Technological developments might result in longer battery life, rechargeable batteries, or batteries charged by kinetic energy. Each development will result in reduced costs of treatment. It is hard to find any factors that might result in higher costs, apart from economic changes in inflation or interest rates.

Taken all in all, the present study has demonstrated that, for patients suffering from chronic RSD, SCS is both more effective and less costly than the conventional treatment protocol. For chronic RSD patients, who are presently often deprived of SCS, the discovery that the only treatment with proven effect on their clinical situation has now clearly been shown to be effectively the cheaper in the long run, can be considered an enormous step forward.

\section{References}

1. Plewes LW. Sudeck's atrophy in the hand. J Bone Joint Surg 1956; 38B: 195-203.

2. Stanton-Hicks $M$, Baron $R$, Boas $R$, et al. Complex regional pain syndromes: guidelines for therapy. Clin J Pain 1998; 14: 155-66.

3. Schwartzman RJ, McLellan TL. Reflex sympathetic dystrophy: a review. Arch Neurol 1987; 55: 555-61.

4. Ochoa JL. Guest editorial: essence, investigation, and management of "neuropathic" pains: hopes from acknowledgment of chaos. Muscle \& Nerve 1993; 16: 997-1008.

5. Jensen MP, McFarland CA. Increasing the reliability and validity of pain intensity measurement in chronic pain patients. Pain 1993; 55: 195-203.

6. Euroqol-Group. EuroQol-a new facility for the measurement of health-related quality of life. Health Policy 1990; 16: 199-208.

7. Euroqol-Group. EQ-5D user guide. Rotterdam: the Euroqol Group, 1996.

8. Dolan P. Modeling valuations for euroqol health states. Med Care 1997; 35: 1095-108.

9. Dolan P, Gudex C, Kind P, Williams A. The time trade-off method: results from a general population study. Health Econ 1996; 5: 141-54.

10. Life tables, 1997 and 1993-7. Mndstat bevolking 1999; 47: 29-31.

11. Turner JA, Loeser JD, Bell KG. Spinal cord stimulation for chronic low back pain: a systematic literature synthesis. Neurosurgery 1995; 37: 1088-95.

12. Boot JM, Knapen MHJM. De Nederlandse gezondheidszorg. Utrecht: Spectrum, 1996.

13. Elsevier Belasting Almanak. Amsterdam: Elsevier Bedrijfsinformatie, 1999.

14. Drummond MF, O'Brien B, Stoddart GL, Torrance GW. Methods for the economic evaluation of health care programmes. Oxford: Oxford University Press, 1998. 
15. Laupacis A, Feeney D, Detsky AS, Tugwell PX. How attractive does a new technology have to be to warrant adoption and utilization? Tentative guidelines for using clinical and economic evaluations. Can Med Assoc J 1992; 146: 473-81.

16. Weinstein MC, Siegel JE, Gold MR, Kamlet MS, Russell LB. Recommendations of the panel on cost-effectiveness in health and medicine. JAMA 1996; 276: 1253-8.

17. Bell GK, Kidd D, North RB. Cost-effectiveness analysis of spinal cord stimulation in treatment of failed back surgery syndrome. J Pain Symptom Manag 1997; 13: 286-95.

18. Kemler MA, de Vet HCW. Does randomization introduce bias in unblinded trials? Epidemiology 2000; 11: 228 .

19. Kemler MA, Barendse GAM, van Kleef M, van den Wildenberg FAJM, Weber WEJ. Electrical spinal cord stimulation in reflex sympathetic dystrophy: retrospective analysis of 23 patients. J Neurosurg 1999; 90 (Spine 1): 79-83. 
CHAPTER 9

\section{Impact of Spinal Cord Stimulation on Sensory Characteristics in Reflex Sympathetic Dystrophy: A Randomized Trial}

Marius A. Kemler, Jos P.H. Reulen, Gerard A.M. Barendse, Maarten van Kleef, Henrica C.W. de Vet, and Frans A.J.M. van den Wildenberg 


\section{Introduction}

Spinal cord stimulation (SCS) originated as a direct consequence of the Gate Control Theory for pain. 'The 'gate' in the dorsal horn was thought to control the central transmission of neural activity signalling pain. Excess of large $(A \beta)$ fiber activity over small (C) fiber activity would result in a closed 'gate' and consequently in pain relief. In a mixed population of nerve fibers, the large fibers are more susceptible than the small to recruitment by an externally applied electrical field. This suggests that, at a critical stimulation amplitude, large fibers might be recruited selectively, thereby closing the spinal 'gate'. However, it has been demonstrated experimentally that hyperalgesia can also be signalled by large fibers, a finding directly in conflict with the gate theory. ${ }^{2}$ As a result, the actual working mechanism of SCS still remains to be explained.

SCS has clearly been shown to relieve pain in chronic conditions, such as angina pectoris, ${ }^{3}$ failed back surgery syndrome, ${ }^{4}$ and the neuropathic pain syndrome of reflex sympathetic dystrophy (Chapter 7). The pain-relieving effect of SCS has also been demonstrated objectively in chronic neuropathic pain patients. The amplitude of somatosensory evoked potentials (SSEP) upon peripheral nerve stimulation was found to be decreased owing to SCS; directly upon change in SSEP amplitude, patients reported being pain free. ${ }^{5}$

Neuropathic pain is often accompanied by positive sensory symptoms, such as allodynia (pain due to a stimulus which does not normally provoke pain) and hyperalgesia (increased response to a stimulus which is normally painful). It may also involve negative sensory symptoms, such as hypoalgesia (diminished pain in response to a normally painful stimulus) and hypoesthesia (decreased sensitivity to stimulation) ${ }^{6}$ Whether there is any influence of SCS on these sensory abnormalities has as yet been little studied. Relief of neuropathic pain by SCS might be caused partly by a reduction of the aforementioned positive sensory symptoms; ${ }^{7,8}$ conversely, the paresthesiae that accompany SCS might disturb normal sensibility and produce negative sensory symptoms. ${ }^{9}$ Because these studies investigated patients in fairly small groups, often without control subjects, and ultimately produced equivocal results, the true effect of SCS on sensory characteristics is still unknown.

In the present study, the effects of SCS on positive and negative sensory symptoms were investigated by means of a randomized controlled trial in patients with chronic reflex sympathetic dystrophy (RSD). Patients were allocated either to a group receiving both SCS and physical therapy or to a group treated with physical therapy alone. Detection thresholds and pain thresholds for pressure, warmth and cold, and the extent of dynamic and static hyperalgesia were determined at baseline and at one, three, six and twelve months following implantation of the SCS system. The findings will be used to increase our understanding of the mechanism of action of SCS. In order to rule out initial adaptation effects, this paper will focus mainly on the twelve-month results. 


\section{Patients and methods}

\section{Patients}

Patients meeting the following criteria were considered for participation in the study: aged 18 to $65 ; \mathrm{RSD}$ according to diagnostic criteria of the International Association for the Study of Pain; ${ }^{10}$ RSD clinically restricted to one extremity, but affecting the whole of the hand or foot; duration of RSD of at least six months; no lasting success with standard therapy, that had to include six months PT, sympathetic blocks, transcutaneous electrical nerve stimulation and medication; a mean pain intensity of at least 5 , measured on a visual analog scale (VAS) ranging from zero (no pain) to 10 (very severe pain), according to Jensen. ${ }^{11}$ Exclusion criteria were: a previous diagnosis of Raynaud's disease; a history of neurological abnormalities not related to RSD; conditions affecting function of the diseased or the contralateral extremity other than RSD itself; blood clotting disturbances, or anticoagulant drug therapy; an implanted cardiac pacemaker. All patients completed a standardized psychological test, namely, the Symptom Check List-90. ${ }^{12}$ Patients scoring 200 or more on this scale underwent a full examination by a psychologist in order to rule out significant drug habituation problems, major psychiatric diagnoses or significant personality disorders, and to address issues of secondary gain. Patients who were considered on the basis of the examination to have substantial psychopathology were to be excluded. The study complied with the Declaration of Helsinki regarding investigations in humans and was approved by the Medical Ethics Committee of Maastricht University Hospital. All patients gave written informed consent.

\section{Power Calculation and Randomization}

The study protocol is illustrated in Figure 9.1. After completion of the baseline assessment ( $\mathrm{T} 0$ ), a concealed randomization procedure was employed and patients were assigned either to a group with SCS plus a standardized PT program (SCS+PT group), or to a group with the standardised PT program alone (PT group). All SCS+PT patients underwent one week of test stimulation. The decision to implant the SCS-system permanently was made if during the last four testing days a $50 \%$ decrease in original (T0) VAS score was measured, or if the patient reported 'much improved' or 'best ever' on a global perceived effect scale (a seven-point scale, indicating 'worst ever, much worse, worse, not improved/not worse, improved, much improved and best ever ${ }^{\prime 3}$ ). Patients who did not meet these criteria continued to participate in the study with PT alone. The surgical procedures of test stimulation and SCS-implantation have been described previously. ${ }^{14}$

For randomization, a computer-generated table was used with random numbers having a prestratification for location of RSD, i.e. upper or lower extremity. The patients were assigned by a person independent of the study to SCS+PT or to PT using the random number table. To estimate the required study sample size, VAS (pain intensity) data of a pilot study were used with a change of $3.5 \mathrm{~cm}$ defined as 
the minimum important difference. ${ }^{14}$ On this basis, the randomization used a 2:1 ratio in favour of the SCS+PT group. As a result of the 2:1 randomization ratio, 36 patients were allocated to SCS+PT and 18 to PT. Twenty-four SCS+PT patients responded successfully to test stimulation and then underwent SCS-implantation. Thus, 24 patients received a SCS-system (with implant; SCS group), while this was not true for the remaining 30 patients (without implant; control group).

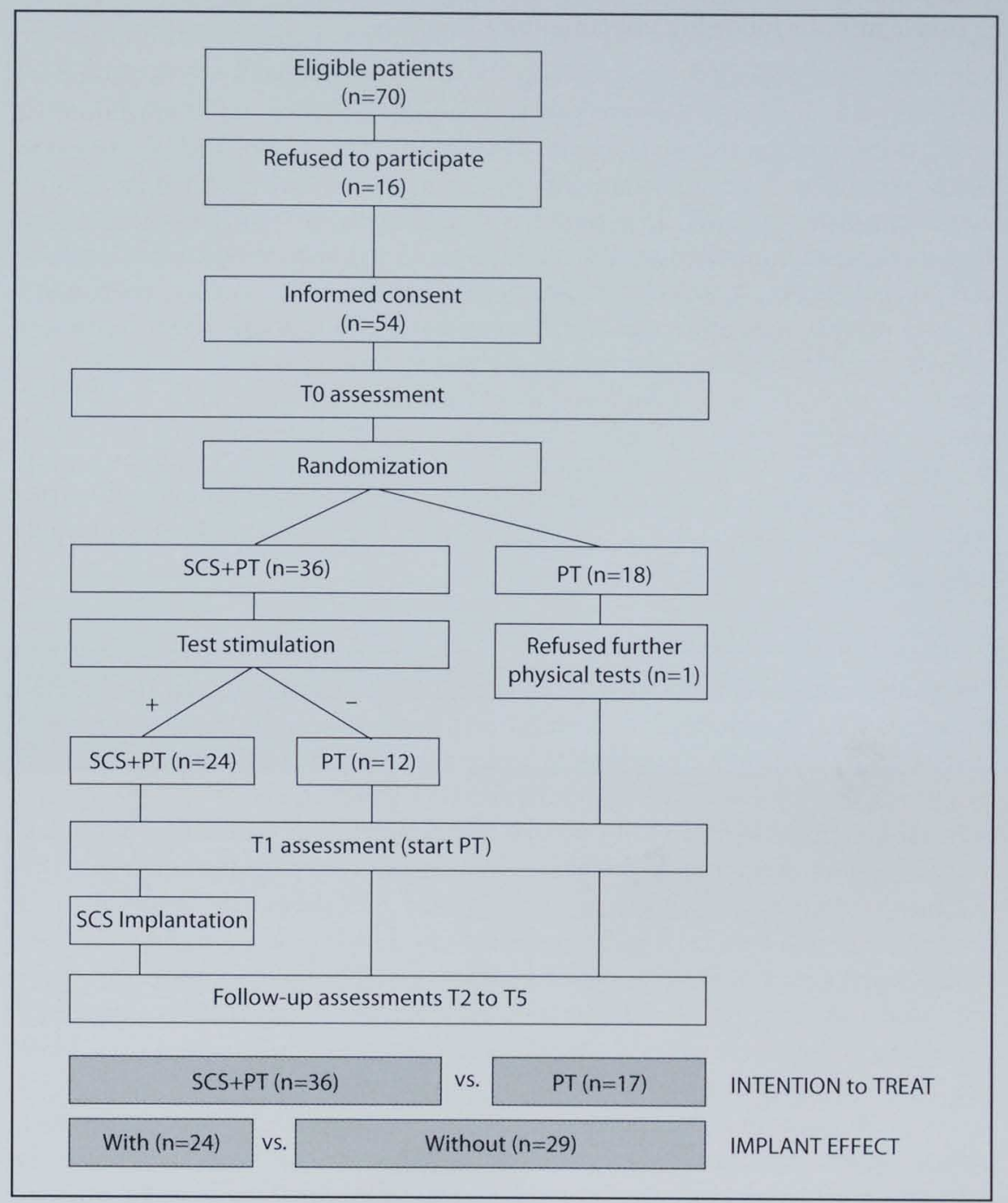

Figure 9.1. Flow chart of the study protocol, indicating the groups compared in the Intention to treat analysis and in the Implant effect analysis. 


\section{Data Collection and Follow-up}

The patients were examined at the following points in the study:

- Before randomization (T0)

- On the day prior to implantation (T1)

- One month following implantation (T2)

- Three months following implantation (T3)

- Six months following implantation (T4)

- Twelve months following implantation (T5)

Note that the $\mathrm{T} 1$ assessment of patients not receiving an implant was planned to take place close to the assessment date of implant patients. Randomization was employed for blocks of six patients - patients from the same block being always examined within one week. In all cases, the unaffected side was tested first, followed by the affected side. Subjects were tested in a quiet room after the procedure had been explained. Room temperature was maintained at $21-23^{\circ} \mathrm{C}$. Assessments of SCS patients were performed while stimulation intensity of the system was at a constant level resulting in pain relief. The full examination was completed within two hours.

Pressure Sensibility The Semmes-Weinstein Pressure Aesthesiometer (Smith \& Nephew Rolyan Inc., Germantown, WI, USA) was used to measure pressure detection and pain thresholds. The instrument includes a kit of 20 probes, each probe consisting of a nylon monofilament attached to a rod. The probes are all marked with a number ranging from 1.65 to 6.65 representing in tenths of a milligram the
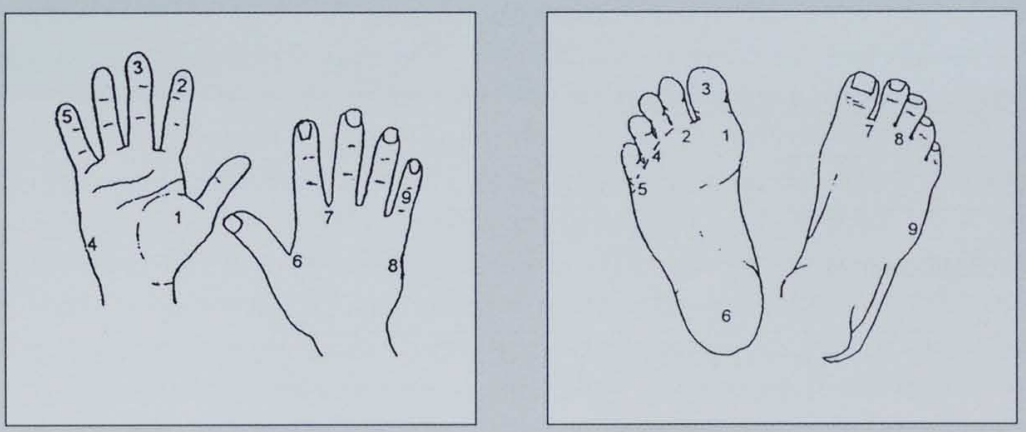

Figure 9.2. Hand and foot testing sites for pressure sensibility and mechanical hyperalgesia. Hand sites are innervated by the median nerve $(1,2,3)$, the ulnar nerve $(4,5,8,9)$ and the radial nerve $(6,7)$. Foot sites are innervated by the medial plantar nerve $(1,2,3)$, the lateral plantar nerve $(4,5,6)$, the deep peroneal nerve $(7)$, the superficial peroneal nerve (8) and the sural nerve (9). 
logarithm of the force required to bend the monofilament. ${ }^{15}$ This force is reproducible as long as the monofilament is pressed into a $\mathrm{C}$-shape. Thus, the finest filament, labeled 1.65, will bend when applied at an angle of $90^{\circ}$ to the skin with a force of $0.0045 \mathrm{~g}$, while the thickest filament, labeled 6.65 , will bend at $447 \mathrm{~g}$.

To evaluate all nerves supplying the hand or foot, nine stimulation sites representative of various peripheral nerves and dermatomes were tested (Figure 9.2); the mean of nine pressure scores was used in further calculations. Ascending levels of filament forces were applied up to the pressure detection threshold-a level that the subject is able to detect in at least two out of three trials. The pressure pain threshold-the minimum force at which the subject reports pain-was then determined in a similar manner. The filament was applied perpendicularly to the skin, care being taken to avoid contact with hairs or skidding. Stimulus timing was as follows: one second for placement, one second for bending and one second for removal of the filament. From the thresholds obtained at the aforementioned nine sites, the mean detection and pain thresholds for the hand and foot were calculated in grams. The hands were investigated while the subject was sitting; evaluation of the feet was performed with the subject in a supine position. During testing, subjects were required to keep their eyes closed and were thus unable to observe either their hands and feet or the probes. On the unaffected side, pressure pain cannot be measured with monofilaments; here the maximal filament load $(447 \mathrm{~g})$ is not perceived as painful.

Warmth and Cold Sensibility Thresholds for warmth, cold, heat-induced pain and cold-induced pain were measured using a Thermal Sensory Analyser (TSA2001; Medoc Ltd., Ramat Yishai, Israel). The TSA2001 operates on the Peltier principle: passing an electrical current through two dissimilar semiconductors displaces heat in the direction of the current. If a good heat conductor, such as a metallic plate, is juxtaposed to one side of the semiconductor system, it will be heated or cooled depending on the direction of the current. The opposite side of the system is buffered by water at a temperature of $20^{\circ} \mathrm{C}$, this acting as a heat sink or heat source depending on the direction of current. The temperature at the surface of the stimulator probe (thermode) is measured through a built-in thermocouple made of dissimilar wires (copper and constantin) the voltage difference of which varies in response to change in temperature. A rectangular thermode with a surface of 5 by 2.5 $\mathrm{cm}$ was used for cutaneous stimulation and was attached to the skin by means of an elastic Velcro tape, care being taken to minimize variation of thermode application pressure. The thermode was applied at a standard baseline temperature of $32^{\circ} \mathrm{C}$ while to prevent thermal injury and protect the Peltier instrument, the temperature limits were set at $0^{\circ} \mathrm{C}$ and $50^{\circ} \mathrm{C}$. Upon reaching these temperatures, current direction was automatically reversed, thus returning the temperature to the baseline value.

Warmth and cold detection thresholds were assessed using the Method of Levels; ${ }^{16}$ at each temperature step, subjects responded with 'yes' (if a thermal sensa- 
tion was perceived) or 'no' (if this was not the case). For warmth, there was an initial temperature step of $2^{\circ} \mathrm{C}$, with the temperature returning to adaptation immediately upon stimulus termination. The extent of increase or decrease of the subsequent stimulus was dependent on the subject's reaction - it remained constant as long as the patient went on providing a sequence of wholley positive, or a sequence of wholley negative responses, but was halved if either sequence was broken. The procedure was continued until interval size reached $0.1^{\circ} \mathrm{C}$. For cold, an initial temperature step of $1^{\circ} \mathrm{C}$ was used, this being the only difference compared with the procedure to assess the warmth perception threshold. The time interval between subject response and the subsequent stimulus was 6 seconds, the final result being the mean of two measures. Warmth and cold pain thresholds were assessed with the Method of Limits (a linear change in temperature of $1.5^{\circ} \mathrm{C} / \mathrm{s}$, an interstimulus interval of $10 \mathrm{~s}$ and a mean derived from four stimuli). Thresholds for the foot were assessed at the dorsal aspects of both feet, immediately proximal to the bases of the second and third toes. Thresholds for the hand were assessed at the volar aspects of both wrists, immediately proximal to the base of the hand.

Mechanical Hyperalgesia Dynamichyperalgesia was assessed by transientlystroking the skin with a soft brush, while static hyperalgesia was evaluated by applying gentle mechanical force by manual pressure. ${ }^{17}$ The tests were performed on the aforementioned nine stimulation sites. Patients were asked to rank on a scale from zero to 10 the degree of pain evoked when the mechanical stimuli were applied. The tests were performed only on affected extremities - the described stimuli being in general not painful for unaffected extremities.

\section{Statistical Analysis}

In this explanatory trial, ${ }^{18}$ patients with an implanted SCS-system were compared with those without: the implant effect analysis. The decision to combine data from patients in the SCS+PT group with failed test stimulation and those from patients in the PT group was based on clinical grounds (both groups did eventually receive the same treatment). A secondary analysis was carried out according to the intention-to-treat principle: all patients remained in the group to which they had been assigned by randomization.

Differences between $\mathrm{Tl}$ (just before start of treatment) and $\mathrm{T} 5$ (twelve month) values for each individual were calculated and compared between the two groups using means, standard deviations and $t$-tests for normal distributed parameters (warmth and cold thresholds) or medians, interquartile ranges and nonparametric tests if the results were not normally distributed (pressure thresholds and mechanical hyperalgesia). The decision to use $\mathrm{T} 1$ instead of $\mathrm{T} 0$ values to measure the effect of treatment was made to prevent bias; improvements prior to the actual start of treatment (between $\mathrm{T} 0$ and $\mathrm{T} 1$ ) have been demonstrated by this study (a project that could not possibly be blinded because of the paresthesiae that accompany stimulation). ${ }^{19}$ Change of detection and pain thresholds, and mechanical hyperalgesia for 
the complete group of patients $(n=53)$ was evaluated through paired samples tests. Two-tailed $p$ values $<0.05$ were considered to indicate statistical significance.

\section{Results}

Fifty-four patients, aged 21 to 65 years ( 37 females and 17 males), with chronic RSD of one extremity, who had been referred to our department during the period March 1997 to July 1998, took part in the study. In 33 cases, an arm was the affected limb; in 21 cases, a leg. Of these 54 patients, one (assigned to PT) refused to undergo any physical test after T0 and this subject was not included in the analysis. Randomization was carried out successfully and both the intention-to-treat analysis groups and the implant effect analysis groups proved largely similar at baseline regarding outcome measures (Table 9.1). Four patients in the PT group and one patient in the SCS+PT group were lost to follow-up after the six month assessment (T4). In order to prevent loss of information, their T4 scores were also used in the T5 analysis.

Table 9.2 presents changes in quantitative sensory test parameters between 12 month and start of treatment results (T5-T1) for the implant effect analysis, and

TABLE 9.1. Baseline (T0) characteristics of 53 RSD patients

\begin{tabular}{|c|c|c|c|c|c|c|}
\hline & \multicolumn{2}{|c|}{ Intention to treat } & \multicolumn{2}{|l|}{ Implant effect } & \multicolumn{2}{|l|}{$p$-values } \\
\hline & $\mathrm{SCS}+\mathrm{PT}$ & $\mathrm{PT}$ & $\begin{array}{l}\text { With } \\
\text { implant }\end{array}$ & $\begin{array}{l}\text { Without } \\
\text { implant }\end{array}$ & $\begin{array}{l}\text { Intention } \\
\text { to treat }\end{array}$ & $\begin{array}{l}\text { Implant } \\
\text { effect }\end{array}$ \\
\hline Characteristic & $(n=36)$ & $(n=17)$ & $(n=24)$ & $(n=29)$ & & \\
\hline Age-years (mean $\pm S D$ ) & $40 \pm 12$ & $35 \pm 8$ & $40 \pm 11$ & $37 \pm 11$ & .05 & .28 \\
\hline Male-no. $(\%)$ & $14(39)$ & $2(12)$ & $9(38)$ & $7(24)$ & & \\
\hline Female-no. $(\%)$ & $22(61)$ & $15(88)$ & $15(62)$ & $22(76)$ & .09 & .45 \\
\hline $\begin{array}{l}\text { Disease duration-months } \\
\text { (mean } \pm \mathrm{SD} \text { ) }\end{array}$ & $40 \pm 28$ & $34 \pm 23$ & $39 \pm 30$ & $38 \pm 23$ & .40 & .87 \\
\hline Pain_VAS (mean $\pm S D$ ) & $7.1 \pm 1.5$ & $6.8 \pm 1.2$ & $7.1 \pm 1.7$ & $7.0 \pm 1.2$ & .41 & .81 \\
\hline \multicolumn{7}{|l|}{ Pressure-gram } \\
\hline DT-A (median, IQR) & $0.3(0.2-1.8)$ & $0.2(0-.05)$ & $0.3(0.2-1.7)$ & $0.2(0.1-1.0)$ & .08 & .59 \\
\hline DT-U (median, IQR) & $0.3(0.1-0.6)$ & $0.1(0-.03)$ & $0.2(0.1-0.6)$ & $0.2(0-.06)$ & .15 & .54 \\
\hline PT-A (median, IQR) & $32(3-166)$ & $11(1-402)$ & $77(3-215)$ & $11(3-258)$ & .83 & .70 \\
\hline \multicolumn{7}{|c|}{ Mechanical Hyperalgesia-0 to 10 scale } \\
\hline DH-A (median, IQR) & $1.0(0-3.4)$ & $1.4(0-6.7)$ & $0(0-2.6)$ & $2.7(0-5.8)$ & .34 & .02 \\
\hline SH-A (median, IQR) & $1.7(0-4.8)$ & $2.9(0-6.8)$ & $0.4(0-4.4)$ & $3.0(0.3-6.3)$ & .39 & .08 \\
\hline \multicolumn{7}{|l|}{ Warmth- ${ }^{\circ} \mathrm{C}$} \\
\hline DT-A (mean $\pm \mathrm{SD})$ & $34.6 \pm 3$ & $33.9 \pm 3$ & $34.3 \pm 3$ & $34.5 \pm 3$ & .41 & .77 \\
\hline DT-U (mean $\pm S D)$ & $33.9 \pm 3$ & $33.8 \pm 3$ & $33.8 \pm 3$ & $33.9 \pm 3$ & .92 & .88 \\
\hline PT-A (mean $\pm S D)$ & $41.5 \pm 4$ & $39.2 \pm 4$ & $41.7 \pm 4$ & $40.0 \pm 4$ & .07 & .13 \\
\hline $\mathrm{PT}-\mathrm{U}($ mean $\pm \mathrm{SD})$ & $44.4 \pm 3$ & $44.5 \pm 3$ & $44.5 \pm 3$ & $44.3 \pm 3$ & .91 & .82 \\
\hline \multicolumn{7}{|l|}{ Cold- ${ }^{\circ} \mathrm{C}$} \\
\hline $\mathrm{DT}-\mathrm{A}($ mean $\pm \mathrm{SD})$ & $29.8 \pm 4$ & $30.9 \pm 1$ & $29.4 \pm 4$ & $30.8 \pm 1$ & .07 & .14 \\
\hline DT-U (mean $\pm S D)$ & $30.7 \pm 2$ & $31.1 \pm 1$ & $30.6 \pm 3$ & $31.0 \pm 1$ & .34 & .42 \\
\hline $\mathrm{PT}-\mathrm{A}($ mean $\pm \mathrm{SD})$ & $19.4 \pm 9$ & $23.3 \pm 8$ & $19.3 \pm 9$ & $21.9 \pm 9$ & .12 & .30 \\
\hline PT-U (mean $\pm S D)$ & $10.0 \pm 7$ & $11.8 \pm 8$ & $9.1 \pm 8$ & $11.8 \pm 6$ & .43 & .20 \\
\hline
\end{tabular}

$\mathrm{DT}=$ detection threshold; $\mathrm{PT}=$ pain threshold; $\mathrm{DH}=$ dynamic hyperalgesia; $\mathrm{SH}=$ static hyperalgesia; $\mathrm{A}=$ affected side; $\mathrm{U}=$ unaffected side; $\mathrm{SD}=$ standard deviation; $\mathrm{IQR}=$ interquartile range. 
TABLE 9.2. Change of quantitative sensory analysis results after twelve months (T5-T1) in patients with and without SCS, and in all patients

\begin{tabular}{llllll}
\hline & $\begin{array}{l}\text { With } \\
\text { implant }\end{array}$ & $\begin{array}{l}\text { Without } \\
\text { implant }\end{array}$ & $p$-values & $\begin{array}{l}\text { Complete } \\
\text { group }\end{array}$ & $p$-values \\
\hline Characteristic & $(\mathrm{n}=24)$ & $(\mathrm{n}=29)$ & $*$ & $(\mathrm{n}=53)$ & $\dagger$ \\
\hline Pressure-gram (median difference, IQR) & & & \\
DT-A & $0(-0.1 / 0.2)$ & $0(-0.2 / 0)$ & .16 & $0(-0.1 / 0.1)$ & .39 \\
DT-U & $0(-0.1 / 0.1)$ & $0(-0.2 / 0)$ & .39 & $0(-0.1 / 0)$ & .17 \\
PT-A & $2.2(0 / 192)$ & $0.2(-0.9 / 6.6)$ & .18 & $0.7(-0.2 / 28)$ & .007 \\
Mechanical Hyperalgesia-0 to 10 scale (median difference, IQR) & \\
DH-A & $-0.4(-1.6 / 0)$ & $0(-0.5 / 0.1)$ & .06 & $-0.1(-1.2 / 0)$ & .007 \\
SH-A & $-0.3(-2.7 / 0)$ & $0(-0.6 / 0.3)$ & .07 & $-0.2(-1.2 / 0)$ & .005 \\
Warmth- ${ }^{\circ} \mathrm{C}$ (mean difference \pm SD) & & & \\
DT-A & $0.1 \pm 1.6$ & $0.4 \pm 1.5$ & .44 & $0.3 \pm 1.5$ & .22 \\
DT-U & $-0.2 \pm 1.8$ & $0.5 \pm 1.5$ & .19 & $0.2 \pm 1.7$ & .43 \\
PT-A & $1.3 \pm 2.4$ & $2.1 \pm 3.2$ & .34 & $1.8 \pm 2.9$ & $<.001$ \\
PT-U & $1.3 \pm 2.5$ & $-0.1 \pm 3.4$ & .12 & $0.5 \pm 3.1$ & .21 \\
Cold-C ${ }^{\circ}$ (mean difference \pm SD) & & & & \\
DT-A & $0.3 \pm 1.8$ & $-0.4 \pm 1.3$ & .11 & $-0.1 \pm 1.6$ & .71 \\
DT-U & $0.1 \pm 1.3$ & $-0.4 \pm 1.3$ & .16 & $-0.2 \pm 1.3$ & .29 \\
PT-A & $-3.3 \pm 6.7$ & $-5.0 \pm 7.7$ & .38 & $-4.2 \pm 7.3$ & $<.001$ \\
PT-U & $-4.1 \pm 5.6$ & $-3.1 \pm 7.8$ & .59 & $-3.6 \pm 6.9$ & $<.001$ \\
\hline
\end{tabular}

${ }^{*} p$-values for the difference between $T_{5}-T_{1}$ change score of the group with implant $(n=24)$ and the group without implant $(n=29)$.

$\dagger p$-values for the difference between $T_{1}$ and $T_{5}$ scores of the complete group of patients $(n=53)$. $\mathrm{DT}=$ detection threshold; $\mathrm{PT}=$ pain threshold; $\mathrm{DH}=$ dynamic hyperalgesia; $\mathrm{SH}=$ static hyperalgesia; $\mathrm{A}=$ affected side; $\mathrm{U}=$ unaffected side; $\mathrm{SD}=$ standard deviation; $\mathrm{IQR}=$ interquartile range.

for the complete group of patients $(n=53)$. On the unaffected, side the changes of SCS patients and controls between T1 and T5 were not significantly different. Of the complete group of patients $(n=53)$, only the cold pain threshold changed on the unaffected side $(p<0.001)$. The findings obtained on the affected side are described below.

\section{Detection thresholds}

Figure 9.3 shows the absolute detection thresholds for pressure, warmth and cold over the study period. Warmth and cold detection thresholds were not influenced by SCS. At T5, the pressure detection threshold did not differ significantly from the $\mathrm{T} 1$ threshold. However, at one $(\mathrm{T} 2, p=0.04)$ and three $(\mathrm{T} 3, p=0.03)$ months following implantation, SCS patients demonstrated mechanical hypoesthesia.

Detection thresholds of the complete group of patients $(n=53)$ did not change between T1 and T5 (Table 9.2). 


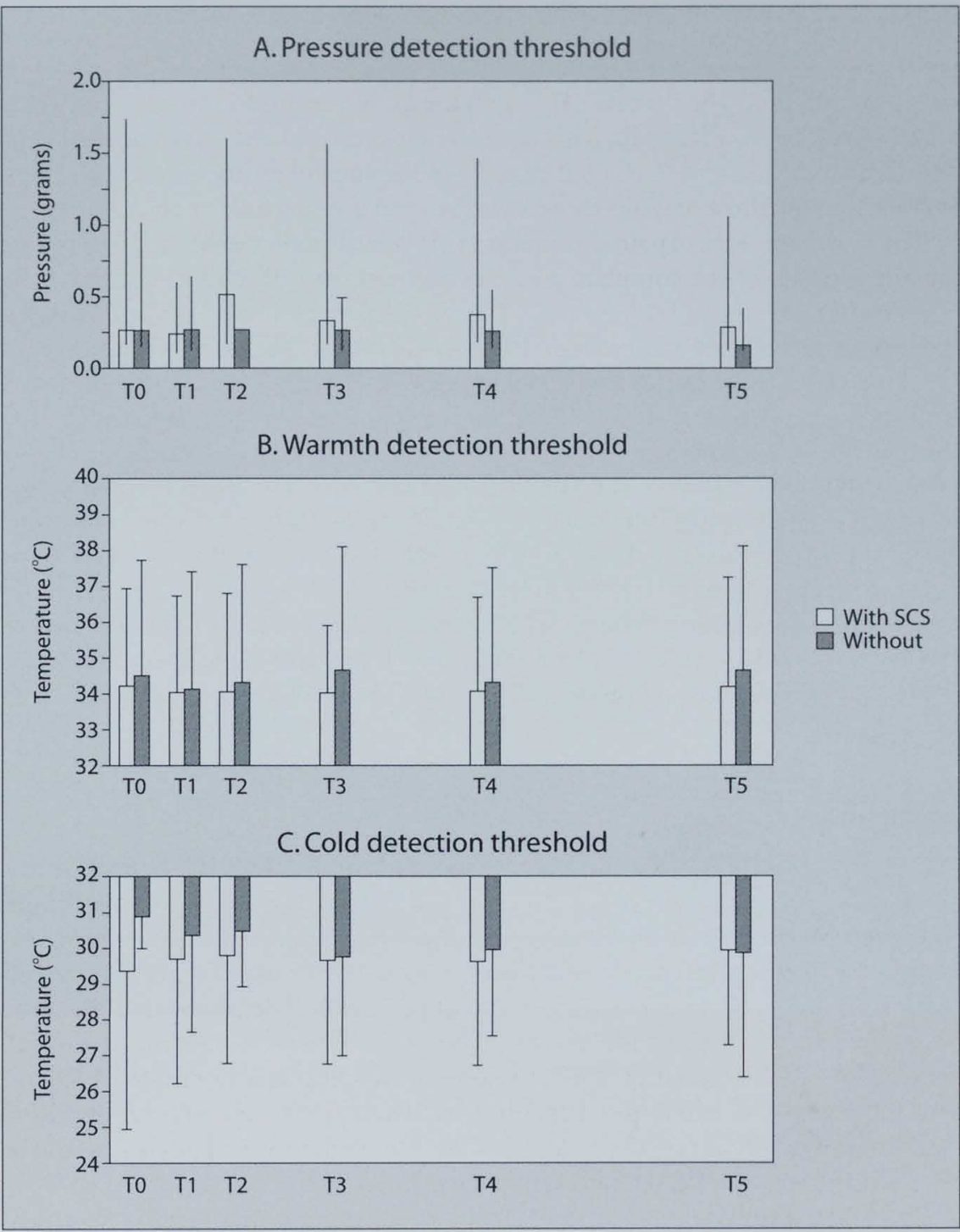

Figure 9.3. Detection thresholds for pressure (A), warmth (B) and cold (C) of RSD patients with SCS (white) or without (shaded). Results for pressure detection are presented as medians with interquartile ranges; warmth and cold detection as means and standard deviations. $\mathrm{T} 0=$ baseline; $\mathrm{T} 1=$ before implantation; $\mathrm{T} 2=$ one month after $\mathrm{T} 1 ; \mathrm{T} 3=$ three months after $\mathrm{T} 1 ; \mathrm{T} 4=$ six months after $\mathrm{T} 1$; and $\mathrm{T} 5=$ twelve months after $\mathrm{T} 1$. 


\section{Pain thresholds}

Figure 9.4 shows the absolute pain thresholds for pressure, warmth and cold over the 12-month follow-up period. Although the graphs seems to show an increase in the pain threshold of SCS patients (especially for pressure), this increase was found not to differ significantly from the increase in the control group (Table 9.2). Thus, SCS showed no effect on pain thresholds for pressure, warmth or cold.

The visible increase of pain thresholds in Figure 9.4 could be measured by testing the affected side of the complete group of patients $(n=53)$ : pain thresholds were significantly warmer and colder at T3, T4 and T5 $(p<0.005)$ as compared with T1. In the case of pressure pain thresholds, this type of effect was found only at T5 $(p=0.007)$ (Table 9.2).

\section{Mechanical hyperalgesia}

The extent of both dynamic and static hyperalgesia were reduced in the SCS group, but not in the control group (Figure 9.5). In the SCS group, the median value of dynamic hyperalgesia reduced by $0.4(p=0.06)$ and the median value of static hyperalgesia by $0.3(p=0.07)$ on a scale from zero to 10 .

Although the decrease of mechanical hyperalgesia between T1 and T5 was not statistically different for SCS patients and controls, the complete group of patients showed a significant reduction of both dynamic $(p=0.007)$ and static hyperalgesia $(p=0.005)$.

\section{Discussion}

Our study-the first randomized controlled trial on SCS in RSD-provides evidence that in chronic RSD patients, SCS neither reduces positive sensory symptoms (it caused no rise of pain thresholds or reduction of hyperalgesia), nor produces negative sensory symptoms (it generated no long-term raise of detection thresholds). Another study with the same group of patients has demonstrated that with strict selection procedures and successful test stimulation, SCS reduces pain, improves health-related quality of life, but does not change functional status (Chapter 7). Pain due to normally painless stimuli (allodynia) is a frequently reported and disabling complaint in RSD. ${ }^{6}$ The fact that SCS does not relieve allodynia should be clearly communicated to potential candidates for this treatment.

Since SCS stimulates in the main A $\beta$ fibers, it is conceivable that the treatment affects the normal functioning of such sensory fibers. Indeed, previous studies have reported diminished sensations of vibration and touch during SCS treatment, ${ }^{9}$ and demonstrated that during peripheral nerve stimulation the evoked SSEP is longer in latency and lower in amplitude, and is also accompanied clinically by a rise in the touch threshold. ${ }^{7}$ However, these investigations involved small groups (in one case, five and in the other case, eight subjects) and focussed purely on short-term effects. Nevertheless, the present study has confirmed the findings in these small patient groups. Interestingly, however, we found that the initial increase of the pressure 


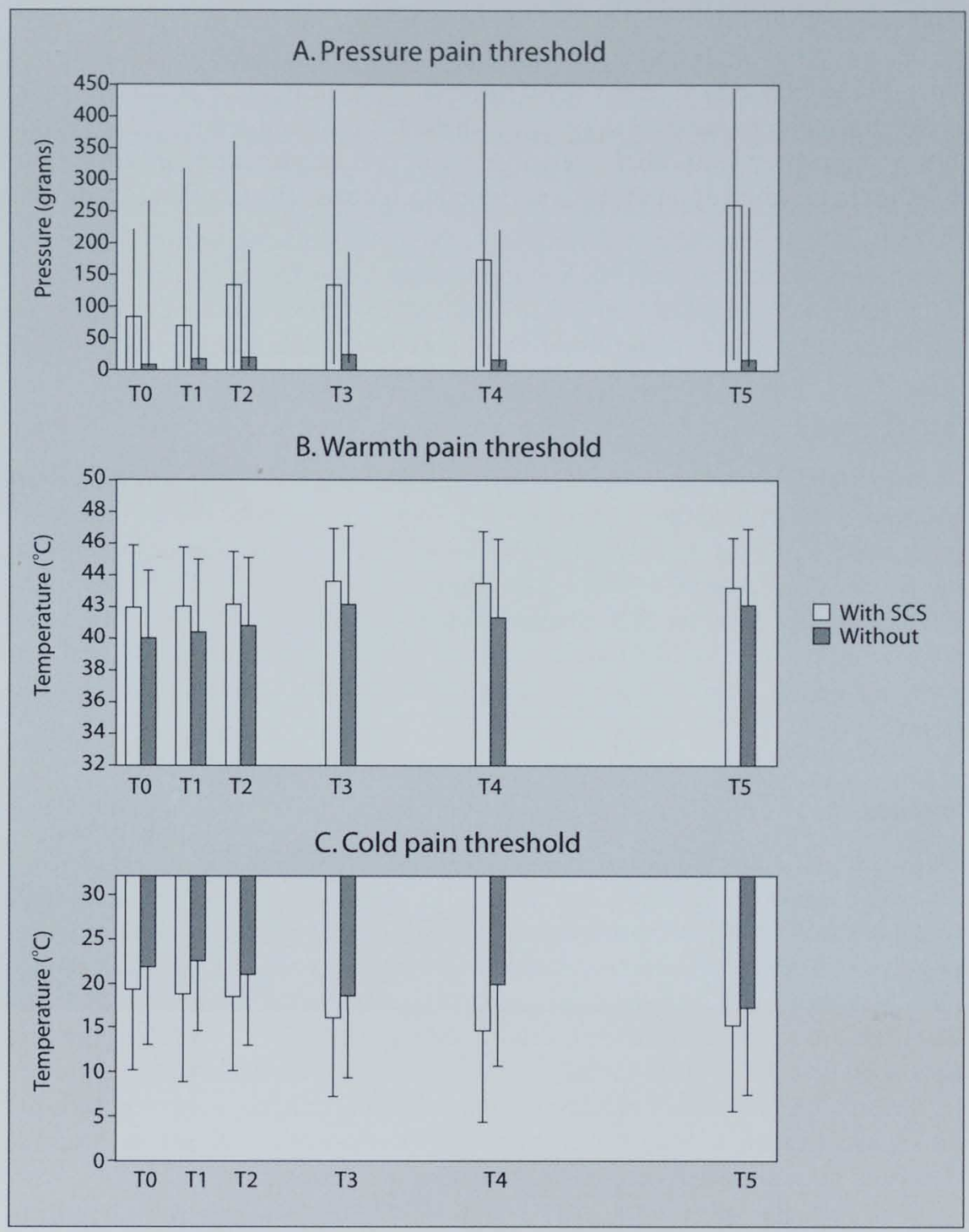

Figure 9.4. Pain thresholds for pressure (A), warmth (B) and cold (C) of RSD patients with SCS (white) or without (shaded). Results for pressure pain are presented as medians with interquartile ranges; warmth and cold pain as means and standard deviations. $\mathrm{T} 0=$ baseline; $\mathrm{T} 1=$ before implantation; $\mathrm{T} 2=$ one month after $\mathrm{T} 1 ; \mathrm{T} 3=$ three months after $\mathrm{T} 1 ; \mathrm{T} 4=$ six months after $\mathrm{T} 1$; and $\mathrm{T} 5=$ twelve months after $\mathrm{T} 1$. 
detection threshold in the SCS group faded after three months and that at six and twelve months SCS patients again demonstrated detection thresholds similar to those of non-implanted patients. This observation indicates that SCS indeed may stimulate $A \beta$ fibers, initially interfering with the normal conduction of these fibers. In time, however, the $A \beta$ fibers seemingly adapt to the distracting electricity from the stimulator, whereupon the original function returns. The fact that SCS did not

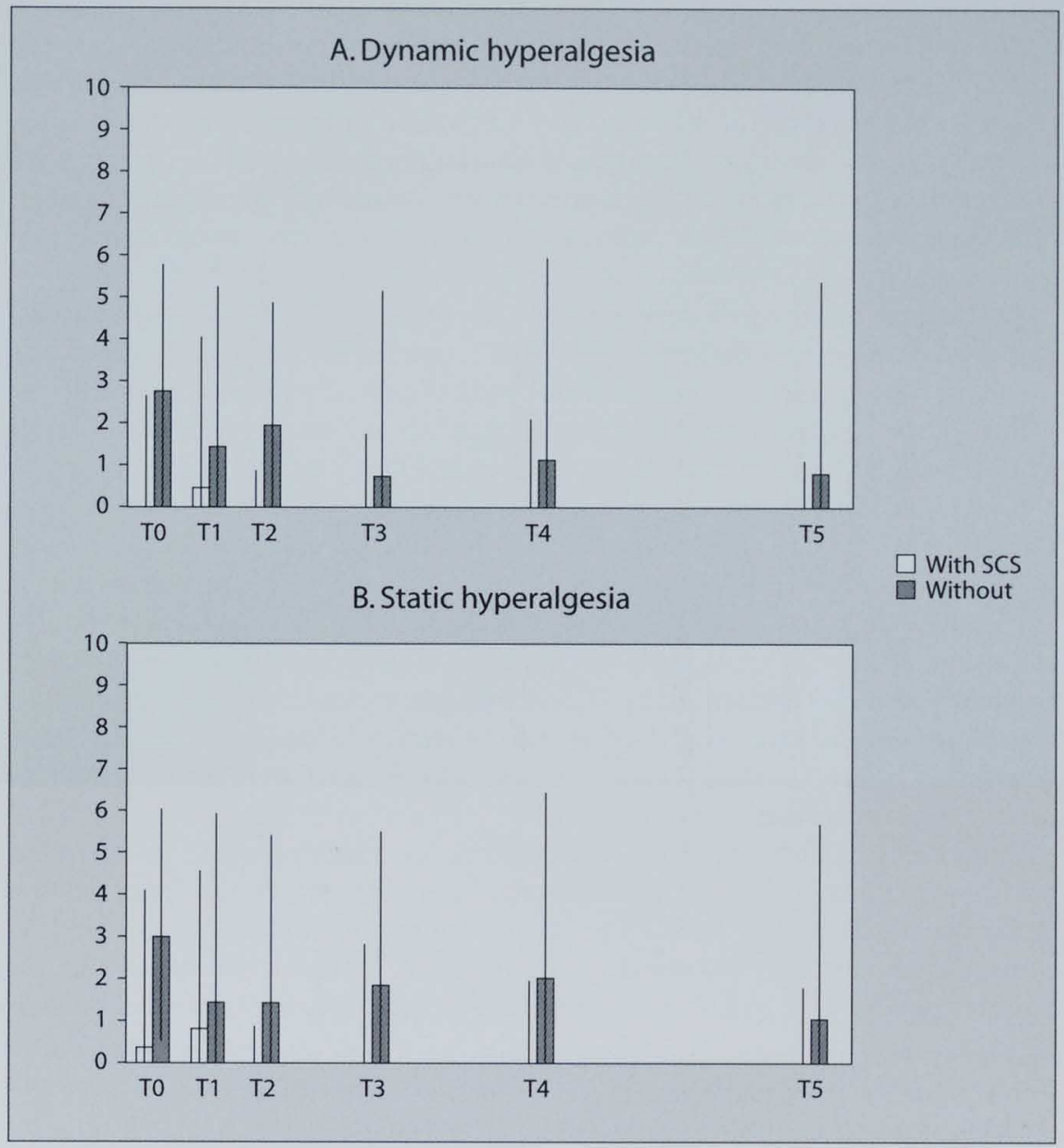

Figure 9.5. Pain scores on a 0 to 10 scale for slightly stroking the skin (dynamic hyperalgesia) or for gentle manual pressure (static hyperalgesia) of RSD patients with SCS (white) or without (shaded). Results are presented as medians with interquartile ranges. $\mathrm{T} 0=$ baseline; $\mathrm{T} 1=$ before implantation; $\mathrm{T} 2=$ one month after $\mathrm{T} 1 ; \mathrm{T} 3=$ three months after $\mathrm{T} 1 ; \mathrm{T} 4=$ six months after $\mathrm{T} 1$; and $\mathrm{T} 5=$ twelve months after $\mathrm{T} 1$. 
influence warmth and cold detection thresholds can be considered indirect evidence that electrical stimulation does not affect $\mathrm{A} \delta$ or $\mathrm{C}$ fiber function.

Although, in our study, SCS in all cases was set to treat one extremity, additional stimulation of the contralateral extremity often could not be prevented. This sideeffect appeared not to affect normal sensibility, since detection thresholds of the unaffected extremity did not change significantly during 12 months of follow-up.

Pain thresholds for pressure, warmth and cold increased significantly in the complete group of patients, but the changes were not significantly different for SCS and control patients. Apparently, the application of quantitative sensory tests in itself would seem to have some desensitizing effect on thresholds of all patients. Apart from habituation, this effect may be explained by the fact that psychophysical tests are influenced by the attention and motivation of test subjects. Simply performing the tests can cause adaptation of subjects to extreme pressure, heat or cold; on successive assessments, subjects may accept increasingly higher stimuli. This finding stresses that treatment evaluation by quantitative sensory tests cannot reliably be conducted in the absence of a control group.

Mechanical hyperalgesia appeared to be the only sensory characteristic that remained reduced in SCS patients, even after 12 months. Effect of SCS has also been found for heat hyperalgesia by Marchand and colleagues. ${ }^{8}$ However, the reduction of both dynamic and static hyperalgesia in our study was smaller than 0.5 on a scale from zero to 10 and not statistically significant. Therefore, this finding might be considered of limited value for the outcome of individual patients. Studies on neuropathic pain patients have indicated that dynamic hyperalgesia is mediated by myelinated A fibers, whereas static hyperalgesia depends on unmyelinated afferents. ${ }^{17}$ Hence, our finding of reduced mechanical hyperalgesia is also of limited value since other pain measures of $A \beta$ (mechanical allodynia) and $C$ fibers (warmth allodynia) were not influenced by SCS. A possible explanation for the changes in mechanical hyperalgesia might be that this measure is dependent on reported pain scores. It is arguable that such measures can easily be influenced, since patients are likely to remember their previous scores.

The effect of clinical use of SCS, considered as a management trial, ${ }^{18}$ was studied using an intention-to-treat analysis (Chapter 7). In that study, one third of patients in the 'intention-to-treat' SCS+PT group did not respond to test stimulation positively and consequently did not receive an implant. Since, on the other hand, the present project was aimed at assessing the effect of SCS treatment on sensory characteristics, the non-implanted patients in the SCS+PT group would have clouded the issue. Therefore, this study has focussed mainly on the implant effect analysis, comparing patients with a SCS-system to those without.

Most work assessing the effect of SCS on experimental detection and pain thresholds is now somewhat dated., ${ }^{9,20,21}$ The main aim of these studies had been to find a measure that could objectively evaluate the effect of SCS. They attempted to extrapolate quantitative sensory test results into some kind of measure of subjectively perceived pain; for example attempts to express pain relief in degrees centi- 
grade. ${ }^{22}$ Nowadays, it is commonly accepted that pain is not a homogeneous sensation, but a constellation of different sensitivities in normal and diseased states. The same symptom may be produced by different mechanisms; and, conversely, a single mechanism may elicit different symptoms. ${ }^{23}$ This implies that subjectively perceived pain is not necessarily parallelled by an increase in experimental pain from various stimuli and, likewise, relief of subjectively perceived pain does not have to be correlated with relief of experimental pain. Hence, the original aim of applying quantitative sensory analyses as objective pain measurements is theoretically impossible. However, presence of important disabling sensory symptoms, such as allodynia and hypoesthesia can be measured exactly only by such sensory analyses. In addition, the acquired information is of value for the classification of pain, ${ }^{23}$ and may help to reveal why SCS results in pain relief.

In summary, although SCS has been shown to produce significant relief of pain in chronic RSD, the present study has demonstrated that the treatment has no effect on experimental pain thresholds for pressure, warmth and cold, and only a slight influence on the extent of dynamic and static hyperalgesia. In addition, SCS appeared not to produce negative sensory symptoms, such as an increase of detection thresholds either on treated RSD limbs or on contralateral extremities.

\section{References}

1. Melzack R, Wall PD. Pain mechanisms: a new theory. Science 1965; 150: 971-8.

2. Campbell JN, Meyer RA. Primary afferents and hyperalgesia. In: Yaksh TL, ed. Spinal afferent processing. New York: Plenum Press, 1986: 59-81.

3. Hautvast RW, DeJongste MJ, Staal MJ, van Gilst WH, Lie KI. Spinal cord stimulation in chronic intractable angina pectoris: a randomized, controlled efficacy study. Am Heart J 1998; 136: 1114-20.

4. North RB, Kidd DH, Zahurak M, James CS, Long DM. Spinal cord stimulation for chronic, intractable pain: experience over two decades. Neurosurgery 1993; 32: 38494.

5. Theuvenet PJ, Dunajski Z, Peters MJ, van Ree JM. Responses to median and tibial stimulation in patients with chronic neuropathic pain. Brain Topogr 1999; 11: 305-13.

6. Verdugo R, Ochoa JL. Quantitative somatosensory thermotest - a key method for functional evaluation of small calibre afferent channels. Brain 1992; 115: 893-913.

7. Campbell JN, Taub A. Local analgesia from percutaneous electrical stimulation. Arch Neurol 1973; 28: 347-50.

8. Marchand S, Bushnell MC, Molina-Negro P, Martinez SN, Duncan GH. The effects of dorsal column stimulation on measures of clinical and experimental pain in man. Pain 1991; 45: 249-57.

9. Lindblom U, Meyerson BA. Influence on touch, vibration and cutaneous pain of dorsal column stimulation in man. Pain 1975; 1: 257-70.

10. Merskey H, Bogduk N. Classification of chronic pain: descriptions of chronic pain syndromes and definitions of pain terms. Seattle: IASP Press, 1994: 40-2.

11. Jensen MP, McFarland CA. Increasing the reliability and validity of pain intensity measurement in chronic pain patients. Pain 1993; 55: 195-203. 
12. Arrindell WA, Ettema JHM. SCL90 Handleiding bij een multidimensionele psychopathologie-indicator. Lisse: Swetz \& Zeitlinger, 1986.

13. Feinstein AR. Clinimetrics. New Haven: Yale University Press, 1987: 91-103.

14. Kemler MA, Barendse GAM, van Kleef M, van den Wildenberg FAJM, Weber WEJ. Electrical spinal cord stimulation in reflex sympathetic dystrophy: retrospective analysis of 23 patients. J Neurosurg 1999; 90(Spine 1): 79-83.

15. Bell-Krotoski JA. Light touch-deep pressure testing using Semmes-Weinstein monofilaments. In: Hunter JM, Schneider LH, Mackin EJ, Callahan AD, ed. Rehabilitation of the hand. St. Louis: The C.V. Mosby Company, 1990: 585-93.

16. Yarnitsky D, Sprecher E. Thermal testing: normative data and repeatability for various test algorithms. J Neurol Sci 1994; 125: 39-45.

17. Ochoa JL, Yarnitsky D. Mechanical hyperalgesias in neuropathic pain patients: dynamic and static subtypes. Ann Neurol 1993; 33: 465-72.

18. Fletcher RH, Fletcher SW, Wagner EH. Clinical epidemiology - the essentials. Baltimore: Williams and Wilkins, 1996; 151-2.

19. Kemler MA, de Vet HCW. Does randomization introduce bias in unblinded trials? Epidemiology 2000; 11: 228.

20. Nashold B, Somjen G, Friedman H. Paresthesias and EEG potentials evoked by stimulation of the dorsal funiculi in man. Exp Neurol 1972; 36: 273-87.

21. Larson SJ, Sances A, Riegel DH, Meyer GA, Dallmann DE, Swiontek T. Neurophysiological effects of dorsal column stimulation in man and monkey. J Neurosurg 1974; 41: 217-23.

22. Price DD. The use of experimental pain in evaluating the effects of dorsal column stimulation on clinical pain. Pain 1991; 45: 225-6.

23. Woolf CJ, Descosterd I. Implications of recent advances in the understanding of pain pathophysiology for the assessment of pain in patients. Pain 1999; Suppl 6: S141. 
CHAPTER 10

\section{Pain Relief in Reflex Sympathetic Dystrophy Due to Spinal Cord Stimulation Does Not Depend on Vasodilation}

Marius A. Kemler, Gerard A.M. Barendse, Maarten van Kleef, and Mirjam G.A. oude Egbrink 


\section{Introduction}

Spinal cord stimulation (SCS) has been used in the treatment of peripheral vascular disease with satisfactory clinical results in terms of increased local blood flow, thus promoting the healing of ischemic ulcers. ${ }^{1-3}$ In studies on healthy rats, SCS has also been shown to cause vasodilation. ${ }^{4,5}$ The mechanisms behind the vasodilatory effect of SCS have not yet been completely elucidated.

Presently, two hypotheses are available to explain the vasodilatory effect of SCS. The first suggests that vasodilation is mediated by an inhibitory effect on sympathetically maintained peripheral vasoconstriction. ${ }^{6}$ The second regards antidromic vasodilation, probably mediated via A-delta fibers in the higher part of the velocity spectrum for this fiber group, as the potential mechanism. ${ }^{5}$ There is evidence that the effect of antidromic vasodilation is mediated by calcitonin gene-related peptide (CGRP) and that the mechanism is nitric oxide dependent., ${ }^{7,8}$

Chronic reflex sympathetic dystrophy (RSD) is a neuropathic pain sydrome. For many years, the syndrome has been considered to result from a hyperactivity of the sympathetic nervous system. ${ }^{9,10}$ However, recent studies have shown that in chronic RSD sympathetic activity appears to be decreased: the vasoconstrictive response to dependency (defined as skin blood flow at heart level divided by skin blood flow in the dependent position) is attenuated in RSD patients, whereas the vasoconstrictor responses to stimulation of intramural adrenergic nerves is reduced in isolated subcutaneous arteries taken from these patients. ${ }^{11}$ In RSD, SCS seems to be successful in relieving pain in more than 50 percent of patients who proved unresponsive to other types of treatment. ${ }^{12,13}$ Little is known about the mechanism behind this beneficial effect. Experimental studies demonstrate that in the dorsal horn the concentration of the inhibiting neurotransmitter gamma-amino butyric acid (GABA), the levels of which are markedly reduced in animals submitted to peripheral nerve lesions, ${ }^{14}$ increases after SCS. ${ }^{15,16}$ Increased GABA levels may result in pain relief.

However, in addition to neuropathic pain components, pain in RSD may be aggravated by disturbed blood flow through the skin. ${ }^{17}$ In most patients, the symptomatic skin is abnormally cold as a consequence of vasospasm, because of sympathetic denervation supersensitivity, caused by dropout of sympathetic efferents. ${ }^{18}$ In addition, both capillary blood cell velocity values - a measure of the nutritive skin capillaries - and laser Doppler flowmetry values--providing an index of thermoregulatory shunt vessels-are significantly lower in the skin of RSD patients as compared with healthy controls. ${ }^{19}$ Dysregulation of peripheral blood flow has been suggested to cause activation of peripheral nociceptors, resulting in pain and swelling. ${ }^{20}$

In the present study, the specific effect of SCS on the skin microcirculation was measured with laser Doppler flowmetry in RSD patients with a low sympathetic tone. We have tried to assess whether SCS improves or otherwise influences the microvascular blood flow. The aim of the study was to answer the following questions: 
1. Is pain relief in RSD after SCS dependent on vasodilation?

2. What explains the vasodilatory effect of SCS? (Is the effect dependent on a normal sympathetic tone?)

\section{Materials and Methods}

Subjects

Enrollment in the study was considered when patients met the following criteria: age between 18 and 65 years; RSD according to diagnostic criteria of the International Association for the Study of Pain $;^{21}$ RSD clinically restricted to one extremity, but at least affecting the whole hand or the whole foot; duration of RSD of at least six months; a mean pain intensity of at least 5 , as measured on a visual analog scale (VAS) ranging from 0 (no pain) to 10 (very severe pain), according to Jensen; ${ }^{22}$ and no lasting success of standard therapy, including medication, six months of physical therapy, transcutaneous electrical nerve stimulation and sympathetic blocks (radiofrequency, chemical neurolysis or surgery). Hence, because of prior sympathectomies all included patients had a low sympathetic tone. Exclusion criteria were a previous diagnosis of Raynaud's disease; (a history of) neurological abnormalities, not related to RSD; conditions affecting function of the diseased or the contralateral extremity, other than RSD itself; blood clotting disturbances or anticoagulant drug therapy; and an implanted cardiac pacemaker. Test stimulation was performed in order to assess whether patients respond to SCS positively. The decision to implant the permanent SCS-system was made when during the last four days of the testing period a $50 \%$ decrease in original VAS score was measured, or if the patient reported 'much improvement' on a seven-point GPE scale, indicating worst ever, much worse, worse, not improved/not worse, improved, much improved, and best ever; these implantation criteria have been described previously. ${ }^{12}$ Of 36 patients who met the criteria, 24 responded to test stimulation positively; two of these patients refused to take part in the study.

We thus studied 22 patients -8 men and 14 women-suffering from chronic RSD of one entire hand or foot. The mean age (SD) was $42 \pm 11$ years, and the mean duration of RSD (SD) was $38 \pm 29$ months. In 14 cases an arm was affected and in 8 cases a leg. Seventeen patients suffered from mechanical allodynia. Implantation of the SCS-system (Itrel 3, model 7425, Medtronic, Minneapolis, MN) had been performed one month before the study started. Patients could control stimulation intensity by adjusting the amplitude from 0 to $10 \mathrm{~V}$ with a patient programmer, whereas the rate was fixed at $85 \mathrm{~Hz}$ and pulse width at $210 \mu \mathrm{sec}$. SCS paresthesiae covered the complete affected area.

Twenty-four hours before the assessment of skin blood flow started, the SCSsystem was switched off and subjects were required to stop smoking. As stated previously, none of the patients responded to pain medication and, consequently, none of the patients used them. The patients also did not use any other medication. To achieve acclimatization, subjects were seated in the investigation room 30 minutes 
before the start of the assessment. All measurements were performed in the morning, starting at 9:30 $\mathrm{AM}$, and were concluded within two hours. Room temperature was maintained between $21^{\circ} \mathrm{C}$ and $23^{\circ} \mathrm{C}$. A group of 20 age-matched volunteers (mean age $38 \pm 8$ years; 6 men and 14 women) served as controls ( 10 controls for each extremity). The study complied with the Declaration of Helsinki regarding investigations in humans and was approved by the Medical Ethics Committee of Maastricht University Hospital; all patients gave written informed consent.

\section{Procedure}

Laser Doppler flowmetry was used to obtain information about total (mainly thermoregulatory) skin blood flow. The laser light illuminates a skin area with a radius of approximately $1 \mathrm{~mm}$ and penetrates the tissue to a depth of several millimeters. ${ }^{23}$ The obtained laser Doppler signal is derived from the Doppler shift of back scattered light and is directly proportional to the microcirculatory blood flow, i.e. the product of the number and mean velocity of the moving blood cells. We applied the output from a $780 \mathrm{~nm}$ diode laser that produced a divergent continuous wave light with a maximum accessible emission of $1 \mathrm{~mW}$ (PeriFlux 4001 Master, Perimed, Järfälla, Sweden) and a standard angled probe. The laser Doppler value was expressed in arbitrary perfusion units; this measure was calibrated using a latex suspension (Perimed) that produces a standard deflection of $2.5 \mathrm{~V}$ or 250 perfusion units. Off-line analysis was performed, using a software programme that had been developed in our institution. Biological zero flow, which is the laser Doppler signal in a 'no flow' situation during arterial occlusion, was subtracted from all laser Doppler values measured.

Using double-sided adhesive tape, the plastic probe holder was attached, without pressure, to either the pulp of the great toe, or to the pulp of the third finger. Next, the probe itself was secured to the holder. The cable was suspended to avoid pressure or traction on the skin area under investigation. Laser Doppler flowmetry was performed firstly with the extremity at heart level. Foot patients were tested in the supine position, whereas hand patients sat, with their hands lying on the top of a desk. After measurement of rest flow and peak flow (defined as the maximum flow during reactive hyperemia, after the release of a 3-min arterial occlusion), the procedure was repeated with the extremity in dependent position. For this purpose, foot patients were tested while sitting with their feet hanging from a bench, whereas hand patients sat with their hands $35 \mathrm{~cm}$ below heart level. The laser Doppler probe was kept in place while the patients changed position. The change of posture itself did not influence the patients' pain. This complete procedure was firstly performed on the unaffected side and then on the affected side. The SCS-system was then switched on and, as soon as the patient reported to perceive the usual pain relief, measurements were repeated, firstly on the affected side and then on the unaffected side. Once SCS was started, stimulation intensity remained constant at a level resulting in pain relief. A 3-min adaptation period was inserted in-between the vari- 
ous processes of assessment during which the parameters were able to return to a steady state once more.

In contrast to patients, control subjects were tested once only in similar conditions and starting at the same time. Because thermoregulatory blood flow is not influenced by diurnal variation but may change as a consequence of acclimatization to the experimental conditions, ${ }^{24,25}$ time controls are not required but all measurements should preferably be performed after a standard period of acclimatization. In both patients and controls, our protocol included an acclimatization period of $30 \mathrm{~min}$.

The following parameters were assessed by laser Doppler flowmetry: (1) rest flow, over a 3-min period; (2) peak flow; and (3) the vasoconstriction index, defined as the individual rest flow obtained at heart level divided by the rest flow obtained in dependent position. The vasoconstriction index is to be regarded as an indicator of the effectiveness of the postural vasoconstrictive mechanism, which is primarily sympathetically controlled at the thermoregulatory level of the skin microcirculation. Henriksen clearly showed that the vasoconstriction index is capable of evaluating the sympathetic tone: ${ }^{26,27}$ the lower the vasoconstriction index, the more the vasoconstrictive mechanism - and hence the sympathetic tone - is impaired. The vasoconstriction index has been applied to evaluate sympathetic tone in several recent studies. ${ }^{28-30}$

On two occasions during the experiment, patients rated the pain intensity in the affected extremity on VAS: (1) before the first assessment of the rest flow, while the SCS-system was switched off; and (2) after activation of the SCS-system, as soon as the patient reported perceiving the usual pain relief.

\section{Statistical Analysis}

Because of the asymmetrical distribution, skin perfusion data are presented as medians with their interquartile ranges, i.e. the spread from 25 th to 75 th percentile. The nonparametric Wilcoxon signed rank test was performed to compare data from the affected and the unaffected side, or to assess changes resulting from SCS. Comparison between control and patient values was performed using the MannWhitney test. Change in pain intensity was assessed by means of a paired t-test. Two-sided $\mathrm{P}$ values $<0.05$, after Bonferroni correction for multiple significance tests, were considered statistically significant.

\section{Results}

\section{Baseline values}

The mean (SD) pain intensity of the 22 patients at baseline, while the SCS-system was switched off, was 6.9 (1.7) on VAS.

Microcirculatory baseline values of affected RSD hands, contralateral clinically unaffected hands and healthy control hands are presented in Table 10.1. Both base- 
TAB LE 10.1. Baseline laser Doppler flowmetry values of hands of RSD patients and controls

Controls Patients

$(n=10) \quad(n=14)$

\begin{tabular}{lllll} 
& & & Affected side & Clinically unaffected side \\
\cline { 1 - 2 } \cline { 5 - 5 } Rest flow (PU) & 121 & & 161 & 125 \\
Peak flow (PU) & $(17-188)$ & & $(62-228)$ & $(39-206)$ \\
& 222 & & 256 & 290 \\
Vasoconstriction index & $(179-283)$ & & $(170-408)$ & $(195-351)$ \\
& 1.64 & & $1.07^{*}$ & 1.17 \\
& $(1.22-4.06)$ & $(0.73-1.29)$ & $(0.99-1.33)$ \\
\hline
\end{tabular}

Baseline LDF values of affected RSD hands, contralateral clinically unaffected hands, and healthy control hands presented as median values and interquartile ranges. Rest flow and peak flow are measured with hands at heart level. The vasoconstriction index expresses the heart level to dependency ratio of the rest flow. ${ }^{*} p<0.05$ versus controls. $\quad \mathrm{PU}=$ Perfusion Units.

line rest flow and peak flow values were found not to be different in affected hands, as compared with clinically unaffected hands and control hands. The vasoconstriction index of the affected side was significantly reduced as compared with controls $(p=0.02)$. A similar tendency was noted on the clinically unaffected side $(p=0.07)$.

Microcirculatory baseline values of affected RSD feet, contralateral clinically unaffected feet and healthy control feet are presented in Table 10.2. Similar to the results for RSD hands, baseline rest flow and peak flow values were not found to be different in affected feet as compared with the clinically unaffected side or control feet. As compared with control values, the vasoconstriction index of the affected side was significantly reduced $(p=0.04)$. On the clinically unaffected side, there was a non-significant reduction of the vasoconstriction index $(p=0.08)$.

TABLE 10.2. Baseline laser Doppler flowmetry values of feet of RSD patients and controls

$\begin{array}{ll}\text { Controls } & \text { Patients } \\ (n=10) & (n=8)\end{array}$

\begin{tabular}{lllll} 
& & & Affected side & Clinically unaffected side \\
\cline { 1 - 2 } Rest flow (PU) & 11 & & 6 & 15 \\
Peak flow (PU) & $(8-29)$ & & $(4-41)$ & $(8-49)$ \\
& 121 & & 94 & 121 \\
Vasoconstriction index & $(52-180)$ & & $(25-258)$ & $(66-142)$ \\
& 5.77 & $2.78^{*}$ & 3.57 \\
& $(3.85-9.14)$ & $(1.85-5.27)$ & $(2.18-5.35)$ \\
\hline
\end{tabular}

Baseline LDF values of affected RSD feet, contralateral clinically unaffected feet, and healthy control feet presented as median values and interquartile ranges. Rest flow and peak flow are measured with feet at heart level. The vasoconstriction index expresses the heart level to dependency ratio of the rest flow. $\quad{ }^{*} p<0.05$ versus controls. $\quad \mathrm{PU}=$ Perfusion Units. 


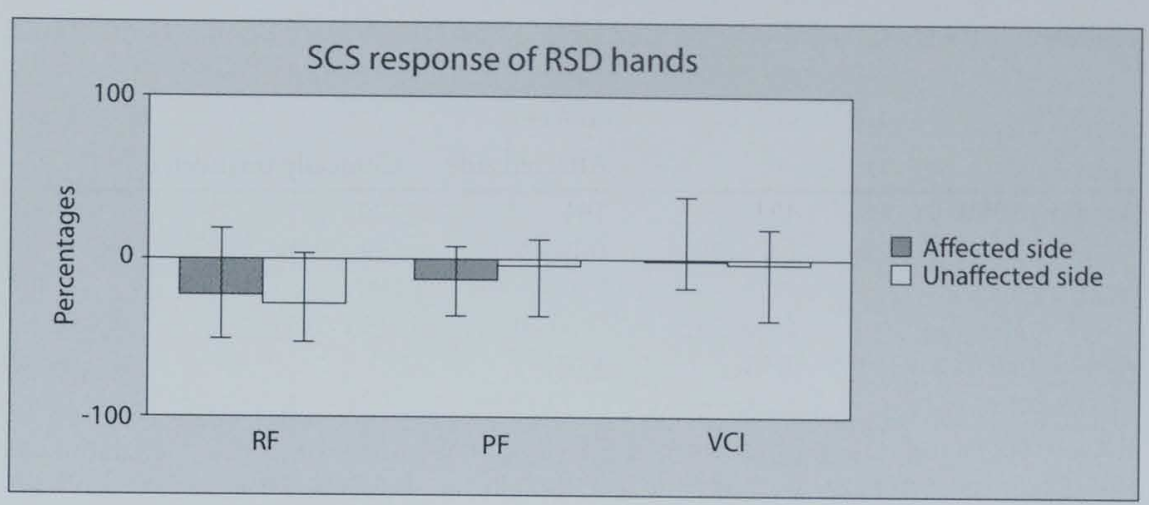

Figure 10.1. Effect of SCS on microcirculatory parameters in affected RSD hands and contralateral clinically unaffected hands, presented as median percentage change from baseline and interquartile ranges. Rest flow (RF) and peak flow (PF) are measured with hands at heart level. The vasoconstriction index (VCI) expresses the heart level to dependency ratio of the rest flow. There are no significant differences from baseline or within groups.

\section{Effect of SCS on microcirculatory parameters}

After activation of the SCS-system, as soon as the patient reported perceiving the usual pain relief, the mean (SD) pain intensity of the 22 patients decreased significantly to $2.2(1.3)$ on VAS $(p<0.001)$. The change in thermoregulatory skin perfusion caused by SCS, if any, was not related to presence or absence of mechanical allodynia.

Figure 10.1 shows the vascular response to SCS in the affected hands of 14 RSD patients. Control responses were obtained from the contralateral clinically unaffected hand, which was in principal not electrically stimulated by SCS and, indeed, showed no statistically significant changes to SCS. However, applying SCS to the affected side did not result in significant microcirculatory changes either. No significant differences were found between the affected and the unaffected side, as far as blood flow changes from baseline under the influence of SCS were concerned.

As demonstrated in Figure 10.2, SCS also had no effect on cutaneous blood flow in the affected feet of eight RSD patients. Both on the affected and unaffected side, no significant changes were noted from baseline, and the recorded changes on the affected and the unaffected side were not significantly different from each other.

\section{Discussion}

The present study failed to show that SCS induces an increase in thermoregulatory skin blood flow in patients with a low sympathetic tone due to RSD and a previous sympathectomy, suggesting the absence of a vasodilatory effect. Therefore, the pain 


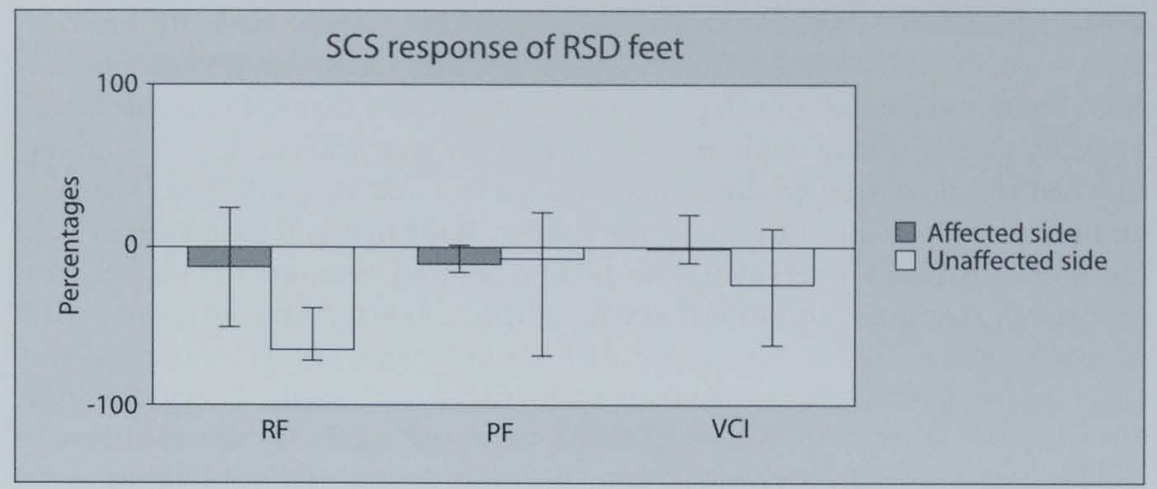

Figure 10.2. Effect of SCS on microcirculatory parameters in affected RSD feet and contralateral clinically unaffected feet, presented as median percentage change from baseline and interquartile ranges. Rest flow (RF) and peak flow (PF) are measured with feet at heart level. The vasoconstriction index (VCI) expresses the heart level to dependency ratio of the rest flow. There are no significant differences from baseline or within groups.

relief in these patients caused by SCS is apparently not mediated by influences of the treatment on skin microcirculation. This result supports the hypothesis that the vasodilatory effect of SCS, which has been measured in patients and animals with a normal sympathetic tone, ${ }^{2-5}$ is due to an inhibitory effect on sympathetically maintained peripheral vasoconstriction.

This is the first study that has applied laser Doppler flowmetry to measure cutaneous blood flow changes secondary to SCS in RSD patients. The laser Doppler signal is primarily generated by movement of blood cells in the thermoregulatory vascular bed, i.e. the subpapillary arterial and venous plexa. ${ }^{31}$ In the area of the finger and toe pulps more than $90 \%$ of the blood flows through this thermoregulatory vascular bed, whereas less than $10 \%$ goes through the nutritional capillaries. ${ }^{31}$ For ethical reasons, the effect of SCS on cutaneous microcirculation in healthy subjects is not attainable; however, because SCS has been shown to improve nutritional $^{2}$ and thermoregulatory ${ }^{3}$ blood flow in humans with severe limb ischemia, as well as thermoregulatory blood flow in rats, ${ }^{4,5}$ it seems appropriate to suggest that in healthy subjects SCS has a vasodilatory effect in the skin.

The high variability in skin perfusion data and the finding that rest flow is lower in feet than in hands are in line with other laser Doppler studies on hands or feet. ${ }^{28-30}$ In addition, since laser Doppler evalues thermoregulatory blood flow, it was to be expected that the figures would be higher in (warm) hands and lower in (cold) feet. In both hands and feet, baseline rest flow and peak flow were similar on the affected and clinically unaffected side and not different from controls. This seems to be contradictory to previous findings, ${ }^{19,32}$ but may be explained by a lacking relationship between disease duration and the stage of RSD. In a large prospec- 
tive patient series, Veldman et al. demonstrated that there is no basis for the classical subdivision of RSD into three consecutive stages-a warm stage, an instable vasomotor stage, and a cold stage. ${ }^{33}$ Their study showed that RSD may start with a cold extremity or may result in a warm extremity after years of disease duration. Reduced rest flow is especially related to stage III (cold stage) disease, whereas a number of the patients included in the present study may still have been in stage I or II disease. Like Kurvers et al, ${ }^{29}$ we did find reduced vasoconstriction indices as compared to controls, indicating that sympathetic tone was decreased in our patient population. Impaired vasoconstrictor responses to dependency of thermoregulatory skin microvessels, which are mainly sympathetically controlled, ${ }^{26-8}$ suggest sympathetic denervation of these vessels..$^{29}$ The vasoconstriction index also tended to be reduced as compared with controls in the clinically unaffected side, although the difference was not statistically significant ( $P$ between 0.05 and 0.1 in both hands and feet). It has previously been reported that the clinically unaffected side in RSD also exhibits microvascular abnormalities as compared with controls. ${ }^{34}$ This has been suggested to indicate that there is a spinal component to microcirculatory abnormalities in RSD, that is initiated by traumatic excitation of a peripheral nerve on the clinically affected side. ${ }^{30}$

Applying SCS to the side of the spinal cord that innervated the RSD extremity did relieve pain, but did not result in any microvascular effect: rest flow, peak flow and vasoconstriction indices all remained constant. Neither were any effects found on the clinically unaffected side, but because the SCS electrode was positioned in such a way that only the affected side was stimulated, this finding was not unexpected. The fact that in our patients SCS failed to increase thermoregulatory skin blood flow, cannot rule out that changes induced by SCS may result from alterations in blood flow in deeper tissues, such as muscles. The animal and human studies that did show alterations in skin perfusion due to SCS also did not measure blood flow in deeper tissues..$^{2-5}$ In addition, a change in flow due to SCS that is restricted to deeper tissues seems unlikely because thermoregulatory blood flow is regulated centrally by the sympathetic nervous system. In controls, skin perfusion measurements were performed once only, implicating that no time controls were used. However, applying time controls would not have influenced the results, because thermoregulatory blood flow is not influenced by diurnal variation, ${ }^{24,25}$ and all measurements were performed within a few hours in identical conditions.

Our data indicate that pain relief in a previously sympathectomized group of RSD patients due to SCS is not secondary to vasodilation. Hence, SCS in RSD can produce pain relief that is not associated with vasodilation. In consequence, the exact mechanism underlying pain alleviation with SCS in RSD patients still remains to be explained. Several neurophysiologic mechanisms have been proposed, for example: simple blocking of pain transmission by a direct effect on the spinothalamic tracts; activation of descending inhibitory pathways; effects on central sympathetic systems; segmental inhibition via coarse fibre activation and brain stem loops; inhibition by increasing GABA levels in the dorsal horn; and thalamo-cortical 
mechanisms masking the nociceptive input. ${ }^{15,16,35-8}$ Further studies are needed to solve this problem, but the net effect will probably be discovered to originate from several sources.

Although we did not find a vasodilatory effect of SCS in RSD patients, our findings may contribute to the discussion on the possible mechanism of this effect in humans. Currently, there are two potential explanations for the cutaneous vasodilatory effect of SCS: (1) an inhibitory effect on efferent sympathetic activity; and (2) an antidromic stimulation of afferent fibers, resulting in a local release of vasoactive substances. Several studies support the idea that the vasodilatory effect of SCS is, to a large extent, mediated by an inhibitory effect on the peripheral vasoconstriction that is maintained via the sympathetic nervous system. ${ }^{4,39}$ In rats, vasodilatory responses were eradicated after any of the following procedures: complete surgical sympathectomy; ${ }^{40}$ blocking nicotinic transmission in the ganglia; and blocking postganglionic $\alpha 1$-adrenoceptors. ${ }^{6}$ Blocking muscarinic transmission in the ganglia or postganglionic $\alpha 2$-adrenoceptors did not alter the effect of SCS, whereas $\beta$-adrenoceptors seemed to be differentially involved in the effects on skin and muscle circulation. ${ }^{6}$

On the other hand, there is evidence that vasodilation during SCS is caused by antidromic activation of sensory afferents in the dorsal roots causing release of calcitonin gene-related peptide in the periphery. After an extensive rhizotomy of the T12-L5 dorsal roots in the rat, SCS no longer increased blood flow in the ipsilateral hindpaw, whereas the same effect was noted after administration of a competitive antagonist of calcitonin gene-related peptide. ${ }^{7}$ The neuronal release of nitric oxide, or the neuronal release of a substance that is nitric oxide-dependent, may also mediate SCS-induced vasodilation, because competitive inhibitors of nitric oxide synthase markedly attenuated cutaneous blood flow increases caused by SCS. ${ }^{8}$ These nitric oxide-dependent nerve fibers do not seem to be reliant on efferent autonomic pathways, because the nicotinic ganglionic antagonist hexamethonium did not affect the cutaneous vasodilation caused by SCS. ${ }^{8}$ However, there must be an additional non-nitric oxide pathway that causes vasodilation, because after giving hexamethonium, nitric oxide synthase inhibitors no longer attenuated the SCS response.

The affected extremities of the RSD patients in the present study all had a low sympathetic tone. Firstly, all patients had undergone previous sympathectomy that had not resulted in pain relief and, hence, their pain type can be classified as sympathetically independent pain ${ }^{9,41,42}$ _in fact, patients responding to sympathetic blocks (sympathetically maintained pain) had been excluded from the study. Secondly, as stated previously, the vasoconstriction index in their affected extremity seemed to be impaired, also indicating a reduced sympathetic activity. Our finding that SCS had no influence on the cutaneous blood flow of these patients supports the autonomic inhibition theory as an explanation for the vasodilation normally found after SCS; in patients with a low sympathetic tone, sympathetic inhibition by SCS cannot have a significant effect. Using microneurography to directly measure sympathetic activity in a patient with causalgia, ${ }^{21}$ it has also been demonstrated that during 
transcutaneous electrical nerve stimulation no apparent changes occurred in the sympathetic outflow. ${ }^{43}$ On the other hand, the results of the present study do not support the antidromic stimulation theory. Antidromic stimulation does not require intact autonomic pathways, so if this theory were the single explanation, SCS should have resulted in cutaneous vasodilation in RSD patients.

In conclusion, the present study has demonstrated that pain relief in RSD due to SCS does not depend on vasodilation. Therefore, it seems unlikely that pain decrease is mediated via sympathetic pathways. In addition, these data support the hypothesis that the vasodilatory effect of SCS, which is present in other situations, is dependent on the sympathetic nervous system.

\section{References}

1. Augustinsson LE, Carlsson CA, Holm J, Jivegård L. Epidural electrical stimulation in severe limb ischemia. Ann Surg 1985; 202: 104-10.

2. Jacobs MJHM, Jörning PJG, Joshi SR, Kitslaar PJEHM, Slaaf DW, Reneman RS. Epidural spinal cord electrical stimulation improves microvascular blood flow in severe limb ischemia. Ann Surg 1988; 207: 179-83.

3. Ghajar AW, Miles JB. The differential effect of the level of spinal cord stimulation on patients with advanced peripheral vascular disease in the lower limbs. Br J Neurosurg 1998; 12: 402-8.

4. Linderoth B, Fedorcsak I, Meyerson BA. Peripheral vasodilation after spinal cord stimulation: animal studies of putative effector mechanisms. Neurosurgery 1991; 28: 187-95.

5. Croom JE, Barron KW, Chandler MJ, Foreman RD. Cutaneous blood flow increases in the rat hindpaw during dorsal column stimulation. Brain Res 1996; 728: 281-6.

6. Linderoth B, Herregodts P, Meyerson BA. Sympathetic mediation of peripheral vasodilation induced by spinal cord stimulation: animal studies of the role of cholinergic and adrenergic receptor subtypes. Neurosurgery 1994; 35: 711-19.

7. Croom JE, Foreman RD, Chandler MJ, Barron KW. Cutaneous vasodilation during dorsal column stimulation is mediated by dorsal roots and CGRP. Am J Physiol 1997; 272: H950-H957.

8. Croom JE, Foreman RD, Chandler MJ, Koss MC, Barron KW. Role of nitric oxide in cutaneous blood flow increases in the rat hindpaw during dorsal column stimulation. Neurosurgery 1997; 40: 565-70.

9. Blumberg H, Jänig W. Clinical manifestations of reflex sympathetic dystrophy and sympathetically maintained pain, Textbook of pain. Edited by Wall PD, Melzack R. Edinburgh, Churchill Livingstone, 1994, pp 685-98.

10. Kurvers HAJM. Reflex sympathetic dystrophy: facts and hypotheses. Vasc Med 1998; 3: 207-14.

11. Kurvers HAJM. Reflex sympathetic dystrophy: a clinical and experimental study. Department of Surgery. Maastricht. Maastricht University, 1997.

12. Kemler MA, Barendse GAM, van Kleef M, van den Wildenberg FAJM, Weber WEJ. Electrical spinal cord stimulation in reflex sympathetic dystrophy: retrospective analysis of 23 patients. J Neurosurg 1999; 90 (Spine 1): 79-83.

13. Simpson BA. Spinal cord stimulation. Pain Rev 1994; 1: 199-230. 
14. Stiller CO, Cui JG, O'Connor WT, Brodin E, Meyerson BA, Linderoth B. Release of gamma-aminobutyric acid in the dorsal horn and suppression of tactile allodynia by spinal cord stimulation in mononeuropathic rats. Neurosurgery 1996; 39: 367-74.

15. Linderoth B, Stiller CO, Gunasekera L, O'Connor WT, Ungerstedt U, Brodin E. Gamma-aminobutyric acid is released in the dorsal horn by electrical spinal cord stimulation: an in vivo microdialysis study in the rat. Neurosurgery 1994; 34; 484-8.

16. Cui JG, O'Connor WT, Ungerstedt U, Linderoth B, Meyerson BA. Spinal cord stimulation attenuates augmented dorsal horn release of excitatory amino acids in mononeuropathy via a GABAergic mechanism. Pain 1997; 73: 87-95.

17. Baron $\mathrm{R}$, Blumberg $\mathrm{H}$, Jänig $\mathrm{W}$. Clinical characteristics of patients with complex regional pain syndrome in Germany with special emphasis on vasomotor function, Reflex sympathetic dystrophy: a reappraisal. Edited by Jänig W, Stanton-Hicks M. Seattle, IASP Press, 1996, pp 25-48.

18. Ochoa JL, Yarnitsky D. The triple cold syndrome. Cold hyperalgesia, cold hypoesthesia and cold skin in peripheral nerve disease. Brain 1994; 117: 185-97.

19. Rosén L, Östergren J, Fagrell B, Stranden E. Skin microvascular circulation in the sympathetic dystrophies evaluated by videophotometric capillaroscopy and laser Doppler fluxmetry. Eur J Clin Invest 1988; 18: 305-8.

20. Blumberg H, Griesser HJ, Hornyak ME. Mechanisms and role of peripheral blood flow dysregulation in pain sensation and edema in reflex sympathetic dystrophy, Reflex sympathetic dystrophy. Edited by Stanton-Hicks M, Jänig W, Boas RA. Boston, Kluwer Academic Publishers, 1990, pp 81-95.

21. Merskey H, Bogduk N. Classification of chronic pain: descriptions of chronic pain syndromes and definitions of pain terms. Seattle, IASP Press, 1994.

22. Jensen MP, McFarland CA. Increasing the reliability and validity of pain intensity measurement in chronic pain patients. Pain 1993; 55: 195-203.

23. Fagrell $B$, Intaglietta $M$, Tsai AG, Östergren J. Combination of laser Doppler flowmetry and capillary microscopy for evaluating the dynamics of skin microcirculation, Techniques in clinical capillary microscopy, Vol. 11. Edited by Mahler F, Messmer K, Hammersen F. Basel, Karger, 1986, pp 125-38.

24. Sundberg $\mathrm{S}$. Acute effects and long-term variations in skin blood flow measured with laser Doppler flowmetry. Scand J Clin Lab Invest 1984; 44: 341-5.

25. Houben AJ, Slaaf DW, Huvers FC, de Leeuw PW, Nieuwenhuijzen Kruseman AC, Schaper NC. Diurnal variation in total and skin microcirculatory blood flow in man. Scand J Clin Lab Invest 1994; 54: 161-8.

26. Henriksen O. Local nervous mechanism in regulation of blood flow in human subcutaneous tissue. Acta Physiol Scand 1976; 97: 385-91.

27. Henriksen $O$. Local reflex in microcirculation in human subcutaneous tissue. Acta Physiol Scand 1976; 97: 447-56.

28. Ubbink DT, Jacobs MJHM, Slaaf DW, Tangelder GJ, Reneman RS. Microvascular reactivity differences between the two legs of patients with unilateral lower limb ischaemia. Eur J Vasc Surg 1992; 6: 269-75.

29. Kurvers HAJM, Jacobs MJHM, Beuk RJ, van den Wildenberg FAJM, Kitslaar PJEHM, Slaaf DW, Reneman RS. Reflex sympathetic dystrophy: result of autonomic denervation? Clin Sci 1994; 87: 663-9. 
30. Kurvers HAJM, Jacobs MJHM, Beuk RJ, van den Wildenberg FAJM, Kitslaar PJEHM, Slaaf DW, Reneman RS. Reflex sympathetic dystrophy: the spinal component to skin blood flow abnormalities. Arch Neurol 1996; 53: 58-65.

31. Fagrell B. Advances in microcirculation network evaluation: an update. Int J Microcirc 1995; 15(suppl 1): 34-40.

32. Kurvers HAJM, Jacobs MJHM, Beuk RJ, van den Wildenberg FAJM, Kitslaar PJEHM, Slaaf DW, Reneman RS. Reflex sympathetic dystrophy: evolution of microcirculatory disturbances in time. Pain 1995; 60: 333-40.

33. Veldman PHIM, Reynen HM, Arntz IE, Goris RJA. Signs and symptoms of reflex sympathetic dystrophy: prospective study of 829 patients. Lancet 1993; 342: 1012-16.

34. Rosén L, Östergren J, Roald OK, Stranden E, Fagrell B. Bilateral involvement and the effect of sympathetic blockade on skin microcirculation in the sympathetic dystrophies. Microvasc Res 1989; 37: 289-97.

35. Linderoth B. Dorsal column stimulation and pain: experimental studies of putative neurochemical and neurophysiological mechanisms. Department of Neurosurgery. Stockholm. Karolinska Institutet, 1992.

36. Roberts MHT, Rees H. Physiological basis of spinal cord stimulation. Pain Reviews 1994; 1: 184-98.

37. Roberts MHT. Physiological mechanisms activated by stimulation of the dorsal columns, Spinal cord stimulation: an innovative method in the treatment of PVD and angina. Edited by Horsch S, Claeys L. Darmstadt, Steinkopff Verlag, 1995, pp 3-9.

38. Stiller CO, Linderoth B, O'Connor WT, Franck J, Falkenberg T, Ungerstedt U, Brodin E. Repeated spinal cord stimulation decreases the extracellular level of gammaaminobutyric acid in the periaqueductal grey matter of freely moving rats. Brain Res 1995; 699: 231-41.

39. Linderoth B, Gherardini G, Ren B, Lundeberg T. Preemptive spinal cord stimulation reduces ischemia in an animal model of vasospasm. Neurosurgery 1995; 37: 266-71.

40. Linderoth B, Gunasekera L, Meyerson BA. Effects of sympathectomy on skin and muscle microcirculation during dorsal column stimulation. Neurosurgery 1991; 29: 874-9.

41. Wilson PR. Reflex sympathetic dystrophy, Clinical autonomic disorders. Edited by Low PA. Philadelphia, Lippincott Raven Publishers, 1997, 537-43.

42. Schott GD. An unsympathetic view of pain. Lancet 1995; 345: 634-6.

43. Torebjörk HE, Hallin RG. Microneurographic studies of peripheral pain mechanisms in man, Advances in Pain Research and Therapy. Vol. 3. Edited by Bonica JJ, Liebeskind JC, Albe-Fessard DG. New York, Raven Press, 1979, 121-31. 

CHAPTER $11 a$

\section{Relapsing Ulcerative Colitis Associated With Spinal Cord Stimulation}

Marius A. Kemler, Gerard A.M. Barendse, and Maarten van Kleef 


\section{Introduction}

This case report describes a patient whose ulcerative colitis (UC) relapsed on two consecutive occasions after use of a spinal cord stimulation (SCS) system. SCS is a pain-relieving treatment with moderate to good effects in many, but not all, pain syndromes unresponsive to other treatments, ${ }^{1,2}$ including reflex sympathetic dystrophy. ${ }^{3}$ SCS originated as an application of the gate control theory, which states that stimulation of $A \beta$-sensory fibers suppresses $C$-sensory fiber activity, resulting in pain relief. ${ }^{4}$ However, the exact mechanism is unclear. Stimulation of $A \beta$-fibers from the painful area is achieved by delivering electrical current through a lead in the epidural space, positioned on the dorsal aspect of the spinal cord at the level of the nerve roots innervating the painful area. Patients perceive current from the lead as paresthesiae in the painful area. Thus, in successful cases, paresthesiae replace the pain. Current for the lead is supplied by a pulse generator, which is connected to it by an extension lead. Patients are able to reduce or increase the intensity of the current supplied by the pulse generator by means of a patient programmer using radiofrequency transmission. Consequently, pulse generators have to be positioned within easy reach for the patients, usually subcutaneously in the anterior abdominal wall.

To our knowledge, electrical current has not been mentioned among the many factors believed to be capable of influencing the recrudescence of inflammatory bowel disease. ${ }^{5}$ However, direct effects of electricity on mobility, or indirect effects resulting from modulation of the brain-gut axis, however, are both potential mechanisms through which electrical stimulation conceptually might affect the symptoms of inflammatory bowel disease.

\section{Case Report}

A 48-year-old non-smoking man with $\mathrm{UC}$, for which he daily used $500 \mathrm{mg}$ mesalamine orally, suffered from reflex sympathetic dystrophy in his right arm after a Colles' fracture 2 years earlier. The UC, characterized by left-sided disease, extending to the descending colon, had started at 23 years of age. Since onset, two relapses had occurred: at 37 and at 43 years of age. At this time, the UC had been in remission for 5 years. Because the reflex sympathetic dystrophy had not responded to conventional pain treatments, including physical therapy, sympathetic blocks and transcutaneous electrical nerve stimulation, the patient was considered suitable for SCS. During trial stimulation, using a temporary lead (model 3861; Medtronic, Minneapolis, $\mathrm{MN}$ ) in the epidural space at vertebra $\mathrm{C} 4$ and an external stimulator (model 3625; Medtronic), his mean 4-day pain score decreased from 6.1 to $3.3 \mathrm{~cm}$ on a $10-\mathrm{cm}$ visual analog scale. In addition, he reported 'much improvement' on a 7-point scale, whereby he met the criteria for implantation of a SCS system. A complete SCS system was then implanted, consisting of a quadripolar electrode (Pisces Quad lead, model 3487A; Medtronic) in the epidural space at vertebra C4 (Figure 11.1), an extension lead (model 7495-66; Medtronic), and a pulse generator 
(Itrel 3, model 7425; Medtronic) in the subcutaneous tissue in the left-lower anterior abdominal wall. The system was set to give paresthesiae in the entire right arm (stimulating nerve roots C5-C8), using a bipolar stimulation (first electrode negative, third electrode positive) with an amplitude of 1-2 Volts, a rate of 85 pulses/s, and a pulse width of 210 microseconds.

One and a half months after implantation and continuous stimulation, the UC relapsed. This was characterized by nausea, distention, abdominal pain, bloody diarrhea and systemic symptoms such as weight loss and general malaise. Sigmoidoscopy revealed proctosigmoiditis consisting of erythema, with loss of vascular pattern but without superficial ulceration (grade I inflammatory activity). Biopsy showed that, microscopically, UC was characterized by a diffuse inflammatory infiltrate of lymphocytes, plasma cells, and few eosinophils in the lamina propria and damage to intestinal crypts, without crypt abscesses. The erythrocyte sedimentation rate was $33 \mathrm{~mm} / \mathrm{h}$; leucocytes increased to $11.1 \times 10^{9} / \mathrm{L}$. Liver function tests were normal, and albumin level was $41.3 \mathrm{~g} / \mathrm{L}$.

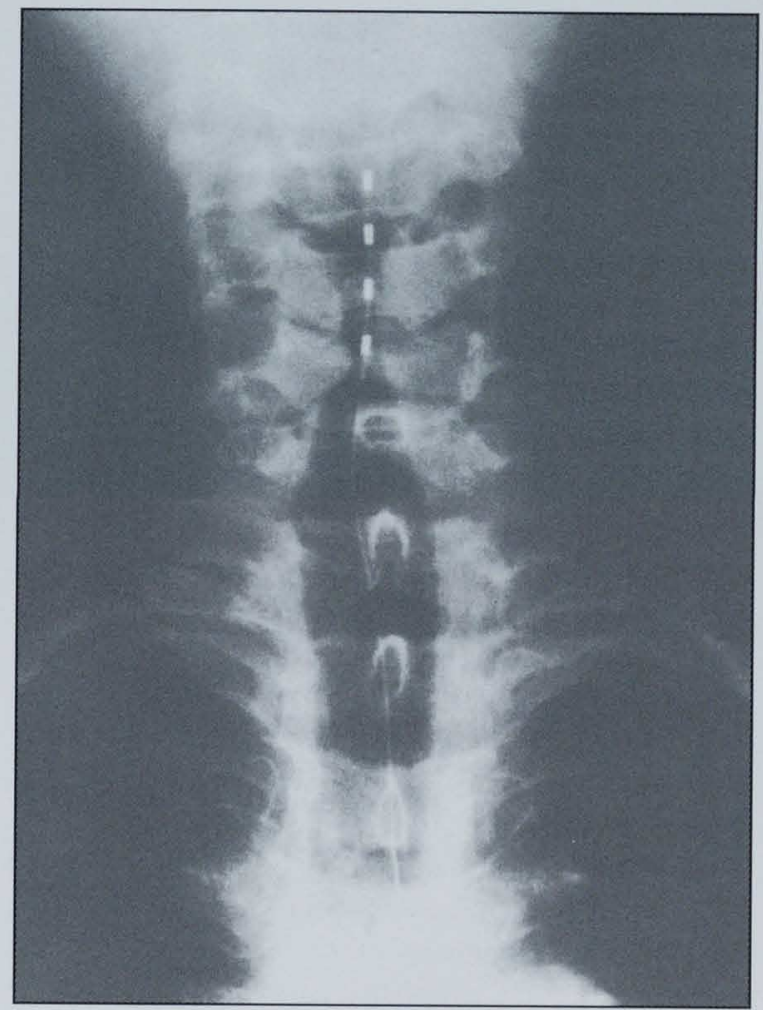

Figure 11.1. Cervical radiograph showing the quadripolar SCS electrode lead. Tip of the lead is at C4. 
The gastroenterologist suggested that UC disease activity might be related to the SCS system. Accordingly, the SCS system was switched off and no longer used. After treatment with mesalamine enemas, the complaints subsided. Because of his fear of a further relapse, the patient was unwilling to return to the SCS system, despite severe pain in his right arm. After reassurance that there was not the least suspicion of a correlation between the relapse and the use of the SCS system, he decided to give the system one more chance, again achieving relief of his arm pain. However, two weeks after the renewed start of treatment, clinical symptoms of UC recurred again, including nausea, abdominal pain, bloody diarrhoea, and general malaise. A similar grade I inflammatory activity was noted by sigmoidoscopy. High doses of mesalamine, given orally and as enemas, eventually resulted in a remission. Remarkably, the patient described that these two relapses had been more severe in terms of abdominal pain, distention, and bowel movements per day than the relapses in the past. After this episode, the patient was no longer willing to accept the assurance that the SCS system was harmless. Fourteen months after implantation, the whole system was removed; in the subsequent year, the UC has remained in remission. The pain in his right arm continues to be severe. The clinical course of the colitis relative to the use of the SCS system is illustrated in Figure 11.2.

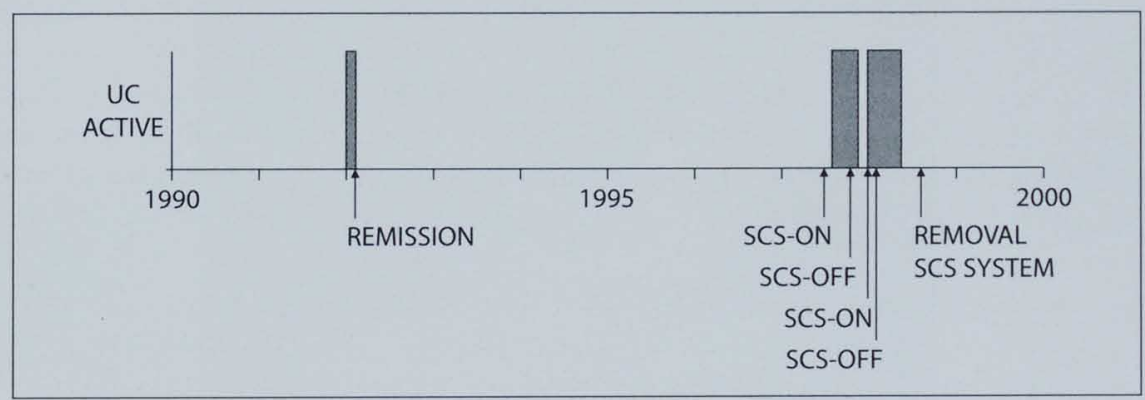

Figure 11.2. Illustration of the clinical course of colitis relative to use of the SCS system.

\section{Discussion}

The natural course of UC is characterized by periods of remission interrupted by relapses, ${ }^{6}$ whose frequency is related to disease activity in the foregoing years. ${ }^{7}$ The fact that within a short period two repeated relapses occurred after use of a SCS system in a patient who had been free of flare-ups for several years, together with the fact that the patient had no relapses after removal of the system, can be seen as evidence against a natural course, suggesting a relationship between the SCS system and relapsing UC. Other potentially confounding influences that may have contributed to the relapses are excluded: the patient was a nonsmoker who in periods of 
severe pain only used paracetamol (maximum, $1000 \mathrm{mg}$ daily). Exposure to other drugs, including antibiotics, did not take place during the time when the two relapses of UC occurred.

Influence of SCS on colonic function could be explained by several mechanisms. First, a direct effect on the gut may be caused by an electromagnetic field (EMF) from the device. Possible health effects of exposure to low-intensity EMFs are presently receiving increased attention in the scientific literature. ${ }^{8}$ In a recent study, EMF of a mobile telephone was shown to increase resting blood pressure, ${ }^{9}$ and use of mobile telephones has been considered a possible cause of interference to cardiac pacemaker function. ${ }^{10}$ No studies have described possible effects of the EMF of the pacemaker itself. Because the pacemaker housing acts like a Faraday cage, current leakage is unlikely. In SCS, in principle, current flows only between two electrodes in the epidural space. Slight defects in the extension lead or in the connection between the pulse generator and the extension lead may bring about an electrical current between the defect and the electrode. Many patients report perceiving paresthesiae in a larger area than originally intended; for example, patients for whom paresthesiae are aimed at the arms often also notice paresthesiae in the legs. Taking all these matters into account, current leakage in the abdominal area is indeed feasible.

Theoretically, the effect of electricity on colonic circular smooth muscle activity is also a possibility; smooth muscle relaxation has been shown during electrical field stimulation in experimental studies. ${ }^{11}$ Voltage levels capable of stimulating large neural structures in the spinal cord should, in principle, also be able to stimulate intramural colonic nerves. The reason cardiac pacemakers are not known to have caused this complication could be that they are never positioned in the abdominal area.

Second, SCS may influence colonic function via the brain-gut axis. ${ }^{12}$ The effect could either be directly, by current affecting normal impulse conduction in the spinal cord (in patients with spinal cord injury the colonic transit time increases significantly ${ }^{13}$ ), or could be peptidergic. One peptide that could be the influencing factor is $\gamma$-aminobutyric acid (GABA). GABA-ergic neurons and nerve fibers are widely distributed in the human colon, ${ }^{14}$ and GABA has been reported to play an important role in the regulation of the peristaltic reflex. ${ }^{15}$ Influence of SCS on colonic peristalsis is an acceptable explanation because SCS induces an increased release of GABA in the dorsal horn. ${ }^{16}$

In summary, the possibility of a correlation between the SCS system and relapsing UC cannot be discounted. Further research is needed to show whether SCS could induce a recurrence of UC, either directly by way of EMFs, or indirectly via influence on the brain-gut axis. In the meantime, caution in using SCS treatment in patients with inflammatory bowel disease is warranted. 


\section{References}

1. Stanton-Hicks $M$, Salomon J. Stimulation of the central and peripheral nervous system for the control of pain. J Clin Neurophysiol 1997; 14: 46-62.

2. Simpson BA. Spinal cord stimulation. Pain Rev 1994; 1: 199-230.

3. Kemler M, Barendse G, van Kleef $M$, van den Wildenberg F, Weber W. Electrical spinal cord stimulation in reflex sympathetic dystrophy: retrospective analysis of 23 patients. J Neurosurg 1999; 90(Spine 1): 79-83.

4. Melzack R, Wall PD. Pain mechanisms: a new theory. Science 1965; 150: 971-978.

5. Jewell DP. Ulcerative colitis. In: Sleisenger MH, Fordtran JS, eds. Gastrointestinal disease: pathophysiology, diagnosis, management. 5th ed. Philadelphia: W.B. Saunders Company, 1993: 1306-1309.

6. Selby W. The natural history of ulcerative colitis. Baillière Clin Gastroenterol 1997; 11: $53-64$.

7. Langholz E, Munkholm P, Davidsen M, Binder V. Course of ulcerative colitis: analysis of changes in disease activity over years. Gastroenterology 1994; 107: 3-11.

8. Hendee WR, Boteler JC. The question of health effects from exposure to electromagnetic fields. Health Phys 1994; 66: 127-136.

9. Braune $S$, Wrocklage $C$, Raczek J, Gailus T, Lücking $\mathrm{CH}$. Resting blood pressure increase during exposure to a radio-frequency electromagnetic field. Lancet 1998; 351: $1857-1858$.

10. Wilke A, Grimm W, Funck R, Maisch B. Influence of D-net (European GSM-standard) cellular phones on pacemaker function in 50 patients with permanent pacemakers. PACE 1996; 19: 1456-1458.

11. Koch TR, Carney JA, Go VLW, Szurszewski JH. Spontaneous contractions and some electrophysiologic properties of circular muscle from normal sigmoid colon and ulcerative colitis. Gastroenterology 1988; 95: 77-84.

12. Aziz Q, Thompson DG. Brain-gut axis in health and disease. Gastroenterology 1998; 114: 559-578.

13. Leduc BE, Giasson M, Favreau-Ethier $M$, Lepage $X$. Colonic transit time after spinal cord injury. J Spinal Cord Med 1997; 20: 416-421.

14. Krantis A, Nichols K, Staines W. Neurochemical characterization and distribution of enteric GABAergic neurons and nerve fibers in the human colon. I Auton Nerv Syst 1998; 68: 33-42.

15. Grider JR, Makhlouf GM. Enteric GABA: mode of action and role in the regulation of the peristaltic reflex. Am J Physiol 1992; 262: G690-694.

16. Cui JG, O'Connor WT, Ungerstedt U, Linderoth B, Meyerson BA. Spinal cord stimulation attenuates augmented dorsal horn release of excitatory amino acids in mononeuropathy via a GABAergic mechanism. Pain 1997; 73: 87-95. 
CHAPTER $11 b$

\section{Recurrent Rejection of a Spinal Cord Stimulation System}

Marius A. Kemler, Gerard A.M. Barendse, and Maarten van Kleef

Published in Contact Dermatitis 2000; 42: 304-5 


\section{Introduction}

Spinal cord stimulation is an increasingly popular form of pain treatment. In this procedure, an electrode is positioned in the epidural space on the dorsal aspect of the spinal cord at the level of the nerve roots innervating the painful area; electrical current from the electrode brings about paraesthesiae, a sensation that suppresses the pain. Current from the electrode is supplied by a pulse generator in the lower anterior abdominal wall. The complication rate related to SCS systems has been reported to vary between 20 and 75 percent of cases. ${ }^{1}$ In five to 15 percent of cases, complications of various character necessitate removal of the system. ${ }^{2,3}$ The main cause for system removal is infection.

\section{Case Report}

A 52-year-old male reflex sympathetic dystrophy patient was being successfully treated by SCS. Two months after implantation, the patient presented with signs of an infected SCS system. The skin overlying the pulse-generator and the extension lead was diffusely touch-sensitive, although there was no erythema or swelling. Body temperature was $37.8^{\circ} \mathrm{C}$, blood sedimentation rate was $22 \mathrm{~mm} / \mathrm{h}$, C-reactive protein was $8 \mathrm{mg} / \mathrm{L}$ and leucocytes had risen to $16.9 \times 10^{9} / \mathrm{L}$. All symptoms remained for a period of ten days, after which time it was decided to remove the complete system. After opening the skin, the system was revealed to be surrounded by a clear liquid exudate. The tissue displayed no signs of infection and there was no pus present. Bacteriological cultures of wound fluid and system material grew no pathogens. Over the course of the following month, after a fourteen day course of daily $2000 \mathrm{mg}$ flucloxacillin orally, clinical signs of infection faded and results of blood counts returned to within the normal range. Two months after removal, the SCS system was implanted again. Nine months later, the signs of infection recurred, completely repeating those observed during the first episode. As the symptoms did not subside, we were forced to remove the complete system once again. The results of operation and bacteriological culture were similar to the former findings. In order to exclude the possibility of an allergic contact hypersensitivity to parts of the SCS system, a patch test was performed. The test included the usual rubber and metal patch test screening tray, as well as silicone rubber and metal products obtained from the pulse-generator. None of the materials tested proved to be a sensitizer. The unknown cause of the recurrent clinical image of infection has excluded this patient from further treatment with SCS.

\section{Discussion}

Because of the position of the SCS electrode in the epidural space the consequences of infection may be dramatic; one patient, for example, developed paraplegia following infection. ${ }^{2}$ Therefore, signs of infection should always lead to immediate removal of the complete SCS system. 
Once signs and symptoms of infection with negative bacteriological cultures had occurred for the second time, we suspected contact hypersensitivity to materials of the SCS system to be the cause of rejection. Although it is a very rare condition, allergic reactions to cardiac pacemakers previously have been reported. Allergic reactions, however, are regularly characterized by responses of the skin overlying the pacemaker, e.g. an erythematous rash ${ }^{4}$ local swelling and pruritis, ${ }^{5}$ or vesicular lesions. ${ }^{6} \mathrm{~A}$ striking feature in the present case was the lack of any such visible skin reactions. The contact eczema in cases reported previously developed after a period varying from two days to 24 months, and consequently the two periods of respectively two and nine months between the SCS system implantation and the start of rejection symptoms does not rule out the possibility of contact hypersensitivity. The negative patch tests, on the other hand, indicate that an allergic reaction is unlikely, although false negativity is a well-known problem of these tests.

In summary, the present case report describes a patient who reacted to SCS positively, but who could not continue to undergo this treatment because of inflammatory-type reactions of unknown pathophysiology.

\section{References}

1. Turner JA, Loeser JD, Bell KG: Spinal cord stimulation for chronic low back pain: a systematic literature synthesis. Neurosurgery 1995; 37: 1088-95.

2. Meglio M, Cioni B, Rossi GF: Spinal cord stimulation in management of chronic pain. J Neurosurg 1989; 70: 519-24.

3. North RB, Kidd DH, Zahurak M, James CS, Long DM: Spinal cord stimulation for chronic, intractable pain: experience over two decades. Neurosurgery 1993; 32: 384-94.

4. Iguchi N, Kasanuki H, Matsuda N, Shoda M, Ohnishi S, Hosoda S: Contact sensitivity to polychloroparaxylene-coated cardiac pacemaker. PACE 1997; 20: 372-3.

5. Peters MS, Schroeter AL, van Hale HM, Broadbent IC: Pacemaker contact sensitivity. Contact Dermatitis 1984; 11: 214-18.

6. Abdallah HI, Balsara RK, O'Riordan AC: Pacemaker contact sensitivity: clinical recognition and management. Ann Thorac Surg 1994; 57: 1017-18.

7. Larsen WG, Maibach HI. Allergic contact dermatitis. In: Moschella SL, Hurley HJ (eds): Dermatology. Philadelphia: WB Saunders Company; 1992, Vol 1, 414-15. 

CHAPTER 12

General Discussion 
Reviewing the literature on RSD that has evolved since its description first by Weir Mitchell $^{1}$ and later by Paul Sudeck ${ }^{2}$ can only leave the objective reader in despair, since it appears that virtually all basic knowledge of the disorder is lacking. Currently, researchers disagree on how to diagnose RSD, ${ }^{3,4}$ how to treat it, ${ }^{5,6}$ and even what to call the condition. ${ }^{7}$ As a consequence of the conflicting diagnostic criteria, no incidence rates, prevalence rates, or figures on the disabling potential of RSD (i.e. the percentage of those developing RSD who will remain disabled) are known. Of the many different treatments in use for RSD, only a few have been studied by means of randomized controlled trials and, hence, there is no certainty about which treatments are effective, or, indeed, which are obviously not. Although no two RSD patients are alike, it is not clear whether consistent subgroups exist, or if such subgroups are sensitive to different forms of therapy. Finally, the sociological impact of RSD has been little studied. There is a poor understanding of the effects of RSD on lives of patients and their families, and on the financial consequences for both sufferers and society in general. Taken together, the best procedure by which to reassess RSD would be to acknowledge the present confusion that has grown up concerning the syndrome. ${ }^{5}$ The following recommendations may be seen as a first attempt to deal with the basic lack of knowledge of RSD.

- Universal agreement has to be obtained on the nomenclature and diagnostic criteria of RSD. Medical journals should refuse any papers not in accordance with this agreement.

- Large population studies are required in order to assess incidence and prevalence rates.

- Effectiveness of treatments should be measured solely by means of randomized controlled trials. These studies should look for differential effects in subgroups which must be selected on the basis of objective criteria.

- Treatment should be restricted to those therapies the effectiveness of which has been demonstrated by randomized controlled trials.

The results of the present study are clear and straightforward and, hence, the implications may also be considered to be such. Firstly, after careful selection and successful test stimulation, SCS was shown to reduce pain and improve HRQL in chronic RSD; functional status was unchanged. Secondly, SCS proved both more effective and less expensive as compared with the standard treatment protocol for chronic RSD, implying that there is compelling evidence for its adoption and appropriate utilization. Thirdly, in chronic RSD, SCS had no long-term effect on detection and pain thresholds for pressure, warmth or cold and the treatment appeared to have only minimal influence on mechanical hyperalgesia. Fourthly, SCS had no influence on skin microcirculation in patients with RSD and a low sympathetic tone; hence, pain relief in RSD, due to SCS, does not depend on vasodilation. In summary, these results indicate that SCS is not only effective but also cost-effective in chronic RSD, notwithstanding the fact that it is not clear what might cause this effectiveness. 
In principle, this can be regarded as an excellent result. In general, very few treatments can influence symptoms caused by RSD, ${ }^{5,6}$ and our chronic cases, in particular, had not even exhibited any reaction to all the standard therapies. Their mean baseline visual analog pain intensity score was 7.0, where a score in excess of 5.4 has been demonstrated to equal severe pain. ${ }^{8}$ A treatment capable of influencing such severe cases must be considered an important improvement.

One might consider SCS lacking any effect on functional status as disappointing, but, in our opinion, this notion is unfounded. SCS treats pain but not RSD itself, and consequently pain reduction finds no expression in function. Moreover, it is important to realize that for these chronic cases, even if their RSD were to be completely cured, functional improvement might be considered effectively impossible. Furthermore, pain is far and away their most critical source of distress.

It might be expected that deterioration of function could be prevented if treatment with SCS commenced before RSD had led to muscle atrophy and joint contractures. However, the question of when to start treatment cannot easily be answered. SCS is a demanding, invasive, life-long treatment which, in principle, is not attractive to patients who still hope to recover spontaneously. In addition, because of its costs, SCS generally is as a matter of policy reserved for severely disabled cases. Therefore, as long as we are unable to predict which early RSD patients will eventually develop a chronic disability, starting to use SCS before chronicity of RSD has occurred does not appear to be feasible.

In our study, only 25 percent of patients suffered complications during the six months after implantation. We say 'only' since the typical reported complication rate after SCS varies from 20 to 75 percent (mean, 42 percent). ${ }^{9}$ Based on findings from larger studies, it is known that various different complications necessitate removal of the system in 5 to 15 percent of cases. ${ }^{10,11}$ Technical defects (e.g. lead shifting and breaking) seem to be inherent in the treatment-the reported incidence being 3 to 5 percent. ${ }^{10,12}$ Although complications affect treatment results, cause patient discomfort and generate costs, these factors rarely cause permanent neurological deficits. ${ }^{101112}$ For these reasons, the relatively high complication rate of SCS should not be seen as an obstacle in treatment consideration, but must be clearly communicated to the future patient.

The following matters should be taken into account when interpreting results of this thesis.

- To achieve the required number of patients for the present study, we had to include both patients with an affected hand and also those with an affected foot. These patients differ with regard to health-related quality of life (HRQL) and function. The subgroup analyses according to affected limb may have hindered finding significant results for those parameters. On the other hand, the policy of including hand and foot affected patients may also be considered, in a sense, a strength of the work, since we aimed to evaluate the effect of spinal cord stimulation (SCS) in reflex sympathetic dystrophy (RSD) in general-not just RSD of either the hand or the foot. 
- As stated in the Introduction (Methodological Considerations), a blinded randomized trial on the effectiveness of SCS is impracticable, because patients perceive paresthesiae during stimulation. In addition, even if blinding were possible from a practical point of view, the decision to undertake sham surgery would be controversial, since this violates the ethical and regulatory principle that the risk of harm to subjects must be minimized when carrying out research. ${ }^{13}$ Besides, comparing SCS with 'no treatment' was thought inappropriate in a group of patients for whom SCS would be effectively the last hope. Therefore, patients in the present study were randomized either into a group with SCS and physical therapy (SCS+PT), or into a group receiving only physical therapy (PT).

- In line with conventional practice, patients were given a permanent SCS system only after successful test stimulation. ${ }^{14}$ As a result, only 66 percent of SCS+PT patients were expected actually to be treated with SCS. To maximize the power of the study, we anticipated this course of events by allocating two thirds of patients to SCS+PT and one third to PT. Applying test stimulation after randomization had two consequences. Firstly, it created three instead of two groups: (A) SCS+PT with implant; (B) SCS+PT without implant; and (C) PT. In the final analyses, we compared $\mathrm{A}+\mathrm{B}$ with $\mathrm{C}$ (intention to treat analysis) as well as $\mathrm{A}$ with $B+C$ (implant effect analysis). Secondly, because test stimulation takes time, in addition to the baseline assessment before randomization (T0), we had to perform a second assessment prior to implantation ( $\mathrm{T} 1$ ). It was the second baseline assessment that enabled us partially to correct for the effect of unblinded randomization: using $\mathrm{Tl}$ instead of $\mathrm{T} 0$ as a baseline, to an extent prevented overestimating treatment effect.

- For the present study, we selected severely disabled patients, as a consequence of which our results cannot be generalized to all RSD sufferers. However, in our opinion, a treatment that is effective for the most severely affected group will also prove effective for less disabled cases.

SCS proved successful in enhancing the mean group results, but unable to achieve improvement in all patients; only 50 to 60 percent of chronic RSD patients actually progress after SCS. Although this result is nevertheless impressive, since patients had not previously reacted to any of the standard therapies, one cannot ignore that up to 50 percent of patients are not being helped by SCS. Solutions for such cases will have to be obtained by either (1) improving our understanding of the causes and treatments of RSD, or (2) enlarging our knowledge of the mode of action of SCS and thereby increasing its effectiveness.

Studies of the possible action mechanisms of SCS in neuropathic pain suggest that the treatment acts on distorted neurochemical mechanisms, and may operate by re-establishing the balance between excitation and inhibition in the dorsal horn, thus recreating a 'near normal state'. ${ }^{15}$ There is no obvious explanation why a subgroup of patients treated by SCS for good indications while obtaining adequate paresthesiae that overlap the topography of the painful area, do not benefit from treatment. Apparently, in the case of a severely disturbed morphology and neuro- 
chemistry within the dorsal horn, even technically adequate stimulation will not be efficacious. Therefore, in order to increase the success rate of SCS, we will either have to find criteria that can exclude patients not reacting to technically adequate stimulation, or discover methods of enhancing the beneficial effects of SCS in such cases.

The selection criteria that are currently used-(1) objective basis for the patients' complaint of pain, (2) alternative treatments being either exhausted or unacceptable, (3) psychopathology having to be ruled out, and (4) technically demonstrated efficacy by test stimulation ${ }^{14}$ _ are unable on their own to select candidates for treatment who will continue to respond after implantation of a SCS system. An evaluation of the validity of these criteria, which are based purely on clinical grounds, is certainly necessary. In addition, other stronger criteria-possibly based on the quality of specific sensory fibers-need to be found.

Several recent studies have indicated that generating an effect of stimulation in subjects who do not respond to plain SCS does not need to be regarded as being unattainable. Rats in which SCS could not suppress the allodynia were transformed into SCS-responders by intrathecal injection of either $\gamma$-amino butyric acid $B$ (GABA-B) agonists, ${ }^{16}$ or adenosine A1 agonists ${ }^{17}$ in low (normally ineffective) doses, combined with SCS. In SCS-responding rats, a combination of a selective GABA-B and an adenosine Al receptor antagonist in low (normally ineffective) doses abolished the SCS-induced threshold normalization. ${ }^{18}$ These results indicate that GABAergic and adenosine-dependent mechanisms are involved in the SCS effect, and further suggest a strategy for enhancing the therapeutic efficacy of SCS.

Taken all in all, the present thesis demonstrates that SCS is an effective and costeffective means to relieve pain in chronic RSD. Results may improve even more if future studies manage to increase our understanding of either the pathophysiology of RSD, or the mode of action of SCS. For the moment, SCS can be considered the most favourable treatment for patients suffering from chronic RSD.

\section{References}

1. Mitchell SW, Morehouse GR, Keen WW. Gunshot wounds and other injuries of nerves. Philadelphia: J.B. Lippincott Co., 1864: 164.

2. Sudeck P. Über die acute entzündliche Knochenatrophie. Arch Klin Chir 1900;62: 147-56.

3. Schott GD. An unsympathetic view of pain. Lancet 1995; 345: 634-6.

4. Merskey H, Bogduk N. Classification of chronic pain: descriptions of chronic pain syndromes and definitions of pain terms. Seattle: IASP Press, 1994: 40-2.

5. Ochoa JL. Guest editorial: essence, investigation, and management of 'neuropathic' pains: hopes from acknowledgment of chaos. Muscle \& Nerve 1993; 16: 997-1008.

6. Schwartzman RJ, McLellan TL. Reflex sympathetic dystrophy: a review. Arch Neurol 1987; 55: 555-61.

7. Veldman PHJM. Clinical aspects of reflex sympathetic dystrophy. Department of Surgery. Nijmegen: Catholic University of Nijmegen, 1995. 
8. Collins SL, Moore RA, McQuay HJ. The visual analogue pain intensity scale: what is moderate pain in millimetres? Pain 1997; 72: 95-7.

9. Turner JA, Loeser JD, Bell KG. Spinal cord stimulation for chronic low back pain: a systematic literature synthesis. Neurosurgery 1995; 37: 1088-95.

10. Meglio M, Cioni B, Rossi GF. Spinal cord stimulation in management of chronic pain. J Neurosurg 1989; 70: 519-24.

11. North RB, Kidd DH, Zahurak M, James CS, Long DM. Spinal cord stimulation for chronic, intractable pain: experience over two decades. Neurosurgery 1993; 32: 384-94.

12. Broggi G, Servello D, Dones I, Carbone G. Italian multicentric study on pain treatment with epidural spinal cord stimulation. Stereotact Funct Neurosurg 1994; 62: 273-8.

13. Macklin R. The ethical problems with sham surgery in clinical research. New Engl J Med 1999; 341: 992-6.

14. North RB. Spinal cord stimulation. In: North RB, Levy RM, eds. Neurosurgical management of pain. New York: Springer-Verlag, 1997: 271-82.

15. Cui JG. Spinal cord stimulation in neuropathy: experimental studies of neurochemistry and behavior. Department of Neurosurgery. Stockholm: Karolinska Institutet, 1999.

16. Cui JG, Linderoth B, Meyerson BA. Effects of spinal cord stimulation on touch-evoked allodynia involve GABAergic mechanisms. An experimental study in the mononeuropathic rat. Pain 1996; 66: 287-95.

17. Cui JG, Sollevi A, Linderoth B, Meyerson BA. Adenosine receptor activation suppresses tactile hypersensitivity and potentiates spinal cord stimulation in mononeuropathic rats. Neurosci Lett 1997; 223: 173-6.

18. Cui JG, Meyerson BA, Sollevi A, Linderoth B. Effect of spinal cord stimulation on tactile hypersensitivity in mononeuropathic rats is potentiated by simultaneous GABA-B and adenosine receptor activation. Neurosci Lett 1998; 247: 183-6. 


\section{Summary}

The current knowledge about RSD and SCS is outlined in Chapter 1 (section A). RSD is a painful and disabling syndrome of unknown pathophysiology that may occur after trauma or operation of a limb. Although, at present, there is still only limited understanding of the pathophysiology of RSD, the key to the causes of RSD is likely to be that in certain individuals peripheral nerve injury leads to development of maladaptive compensatory changes in both the peripheral and central nervous systems. Two potential clues to the causes of RSD have recently emerged. Studies have indicated that specific HLA alleles are associated with RSD, suggesting that certain individuals may be at increased risk of its development. In addition, the incidence of RSD after trauma can be reduced by suppletion of vitamin C. Presently, treatment is purely symptomatic and based on physical therapy, together with medication, or electrical stimulation of the nervous system (transcutaneous or direct stimulation of peripheral nerves or the spinal cord) to reduce neuropathic pain. Blocking the sympathetic nervous system is, in most patients, ineffective.

In SCS, an electrode is positioned in the epidural space on the dorsal aspect of the spinal cord at the level of the nerve roots innervating the painful area; electrical current from the electrode brings about paresthesiae, a sensation that suppresses the pain. SCS came about first as the direct consequence of the Gate Control Theory. The treatment was hypothesized to stimulate the large, rather than the small, fibers in the spinal cord, resulting in a closed 'gate' and thus pain relief. Once it was demonstrated experimentally that hyperalgesia can be signalled by large fibers, a finding totally at variance with the Gate Theory, it became evident that the true working mechanism of SCS was in fact a mystery. At present, our understanding of SCS is still based on hypotheses, since there has been insufficient research carried out on the effect of SCS in RSD, although what retrospective studies are available report optimistic results.

The aim of this thesis is to assess the effectiveness of SCS in patients with chronic RSD and attempts to answer the following questions:

- What is the effect of trying SCS in these patients on pain, global perceived effect, function and health-related quality of life?

- Is treatment of these patients with SCS cost-effective?

- What is the effect of SCS in these patients on sensory abnormalities?

- Is pain relief in these patients due to SCS dependent on vasodilation?

As described in section $B$, prior to the start of the study, several investigations had to take place in order to increase our understanding of (I) the approximate rates of success of trial SCS as well as definite SCS (Chapter 2), (II) the best way to assess health-related quality of life (HRQL) (Chapter 3), foot function (Chapter 4), and warmth or cold perception thresholds (Chapter 5), and (III) the impact of the 
unblinded randomization process on primary outcome measures (Chapter 6).

The description and results of the main studies in this thesis are given in section $\mathrm{C}$. We performed a randomized trial in a 2:1 ratio during which $36 \mathrm{RSD}$ patients were treated with SCS and physical therapy (SCS+PT), and 18 patients received solely physical therapy (PT). SCS+PT patients were given a permanent SCS-system only after successful test stimulation, which occurred in 24 cases; the remaining twelve patients received no permanent SCS-system. Patients were examined before randomization, before implantation and one, three, six and twelve months thereafter. Patients without an implant were examined in the same periods. The statistical analysis was carried out according to the intention to treat' principle: all patients remained in the group to which they were assigned by randomization.

Chapter 7, based on results at six months, reports improvements in the SCS+PT group as compared with the PT group concerning pain intensity and global perceived effect. As compared with the PT group, patients with a SCS-system showed improvements with regard to pain intensity, global perceived effect, and HRQL. SCS did not result in any clinically important improvement of functional status. Hence, after careful selection and successful test stimulation, SCS reduces pain and improves HRQL in chronic RSD.

Chapter 8 evaluates the economic aspects of treatment of chronic RSD with SCS. During the 12 month follow-up, costs (e.g. conventional treatment, SCS-treatment, out-of-pocket expenses) and effects (e.g. pain relief, HRQL improvement) were assessed in both groups. Analyses were carried out (1) up to one year and (2) up to the expected time of death. SCS was found to be both more effective and less costly -i.e. successful cases stop seeking expensive alternatives-than the standard treatment protocol. As a result of high initial costs of SCS, the treatment is more expensive in the first year than control therapy (mean cost per patient: NLG 22,000 vs NLG 13,000). However, in the lifetime analysis the reverse is true (NLG 377,000 vs NLG 506,000). Furthermore, at 12 months SCS had resulted in pain relief and improved HRQL, whereas control therapy values remained constant. The finding that SCS is both more effective, and less expensive, as compared with the standard treatment protocol for chronic RSD, renders SCS a grade A technology, meaning that there is compelling evidence for its adoption and appropriate utilization.

Chapter 9 assesses the effect of SCS on sensory abnormalities in patients with chronic RSD and is based on the 12 month results. SCS showed no effect on detection thresholds for warmth and cold, or on pain thresholds for any sensation. The pressure detection threshold initially increased by SCS, but, after three months, pressure detection thresholds returned to normal. Hence, although SCS has previously been shown to cause a significant pain reduction in RSD, the treatment has no long-term effect on detection and pain thresholds for pressure, warmth or cold.

Chapter 10 assessed whether pain relief in RSD after SCS is in fact dependent on vasodilation and, in addition, tried to determine which mechanisms may cause the vasodilatory effect that is generally found after SCS. Twenty-two patients successfully treated by SCS, who had undergone previous sympathectomy, were included 
in the study. In addition, 20 control subjects were studied. By means of laser Doppler flowmetry, the skin microcirculation of the patients was measured bilaterally (1) while the SCS-system was switched off and (2) while it was activated. Baseline investigation indicated that patients had a decreased sympathetic tone as compared to controls. Applying SCS resulted in pain relief, but not in any microcirculatory change as compared to baseline or to the contralateral clinically unaffected side. Hence, it may be concluded that pain relief in RSD due to SCS is possible without vasodilation. Because sympathetic activity was greatly decreased in our patients, these results support the hypothesis that the vasodilation that is normally found with SCS is due to an inhibitory effect on sympathetically maintained vasoconstriction.

Chapter 11 describes in detail two cases in which unexpected complications developed after SCS and, finally, Chapter 12 elaborates on the lack of knowledge regarding $\mathrm{RSD}$, the interpretation of the trial results and strategies for the future. 


\section{Samenvatting (Summary in Dutch)}

De huidige inzichten met betrekking tot post-traumatische dystrofie (PTD) en ruggenmerg stimulatie (RS) worden besproken in Hoofdstuk 1. PTD is een aandoening van onbekende pathofysiologie, gekenmerkt door pijn en functiestoornissen in een ledemaat, optredend na trauma of een operatie. Hoewel de pathofysiologie nog onbegrepen is, lijkt het waarschijnlijk dat de kern van de oorzaak van PTD ligt in foutieve compensatoire veranderingen in het perifere en centrale zenuwstelsel na beschadiging van perifere zenuwen. Recente studies hebben uitgewezen dat specifieke HLA-allelen geassocieerd zijn met PTD; een indicatie dat bepaalde individuen een verhoogd risico hebben om de aandoening te ontwikkelen. Anderzijds is gebleken dat vitamine $C$ suppletie na een trauma de incidentie van PTD kan verlagen. Op dit moment is de behandeling zuiver symptomatisch, bestaande uit fysiotherapie en pijnbestrijding met medicatie of electrische zenuwstimulatie (transcutane of directe stimulatie van perifere zenuwen of het ruggenmerg). Bij de meeste patiënten is blokkade van sympatische zenuwen ineffectief.

RS houdt in dat met behulp van een electrode ter hoogte van de zenuwwortels die het aangedane lichaamsdeel innerveren het ruggenmerg met electrische stroom wordt geprikkeld. De patiënt neemt de electrische stroom waar als tintelingen die een pijndempend effect hebben. RS vloeide voort uit de 'Poort Theorie' die stelt dat stimulatie in het ruggenmerg van aanrakingsgevoel-geleidende dikke zenuwvezels, de werking remt van pijngeleidende dunne vezels (wrijven na stoten geeft pijnstilling). Bij RS worden alleen de dikke zenuwvezels geprikkeld, wat zou leiden tot pijnstilling. Toen expirimenteel onderzoek liet zien dat ook dikke zenuwvezels pijn kunnen geleiden, en zo de Poort Theorie werd ontkracht, bleek dat de exacte werkingswijze van RS in feite onbekend was. Ook tegenwoordig zijn er enkel hypotheses over het werkingsmechanisme van RS. Voorafgaand aan dit onderzoek waren slechts een paar studies verricht naar het effect van RS op PTD. De uitkomsten waren in deze kleine projecten gunstig.

Dit proefschrift had tot doel te bepalen wat het effect is van RS bij patiënten met chronische PTD. De volgende vragen moesten worden beantwoord:

- Welk effect heeft het aanbieden van RS bij deze patiënten op pijn, globaal effect, functie en kwaliteit van leven?

- Is RS behandeling bij deze patiënten kosten-effectief?

- Welk effect heeft RS bij deze patiënten op sensibiliteitsafwijkingen?

- Is pijn vermindering door RS bij deze patiënten afhankelijk van vaatverwijding? Zoals beschreven in sectie $B$ moesten voor aanvang van de studie verschillende onderzoeken worden uitgevoerd om meer inzicht te verkrijgen in (I) het geschatte succes percentage van proef RS en definitieve RS (Hoofdstuk 2); (II) de bepalingswijze en de uitgangswaarden van kwaliteit van leven (Hoofdstuk 3), voetfunctie (Hoofdstuk 4), en warmte en koude waarnemingsdrempels (Hoofdstuk 5); en 
(III) de invloed van ongeblindeerde loting op de primaire uitkomstmaten (Hoofdstuk 6).

De beschrijving en de resultaten van de belangrijkste studies van dit proefschrift worden gegeven in sectie C. Er werd een gerandomiseerde studie verricht waarbij 36 PTD patiënten werden behandeld met RS en fysiotherapie (RS+FT) en 18 patiënten met alleen fysiotherapie (FT). Patiënten in de RS+FT groep ondergingen alleen implantatie van een RS systeem wanneer proef RS succesvol verliep ( 24 patiënten). De overige 12 patiënten werden verder behandeld met alleen fysiotherapie. Beoordeling vond plaats voor de randomisatie, voor implantatie en 1, 3,6 en 12 maanden na implantatie. Patiënten zonder implantaat werden in de zelfde periodes onderzocht. De statistische analyse was gebaseerd op het "intention-to-treat" principe: alle patiënten bleven in de groep waaraan zij waren toegewezen door randomisatie.

Hoofdstuk 7, gebaseerd op de resultaten na 6 maanden, beschrijft verbeteringen in de RS+FT groep ten opzichte van de FT groep wat betreft pijn intensiteit en globaal effect. Patiënten die een RS systeem kregen gëimplanteerd, hadden minder pijn, meer globaal effect en een betere kwaliteit van leven dan patiënten in de FT groep. RS had geen invloed op functiebeperking. Samengevat toonde de studie dat RS na nauwkeurige selectie en een succesvolle proefperiode leidt tot minder pijn en een betere kwaliteit van leven bij chronische PTD patiënten.

In hoofdstuk 8, gebaseerd op de resultaten na 12 maanden, worden de economische aspecten geëvalueerd van RS behandeling bij PTD. Gedurende 12 maanden werden in beide groepen de kosten (standaard therapie, RS behandeling, eigen bijdragen van patiënt) en effecten (pijnvermindering, kwaliteit van leven verbetering) gemeten. Er werd een analyse verricht tot 1 jaar en een analyse tot het geschatte tijdstip van overlijden. RS bleek effectiever en minder kostbaar-successvol behandelde patiënten stoppen met het zoeken van dure alternatieven-dan standaard therapie. Door de hoge aanvangskosten van RS bleek de behandeling in het eerste jaar duurder te zijn dan controle therapie (gemiddelde kosten per patiënt: $f 22.000$,vs. $f 13.000,-)$. In de analyse tot hét levenseinde is de situatie omgekeerd ( $f 377.000,-$ vs. $f 506.000,-)$. Verder bleek dat RS na 12 maanden had geleid tot pijnvermindering en kwaliteit van leven verbetering, terwijl de waarden na controle therapie constant bleven. Doordat RS zowel effectiever als goedkoper is dan controle therapie, wordt de behandeling geklasseerd als een A technologie. Dit betekent dat er dwingende aanwijzingen zijn om de therapie bij PTD te gaan toepassen.

Hoofdstuk 9 bepaalt het effect van RS op sensibiliteitsafwijkingen bij patiënten met PTD en is gebaseerd op de resultaten na 12 maanden. RS had geen effect op waarnemingsdrempels voor koude en warmte, of op pijndrempels voor koude, warmte en druk. De waarnemingsdrempel voor druk was verhoogd na 1 maand RS, maar normaliseerde zich na 3 maanden. Hoewel eerder werd aangetoond dat RS bij PTD tot significante pijnvermindering leidt, lijkt de behandeling geen lange-termijn effect te hebben op waarnemings- en pijndrempels voor warmte, koude en druk.

In hoofdstuk 10 werd gekeken of pijnvermindering bij PTD ten gevolge van RS kon worden toegeschreven aan vaatverwijding. Daarnaast werd getracht te bepalen 
via welke mechanismen de vaatverwijding tot stand komt die normaal gesproken optreedt tijdens RS. De studie onderzocht 20 controle personen en 22 PTD patienten die succesvol werden behandeld met RS en in het verleden een sympathectomie hadden ondergaan. Met behulp van laser Doppler werd bilateraal de microcirculatie van de huid gemeten (1) terwijl het RS systeem was uitgeschakeld en (2) terwijl het was geactiveerd. De metingen vooraf gaven aanwijzingen dat bij patienten sprake was van een verlaagde sympatische activiteit. Toepassing van RS resulteerde in pijnvermindering, maar niet in veranderingen van de microcirculatie ten opzichte van de uitgangswaarden of ten opzichte van de contralaterale, klinisch gezonde extremiteit. Dit betekent dat pijnvermindering door RS bij PTD patiënten mogelijk is zonder vaatverwijding. Omdat bij deze patiënten sprake is van een verlaagde sympatische activiteit, steunen de resultaten de hypothese dat de vaatverwijding, die normaal gesproken optreedt tijdens RS, het gevolg is van een remmend effect op sympatisch afhankelijke vasoconstrictie.

In hoofdstuk 11 worden twee patiënten gepresenteerd die opmerkelijke complicaties ontwikkelden door RS en in hoofdstuk 12, ten slotte, wordt ingegaan op de ontbrekende kennis omtrent PTD, de interpretatie van de resultaten van dit proefschrift en er worden strategieën voorgesteld voor onderzoek in de toekomst. 


\section{Dankwoord (Acknowledgements)}

$\mathrm{Na}$ bijna vier enerverende jaren van onderzoek in Maastricht, aangevuld met congressen en cursussen in Barcelona, Tenerife, Luzern, Toronto, San Diego, Wenen, Philadelphia, Stockholm, Texel, Den Haag en San Francisco, realiseer ik mij hoeveel mensen hebben geholpen bij het tot stand komen van dit proefschrift. Een aantal wil ik met name noemen.

Gauke Kootstra, mijn promotor, wil ik graag bedanken voor de onvoorwaardelijke steun. Hoewel je pas laat werd betrokken bij het onderzoek was je altijd oprecht geinteresseerd in de bevindingen en vorderingen. De mogelijkheid om een half jaar op de afdeling Chirurgie praktische ervaring op te doen heeft mij enorm vooruit geholpen.

Frans van den Wildenberg, mijn directe begeleider. Jouw tweezijdige karakter heeft mijn werk erg gestimuleerd. Enerzijds de razendgezellige en geestige vriend met wie het tijdens etentjes en reizen goed toeven is. Anderzijds de paternalistische begeleider (vergeet je je tandenborstel en onderbroek niet?) met eerzucht opzwepende uitspraken als 'jou lukt dit nooit in drie jaar' of 'is dat blad niet een beetje hoog gegrepen?'. Ik ben blij dat je je baan weer in Sittard hebt kunnen oppakken.

Riekie de Vet, co-promotor en het brein achter de meeste analyses. Het is mij volstrekt onduidelijk hoe jij-meer dan wie ook —zo goed overzicht kon houden, ondanks al die wisselende contacten. Telkens als ik een half uurtje voor raad langs kwam was je nog bezig om iemand te helpen; nooit dezelfde. Je gave om indirect te zeggen dat ik een nitwit was, waarbij ik toch het gevoel kreeg een fantastische prestatie te hebben geleverd, is wonderbaarlijk.

Maarten van Kleef, co-promotor. Aanvankelijk had je wat moeite met zo'n eigenwijze promovendus (dat maken wij wel uit) maar aldoor was je geïnteresseerd en had je een moment om te overleggen. Wanneer logistieke zaken of artikeldiscussies niet volledig soepel liepen heb ik altijd dankbaar gebruik kunnen maken van je gave om razendsnel verassend ideale oplossingen te vinden.

In feite was dit proefschrift een evaluatie van de capaciteiten van Gerard Barendse. Niet alleen ben je een geweldig operateur, wat tot een opvallend laag complicatiepercentage heeft geleid. Je bent ook een vriend en een sympathieke collega, waardoor prima samenwerking en gezelligheid (biertje op vrijdagmiddag, congressen) mogelijk was. Ik hoop dat je de ruggenmerg stimulatie binnenkort in Amsterdam van de grond krijgt.

Met Carina Furnée heb ik waarschijnlijk het intensiefst samen gewerkt. Ellenlange telefoon- en schrijfsessies om de financiële gegevens boven tafel te krijgen en vervolgens noest telwerk om de stapels papier om te zetten in bruikbare getallen. De ondraaglijke saaiheid van dit werk kon niet verhinderen dat we een boel lol en 
gezellige lunches hebben beleefd. Bovendien heeft onze 'niet zeiken maar doorgaan' mentaliteit verdomd goed werk opgeleverd.

Dankzij Koen Rijks verliep de fysiotherapie tijdens het onderzoek gesmeerd. Wanneer ik weer eens een patiënt includeerde uit een regio ver buiten Limburg, ging bij jou hooguit een wenkbrauw omhoog voordat je afreisde om het protocol daar te gaan uitleggen. Veel dank voor je hulp bij de goniometrie (ook voor Albère Köke en Alex van Wameren).

Mirjam oude Egbrink heeft me fantastisch geholpen toen ik op het punt stond alle laser Doppler uitslagen weg te gooien. Je snelle en efficiënte aanpak heeft tot een mooi hoofdstuk 10 geleid; veel dank daarvoor.

Jos Reulen en professor Frank Spaans wil ik bedanken voor de mogelijkheid om op de afdeling Klinische Neurofysiologie warmte en koude-gevoelsmetingen te verrichten en voor belangrijke bijdrages aan hoofdstukken 5 en 9 .

Voor vriendschap, samen lijden, lol en veel warmte (mede dankzij de kapotte airco) dank ik mijn kamergenoten op B4.02 Bernadette van Acker, Frans Dekker, Carmen Dirksen, Henk Pietersen (samen de tafel van vijf hardcore) en later David Cobben, Hugo Lambriex, Kadri el Naggar† en Özenç Uludag. Bernadette en Frans, ik ben trots dat jullie mij als paranimf terzijde willen staan.

Van het pijnteam wil ik Wim Weber, Anton van de Vusse, Tim Forouzanfar, Suzanne Stomp en Margriet Rouflart danken voor hun hulp en fijne samenwerking, en natuurlijk zijn er een paar heerlijke zoenen voor Émiliènne Christophe en Marianne Groeneweg voor jullie geweldige steun en gezelligheid.

Miranda Thimister, dankje voor secretariële en allerhande andere ondersteuning en omdat ik op cruciale momenten altijd een beroep op je kon doen. Op het secretariaat Chirurgie hebben verder Johanna Boesten, Yvonne Damen en Marjan Siep mijn leven regelmatig vergemakkelijkt; allen dank.

Ria Vranken en Yvonne van der Meer van de vakgroep Epidemiologie wil ik bedanken voor hulp bij de randomisatie, en Raymond Ostelo voor veelvuldig meedenken.

Natuurlijk ben ik veel dank verschuldigd aan alle specialisten die potentiële kandidaten verwezen naar ons ziekenhuis, de therapeuten die tijdens het onderzoek de fysiotherapie verzorgden, en aan alle patiënten en vrijwilligers voor hun bereidwilligheid om deel te nemen aan de studie. Ook alle medewerkers van het dagcentrum en van verpleegafdeling A1 wil ik bedanken voor hun inzet tijdens de studie.

De leden van de beoordelingscommissie, prof. dr. J. Troost (voorzitter), prof. dr. E.A. Beuls, prof. dr. R.J.A. Goris, prof. dr. F. Spaans en prof. dr. W.W.A. Zuurmond, wil ik bedanken voor het kritisch doorlezen van het manuscript.

Dat dit droge werkje toch een aantrekkelijk boekje is geworden is te danken aan Erik Boot, die een wonderschone omslag heeft gesmeed en aan Peter Kahrel, die op formidabele wijze de lay-out heeft verzorgd.

Heel veel dank ben ik verschuldigd aan Beverley Collins voor de ontelbare verduidelijkingen en verbeteringen van het Engels. Ondanks je afkeer van bloed en medische hoogstandjes ben je onmiskenbaar degene die de teksten het intensiefst 
heeft doorgenomen. Mijn plezier in onze 'Saturday at 11 o'clock' sessies, waarin je volkomen vastgelopen alinea's in elegante constructies omtoverde, heeft mijn schrijflust zo bevorderd dat je nooit meer van me afkomt.

Lieve pap en mam, jullie wil ik ontzettend bedanken voor niet-aflatende belangstelling. Het is fijn dat ik dankzij jullie nog geen artikel heb gemaakt dat door niemand is gelezen. Ik hoop dat met mijn promotie de tijd voorbij is dat jullie in ruzies verzanden wanneer jullie aan vrienden proberen uit te leggen wat ik nou eigenlijk onderzoek. Alle familieleden en vrienden wil ik ook graag bedanken voor de voortdurende interesse.

En natuurlijk mijn lieve Bettien. Jij was er altijd om mij aan te moedigen en te ondersteunen, maar ook om me aan te sporen als ik geen puf meer had. Ik hou van je en hoop dat je, zeker nu de gedwongen LAT-relatie voorbij is, weer wat minder streng wordt. 



\section{List of Publications}

Kemler MA, Logeman F, v Vroonhoven ThJMV. Behandeling van obstructie-ileus zinvol bij patiënten met een maligniteit in de voorgeschiedenis.

Ned Tijdschr Geneesk 1993; 137: 1875-8.

Kemler MA, Deenstra W, Kon M. Xanthelasma palpebrarum.

Ned Tijdschr Geneesk 1996; 140: 1014-17.

Kemler MA, Oostvogel HJM. Femoral hernia: Is a conservative policy justified? Eur J Surg 1997; 163: 187-90.

Kemler MA, Kolkman WFA, Slootweg PJ, Kon M. Adventitial stripping does not strip the adventitia.

Plast Reconstr Surg 1997; 99: 1626-31.

Kemler MA, Tordoir JHM. Reflex sympathetic dystrophy following vascular access surgery for haemodialysis: influence of peripheral ischaemia?

Nephrol Dial Transplant 1998; 13: 784-6.

Kemler MA, Barendse GAM, v Kleef M, vd Wildenberg FAJM, Weber WEJ. Electrical spinal cord stimulation in reflex sympathetic dystrophy: retrospective analysis of 23 patients.

J Neurosurg 1999; 90 (Spine 1): 79-83.

Kemler MA, Barendse GAM, v Kleef M. Relapsing ulcerative colitis associated with spinal cord stimulation.

Gastroenterology 1999; 117: 215-17.

Kemler MA, vd Vusse AC, vd Berg-Loonen EM, Barendse GAM, v Kleef M, Weber WEJ. HLA-DQ1 associated with reflex sympathetic dystrophy.

Neurology 1999; 53: 1350-1.

Kemler MA, v Kleef M. Principles of spinal cord stimulation.

Eur J Anaesth 2000; 17 (Suppl.18): 41-2.

Kemler MA, de Vet HCW. Does randomization introduce bias in unblinded trials? Epidemiology 2000; 11: 228.

Kemler MA, Barendse GAM, van Kleef M. Recurrent rejection of a spinal cord stimulation system.

Contact Dermatitis 2000; 42: 304-5.

Kemler MA, Barendse GAM, van Kleef M, oude Egbrink MGA. Pain relief in complex regional pain syndrome due to spinal cord stimulation system does not depend on vasodilation.

Anesthesiology 2000; 92: 1653-60.

Kemler MA, Barendse GAM, v Kleef M, vd Wildenberg FAJM, Weber WEJ. Ruggenmerg stimulatie bij post-traumatische dystrofie: retrospectieve analyse van 23 patiënten.

Ned Tijdschr Geneesk 2000; in press. 
Kemler MA, de Vet HCW. Health-related quality of life in chronic refractory reflex sympathetic dystrophy (complex regional pain syndrome type I).

J Pain Symptom Manag 2000; in press.

Kemler MA, de Vet HCW. An objective and standardized test of foot function: normative values and validation in patients with reflex sympathetic dystrophy.

Arch Phys Med Rehabil 2000; in press.

Kemler MA, Schouten HJA, Gracely RH. Diagnosing sensory abnormalities with either normal values or values from contralateral skin: comparison of two approaches in complex regional pain syndrome $\mathrm{I}$.

Anesthesiology 2000; in press.

Kemler MA, Reulen JPH, van Kleef M, Barendse GAM, van den Wildenberg FAJM, Spaans F. Thermal thresholds in complex regional pain syndrome type I: sensitivity and repeatability of the methods of limits and levels.

Clin Neurophysiol 2000; in press.

Kemler MA, Rijks CPH, de Vet HCW. Which chronic reflex sympathetic dystrophy patients are most likely to benefit from physical therapy?

JManip Physiol Ther 2000; in press.

Kemler MA, Barendse GAM, van Kleef M, de Vet HCW, Rijks CPM, Furnée CA, van den Wildenberg FAJM. The effect of spinal cord stimulation in patients with chronic reflex sympathetic dystrophy: a randomized controlled trial.

New Engl J Med 2000; in press. 


\section{Curriculum Vitae}

Marius Kemler was born in Enschede in the Netherlands on 18 January 1971. After obtaining his high school diploma from Twickel College, Hengelo, in 1989, he read medicine at the University of Utrecht, graduating in 1996. He began his professional career as an intern in surgery at the Lorentz Hospital, Zeist, and in November 1996 took up a post in medical research in the Department of Surgery at Maastricht University Hospital. The work undertaken for this thesis was carried out there in the years from 1996 to 2000. Between March and September 2000, he combined his research commitments with a post as intern in surgery. In September 2000 he began work as an intern at the Plastic Surgery Department of the University Hospital at the Free University of Amsterdam. 